\title{
Assessment of antibiotic resistance in soil and its link to different land use types and intensities
}

\author{
Dissertation \\ for the award of the degree \\ "Doctor rerum naturalium" (Dr. rer. nat.) \\ of the Georg-August-Universität Göttingen
}

within the doctoral program Biology

of the Georg-August University School of Science (GAUSS)

submitted by

Inka Marie Willms

from Westerstede

Göttingen, 2020 


\section{Thesis Committee}

Dr. Heiko Nacke, Department of Genomic and Applied Microbiology, Institute of Microbiology and Genetics, Georg-August University Göttingen

PD. Dr. Michael Hoppert, Department of General Microbiology, Institute of Microbiology and Genetics, Georg-August University Göttingen

\section{Members of the Examination Board}

Referent: Dr. Heiko Nacke, Department of Genomic and Applied Microbiology, Institute of Microbiology and Genetics, Georg-August University Göttingen

Coreferent: PD. Dr. Michael Hoppert, Department of General Microbiology, Institute of Microbiology and Genetics, Georg-August University Göttingen

Further Members of the Examination Board

Prof. Dr. Rolf Daniel, Department of Genomic and Applied Microbiology, Institute of Microbiology and Genetics, Georg-August University Göttingen

Prof. Dr. Jörg Stülke, Department of General Microbiology, Institute of Microbiology and Genetics, Georg-August University Göttingen

Prof. Dr. Stefanie Pöggeler, Department of Genetics of Eukaryotic Microorganisms, Institute of Microbiology and Genetics, Georg-August University Göttingen

Prof. Dr. Kai Heimel, Department of Molecular Microbiology and Genetics, Institute of Microbiology and Genetics, Georg-August University Göttingen

Date of oral examination: 26.05 .2020 
"Wisdom comes out of dialogue.

You have to develop a capacity to expose your own ignorance so that they may discover their own wisdom."

John Goodenough 


\section{Table of contents}

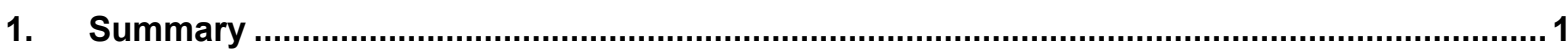

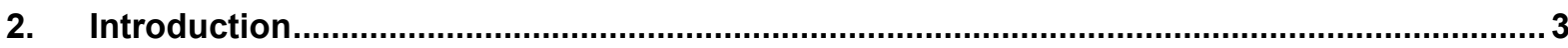

2.1. Antibiotic synthesis and resistance in the soil microbiome .............................................. 3

2.2. Antibiotic resistance crisis and the influence of land use practices ..................................6

2.3. Candidatus Udaeobacter's relevance for the soil bacterial resistome ..............................10

2.4. The Biodiversity Exploratories research project ......................................................... 11

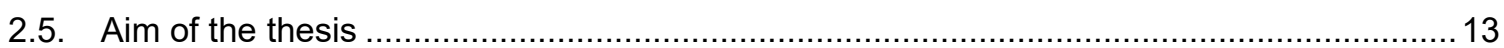

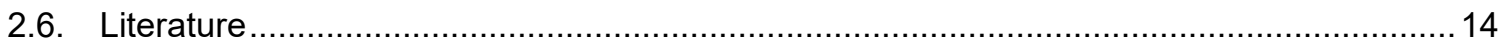

3. Distribution of Medically Relevant Antibiotic Resistance Genes and Mobile Genetic

Elements in Soils of Temperate Forests and Grasslands Varying in Land Use ...............20

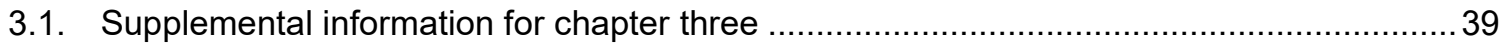

4. Discovery of Novel Antibiotic Resistance Determinants in Forest and Grassland Soil

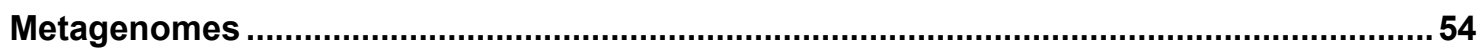

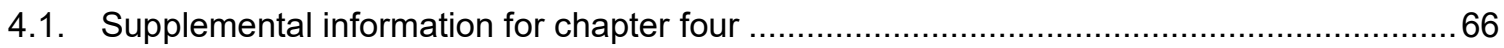

5. Globally abundant Candidatus Udaeobacter benefits from release of antibiotics in soil and potentially performs trace gas scavenging .............................................................69

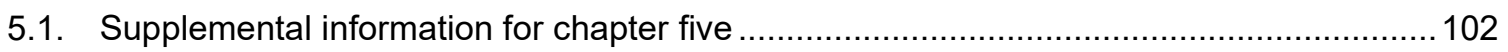

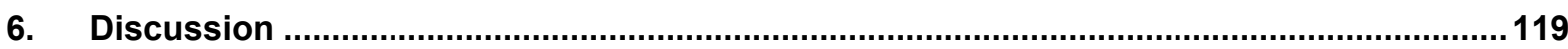

6.1. Anthropogenic and natural effectors of the soil resistome .......................................... 120

6.2. Novel sulfonamide and tetracycline resistance genes from forest and grassland soils .... 124

6.3. Antibiotic resistance properties and lifestyle features of $\mathrm{Ca}$. Udaeobacter ......................128

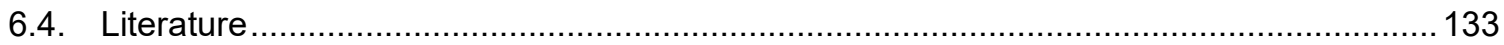

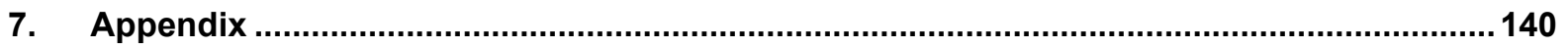

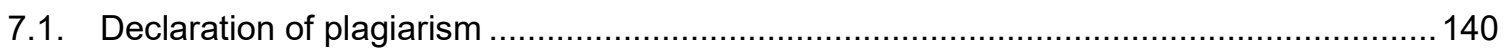

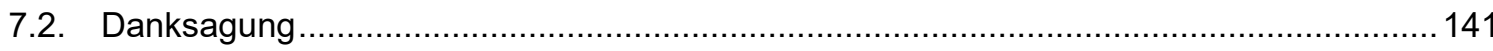

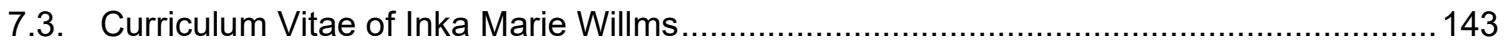




\section{Summary}

Nowadays, bacterial infections pose a serious risk for human health again, due to multi-resistant pathogens insensitive to antibiotic treatment. Some of the antibiotic resistance genes (ARGs) carried by these pathogens were most likely acquired through horizontal gene transfer (HGT), as this is a more efficient means to adapt to exposition to antibiotics than the invention of protective mechanisms by mutational changes. Many of the ARGs, identified in human pathogens, are believed to originate from microorganisms colonizing soil, where antibiotic synthesis and resistance development have coevolved for millions of years, leading to an inconceivable variety of resistance genes, also termed the soil resistome. Due to knowledge gaps in this field, the soil resistome was investigated in three different work packages within this thesis.

First, anthropogenic effectors influencing the distribution of medically relevant ARGs and mobile genetic elements (MGEs) in 300 different soils with divergent land use history were analyzed. In this context, it was determined that, except for the considered beta-lactamase genes, all target ARGs and MGEs were more frequently detected in grassland soils which are in closer proximity to human activities than the investigated forest soils. The macrolide resistance gene mefA and the sulfonamide resistance gene sul2 showed higher abundances in grassland soils that experienced organic fertilization. To potentially reduce the influence of organic fertilizers, which can originate from animals treated with antimicrobial compounds, it was proposed that the frequent veterinary utilization of macrolide preparations with long elimination half-lives should be limited and the prescription range of veterinary utilized sulfonamides reconsidered. However, the input of veterinary antibiotics, ARGs and antibiotic-resistant bacteria into the soil microbial community may be limited best, by reducing factory farming. This would decrease the infection frequency of livestock and thereby the amount of utilized antibiotics. Besides a significant effect of organic fertilization on mefA and sul2, the abundance of the aminoglycoside resistance gene $\operatorname{aac}\left(6^{\prime}\right)-1 b$ increased with mowing frequency in grassland soil and a positive correlation between the beta-lactamase gene b/aIMP-12 and fungal diversity was detected in beech forest soil.

In the second work package, parts of the so far unexplored variety of resistances against tetracyclines and the synthetic sulfonamides were investigated using function-based screenings of 
grassland and forest soil metagenomic libraries. Thereby, four major facilitator superfamily (MFS) efflux pumps conferring tetracycline resistance and four dihydropteroate synthases (DHPS) conferring sulfonamide resistance, were identified. The DHPS genes were detected in metagenomic libraries from forest soils without a history of antibiotic exposure. They support the hypothesis that resistance genes against synthetic antibiotics naturally occur in complex microbial communities and are most likely caused by mutational changes which confer resistance as a side effect. This confirms that the soil resistome is a probable source of resistance mechanisms against novel synthetic or semisynthetic antibiotics and underlines the necessity for further screenings with respect to genes conferring resistance against critically important antibiotics.

Throughout the third work package, a globally abundant soil verrucomicrobial genus, Candidatus Udaeobacter, was analyzed as the composition of the bacterial community is considered the primary determinant of the composition of the soil resistome. Thereby, it was found that these largely unexplored soil bacteria show multi-resistance and benefit from the release of antibiotics in soil. A metagenome assembled genome (MAG) from a Ca. Udaeobacter representative that showed increased growth upon antibiotics release, was analyzed in terms of features explaining this observed behavior as well as its global distribution in soil. In this context, vitamin and amino acid transporter as well as several vitamin salvage pathways were detected. This indicates that $\mathrm{Ca}$. Udaeobacter efficiently utilizes nutrients which are released by other soil bacteria as a consequence of antibiotic-driven cell lysis. Furthermore, a variety of different ARGs are encoded on the investigated MAG, including several multidrug and macrolide resistance pumps as well as beta-lactam resistance genes. Considering the globally high abundance of $\mathrm{Ca}$. Udaeobacter in soil, its ARG repertoire constitutes a huge fraction of the soil resistome. Components of this repertoire can potentially be mobilized and transferred to clinically relevant strains. These mobilization events may be fostered by environmental antibiotic pollution, especially as $\mathrm{Ca}$. Udaeobacter shows increased growth upon antibiotic exposure which further increases the proportion of the respective ARGs in the resistome. The MAG further indicated that these bacteria are able to perform hydrogen scavenging and are protected against acidic conditions which also may have contributed to the dissemination of $\mathrm{Ca}$. Udaeobacter in soils worldwide. 


\section{Introduction}

\subsection{Antibiotic synthesis and resistance in the soil microbiome}

Soil is "the most complicated biomaterial on the planet" (Surette and Wright 2017; Young and Crawford 2004). It is characterized by spatially and temporally fluctuating conditions including changes in soil moisture, oxygen saturation, $\mathrm{pH}$, salinity, temperature, accessible nitrogen or organic carbon concentration (Fierer 2017; Heuer and Smalla 2012). This high variability across small spatial scales causes the formation of innumerable microhabitats with divergent living conditions, explaining the tremendous microbial diversity in soil. In fact, estimates of the bacterial species number per gram of soil range between $10^{3}$ to $10^{5}$ whereas the bacterial cell count can exceed $10^{10}$ (Gans, Wolinsky, and Dunbar 2005; Heuer and Smalla 2012; Schloss and Handelsman 2006; Roesch et al. 2007). As a consequence of this dense colonization by a diverse prokaryotic community, different bacterial taxa compete with each other for living space and limited resources (Hibbing et al. 2010). Since competition is a strong selection pressure, the involved players must constantly adapt to their neighbors, producing a continuously evolving, highly interdependent soil bacterial community (Hibbing et al. 2010). In this context, survival strategies such as biofilm production, motility or toxin excretion can be advantageous to prevail in many different microhabitats or to conquer specific environmental niches.

Regarding toxin excretion, synthesis of antibiotics is of special interest, as these microbial secondary metabolites have become important compounds with respect to the treatment of bacterial infections throughout the past century. They are synthesized not only by bacteria but also by fungi which further increase the selection pressure and the need for adaptation within the soil bacterial community. Besides Penicillium, the fungal genus which synthesizes the first discovered natural antibiotic (penicillin) (Houbraken, Frisvad, and Samson 2011; Fleming 1929), Actinobacteria, and in particular the genus Streptomyces, are notorious for the vast variety of antibiotic classes they produce. For example, S. clavuligerus is known to synthesize different cephalosporins which belong to the beta-lactam antibiotics, S. aureofaciens produces tetracycline and Saccharopolyspora erythraea, formerly known as Streptomyces erythreae, synthesizes the macrolide erythromycin (de Lima Procópio et al. 2012). 
Different antibiotic classes are characterized by distinct modes of action, allowing their producers to kill rivals (bactericidal) or to inhibit their growth (bacteriostatic). Beta-lactam antibiotics for instance target the bacterial cell wall. In this context, the antibiotic binds to penicillin-binding proteins (PBPs). These enzymes represent transpeptidases which are responsible for the 4-3 cross-linkages between $N$-acetylmuramic acids, one of the two major building blocks of peptidoglycan (Macheboeuf et al. 2006). Since cell-growth is achieved through a balance between transpeptidases and autolysins, the binding of beta-lactam antibiotics to PBPs causes an imbalance in this interactive process and consequently cell lysis (Cho, Uehara, and Bernhardt 2014; Finch and Roger 2010). In contrast to betalactam antibiotics, tetracyclines and macrolides function bacteriostatic by inhibiting protein synthesis. Tetracyclines interact with the $30 \mathrm{~S}$ ribosomal subunit and prevent aminoacyl-tRNAs from binding to the A-site of the ribosome, whereas macrolides block the exit path of the growing peptide chain, located on the 50 S ribosomal subunit (Finch and Roger 2010). These compounds probably only make up a small part of the various antibiotics that are naturally produced in soil. However, new compounds are rarely discovered nowadays, probably because they are synthesized by uncultivatable species, making the screening process more complicated, labor-intensive and thereby unprofitable (Ling et al. 2015).

Soil bacterial communities can adapt to selective pressure, generated by antibiotic production via development of defense mechanisms encoded on antibiotic resistance genes (ARGs). Considering that this co-evolution has been taking place for millions of years, soil bacteria have had plenty of time to evolve an inconceivable variety of ARGs, the so-called soil bacterial resistome, which still conceals a vast array of unknown resistance mechanisms. In fact, novel ARGs are frequently discovered within soils by functional screenings based on metagenomic DNA or via bioinformatic analysis of metagenomic data (Lau et al. 2017; Arango-Argoty et al. 2018; Berglund et al. 2019). The corresponding resistance mechanisms either comprise intrinsic properties, allowing a general response to toxic molecules, or are received through horizontal gene transfer (HGT) and typically target specific antibiotics which is termed acquired resistance (Surette and Wright 2017). Intrinsic features constitute permeability barriers of the cell envelope which restrict antimicrobial access to target sites (e.g. the outer membrane of gramnegative bacteria), broad spectrum efflux pumps, chromosomally encoded antibiotic degradation mechanisms and the upregulation of mutational changes throughout the complete chromosome (Surette and Wright 2017; Zgurskaya, Löpez, and Gnanakaran 2015). Acquired resistance mechanisms 
include the expression of alternative target proteins, enzymes which degrade the antimicrobial agent and compound specific efflux pumps (Surette and Wright 2017; van Hoek et al. 2011). These resistance mechanisms are often encoded on mobile genetic elements (MGEs) which enable transmission via HGT throughout bacterial communities. Intrinsic resistance genes can also become acquired ARGs through integration into MGEs, referred to as gene mobilization (Bengtsson-Palme, Kristiansson, and Larsson 2018; Hall et al. 2017). A recent example for this phenomenon is the novel mobile sulfonamide resistance gene sul4 that encodes an alternative dihydropteroate synthase and was detected within a class 1 integron (Razavi et al. 2017). The difference between intrinsic and acquired resistance mechanisms and the role of MGEs is depicted in Figure 1.

Three types of MGEs, known to be relevant with respect to the spread of ARGs, are conjugative plasmids, transposons and integrons. A well-known group of conjugative broad-host range plasmids are the members of the incompatibility group 1 , also called IncP-1 plasmids. These plasmids can spread amongst virtually all gram-negative bacterial phyla and have also been detected in some gram-positive species (Popowska and Krawczyk-Balska 2013, Musovic et al. 2006). They are broadly distributed throughout all sorts of environments, including hospitals, wastewater treatment plants, manure as well as soil. They can encode a large variety of different accessory genes, including diverse families of ARGs (Popowska and Krawczyk-Balska 2013). Interactions between different types of MGEs can increase the efficiency of HGT (Dionisio, Zilhão, and Gama 2019). For instance, the IncP-1 plasmids pTB11 and pSP21 encode the transposon Tn402 which contains a class 1 integron, carrying aminoglycoside resistance genes (Popowska and Krawczyk-Balska 2013; Schlüter et al. 2007). Transposons are elements, which can translocate DNA between plasmids and chromosomes, via transposases and terminal inverted repeat regions (Partridge et al. 2018). Integrons are immobile, except when integrated into a transposon or plasmid. They capture gene cassettes into an attachment site downstream of a promoter with the action of an encoded integrase (Partridge et al. 2018).

In general, MGEs allow by far more efficient adaptation to environmental challenges than the invention of novel resistance mechanisms via mutational changes (Jain et al. 2003; Hermisson and Pennings 2005; Heuer and Smalla 2012). 


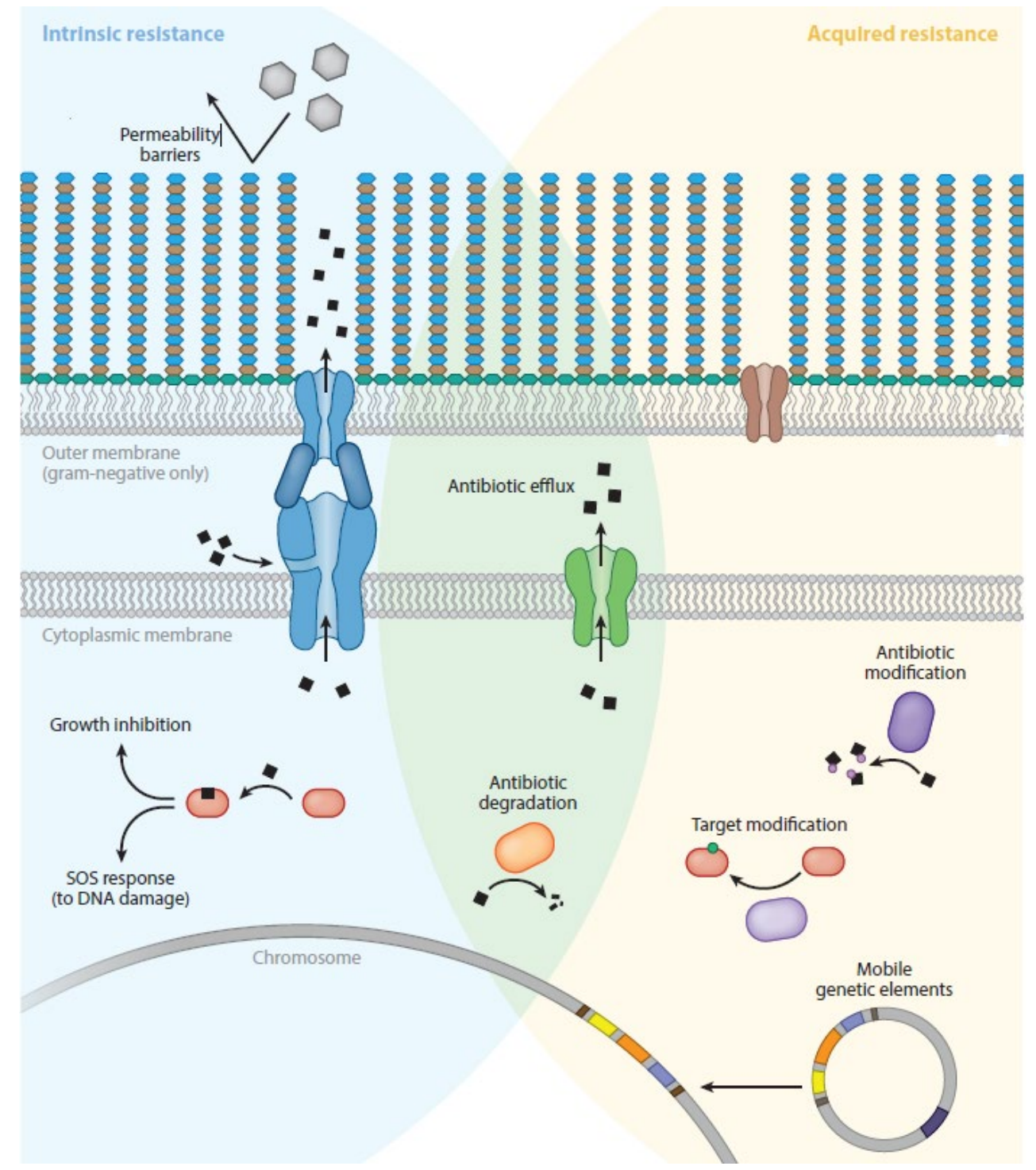

Figure 1 The intrinsic and acquired antibiotic resistomes. Intrinsic mechanisms, include drug permeability, efflux, degradation, and upregulation of genomic mutation. Acquired resistance includes altered targets, drug inactivation and efflux. The latter were mostly received through horizontal gene transfer from other species and genera. Adapted from Surette and Wright, 2017.

\subsection{Antibiotic resistance crisis and the influence of land use practices}

Nowadays, we are in an antibiotic resistance crisis as antibiotic-resistant bacteria (ARBs) have become a medical priority problem. Infections that were treatable in the past cause acute problems today and, in increasing numbers, even death. In fact, it is estimated that ARBs are responsible for 670,000 infections in Europe per year, whereof 33,000 lead to the patient's death (Cassini et al. 2019). Furthermore, they are the cause for 870,000 years under disability adjusted conditions and lead in 
Europe to health care associated costs of 1.5 billion Euro, yearly (Cassini et al. 2019, Antoñanzas and Goossens 2019). Bacterial pathogens are often not only drug resistant but can contain MGEs stocked with several different resistance mechanisms, rendering them multidrug resistant (MDR) (Partridge et al. 2018). Examples for bacteria that are frequently MDR are the ESKAPEE pathogens Enterococcus faecium, Staphylococcus aureus, Klebsiella pneumoniae, Acinetobacter baumannii, Pseudomonas aeruginosa, Enterobacter spp. and Escherichia coli (Santajit and Indrawattana 2016; Partridge et al. 2018). Another name that should be mentioned in this context is MDR Clostridium difficile which can cause infections of the gastro-intestinal tract as a consequence of an imbalance in the intestinal microflora, due to antibiotic treatment (Spigaglia, Mastrantonio, and Barbanti 2018). The ESKAPEE pathogens as well as C. difficile are notorious with respect to globally occurring nosocomial (hospital acquired) infections which are extremely difficult to treat and therefore a serious threat to human health.

Even though the highest density of ARGs is prevalent in bacteria from clinical settings (Surette and Wright 2017), the true origin of the respective genes is in most cases still unclear. As outlined above, the soil bacterial resistome comprises an inconceivably large variety of resistance genes which is very likely the origin of many pathogen encoded ARGs. This theory is supported by the mentioned fact that intrinsic resistance mechanisms can be mobilized and acquisition of ARGs through HGT is by far more efficient than the invention of novel resistance mechanisms via mutational changes. In fact, it has been discovered that specific ARGs which are encoded by known human pathogens, such as K. pneumoniae or Salmonella typhimurium, show $100 \%$ identity to genes of soil bacteria (Forsberg et al. 2012). Furthermore, evidence suggests that $A R G$ s can be transferred from harmless soil bacteria to hazardous pathogens via HGT events (Forsberg et al. 2012; Pärnänen et al. 2016). Therefore, it can be concluded that ARGs and ARBs can spread to humans through direct or indirect contact with the soil microbial community (EMA 2018; Forsberg et al. 2012; Canteón 2009). These circumstances underline the importance of the in depth study of the soil resistome in order to identify unknown resistance mechanisms that may become problematic in the future.

The occurrence of MDR pathogens is closely linked to human use of antibiotics since the middle of the $20^{\text {th }}$ century (Surette and Wright 2017). An accumulation of ARGs in MGEs and their efficient spread over species borders probably occurs much more frequently nowadays because of the selection 
pressure, established through anthropogenic antibiotic pollution (Bengtsson-Palme, Kristiansson, and Larsson 2018). Particularly relevant in this regard is the treatment of livestock in agriculture, a practice that is quite common, due to the prevalent factory farming and the associated higher infection risk of farm animals. A major fraction of all human diseases develops in animals (van Doorn 2014) that are potentially colonized by bacteria which have evolved resistance mechanisms as a result of continuous antibiotic exposure. Humans can pick up these antibiotic resistant pathogens via the food chain and fall sick with hard-to-treat infections. An example for such a food-borne infection is campylobacteriosis, a gastro-intestinal disease that is caused by Campylobacter species which are very frequently resistant to fluoroquinolones (EFSA and ECDC 2019) (bacteriocidal antibiotics that inhibit DNA replication). Another reason why antibiotic treatment of livestock is problematic is the large proportion of antibiotics that are excreted functionally by the treated animals. Consequently, manure is often enriched with the active compounds as well as with bacteria that have developed resistance against these harmful substances (Berendsen et al. 2015). When manure is applied as organic fertilizer, an increase in the abundance of medically relevant ARGs and MGEs within the soil microbial community can occur (Graham et al. 2016; Jechalke et al. 2014; Binh et al. 2007). Additionally, antibiotics, ARBs and ARGs can disseminate throughout the environment via surface water run offs, dust and migrating wild animals (Allen et al. 2010). This leads to a circulation of ARGs between soil, human and livestock, driven by the evolutionary pressure established through antibiotic application or pollution (Figure 2). 


\section{Evolution of ARGs}

in environmental bacteria

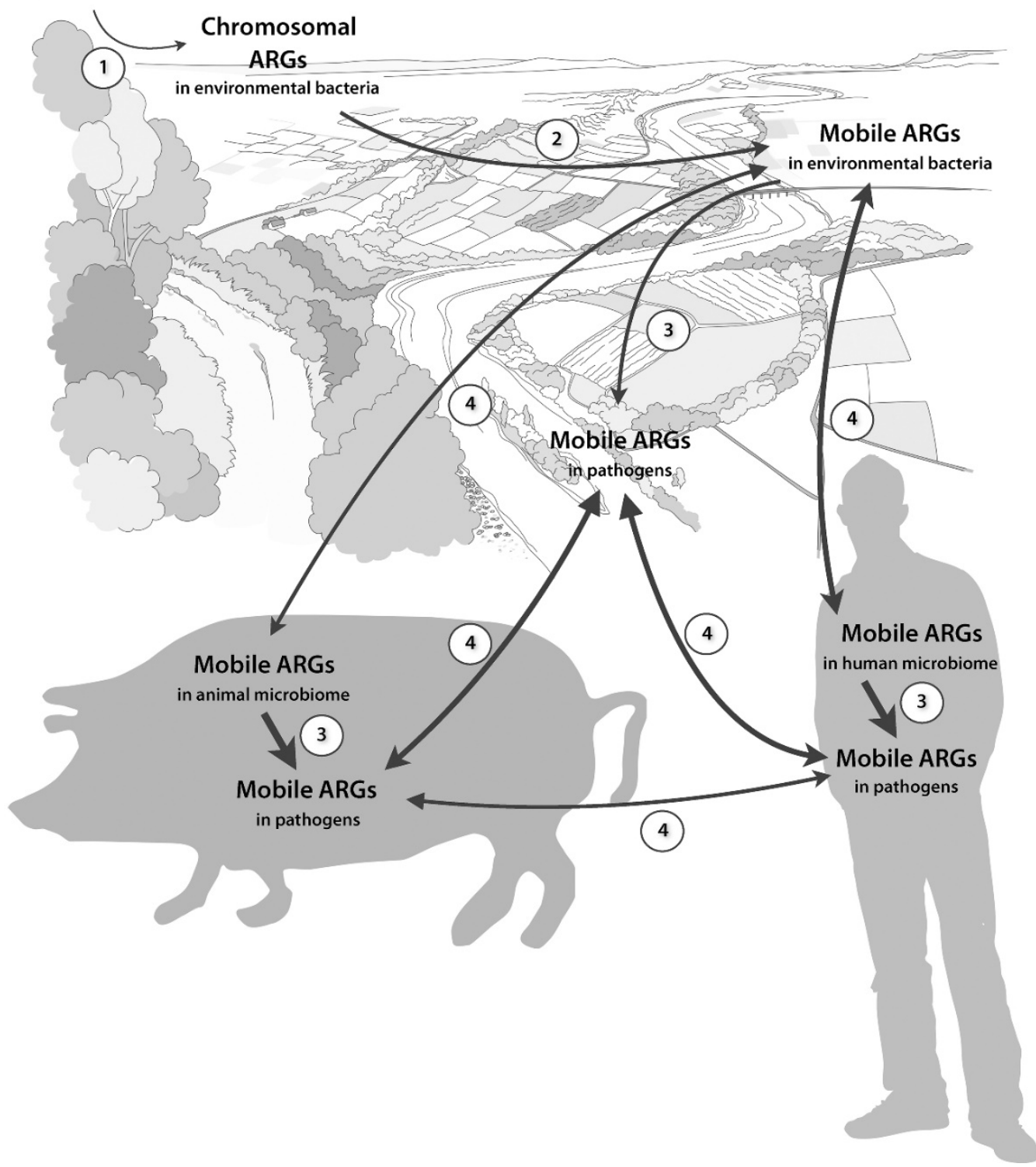

Figure 2. The role of the environment in the recruitment of antibiotic resistance genes (ARGs) to human pathogens. This takes place in four major steps: (1) emergence of novel resistance factors in the environment, (2) mobilization onto mobile genetic elements, (3) transfer of ARGs to human pathogens, and (4) dissemination of ARGs into the human microbiome. The arrow widths approximately mirror the estimated frequency of each event. Adapted from Bengtsson-Palme, Kristiansson, and Larsson 2018.

To find ways to counteract the dissemination of ARGs, it is necessary to consider the contribution of a variety of parameters, many of which are presently still elusive. For example, detailed information on the overall contribution of land use types and intensities that influence the development and transmission of ARGs in soil microbiomes need to be evaluated. Currently, most studies that address this issue focus on a small number of study plots, or set up microcosms from just one or two 
soils, and simulate land use by e.g. spiking manure with antibiotics. However, data from various soil sites over a large spatial scale with a variety of realistic land use histories is still lacking. This would allow a deeper understanding of the effect of different land use types and intensities on the abundance and transmission of ARGs and MGEs throughout soil ecosystems which could be, together with data on other environmental resistomes, useful for the development of approaches to overcome the antibiotic resistance crisis.

\subsection{Candidatus Udaeobacter's relevance for the soil bacterial resistome}

A metagenomic survey conducted by Forsberg et al. (2014) indicates that bacterial community composition is the primary determinant of ARG content in soil. Understanding how different bacterial species are involved in shaping soil resistomes requires knowledge about their lifestyle, genetic content and global abundance. Nevertheless, soil microbiomes are very challenging to study and even referred to as a black box (Tiedje et al. 1999; Cortois and De Deyn 2012). The interdependence within the soil microbial community and the diverse abiotic conditions in soil ecosystems are important reasons why the majority of soil bacteria are still uncultivated. Furthermore, due to soil microdiversity, assigning metagenomic data precisely to distinct species is very complex and bioinformatically challenging.

It is estimated that only $1 \%$ of microbial soil species have been cultivated so far (Gans, Wolinsky, and Dunbar 2005; Pedrós-Alió and Manrubia 2016). One example for an uncultivatable soil bacterial genus is Candidatus Udaeobacter (Brewer et al. 2016). Even though soil bacterial communities are commonly very diverse in response to parameters like oxygen availability, soil texture, soil moisture and pH (Kaiser et al. 2016; Delgado-Baquerizo et al. 2018), Ca. Udaeobacter was found to be amongst the $2 \%$ of bacterial phylotypes accounting for almost half of the soil bacterial communities globally (Delgado-Baquerizo et al. 2018). However, bacteria of the respective phylum (Verrucomicrobia) have long been excluded from studies uncovering the composition of soil microbial communities, due to primer-template mismatches (Bergmann et al. 2011). Therefore, only very limited information about the distribution of these bacteria is available. Nonetheless, based on a recently published metagenome assembled genome (MAG) from Ca. Udaeobacter copiosus (Brewer et al. 2016), insights into the genetic content and possible lifestyle features were revealed. The MAG indicated that $\mathrm{Ca}$. Udaeobacter copiosus exhibits auxotrophies for many putative vitamin and costly amino acid synthesis pathways. 
Furthermore, the complete genome of this species is estimated to encode approximately $2.81 \mathrm{Mbp}$ (Brewer et al. 2016). Typically, ubiquitous soil bacteria encode for larger genomes enabling flexibility toward rapidly changing conditions within their complex habitat (Barberán et al. 2014; Konstantinidis and Tiedje 2004). However, Ca. Udaeobacter seems to compensate for its limited genetic content with efficient uptake mechanisms comprising a high density of encoded peptide and amino acid transporters (Brewer et al. 2016). Hence, this species probably favors uptake of essential metabolites over synthesis. Being dependent on extracellular metabolites in a densely colonized ecosystem such as soil (Fierer 2017), likely entails increased influx and therefore vulnerability to toxic agents secreted by microorganisms competing for scarce nutrients (Leisner, Jørgensen, and Middelboe 2016). Therefore, a strategy for protection against harmful substances becomes advantageous and has potentially contributed to the evolutionary success of $\mathrm{Ca}$. Udaeobacter. This theory is supported by the enrichment of beta-lactam resistance genes, identified through functional metagenomic screening, within the phylum Verrucomicrobia (Forsberg et al. 2014). However, the actual response of Ca. Udaeobacter to antibiotics release has so far not been studied and therefore remains unclear. If the propagated hypothesis about its antibiotic resistance properties holds true, Ca. Udaeobacter is an important player to consider when analyzing the abundance and spread of ARGs due to its high occurence in soils globally.

\subsection{The Biodiversity Exploratories research project}

To evaluate the interconnectedness between different species, the influence of biodiversity on ecosystem processes and the effects of land use change on biodiversity, three large scale research sites, termed Biodiversity Exploratories, were established in 2006. They serve as study regions for scientific working groups covering various research fields such as microbiology, zoology and botany, and therefore allow comprehensive interdisciplinary research (Fischer et al. 2010). The UNESCO Biosphere Reserve Schorfheide-Chorin in Brandenburg, the National Park Hainich and surrounding areas (Hainich-Dün) in Thuringia and the UNESCO Biosphere Reserve Schwäbische-Alb in BadenWürttemberg, constitute the three exploratories which are distributed on a north-east to south-west gradient (Figure 3) (Fischer et al. 2010). The Schorheide-Chorin exploratory comprises a postglacial landscape with many wetlands, the hilly Hainich-Dün exploratory is characterized by the largest 
contiguous deciduous forest in Germany, and the Schwäbische Alb contains sub-montane to montane plateaus and a higher proportion of grasslands than forests (Fischer et al. 2010; BEO 2019).
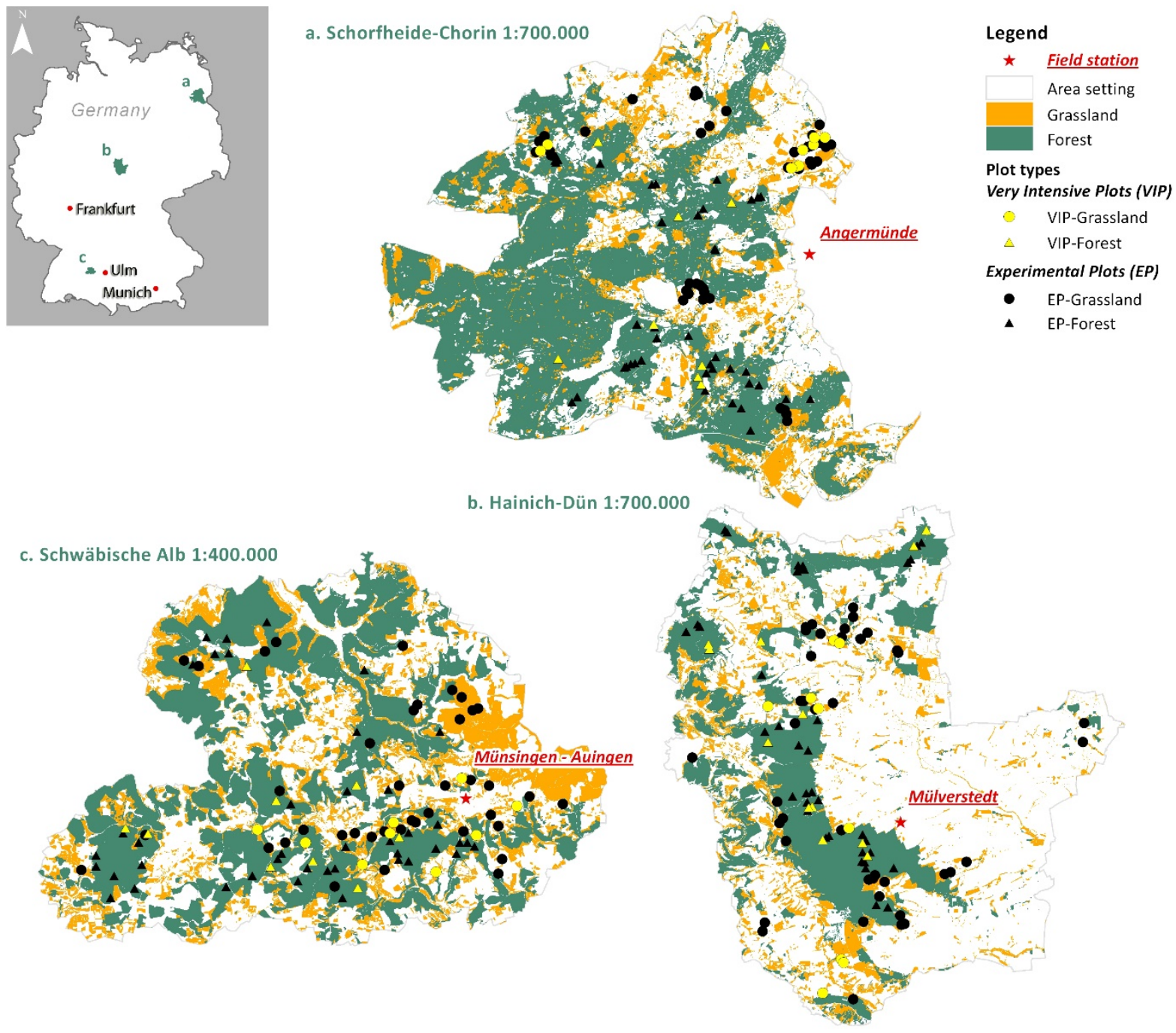

Figure 3 Locations, landscapes and sample plots of the three Biodiversity Exploratories. The figure was generated by the coordination office of the Biodiversity Exploratories (BEO).

All three exploratories have unique features that distinguish them from each other and together reflect a variety of different landscapes, soil parameters as well as land use types and intensities. Each exploratory is subdivided into 50 grassland $(50 \mathrm{~m} \times 50 \mathrm{~m})$ and 50 forest $(100 \mathrm{~m} \times 100 \mathrm{~m})$ experimental plots (EPs). The ten most intensively studied grassland and forest EPs of each exploratory are further referred to as very intensive plots (VIPs). Since 2008, a soil sampling campaign has taken place in all exploratories every three years, which enables comparability of the research results from the participating scientific groups. In this context, 14 soil cores from the upper mineral soil were collected 
at each EP along two $20 \mathrm{~m}$ (grassland EPs) or $40 \mathrm{~m}$ transects (forest EPs) (Solly et al. 2014). Furthermore, the landowners of the grassland EPs are interviewed annually about the kind and number of grazing animals, mowing frequencies as well as about the type, amount and frequency of fertilizer application (Vogt et al. 2019). Characteristics like the predominant tree species and management type of the forest EPs are determined, as well. The evaluated information is standardized and available to all participating researchers. This enables a multidisciplinary data interpretation and underlines the advantages of the Biodiversity Exploratories.

\subsection{Aim of the thesis}

This work was aimed at identifying previously unknown ARGs as well as gaining a deeper understanding on the factors that influence the transmission and accumulation of ARGs in the soil microbiome. In this context, a major focus is the globally abundant soil bacterial genus Ca. Udaeobacter, which potentially affects soil resistomes worldwide.

Three projects, comprising an array of appropriate molecular methods, were designed to address the mentioned objectives. In the first project, the occurrence and abundance of medically relevant ARGs and MGEs was determined in soil DNA from 300 forest and grassland plots via quantitative real-time PCR. The corresponding data were evaluated with respect to correlations with land use types and intensities as well as plot characteristics such as $\mathrm{pH}$, water content or dominant tree species. In the second project, functional screenings of forest and grassland soil metagenomic libraries were conducted to identify novel ARGs. Importantly, besides natural antibiotics also synthetic antimicrobials were used as selective compounds during screening. The third project was focused on Ca. Udaeobacter and its response to antibiotics release. In this context, lifestyle characteristics of this largely unexplored verrucomicrobial genus were evaluated in terms of antibiotic resistance and other specific strategies that potentially have contributed to its high and widespread occurrence in soils and thus have influenced the global soil resistance pattern. 


\subsection{Literature}

Allen HK, Donato J, Wang HH, Cloud-Hansen KA, Davies J, Handelsman J. 2010. Call of the wild: antibiotic resistance genes in natural environments. Nat Rev Microbiol 8:251-259.

Antoñanzas F, Goossens H. 2019. The economics of antibiotic resistance: a claim for personalised treatments. Eur J Heal Econ 20:483-485.

Arango-Argoty G, Garner E, Pruden A, Heath LS, Vikesland P, Zhang L. 2018. DeepARG: a deep learning approach for predicting antibiotic resistance genes from metagenomic data. Microbiome 6:23.

Barberán A, Ramirez KS, Leff JW, Bradford MA, Wall DH, Fierer N. 2014. Why are some microbes more ubiquitous than others? Predicting the habitat breadth of soil bacteria. Ecol Lett 17:794802.

Bengtsson-Palme J, Kristiansson E, Larsson DGJ. 2018. Environmental factors influencing the development and spread of antibiotic resistance. FEMS Microbiol Rev 42:fux053.

BEO. 2019. Exploratories. Accessed December 12, 2019. https://www.biodiversityexploratories.de/1/exploratories/.

Berendsen BJA, Wegh RS, Memelink J, Zuidema T, Stolker LAM. 2015. The analysis of animal faeces as a tool to monitor antibiotic usage. Talanta 132:258-268.

Berglund F, Österlund T, Boulund F, Marathe NP, Larsson DGJ, Kristiansson E. 2019. Identification and reconstruction of novel antibiotic resistance genes from metagenomes. Microbiome 7:52.

Bergmann GT, Bates ST, Eilers KG, Lauber CL, Caporaso JG, Walters WA, Knight R, Fierer N. 2011. The under-recognized dominance of Verrucomicrobia in soil bacterial communities. Soil Biol Biochem 43:1450-1455.

Binh CTT, Heuer H, Gomes NCM, Kotzerke A, Fulle M, Wilke B-M, Schloter M, Smalla K. 2007. Shortterm effects of amoxicillin on bacterial communities in manured soil. FEMS Microbiol Ecol 62:290-302.

Brewer TE, Handley KM, Carini P, Gilbert JA, Fierer N. 2016. Genome reduction in an abundant and 
ubiquitous soil bacterium 'Candidatus Udaeobacter copiosus'. Nat Microbiol 2:16198.

Canteón R. 2009. Antibiotic resistance genes from the environment: a perspective through newly identified antibiotic resistance mechanisms in the clinical setting. Clin Microbiol Infect 15:20-25.

Cassini A, Högberg LD, Plachouras D, Quattrocchi A, Hoxha A, Simonsen GS, Colomb-Cotinat M, Kretzschmar ME, Devleesschauwer B, Cecchini M, Ouakrim DA, Oliveira TC, Struelens MJ, Suetens C, Monnet DL and the Burden of AMR Collaborative Group. 2019. Attributable deaths and disability-adjusted life-years caused by infections with antibiotic-resistant bacteria in the EU and the European Economic Area in 2015: a population-level modelling analysis. Lancet Infect Dis 19:56-66.

Cho H, Uehara T, Bernhardt TG. 2014. Beta-Lactam Antibiotics Induce a Lethal Malfunctioning of the Bacterial Cell Wall Synthesis Machinery. Cell 159: 1300-1311.

Cortois R, De Deyn GB. 2012. The curse of the black box. Plant Soil 350:27-33.

Delgado-Baquerizo M, Oliverio AM, Brewer TE, Benavent-González A, Eldridge DJ, Bardgett RD, Maestre FT, Singh BK, Fierer N. 2018. A global atlas of the dominant bacteria found in soil. Science 359:320-325.

Dionisio F, Zilhão R, Gama JA. 2019. Interactions between plasmids and other mobile genetic elements affect their transmission and persistence. Plasmid 102:29-36.

Van Doorn HR. 2014. Emerging infectious diseases. Medicine (Abingdon) 42:60-63.

EFSA, ECDC. 2019. The European Union summary report on antimicrobial resistance in zoonotic and indicator bacteria from humans, animals and food in 2017. EFSA J 17:e05598.

EMA. 2018. Antimicrobial resistance in the environment: considerations for current and future risk assessment of veterinary medicinal products.

Fierer N. 2017. Embracing the Unknown: Disentangling the Complexities of the Soil Microbiome. Nature Reviews Microbiology 15:579-90.

Finch RG, Greenwood D, Whitley R, Norrby SR. 2010. Antibiotic and Chemotherapy: Anti-Infective Agents and Their Use in Therapy. $9^{\text {th }}$ ed. Saunders, Edinburgh, NY. 
Fischer M, Bossdorf O, Gockel S, Hänsel F, Hemp A, Hessenmöller D, Korte G, Nieschulze J, Pfeiffer S, Prati D, Renner S, Schöning I, Schumacher U, Wells K, Buscot F, Kalko EKV, Linsenmair KE, Schulze E-D, Weisser WW. 2010. Implementing large-scale and long-term functional biodiversity research: The Biodiversity Exploratories. Basic Appl Ecol 11:473-485.

Fleming A. 1929. On the Antibacterial Action of Cultures of a Penicillium, with Special Reference to Their Use in the Isolation of B. Influenzae. Br. J. Exp. Pathol. 10: 226-36.

Forsberg KJ, Patel S, Gibson MK, Lauber CL, Knight R, Fierer N, Dantas G. 2014. Bacterial phylogeny structures soil resistomes across habitats. Nature 509:612-616.

Forsberg KJ, Reyes A, Wang B, Selleck EM, Sommer MOA, Dantas G. 2012. The shared antibiotic resistome of soil bacteria and human pathogens. Science 337:1107-11.

Gans J, Wolinsky M, Dunbar J. 2005. Computational Improvements Reveal Great Bacterial Diversity and High Metal Toxicity in Soil. Science 309: 1387-90.

Graham DW, Knapp CW, Christensen BT, McCluskey S, Dolfing J. 2016. Appearance of $\beta$-lactam Resistance Genes in Agricultural Soils and Clinical Isolates over the $20^{\text {th }}$ Century. Sci Rep 6:21550.

Hall JPJ, Williams D, Paterson S, Harrison E, Brockhurst MA. 2017. Positive selection inhibits gene mobilization and transfer in soil bacterial communities. Nat Ecol Evol 1:1348-1353.

Hermisson J, Pennings PS. 2005. Soft Sweeps: Molecular Population Genetics of Adaptation From Standing Genetic Variation. Genetics 169:2335-2352.

Heuer H, Smalla K. 2012. Plasmids Foster Diversification and Adaptation of Bacterial Populations in Soil. FEMS Microbiol. Rev 36: 1083-1104.

Hibbing ME, Fuqua C, Parsek MR, Peterson SB. 2010. Bacterial Competition: Surviving and Thriving in the Microbial Jungle. Nat. Rev. Microbiol 8:15-25.

Van Hoek AHAM, Mevius D, Guerra B, Mullany P, Roberts AP, Aarts HJM. 2011. Acquired Antibiotic Resistance Genes: An Overview. Front Microbiol 2:203.

Houbraken J, Frisvad JC, Samson RA. 2011. Fleming's Penicillin Producing Strain Is Not Penicillium 
Chrysogenum but $P$. Rubens. IMA Fungus 2: 87-95.

Jain R, Riverae MC,Moore JE, Lake JA. 2003. Horizontal Gene Transfer Accelerates Genome Innovation and Evolution. Mol Biol Evol 20:1598-1602.

Jechalke S, Heuer H, Siemens J, Amelung W, Smalla K. 2014. Fate and effects of veterinary antibiotics in soil. Trends Microbiol 22:536-545.

Kaiser K, Wemheuer B, Korolkow V, Wemheuer F, Nacke H, Schöning I, Schrumpf M, Daniel R. 2016. Driving forces of soil bacterial community structure, diversity, and function in temperate grasslands and forests. Sci Rep 6:33696.

Konstantinidis KT, Tiedje JM. 2004. Trends between gene content and genome size in prokaryotic species with larger genomes. Proc Natl Acad Sci U S A 101:3160-3165.

Lau CH-F, van Engelen K, Gordon S, Renaud J, Topp E. 2017. Novel Antibiotic Resistance Determinants from Agricultural Soil Exposed to Antibiotics Widely Used in Human Medicine and Animal Farming. Appl Environ Microbiol 83:e00989-17.

Leisner JJ, Jørgensen NOG, Middelboe M. 2016. Predation and selection for antibiotic resistance in natural environments. Evol Appl 9:427-434.

De Lima Procópio RE, da Silva IR, Martins MK, de Azevedo JL, de Araújo JM. 2012. Antibiotics Produced by Streptomyces. Bras J Infect Dis 16:466-71.

Ling LL, Schneider T, Peoples AJ, Spoering AL, Engels I, Conlon BP, Mueller A, Schäberle TF, Hughes DE, Epstein S, Jones M, Lazarides L, Steadman VA, Cohen DR, Felix CR, Fetterman KA, Millett WP, Nitti AG, Zullo AM, Chen C, Lewis K. 2015. A new antibiotic kills pathogens without detectable resistance. Nature 517:455-459.

Macheboeuf P, Contreras-Martel C, Job V, Dideberg O, Dessen A. 2006. Penicillin Binding Proteins: Key Players in Bacterial Cell Cycle and Drug Resistance Processes. FEMS Microbiol Rev 30:673-91.

Musovic S, Oregaard G, Kroer N, Sørensen SJ. 2006. Cultivation-Independent Examination of Horizontal Transfer and Host Range of an IncP-1 Plasmid among Gram-Positive and Gram- 
Negative Bacteria Indigenous to the Barley Rhizosphere. Appl Environ Microbiol 72:6687-6692.

Pärnänen K, Karkman A, Tamminen M, Lyra C, Hultman J, Paulin L, Virta M. 2016. Evaluating the mobility potential of antibiotic resistance genes in environmental resistomes without metagenomics. Sci Rep 6:35790.

Partridge SR, Kwong SM, Firth N, Jensen SO. 2018. Mobile Genetic Elements Associated with Antimicrobial Resistance. Clin Microbiol Rev 31:e00088-17.

Pedrós-Alió C, Manrubia S. 2016. The vast unknown microbial biosphere. Proc Natl Acad Sci U S A 113:6585-7.

Popowska M, Krawczyk-Balska A. 2013. Broad-host-range IncP-1 plasmids and their resistance potential. Front Microbiol 4:44.

Razavi M, Marathe NP, Gillings MR, Flach C-F, Kristiansson E, Joakim Larsson DG. 2017. Discovery of the fourth mobile sulfonamide resistance gene. Microbiome 5:160.

Roesch LFW, Fulthorpe RR, Riva A, Casella G, Hadwin AKM, Kent AD, Daroub SH, Camargo FAO, Farmerie WG, Triplett EW. 2007. Pyrosequencing enumerates and contrasts soil microbial diversity. ISME J 1: 283-290.

Santajit S, Indrawattana N. 2016. Mechanisms of Antimicrobial Resistance in ESKAPE Pathogens. Biomed Res Int 2016:1-8.

Schloss PD, Handelsman J. 2006. Toward a Census of Bacteria in Soil. PLOS Comput Biol 2:e92.

Schlüter A, Szczepanowski R, Pühler A, Top EM. 2007. Genomics of IncP-1 antibiotic resistance plasmids isolated from wastewater treatment plants provides evidence for a widely accessible drug resistance gene pool. FEMS Microbiol Rev 31:449-477.

Solly EF, Schöning I, Boch S, Kandeler E, Marhan S, Michalzik B, Müller J, Zscheischler J, Trumbore SE, Schrumpf M. 2014. Factors controlling decomposition rates of fine root litter in temperate forests and grasslands. Plant Soil 382:203-218.

Spigaglia P, Mastrantonio P, Barbanti F. 2018. Antibiotic resistances of Clostridium difficile. Adv in Exp Med Biol 1050:137-159. 
Surette MD., Wright GD. 2017. Lessons from the Environmental Antibiotic Resistome. Annu. Rev. Microbiol 71:309-29.

Tiedje JM, Asuming-Brempong S, Nüsslein K, Marsh TL, Flynn SJ. 1999. Opening the black box of soil microbial diversity. Appl Soil Ecol 13:109-122.

Vogt J, Klaus VH, Both S, Fürstenau C, Gockel S, Gossner MM, Heinze J, Hemp A, Hölzel N, Jung K, Kleinebecker T, Lauterbach R, Lorenzen K, Ostrowski A, Otto N, Prati D, Renner S, Schumacher U, Seibold S, Simons N, Steitz I, Teuscher M, Thiele J, Weithmann S, Wells K, Wiesner K, Ayasse M, Blüthgen N, Fischer M, Weisser WW. 2019. Eleven years' data of grassland management in Germany. Biodivers data J 7:e36387.

Young IM, Crawford JW. 2004. Interactions and Self-Organization in the Soil-Microbe Complex. Science 304:1634-1637.

Zgurskaya HI, Löpez CA, Gnanakaran S. 2015. Permeability Barrier of Gram-Negative Cell Envelopes and Approaches To Bypass It. ACS Infect Dis 1:512-522. 


\section{Distribution of Medically Relevant Antibiotic}

\section{Resistance Genes and Mobile Genetic Elements in Soils of Temperate Forests and Grasslands Varying in Land Use}

Inka M. Willms ${ }^{1}$, Jingyue Yuan ${ }^{1}$, Caterina Penone ${ }^{2}$, Kezia Goldmann ${ }^{3}$, Juliane Vogt ${ }^{4}$, Tesfaye Wubet ${ }^{5,6}$, Ingo Schöning ${ }^{7}$, Marion Schrumpf ${ }^{7}$, François Buscot ${ }^{3,6}$ and Heiko Nacke ${ }^{1^{*}}$

${ }^{1}$ Department of Genomic and Applied Microbiology and Göttingen Genomics Laboratory, Institute of Microbiology and Genetics, Georg-August University of Göttingen, D-37077 Göttingen, Germany

2 Institute of Plant Sciences, University of Bern, CH-3013 Bern, Switzerland

3 Department of Soil Ecology, UFZ - Helmholtz Centre for Environmental Research, D-06120 HalleSaale, Germany

4 Terrestrial Ecology Research Group, Department of Ecology and Ecosystem Management, Technical University of Munich, D-85354 Freising, Germany

${ }^{5}$ Department of Community Ecology, UFZ - Helmholtz Centre for Environmental Research, D-06120 Halle-Saale, Germany

6 German Centre for Integrative Biodiversity Research (iDiv) Halle-Jena-Leipzig, D-04103 Leipzig, Germany

7 Max Planck Institute for Biogeochemistry, D-07745 Jena, Germany

Genes (2020), 11:150

\section{Author contribution to the work:}

Conceptualization, I.M.W and H.N.; formal analysis, I.M.W, J.Y, C.P. and H.N.; investigation, I.M.W, J.Y, K.G.; resources, H.N., M.S., T.W. and F.B.; data curation, I.M.W, K.G., I.S. J.V. ;writing-original draft preparation, I.M.W and H.N.; writing-review and editing, I.M.W, H.N., K.G., J.V., I.S., M.S., T.W. and F.B. ; visualization, I.M.W; supervision, I.M.W and H.N.; project administration, H.N.; funding acquisition, H.N. 
Article

\title{
Distribution of Medically Relevant Antibiotic Resistance Genes and Mobile Genetic Elements in Soils of Temperate Forests and Grasslands Varying in Land Use
}

\author{
Inka M. Willms ${ }^{1}$, Jingyue Yuan ${ }^{1}$, Caterina Penone ${ }^{2}{ }^{(D)}$, Kezia Goldmann $^{3}{ }^{(\mathbb{D}}$, Juliane Vogt ${ }^{4}$, \\ Tesfaye Wubet ${ }^{5,6}$, Ingo Schöning ${ }^{7}\left(\mathbb{D}\right.$, Marion Schrumpf ${ }^{7}$, François Buscot ${ }^{3,6}{ }^{(D)}$ and \\ Heiko Nacke ${ }^{1, *}$ \\ 1 Department of Genomic and Applied Microbiology and Göttingen Genomics Laboratory, \\ Institute of Microbiology and Genetics, Georg-August University of Göttingen, D-37077 Göttingen, \\ Germany; inka.willms@uni-goettingen.de (I.M.W.); jingyue.yuan@stud.uni-goettingen.de (J.Y.) \\ 2 Institute of Plant Sciences, University of Bern, CH-3013 Bern, Switzerland; caterina.penone@ips.unibe.ch \\ 3 Department of Soil Ecology, UFZ-Helmholtz Centre for Environmental Research, D-06120 Halle-Saale, \\ Germany; kezia.goldmann@ufz.de (K.G.); francois.buscot@ufz.de (F.B.) \\ 4 Terrestrial Ecology Research Group, Department of Ecology and Ecosystem Management, \\ Technical University of Munich, D-85354 Freising, Germany; juliane.vogt@tum.de \\ 5 Department of Community Ecology, UFZ—Helmholtz Centre for Environmental Research, \\ D-06120 Halle-Saale, Germany; tesfaye.wubet@ufz.de \\ 6 German Centre for Integrative Biodiversity Research (iDiv) Halle-Jena-Leipzig, D-04103 Leipzig, Germany \\ 7 Max Planck Institute for Biogeochemistry, D-07745 Jena, Germany; Ingo.Schoening@bgc-jena.mpg.de (I.S.); \\ mschrumpf@bgc-jena.mpg.de (M.S.) \\ * Correspondence: hnacke@gwdg.de; Tel.: +49-551-3933841
}

Received: 18 December 2019; Accepted: 24 January 2020; Published: 30 January 2020

\begin{abstract}
Antibiotic-resistant pathogens claim the lives of thousands of people each year and are currently considered as one of the most serious threats to public health. Apart from clinical environments, soil ecosystems also represent a major source of antibiotic resistance determinants, which can potentially disseminate across distinct microbial habitats and be acquired by human pathogens via horizontal gene transfer. Therefore, it is of global importance to retrieve comprehensive information on environmental factors, contributing to an accumulation of antibiotic resistance genes and mobile genetic elements in these ecosystems. Here, medically relevant antibiotic resistance genes, class 1 integrons and IncP-1 plasmids were quantified via real time quantitative PCR in soils derived from temperate grasslands and forests, varying in land use over a large spatial scale. The generated dataset allowed an analysis, decoupled from regional influences, and enabled the identification of land use practices and soil characteristics elevating the abundance of antibiotic resistance genes and mobile genetic elements. In grassland soils, the abundance of the macrolide resistance gene mef $A$ as well as the sulfonamide resistance gene sul 2 was positively correlated with organic fertilization and the abundance of $a a c\left(6^{\prime}\right)-l b$, conferring resistance to different aminoglycosides, increased with mowing frequency. With respect to forest soils, the beta-lactam resistance gene $b a_{I M P-12}$ was significantly correlated with fungal diversity which might be due to the fact that different fungal species can produce beta-lactams. Furthermore, except $b l a_{I M P-5}$ and $b l a_{I M P-12}$, the analyzed antibiotic resistance genes as well as IncP-1 plasmids and class-1 integrons were detected less frequently in forest soils than in soils derived from grassland that are commonly in closer proximity to human activities.
\end{abstract}

Keywords: antibiotic resistance genes; mobile genetic elements; land use; fertilization; mowing; horizontal gene transfer; forest; grassland; class 1 integrons; IncP-1 plasmids 


\section{Introduction}

Bacterial infections are still a major concern for human health due to the increasing number of antibiotic-resistant pathogens. According to a recent review on antimicrobial resistance, the number of deaths from infections with antibiotic-resistant bacteria (ARBs) might even exceed those from cancer in 2050 [1]. To counteract this prediction, a reduction of antibiotic use to a minimum is necessary. However, antibacterial preparations are still widely overused globally and sufficient knowledge on the various products is frequently lacking [2-4]. In recent years, efforts have been made to control the spread of antibiotic resistance genes (ARGs) by agencies such as the World Health Organization (WHO), the European Union agency for Disease Prevention and Control (ECDC), the European Medicines Agency (EMA) and the European Food Safety Authority (EFSA) [5]. In this context, the WHO published a report on critically important antibiotics for human medicine, based on which risk management strategies for antimicrobial use in food-producing animals can be formulated [6]. This is of high importance as a major fraction of all human diseases develop in animals [7], potentially harboring bacteria that acquired resistance as a result of exposure to antibiotics. Some of these bacteria pose risks to public health as they might cause difficult to treat infections [8]. Therefore, the European Union banned the use of antibiotic growth promoters in agriculture in 2006 [9], allowing antibiotic application only for veterinary purposes. Nevertheless, it remains questionable whether this is sufficient to significantly limit the spread of ARBs and ARGs, as veterinary antibiotics are widely used due to prevalent factory farming and the associated higher infection risk of farm animals $[10,11]$.

Although high densities of ARGs can be found in bacteria from clinical settings, the original sources of the respective genes remain largely unknown. ARGs and ARBs can potentially spread to humans through direct or indirect contact with the soil microbial community [12-14], which comprises numerous antibiotic producers but also bacteria which evolved resistance mechanisms against these harmful substances. This co-evolution resulted in an inconceivably large variety of resistance genes [15]. Moreover, the selection pressure, established through anthropogenic antibiotic pollution, can even increase the ARG abundance in soil [15-17]. Antibiotic pollution of soil is partly due to agricultural land use practices such as application of organic fertilizers (e.g., manure) [17-19]. Through antibiotic treatment of livestock, a selection pressure is established which leads to a higher proportion of resistant bacteria in the gut microbial community of the animals [20]. Additionally, antibiotics are to a large extent eliminated functionally through feces and accumulate in manure [21]. As a consequence, ARGs harbored by bacteria in organic fertilizers as well as the antibiotics themselves potentially cause the pronounced development of resistance genes in soil [22,23]. These ARGs can be encoded on mobile genetic elements (MGEs) such as IncP-1 plasmids or class 1 integrons and potentially spread to human pathogens via horizontal gene transfer (HGT) [24].

Many studies on the distribution of ARGs in non-clinical environments were focused on grassland soils. In contrast, almost no comprehensive surveys on antibiotic resistance profiles of forest soils are available [25], even though they provide information about the natural abundance and spread of resistance genes in habitats with comparably low anthropogenic influence. As grasslands are often affected by agricultural land use and typically in closer proximity to human activities than forests, direct comparisons between resistomes derived from these ecosystems are necessary to predict possible consequences of anthropogenic impacts. Furthermore, forest soil resistomes are of great interest, as effects of environmental parameters can be analyzed in natural settings. These parameters include the diversity of fungi, some of which are known to produce antibiotics such as penicillin [26], and dominant tree species as it has been shown that they can shape soil microbial communities $[27,28]$.

Here, 150 grassland and 150 forest soil samples from three geographic regions in Germany, located up to $700 \mathrm{~km}$ apart, were analyzed for the abundance of medically relevant ARGs. In addition, class 1 integrons and IncP-1 plasmids, which can contribute to the spread of antibiotic resistance, were quantified. With respect to the analyzed grassland plots, land use comprises livestock grazing, fertilization as well as mowing, and the forest plots harbor different dominant broad-leaved and coniferous tree species. 
Our comprehensive dataset allowed an analysis, decoupled from regional influences, and enabled the identification of general land use practices and soil properties increasing the abundance of ARGs and MGEs over a large spatial scale. Additionally, the study was conducted in Germany, a country, which prohibits antibiotic growth promotion in agriculture. This allowed gaining information about potential impacts of antibiotics, used for veterinary purposes but not as growth promoters, on the ARG and MGE abundance level in soil.

\section{Materials and Methods}

\subsection{Sampling, Soil Characteristics and DNA Extraction}

Samples from the upper mineral soil (0-10 $\mathrm{cm}$ without the organic layer) were derived from 300 experimental plots of the Biodiversity Exploratories Schorfheide-Chorin (northeastern Germany), Hainich-Dün (central Germany), and Schwäbische Alb (southwestern Germany) [29] in May 2017, as described by Solly et al. [30]. Each study region covers the land use types grassland and forest. Grassland plots are $50 \mathrm{~m} \times 50 \mathrm{~m}$ and forest plots are $100 \mathrm{~m} \times 100 \mathrm{~m}$ in size. The $\mathrm{pH}$ of each soil was determined as described by Solly et al. [30]. Furthermore, soil moisture was assessed daily at ten $\mathrm{cm}$ below surface with the ML2X soil Humidity Probe (Delta-T Devices, Ltd., Cambridge, UK) and the mean with respect to measurements in May 2017 was calculated. Information about organic and mineral fertilization in grasslands were derived as described by Vogt et al. [31], based on interviews with the land users. Nitrogen contents of mineral fertilizer were directly determined according to manufacturer specifications, and for organic fertilizer calculated by conversion factors according to the amount and type of slurry or manure. Furthermore, mowing frequency equates to the number of cuts per year and grazing intensity is composed of the number and type of livestock multiplied with the grazing days on a hectare. Based on these three grassland management compounds a Land Use Index (LUI) was developed by Blüthgen et al. [32] to reflect the management intensity with respect to the study plots. Detailed information on soil characteristics and land use is given in Table S1.

Microbial community DNA was isolated from the 300 soil samples by using the DNeasy PowerSoil Kit (Qiagen, Hilden, Germany) according to the manufacturer's instructions. DNA concentrations were determined using a NanoDrop ND-1000 UV-Vis Spectrophotometer (NanoDrop Technologies, Wilmington, NC, USA) as recommended by the manufacturer. Additionally, for real time quantitative PCR (qPCR) DNA concentrations were determined in quadruplicate by using the Microplate reader Synergy2 (BioTek, Winooski, VT, USA) and the QuantiFluor dsDNA System (Promega, Mannheim, Germany) following the manufacturer's instructions. Outliers were detected and discarded via the Dixon's Q-test [33].

\subsection{Soil Fungal Diversity}

The assessment of fungal diversity was based on the internal transcripted spacer (ITS) region 2. We amplified fungal ITS DNA by using proofreading Kapa Hifi polymerase (Kapa Biosystems, Boston, MA, USA) and the primers fITS7 (5'-GTGARTCATCGAATCTTTG-3') [34] and ITS4 (5'-TCCTCCGCTTATTGATATGC-3') [35] which contained Illumina adapter sequences. The PCR reactions were initiated at $95^{\circ} \mathrm{C}(3 \mathrm{~min})$ followed by 30 cycles of $98^{\circ} \mathrm{C}(20 \mathrm{~s}), 56^{\circ} \mathrm{C}(20 \mathrm{~s})$ and $72^{\circ} \mathrm{C}(20 \mathrm{~s})$, and ended with incubation at $72{ }^{\circ} \mathrm{C}$ for $5 \mathrm{~min}$. Each PCR reaction was carried out in triplicate and the created amplicons were checked by gel electrophoresis and purified with an Agencourt AMPure XP kit (Beckman Coulter, Krefeld, Germany). Illumina Nextera XT Indices were added in an additional PCR and subsequently products were purified with AMPure beads (Beckmann Coulter, Vienna, Austria). Libraries were quantified by performing PicoGreen assays (Molecular Probes, Eugene, OR, USA) and pooled to provide equimolar representation. Fragment sizes and quality of the libraries were checked using an Agilent 2100 Bioanalyzer (Agilent Technologies, Palo Alto, CA, USA). Sequencing was carried out using an Illumina MiSeq sequencer (Illumina Inc., San Diego, CA, USA) in paired-end mode and the MiSeq Reagent kit v3. 
Fungal amplicon sequencing data processing was carried out using a customized bioinformatics pipeline, mainly based on MOTHUR [36] and OBITools [37]. Prior to running this pipeline, Illumina adaptors, indices and primer sequences were removed by the software provided by Illumina. The resulting paired-end reads were merged with a minimum overlap of $20 \mathrm{bp}$ using PandaSeq [38]. Subsequently, sequences shorter than $200 \mathrm{bp}$ and those containing ambiguous nucleotides or homopolymers were removed. The average quality trimming parameter was set to Phred score 22. Potential chimeric reads were detected and removed from each sample using the UCHIME algorithm [39]. De-replicated reads were clustered into operational taxonomic units (OTUs) using the vsearch algorithm [40]. Afterwards, OTU-representative sequences were taxonomically assigned based on reference sequences provided by the Unite.v7.2 database [41]. Only OTUs affiliated to Fungi were used for further analysis. Singleton, doubleton and tripleton sequences were discarded. Remaining representative sequences were additionally checked with ITSx [42] to finally exclude non-ITS2 sequences from the dataset.

The datasets were rarefied to the smallest number of sequences per sample $(12,532)$ using the package phyloseq [43] in R version 3.5.3 [44]. This resulted in a total of 36,655 fungal OTUs in 300 soil samples. Based on this final OTU matrix, the fungal Shannon $\mathrm{H}^{\prime}$ diversity index was calculated using the R package vegan [45].

\subsection{Quantification of $16 S$ rRNA Genes, IncP-1 Plasmids and Class 1 Integrons}

All quantifications were conducted with an iQ5 real-time PCR detection system (Bio-Rad, Hercules, CA, USA). Quantification of $16 \mathrm{~S}$ rRNA genes was performed by using $12 \mathrm{ng}$ template DNA, $0.4 \mu \mathrm{M}$ of the primers BACT1369F (5'-CGGTGAATACGTTCYCGG-3') and PROK1492R (5'-GGWTA CCTTGTTACGACTT-3'), and $0.2 \mu \mathrm{M}$ of the TaqMan probe TM1389F ([FAM] 5' -CTTGTACA CACCGCCCGTC-3' [TAM]) [46]. A DNA fragment obtained via PCR using the BACT1369F and PROK1492R primer set was cloned into the vector pCR4-TOPO (Thermo Fisher Scientific, Braunschweig, Germany), as recommended by the manufacturer, to serve as standard. To quantify IncP-1 plasmids $18 \mathrm{ng}$ template DNA, $0.4 \mu \mathrm{M}$ of each of the primers $\mathrm{F}\left(5^{\prime}\right.$-TCATCGACAACGAC TACAACG-3'), R (5'-TTCTTCTTGCCCTTCGCCAG-3'), Fz (5'-TCGTGGATAACGACTACAACG-3'), Rge (5'-TTYTTCYTGCCCTTGGCCAG-3'), and Rd (5'-TTCTTGACTCCCTTCGCCAG-3'), and 0.2 $\mu \mathrm{M}$ of the TaqMan probe P ([Fam] 5'-TCAGYTCRTTGCGYTGCAGGTTCTCVAT-3' [Tam]) were used [47]. The pCR2.1-TOPO vector (Thermo Fisher Scientific) comprising an insert, amplified with the F and R primers targeting the korB gene of the RP4 plasmid [48], served as standard throughout quantification. The class 1 integron-integrase gene intI1 was quantified using $18.5 \mathrm{ng}$ template DNA, $0.4 \mu \mathrm{M}$ of each of the primers intI1-LC1 (5'-GCCTTGATGTTACCCGAGAG-3') and intI1-LC5 (5'-GATCGGTCGAATGCGTGT-3'), and $0.2 \mu \mathrm{M}$ of the intI1-probe ([FAM] 5'-ATTCCTGGCC GTGGTTCTGGGTTTT-3' [BHQ1]) [49]. Quantification of 16S rRNA genes, IncP-1 plasmids and class 1 integrons was conducted using the QuantiNova Probe PCR Kit. The cycler program for the quantification of these three targets started with an initial activation step at $95^{\circ} \mathrm{C}$ for 2 min followed by 40 cycles of denaturation at $95^{\circ} \mathrm{C}$ for $6 \mathrm{sec}$ and a combined annealing and extension step at $60{ }^{\circ} \mathrm{C}$ for $6 \mathrm{~s}$. To get comparable results from all reaction plates of the class 1 integron quantifications, four selected DNA samples were included into each of the plates, based on which the base lines were standardized.

\subsection{Detection of Antibiotic Resistance Genes via qPCR Array}

Comprehensive qPCR arrays including a total of 84 ARGs were performed based on DNA, extracted from a subset of collected soil samples. These soil samples were derived from grassland (AEG8, AEG21, HEG7, HEG21 SEG32, and SEG43) and forest (AEW2, AEW7, HEW3, HEW5, and SEW6) experimental plots located in the Schwäbische Alb, Hainich-Dün, and Schorfheide-Chorin exploratory. We selected the experimental plots as they cover different land use types and intensities as well as variations in soil properties (e.g., soil pH). Quantification of ARGs was conducted by using the Antibiotic Resistance Genes qPCR Array for microbial DNA testing (BAID-1901Z, QIAGEN). This array 
allows the quantification of 84 different ARGs in a single qPCR run (primers and probes are supplied in each well of the qPCR array). More precisely, five aminoglycoside, $57 \beta$-lactam, 14 erythromycin, five macrolide, two tetracycline and two vancomycin resistance genes were analyzed. Each reaction mixture (final volume, $25 \mu \mathrm{L}$ ) contained $12.5 \mu \mathrm{L} 2 \times$ microbial qPCR master mix (QIAGEN), $6.5 \mu \mathrm{L}$ microbial DNA-free water, and $12 \mathrm{ng}$ template DNA. A control reaction plate was set up with $10 \mathrm{mM}$ Tris buffer instead of template DNA. The following cycling conditions were used: $95^{\circ} \mathrm{C}$ for $10 \mathrm{~min}$ and 40 cycles of $95^{\circ} \mathrm{C}$ for $15 \mathrm{~s}$ and combined annealing and extension at $60^{\circ} \mathrm{C}$ for $2 \mathrm{~min}$. Based on the threshold cycle $\left(\mathrm{C}_{\mathrm{T}}\right)$ values of all detected genes, seven ARGs were selected for quantification in soil samples of all 300 experimental plots.

\subsection{Quantification of ARGs in Soils Derived from 300 Study Plots}

The aminoglycoside resistance genes $a a c\left(6^{\prime}\right)-I b$ and $a a c C 1$, the $\beta$-lactam resistance genes $b l a_{\mathrm{IMP}-12}$ and $b l a_{\mathrm{IMP}-5}$, the macrolide-lincosamide-streptogramin B (MLS) resistance gene ermB, the macrolide resistance gene mefA as well as the tetracycline resistance gene tet $A$ were quantified based on soil DNA derived from all 300 experimental plots by using a customized qPCR array kit (QIAGEN). Each customized qPCR array contained quantification reactions of the seven selected ARGs in 11 different soil DNA samples and a negative control. Positive control reactions were included to test for the presence of inhibitors. The reaction mixture (final volume, $25 \mu \mathrm{L}$ ) contained $12.5 \mu \mathrm{L} 2 \times$ microbial qPCR master mix (QIAGEN) and $25 \mathrm{ng}$ template DNA. In case of negative controls, buffer was added instead of DNA. The cycling conditions were the same as for the qPCR arrays mentioned above.

The reactions were standardized by adjusting the baseline manually to the level of the 12 positive control reactions in each array across all qPCR runs.

Besides the seven ARGs that were selected based on comprehensive qPCR arrays, we quantified the sulfonamide resistance gene sul2. For the quantification of sul2, the QuantiNova SYBR Green PCR Kit (Qiagen), $19 \mathrm{ng}$ template DNA, and $0.7 \mu \mathrm{M}$ of each of the primers sul2-forward (5'-TCATCTGCCAAACTCGTCGTTA-3') and sul2-reverse (5'-GTCAAAGAACGCCGCAATGT-3') [50,51] were used. Results of the quantifications from different reaction plates were standardized by including four selected samples into each plate, based on which the baseline was adjusted. The cycler program comprised an initial activation step at $95^{\circ} \mathrm{C}$ for $10 \mathrm{~min}$ followed by 40 cycles of $95^{\circ} \mathrm{C}$ for $5 \mathrm{~s}$ and a combined annealing and extension step at $60^{\circ} \mathrm{C}$ for $10 \mathrm{~s}$. A melting curve analysis was conducted to determine the specificity of amplification during PCR. Reactions with aberrant melting curves were designated as not accessible (NA).

\subsection{Statistical Analysis}

With respect to all conducted quantification reactions, samples that did not exceed the baseline before the 37th cycle, were regarded as non-detects as described by Hu et al. and Zhao et al. [52,53].

The abundance and occurrence of IncP-1 plasmids, class 1 integrons and the eight selected ARGs were analyzed with $\mathrm{R}$. In order to identify soil characteristics as well as land use practices affecting the quantified genes, two regression approaches were carried out:

(1) A binomial regression approach to analyze the distribution of positive quantifications against non-detects. In this context, the original $\mathrm{C}_{\mathrm{T}}$ values were transformed into binary data. More precisely, $C_{T}$ values $<37$ were replaced with a one and $C_{T}$ values $\geq 37$ with a zero.

(2) A left censored regression analysis was performed with the tobit function of the R package AER [54] to address the differential relative gene abundance in all sample plots without having to substitute or discard non-detects. For this purpose, $\Delta C_{T}$ values were calculated as follows:

$$
C_{T(\text { Reference Gene })}-C_{T(\text { Target Gene })}=\Delta C_{T}
$$

where $C_{T}$ values from the $16 \mathrm{~S}$ rRNA gene quantifications served as $C_{T(\text { Reference Gene). The }} \Delta C_{T}$ values of all target sequences are listed in Table S2. They were used for tobit regression analysis, where large 
$\Delta C_{T}$ values indicate high gene abundance. Furthermore, the lowest $\Delta C_{T}$ value of a positive reaction reduced by 0.01 was assigned to quantifications of specific genes, which resulted in non-detects. The non-detect $\Delta \mathrm{C}_{\mathrm{T}}$ value was used as left limit for the censored dependent variable in the tobit formula. In case of all tobit models, a Gaussian distribution was applied.

For the statistical analysis, independent variables were scaled and centered with the basic scale function of $\mathrm{R}$ and checked for collinearity with the basic $\mathrm{R}$ function rcorr and the corrplot function of the R package corrplot [55]. Afterwards, it was tested whether specific genes occur notably more often in grassland than in forest soil. In this context, the occurrence (binomial model) or relative abundance (tobit model) of the respective genes, which showed less than $80 \%$ non-detects ( $80 \%$ censoring), were modeled against the two independent variables forest ( 1 or 0 ) and exploratory (Schorfheide-Chorin, Hainich-Dün or Schwäbische Alb). The $2^{\Delta \mathrm{CT}}$ values of targets that were less than $80 \%$ censored (IncP-1 plasmids, class 1 integrons, mefA, aac (6')-Ib, sul2, tet $A$, bla $a_{\mathrm{IMP}-12}$ and $\left.b l a_{\mathrm{IMP}-5}\right)$ were visualized with the cenboxplot function of the NADA package [56] with a range of 1.5 for forests, grasslands and each exploratory. When insufficient numbers of uncensored observations were available to estimate the distribution below the censoring threshold in the respective area $\left(m e f A, a a c\left(6^{\prime}\right)-l b\right.$, tet $A$ and class 1 integrons in forest plots), the boxplot function of basic $\mathrm{R}$ was utilized which does not allow an estimation for the censored values. The highest censoring threshold of all candidate genes was indicated with a horizontal red line. Everything below this line was calculated based on the proportion of censored data and the values of uncensored data with cenros of NADA.

When targets were less than 70\% censored in grassland plots, the impact of agricultural land use such as mowing, fertilization, and grazing was analyzed. This analysis comprised the LUI. The $\mathrm{pH}$ or the mean soil moisture in \%, determined in May 2017, was added as independent variable in the models for the grassland soils to account for the different soil characteristics of the 300 experimental plots, because they turned out to be the best soil descriptors for the analyzed genes. Due to variable collinearity, only one of these two parameters was chosen, based on quality comparisons of the respective gene models. In the first step, only one land use variable along with the $\mathrm{pH}$ or the soil moisture was modeled at a time, to evade the influence of collinearity between the different land use practices onto the model output. Based on these preliminary models, final models were derived, containing the most influential land use variables.

Regarding forest soils, the influence of the tree type and the fungal Shannon diversity on the abundance and occurrence of the two $\beta$-lactamase genes was statistically analyzed.

The residuals of all tobit models were tested for normality and constant variance with quantile-quantile plots and residual plots. Furthermore, in order to compare the influence of variable exchange on model quality, the McFadden's pseudo- $R^{2}$ [57] was determined for all generated models. With respect to the final models for analysis of land use effects in grassland or forest, either the binomial or tobit approach was supposed to construct a model with an $\mathrm{R}^{2}$ of at least 0.1 . Furthermore, the two approaches were supposed to reveal the same correlation (positive or negative) and yield similar p-values. When final models explained less than $10 \%$ of the variance with respect to the dependent variable for both approaches (binomial and tobit) or only the binomial approach was applicable due to too high censoring, no conclusions with respect to the impact of land use were drawn.

\section{Results}

\subsection{Selection of Targets for ARG Quantification in Forest and Grassland Soils}

A total of 84 ARGs were quantified in a subset of soil samples derived from three different geographic regions in Germany (Hainich-Dün, Schorfheide-Chorin and Schwäbische Alb). This subset covers beech and spruce forest soils as well as grassland soils affected by different land use intensities. The very low $C_{T}$ values and detection frequencies with respect to the majority of the 84 ARGs restricted the selection of targets for qPCR-based analysis comprising DNA extracted from each of the 300 experimental plots. The aminoglycoside resistance genes $a a c\left(6^{\prime}\right)-\mathrm{Ib}$ and $a a c C 1$, the beta-lactam resistance 
genes $b l a_{\mathrm{IMP}-12}$ and $b l a_{\mathrm{IMP}-5}$, the MLS resistance gene $\mathrm{erm} B$, the macrolide resistance gene mef $A$ and the tetracycline resistance gene $t e t A$, were chosen for this analysis, which allowed the identification of factors significantly shaping forest and grassland soil resistomes. The analyzed factors comprise land use practices (fertilization, grazing and mowing) as well as dominant tree species and soil fungal diversity. Furthermore, besides resistances to representatives of the mentioned antibiotic classes, the sulfonamide resistance gene sul2 was considered.

\subsection{IncP-1 Plasmids, mefA and sul2 Are More Abundant in Grassland than in Forest Soils}

In order to identify differences in occurrence and relative abundance of the selected ARGs, IncP-1 plasmids as well as class 1 integrons between forest and grassland soils, statistical analysis was carried out. Binomial generalized linear models revealed that the occurrence of $a a c\left(6^{\prime}\right)-l b, \operatorname{mef} A, \operatorname{sul2,}$ tet $A$, IncP-1 plasmids and class 1 integrons was significantly negatively correlated with forest soils ( $p$-values: $4.29 \times 10^{-6}, 4.62 \times 10^{-11}, 1.81 \times 10^{-6}, 0.00145,2.27 \times 10^{-15}$ and 0.00159 , respectively; estimates: -4.7632 , $-4.01039,-1.5767,-3.2825,-2.2824$ and -3.2585 , respectively; $R^{2}: 0.39,0.33,0.09,0.20,0.21$ and 0.17 , respectively). This trend could be validated for $m e f A$, sul2 and the IncP-1 plasmids by modelling their relative abundances based on censored tobit models. Again, a statistically significant negative impact of forest soils on mef $A$, sul2 and IncP-1 plasmid abundance could be determined ( $p$-values: $7.85 \times 10^{-14}$, $3.08 \times 10^{-7}$ and $<2 \times 10^{-16}$, respectively; estimates: $-5.45,-5.56$ and -3.74 , respectively; $R^{2}: 0.19,0.06$, and 0.09 , respectively). Due to a very low abundance of $a a c\left(6^{\prime}\right)-l b$, tet $A$ and class 1 integrons in forest soils, increasing the proportional number of censored samples to over $80 \%$, statistical analysis was restricted to binomial generalized models with respect to these genes.

Both, the occurrence and relative abundance, of the two $\beta$-lactamase genes $b l a_{\mathrm{IMP}-12}$ and $b l a_{\mathrm{IMP}-5}$ did not significantly differ between grassland and forest soils. This was revealed by the binomial model approach ( $p$-values: 0.79 and 0.78 , respectively; estimate: 0.06 and 0.08 , respectively; $R^{2}: 0.05$ and 0.1 , respectively) and the tobit models ( $p$-values: 0.98 and 0.7 , respectively; estimate: 0.01 and -0.17 , respectively; R2: 0.03 and 0.06, respectively). The relative abundance of the quantified ARGs and MGEs in forest and grassland soils is depicted in censored boxplots (Figure 1). As ermB and aacC1 were only detected in 13 and 5 of the 300 soil samples, respectively, they could not be considered in the statistical analysis. 

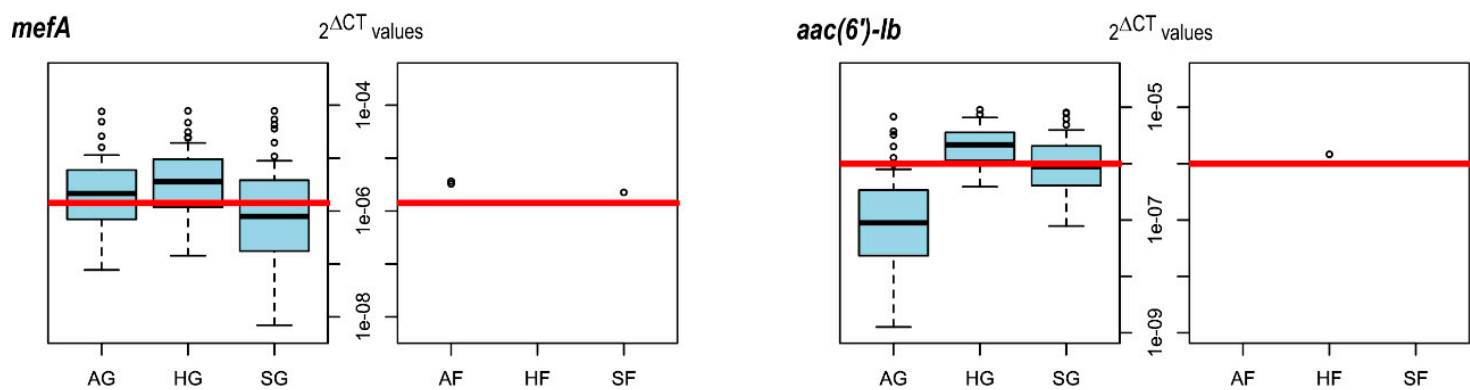

sul2 ${ }_{2}^{\Delta C T}$ values

tetA
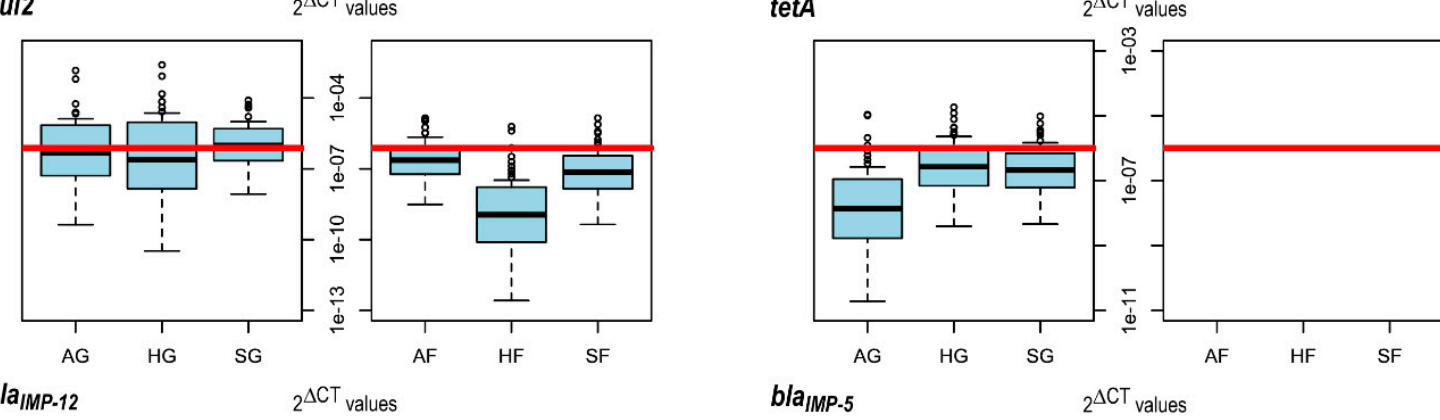

blaIMP-12 $2^{\Delta C T}$ values
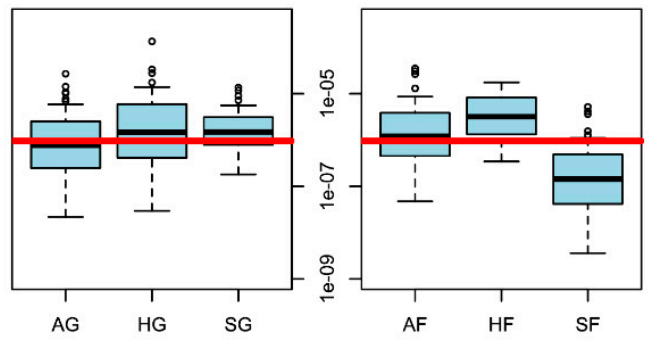

IncP-1 plasmids $2^{\Delta C T}$ values
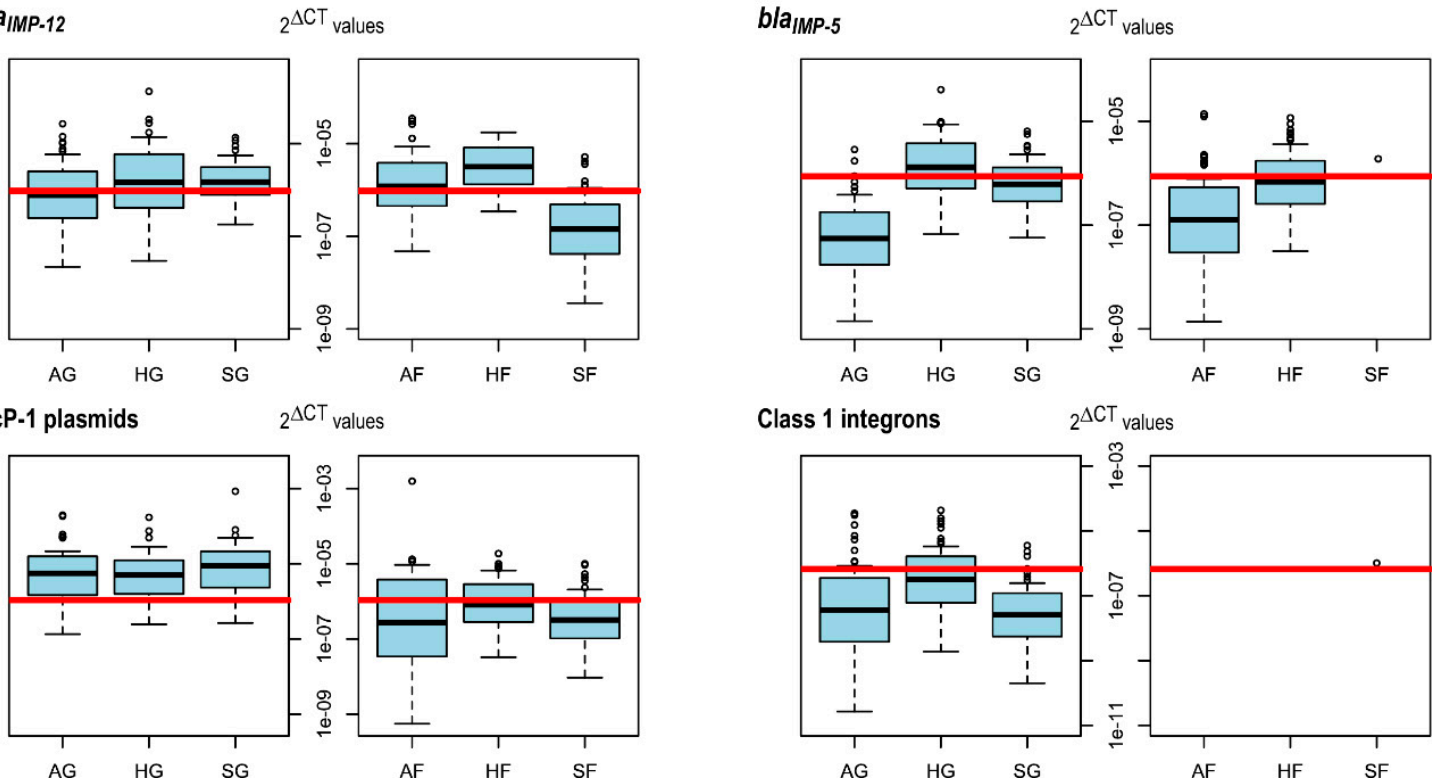

Figure 1. Censored boxplots depicting $2^{\Delta \mathrm{CT}}$ values of quantified antibiotic resistance genes and mobile genetic elements. The red horizontal line indicates the highest censoring threshold. Everything below this line was estimated. The whiskers represent 1.5 times the outer quartile range. AG, HG and SG represent Schwäbische-Alb, Hainich-Dün and Schorfheide-Chorin grassland soils, respectively, whereas AF, HF and SF represent Schwäbische-Alb, Hainich-Dün and Schorfheide-Chorin forest soils, respectively.

\subsection{Land Use Practices in Grassland Affect the Abundances of aac ( $\left.6^{\prime}\right)-l b$, mefA and sul2}

With respect to the occurrence and relative abundance of $a a c\left(6^{\prime}\right)-l b$, mef $A$ and sul2 in grassland soils, statistically significant correlations with land use were identified (Table 1$)$. The occurrence of $a a c\left(6^{\prime}\right)-l b$ is positively correlated with the mowing frequency and soil $\mathrm{pH}$ ( $\mathrm{p}$-values: 0.03 and $7.4 \times 10^{-7}$; estimate: 0.45 and $\left.1.74 ; R^{2}: 0.21\right)$. This trend could be validated with the tobit model focusing on the relative gene abundance ( $p$-values: 0.044 and $1.5 \times 10^{-7}$; estimate 0.37 and $1.65 ; \mathrm{R}^{2}: 0.12$ ). Furthermore, the occurrence of mefA is positively influenced by nitrogen input from organic fertilizers and negatively influenced by the soil moisture content ( $p$-values: $9.4 \times 10^{-4}$ and $3 \times 10^{-3}$, estimate: 1.14 and -0.68 ; $\left.R^{2}: 0.24\right)$, which was again validated by the tobit model ( $p$-values: $3.9 \times 10^{-3}$ and $9.2 \times 10^{-5}$; estimate: 0.64 and $\left.-1.01 ; R^{2}: 0.11\right)$. The occurrence and relative abundance of the sul2 gene is also significantly 
more pronounced in grassland soils, which experienced high nitrogen input from organic fertilizers (binomial model: $p$-value: 0.01 ; estimate: $0.53 ; \mathrm{R}^{2}$ : 0.1 ; tobit model: $p$-value: $2.2 \times 10^{-3}$; estimate: 1.6 ; $\left.\mathrm{R}^{2}: 0.08\right)$.

Table 1. Final regression models of the occurrence (binomial model: A) or relative abundance (tobit model: B) of antibiotic resistance genes. At least one of the two models was supposed to explain $\geq 10 \%$ of the variance $\left(\mathrm{R}^{2}\right)$ and $p$ values $<0.05$ were considered significant (highlighted in bold). The outer left column lists the dependent (shown in bold) and independent variables of each model (also intercept is considered with respect to each model). The models below the dashed bar focus on bla $_{I M P-12}$ in forest soils and the other models focus on $a a c\left(6^{\prime}\right)-l b$, mefA and sul2 in grassland soils. Est. is the abbreviation for estimate, Moisture for soil moisture, Shan- $\mathrm{H}$ for fungal diversity as assessed by Shannon index, Df stands for degrees of freedom and Null/Resid. for the null or residual deviance, respectively.

\begin{tabular}{|c|c|c|c|c|c|c|c|c|c|c|}
\hline & A & & & & & B & & & & \\
\hline & $p$ & Est. & $\mathbf{R}^{2}$ & Df & Null/Resid. & $p$ & Est. & $\mathbf{R}^{2}$ & Df & Null/Resid. \\
\hline $\begin{array}{l}\text { aac }\left(6^{\prime}\right)-l b \\
\text { Intercept } \\
\text { Mowing } \\
\text { pH }\end{array}$ & $\begin{array}{l}3.8 \times 10^{-7} \\
\mathbf{0 . 0 3} \\
\mathbf{7 . 4} \times \mathbf{1 0}^{-7}\end{array}$ & $\begin{array}{l}-12.29 \\
0.45 \\
1.74 \\
\end{array}$ & 0.21 & 143 & $191.3 / 152$ & $\begin{array}{l}<2 \times 10^{-16} \\
4.4 \times 10^{-2} \\
1.5 \times 10^{-7}\end{array}$ & $\begin{array}{l}-31.49 \\
0.37 \\
1.65 \\
\end{array}$ & 0.12 & 142 & $333.7 / 292.7$ \\
\hline $\begin{array}{l}m e f A \\
\text { Intercept } \\
\text { Mowing } \\
\text { Org. N } \\
\text { Moisture }\end{array}$ & $\begin{array}{l}0.02 \\
0.13 \\
9.4 \times 10^{-4} \\
3.0 \times 10^{-3}\end{array}$ & $\begin{array}{l}0.52 \\
0.33 \\
\mathbf{1 . 1 4} \\
\mathbf{- 0 . 6 8}\end{array}$ & 0.24 & 140 & $198.6 / 163$ & $\begin{array}{l}<2 \times 10^{-16} \\
8.1 \times 10^{-2} \\
3.9 \times 10^{-3} \\
\mathbf{9 . 2} \times \mathbf{1 0}^{-5}\end{array}$ & $\begin{array}{l}-18.81 \\
0.41 \\
\mathbf{0 . 6 4} \\
\mathbf{- 1 . 0 1}\end{array}$ & 0.11 & 141 & 198.6/178.5 \\
\hline $\begin{array}{l}\text { sul2 } \\
\text { Intercept } \\
\text { Org. N } \\
\text { Moisture }\end{array}$ & $\begin{array}{l}9.3 \times 10^{-4} \\
\mathbf{0 . 0 1} \\
0.10\end{array}$ & $\begin{array}{l}-0.62 \\
\mathbf{0 . 5 3} \\
-0.37\end{array}$ & 0.1 & 140 & 182.5/171.6 & $\begin{array}{l}<2 \times 10^{-16} \\
2.2 \times 10^{-3} \\
8.9 \times 10^{-2}\end{array}$ & $\begin{array}{l}-22.18 \\
1.60 \\
-\mathbf{1 . 1 4}\end{array}$ & 0.08 & 140 & $182.5 / 177.9$ \\
\hline $\begin{array}{l}b l a_{\text {IMP-12 }} \\
\text { Intercept } \\
\text { Beech } \\
\text { Shan-H }\end{array}$ & $\begin{array}{l}8.4 \times 10^{-4} \\
7.0 \times 10^{-5} \\
4.6 \times 10^{-3}\end{array}$ & $\begin{array}{l}-1.64 \\
2.13 \\
0.65\end{array}$ & 0.17 & 133 & $188.5 / 155.6$ & $\begin{array}{l}<2 \times 10^{-16} \\
7.4 \times 10^{-6} \\
2.4 \times 10^{-3}\end{array}$ & $\begin{array}{l}-21.93 \\
2.75 \\
0.73\end{array}$ & 0.09 & 132 & $417.1 / 380.7$ \\
\hline
\end{tabular}

With respect to tet $A$ and class 1 integrons, statistical analysis was restricted to binomial models (Table S3) as both genes were over 70\% censored in grassland samples. Only the binomial model comprising the LUI indicated a significantly positive correlation with the gene occurrence of tet $A$ ( $p$-value: 0.03 ; estimate: $0.48 ; \mathrm{R}^{2}: 0.11$ ). Moreover, the class 1 integrons seem to be affected by a number of land use variables. The occurrence of these MGEs was positively correlated with grazing and negatively correlated with mowing, fertilization, mineral $\mathrm{N}$ input, organic $\mathrm{N}$ input and LUI.

When analyzing IncP-1 plasmids as well as bla-IMP12 and bla-IMP5 in grassland soils, none of the two approaches (binomial and tobit model approach) revealed a statistically significant influence of a land use variable with a sufficient $\mathrm{R}^{2}$ (Table S3).

\subsection{The Abundance of bla ${ }_{I M P-12}$ Increases with Fungal Diversity in Forest Soil}

The gene $b l a_{\mathrm{IMP}-12}$ could be detected more frequently in beech forest and at sites with a high fungal diversity compared to other considered forest sites ( $p$-values: $7 \times 10^{-5}$ and $4.6 \times 10^{-3}$; estimate: 2.13 and $0.65 ; \mathrm{R}^{2}: 0.17$ ) (Table 1). The tobit approach, modelling the relative abundance of this gene, supports this finding ( $p$-values: $7.4 \times 10^{-6}$ and $2.4 \times 10^{-3}$; estimate: 2.75 and $0.73 ; \mathrm{R}^{2}: 0.09$ ). With respect to $b l a_{\mathrm{IMP}-5}$ the same trend could be detected, but the model quality is below the quality threshold (Table S3). In general, $b l a_{\mathrm{IMP}-12}$ and $b l a_{\mathrm{IMP}-5}$ were the only analyzed genes, which were not significantly more abundant in grassland than in forest soils. Regarding the grassland soils, no environmental parameter could be identified which impacts the abundance of these genes. 


\section{Discussion}

In this study, a general difference between grassland and forest soils with respect to the occurrence of selected ARGs and MGEs was visible. All selected ARGs, except the two $\beta$-lactamase genes $b l a_{\mathrm{IMP}-12}$ and $b l a_{\mathrm{IMP}-5}$, as well as IncP-1 plasmids and class 1 integrons were more frequently detected in grassland than in forest soils (Figure 1). This might partly be due to differences in soil bacterial community composition between forest and grassland, which were detected in a previous study comprising all analyzed experimental plots [58]. In accordance with this theory, Forsberg et al. [59] identified bacterial community composition as a major determinant of antibiotic resistance gene content based on metagenomic analysis of agricultural and grassland soil. The lower $\mathrm{pH}$ in forest soils (Table S1) potentially contributes to variations in ARG as well as MGE abundance as this abiotic parameter has previously been shown to be a key driver of soil bacterial community composition $[58,60,61]$. This assumption is supported by the identified significant positive correlation between $\mathrm{pH}$ and the abundance of the $a a c\left(6^{\prime}\right)-l b$ gene in grassland soil. Another possible explanation for the identified differences between forest and grassland ecosystems might be proximity to anthropogenic activities with respect to grassland sites, which comprise the use of antibiotics in human and veterinary medicine as well as associated ARBs, ARGs and MGEs [62]. When the two ecosystems were analyzed separately, we determined a statistically sound relationship between land use and the abundance of the medically relevant ARGs mefA, sul2 and $a a c\left(6^{\prime}\right)-l b$ in grassland soil. Additionally, it was possible to identify factors controlling the abundance of the $\beta$-lactamase gene $b a_{\mathrm{IMP}-12}$ in forest soil (Table 2).

Table 2. Summary of factors significantly affecting target antibiotic resistance genes and mobile genetic elements in soil ecosystems analyzed in this study. Targets showing increased occurrence as well as relative abundance in grassland compared to forest soil are depicted. Furthermore, factors significantly influencing the occurrence as well as relative abundance of targets in grassland (mowing frequency and organic nitrogen input) or forest soil (fungal diversity and beech as dominant tree species) are depicted.

\begin{tabular}{|c|c|c|c|}
\hline Target & $\begin{array}{l}\text { Occurrence and Relative } \\
\text { Abundance Significantly } \\
\text { Increased in Grassland } \\
\text { Compared to Forest Soil }\end{array}$ & $\begin{array}{c}\text { Factors Significantly } \\
\text { Influencing Target } \\
\text { Occurrence and Relative } \\
\text { Abundance in Grassland Soil }\end{array}$ & $\begin{array}{l}\text { Factors Significantly } \\
\text { Influencing Target } \\
\text { Occurrence and Relative } \\
\text { Abundance in Forest Soil }\end{array}$ \\
\hline IncP-1 & Yes & - & - \\
\hline$a a c\left(6^{\prime}\right)-l b$ & Further analysis required * & Mowing frequency and $\mathrm{pH}$ & - \\
\hline mefA & Yes & Organic nitrogen input & - \\
\hline sul2 & Yes & $\begin{array}{l}\text { Organic nitrogen input and } \\
\text { soil moisture }\end{array}$ & - \\
\hline$b l a_{\mathrm{IMP}-12}$ & No & 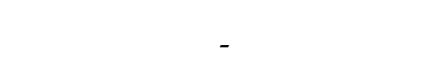 & $\begin{array}{l}\text { Fungal diversity and beech } \\
\text { as dominant tree species }\end{array}$ \\
\hline
\end{tabular}

\section{1. sul2 and mefA}

Both, the occurrence as well as the relative abundance of sul2 and mefA were affected by organic fertilizer application in grassland. The sulfonamide resistance gene sul2 encodes an alternative dihydropteroate synthase and is often located on small promiscuous plasmids of the IncQ incompatibility group $[63,64]$. These plasmids allow the dissemination of sul2 among gram-positive and gram-negative bacterial hosts [65]. They have already been identified in a variety of different species including the pathogenic Enterobacteriaceae Salmonella enterica [66], Klebsiella pneumoniae [67] and Escherichia coli, isolated from German cattle [68]. Based on communications with veterinarians working in the study regions, it was confirmed that sulfonamides together with trimethoprim are frequently used to treat cattle, as the authorization for corresponding pharmaceutical preparations 
have a broad spectrum, including infections of the gastrointestinal tract, the urinary- and reproductive system as well as the skin, joints and hoof.

The quantified resistance gene $m e f A$ encodes an efflux protein of the major facilitator superfamily class which extrudes 14- and 15-membered macrolides (e.g., erythromycin or tulathromycin) out of the bacterial cell [69]. It has originally been identified in Streptococcus pyogenes, which causes infections of the upper respiratory tract and the skin as well as a variety of systemic infections in humans [70], but also in the pathogen Streptococcus pneumoniae [71]. In fact, mefA can be carried by conjugative transposons like Tn1207.3, which enable its spread among different streptococcal species [72,73]. Despite the recent categorization of macrolides as critically important in veterinary medicine according to the World Organization for Animal Health (OIE) [74], especially tulathromycin is still frequently applied for bovine respiratory diseases of calves and young cattle [75], which was confirmed by the contacted veterinarians. When several animals from a group of calves purchased from different sources fall ill, it is also common to treat the entire group. This procedure is called metaphylactic treatment. Organic cattle farms usually forego metaphylactic applications with tulathromycin, but individual treatments of calves with respiratory diseases are still conducted when necessary. A reason for the frequent application of tulathromycin is its functionality against mycoplasma species, one of the major causative agents for respiratory infections in calves [76]. As these bacteria lack a cell wall, they are intrinsically resistant against $\beta$-lactam antibiotics. Tulathromycin has to be administered only once due to a consistently high drug-level over longer times. It has an elimination half time in cattle of approximately $90 \mathrm{~h}$, which is far higher than that of erythromycin (3-16 h) [75,77]. Macrolides with longer elimination half times are suspected to promote higher resistance development due to longer exposure of bacteria to sub-inhibitory drug concentrations [78]. Therefore, the frequent usage of tulathromycin in bovine agriculture could promote the resistance development of different Streptococci species within animal microbiomes.

As Streptococci species are also part of the gastrointestinal microbiome in cattle [79], resistant strains in manure, which is frequently applied as organic fertilizer with respect to the analyzed grassland plots, could get in contact with the soil microbiome, whereby HGT events can potentially take place. This might also be the case for bacteria in manure harboring the sul2 gene, especially as this ARG is known to be frequently encoded by Enterobacteriaceae. It has been shown in a microcosm study by $\mathrm{Hu}$ et al. [52], that application of manure, which has not been treated with antibiotics, increases the ARG abundance in soil notably. However, as only $50 \%$ of the tulathromycin, $17.9 \%$ of sulfadimethoxine and $11-37 \%$ of sulfamethazine, used for treatment, are eliminated functionally by cattle $[80,81]$, it seems probable, that besides ARB along with their ARGs also the antibiotics themselves are transferred to the soil through organic fertilization. Thus, besides other manure constituents, this antibiotic input into soil could also increase the $m e f A$ and sul2 abundance due to selective pressure.

\section{2. $\operatorname{aac}\left(6^{\prime}\right)-l b$}

The gene $a a c\left(6^{\prime}\right)$-lbconfers resistance to different aminoglycosides and is of clinical importance as it is predominantly harbored by MGEs of gram-negative bacteria [82]. Importantly, mutations in this gene can lead to resistance toward representatives of a second class of antibiotics, the fluoroquinolones [82-84].

According to contacted veterinarians, aminoglycosides are not very often used to treat cattle present in the analyzed study region. However, they are sometimes byproducts of antimicrobial preparations to treat acute udder diseases and to prevent udder infections during dry period. As all lactating cows from conventional dairy farms go through the about six weeks lasting dry period before each calving, it is a considerable factor that could influence cattle resistomes notably [85]. Apart from the aminoglycosides, fluoroquinolones are also used to treat febrile udder diseases of cattle. As the WHO declared them as critically important antimicrobials, it is required that fluoroquinolones are only used when susceptibility testing identifies the drug as only treatment option [86]. Since febrile udder diseases are very serious and, if not treated effectively, usually lead to death, animals often receive fluoroquinolones before the result of the susceptibility test is available $[87,88]$. This inevitably leads to 
the treatment of some bacterial infections with fluoroquinolones that would have been sensitive to other antimicrobial agents.

Although $a a c\left(6^{\prime}\right)-l b$ was not correlated with nitrogen input from organic fertilizers, manure could contribute to transfer of fluoroquinolones and aminoglycosides into soils, as surface water run-offs, dust or wild animals could distribute the antibiotics or ARB into different areas [62,89-91]. This might partly explain the frequent detection of $a a c\left(6^{\prime}\right)-l b$ in grassland soils with and without history of organic fertilization.

With respect to the applied land use practices in grasslands of the study region, a clear correlation between mowing and the abundance of the $a a c\left(6^{\prime}\right)$-lb gene could be identified. Plants have been shown to be a potential reservoir of ARB, due to uptake and accumulation of antibiotics [92,93]. Hence, mowing could increase the contact between antibiotic-resistant endophytes and the soil community, and thereby promote HGT, which would explain the positive influence of the mowing frequency on ARG abundance in soil. In addition, mowing might induce changes in release of potentially toxic aromatic compounds from degradation processes as well as plant exudates such as specialized antimicrobial compounds (e.g., phytoalexins and flavonoids) and signaling molecules, which could increase expression of antibiotic resistance in soil [94,95].

\section{3. $b l a_{I M P-12}, b l a_{I M P-5}$ and $M G E S$}

The IMP enzymes represent broad-spectrum metallo- $\beta$-lactamases, rapidly spreading globally among the gram-negative bacteria including Enterobacteriaceae, Pseudomonas and Acinetobacter species as they are mainly encoded on class 1 integrons within transferable plasmids [96-100]. The $\beta$-lactamase $b l a_{\mathrm{IMP}-12}$ was originally identified in a clinical Pseudomonas putida isolate and its preferred substrates include aminopenicillins, cephalosporins and carbapenems [98].

$\beta$-Lactam antibiotics (penicillins, aminopenicillins and cephalosporins of the first to fourth generation) are the most commonly applied substances in veterinary medicine, which was also confirmed for the study regions based on communication with veterinarians. They are applied against mastitis, during the beginning of the dry period of dairy cows and are a first treatment option for a series of different infections, including the respiratory tract, the digestive tract and the urinary and reproductive system of cattle. However, despite their frequent use in veterinary medicine, no statistically sound difference in $b l a_{\mathrm{IMP}-12}$ and $b l a_{\mathrm{IMP}-5}$ abundance between grassland and forest plots was identified. An explanation for this observation could be their fast hydrolytic degradation which can take place, depending on the soil moisture, within hours to a few days [101,102]. The rapid $\beta$-lactam hydrolysis and the concordant loss in selective pressure could promote the development of sensitive strains due to e.g., the loss of resistance plasmids [103]. This might be the reason for similar $b l a_{\mathrm{IMP}-12}$ and $b l a_{\mathrm{IMP}-5}$ abundances in forest as well as grassland soil and potentially explains why land use practices showed no clear effect on the distribution of these genes. Nevertheless, it is also possible that both genes efficiently spread across distinct ecosystems, as they were detected as part of mobile genetic elements $[98,104]$, and protect phylogenetically diverse bacteria against the lethal effect of several beta lactam antibiotics which are naturally produced by soil microorganisms.

Strikingly, the $b l a_{\mathrm{IMP}} 12$ gene showed a significant positive correlation with beech forest plots as well as soil fungal diversity. This is most probably due to the connectedness between soil fungal communities and tree species [105]. Furthermore, as penicillins and cephalosporins are synthesized by the filamentous fungi Penicillium rubens [106,107] and Acremonium chysogenum (priorily Cephalosporium acremonium) $[108,109]$, it is not surprising, that the soil fungal community has a significant impact on $b l a_{\mathrm{IMP}-12}$ abundance. It is possible that soil fungi intensify the synthesis of $\beta$-lactams to compete for scarce resources or to receive access to nutrients released due to lysis of sensitive bacteria when fungal diversity in soil increases. This potentially explains the pronounced occurrence and abundance of $b l a_{\mathrm{IMP}-12}$ in soils with a higher fungal diversity.

An effect of land use practices on the abundance of IncP-1 plasmids, class 1 integrons and tet $A$, which would explain their pronounced occurrence in grassland sites was not found. The 
IncP-1 plasmids have been shown to encode a variety of different ARGs and heavy metal resistance genes [110-112]. Therefore, several environmental parameters can potentially impact their occurrence in soil. With respect to class 1 integrons and the tetracycline efflux pump-encoding gene tet $A$, we could not untangle statistically sound correlations between their abundance and land use practices as they were only detected in a small fraction of the analyzed soils.

Supplementary Materials: The following are available online at http://www.mdpi.com/2073-4425/11/2/150/s1, Table S1: Plot characteristics and soil properties of all 300 experimental plots, Table S2: $\Delta$ Ct values of all analyzed target sequences in the 300 experimental plots, Table S3: Preliminary binomial (A) or tobit regression models (B).

Author Contributions: Conceptualization, I.M.W. and H.N.; formal analysis, I.M.W., J.Y., C.P. and H.N.; investigation, I.M.W., J.Y., K.G.; resources, H.N., M.S., T.W. and F.B.; data curation, I.M.W., K.G., I.S., J.V.; writing-original draft preparation, I.M.W. and H.N.; writing-review and editing, I.M.W., H.N., K.G., J.V., I.S., M.S., T.W. and F.B.; visualization, I.M.W.; supervision, I.M.W. and H.N.; project administration, H.N.; funding acquisition, H.N. All authors have read and agreed to the published version of the manuscript.

Funding: This research was funded by the DFG Priority Program 1374 "Infrastructure-Biodiversity-Exploratories" (NA 848/2-1).

Acknowledgments: We thank the managers of the three Exploratories, Kirsten Reichel-Jung, Iris Steitz, Sandra Weithmann, Florian Straub, Katrin Lorenzen, Miriam Teuscher and all former managers for their work in maintaining the plot and project infrastructure; Christiane Fischer and Jule Mangels for giving support through the central office, Andreas Ostrowski for managing the central data base, and Markus Fischer, Eduard Linsenmair, Dominik Hessenmöller, Daniel Prati, Ernst-Detlef Schulze, Wolfgang W. Weisser and the late Elisabeth Kalko for their role in setting up the Biodiversity Exploratories project. Furthermore, we would like to thank Jochen Wilhelm, for providing feedback about statistical procedures. Special thanks goes to the veterinarians that were willing to answer our questions. In this context, Andrea Lawall has provided particularly valuable information about common practices of veterinarians in Germany and we are very grateful for this contribution. Without this first hand information about common farm veterinary practices in Germany it would have been much more difficult to interpret the results and the evaluation would probably not have been so detailed. Field work permits were issued by the responsible state environmental offices of Baden-Württemberg, Thüringen, and Brandenburg. We acknowledge support by the Open Access Publication Funds of the University of Göttingen.

Conflicts of Interest: The authors declare no conflict of interest. The funders had no role in the design of the study; in the collection, analyses, or interpretation of data; in the writing of the manuscript, or in the decision to publish the results.

\section{References}

1. O'Neill, J. Tackling Drug-Resistant Infections Globally: Final Report and Recommendations; Review on Antimicrobial Resistance: London, UK, 2016.

2. Auta, A.; Hadi, M.A.; Oga, E.; Adewuyi, E.O.; Abdu-Aguye, S.N.; Adeloye, D.; Strickland-Hodge, B.; Morgan, D.J. Global access to antibiotics without prescription in community pharmacies: A systematic review and meta-analysis. J. Infect. 2019, 78, 8-18. [CrossRef] [PubMed]

3. Versporten, A.; Bolokhovets, G.; Ghazaryan, L.; Abilova, V.; Pyshnik, G.; Spasojevic, T.; Korinteli, I.; Raka, L.; Kambaralieva, B.; Cizmovic, L.; et al. Antibiotic use in eastern Europe: A cross-national database study in coordination with the WHO regional office for Europe. Lancet Infect. Dis. 2014, 14, 381-387. [CrossRef]

4. WHO Regional Office for Europe. Assessing Non-Prescription and Inappropriate Use of Antibiotics: Report on Survey; WHO: Copenhagen, Denmark, 2019.

5. Anderson, M.; Clift, C.; Schulze, K.; Sagan, A.; Nahrgang, S.; Ait Ouakrim, D.; Mossialos, E. Averting the AMR crisis: What are the avenues for policy action for countries in Europe? In European Observatory Policy Briefs; European Observatory on Health Systems and Policies: Copenhagen, Denmark, 2019.

6. World Health Organization. Critically Important Antibacterial Agents for Human Medicine for Risk Management Strategies of Non-Human Use: Report of a WHO Working Group Consultation; World Health Organization: Canberra, Australia, 2005.

7. Van Doorn, H.R. Emerging infectious diseases. Medicine 2014, 42, 60-63. [CrossRef]

8. World Health Organization. Of All Human Diseases, 60\% Originate in Animals— “One Health" Is the Only Way to Keep Antibiotics Working. Available online: http://www.euro.who.int/en/health-topics/diseaseprevention/food-safety/news/news/2018/11/of-all-human-diseases,-60-originate-in-animals-one-health-isthe-only-way-to-keep-antibiotics-working (accessed on 28 August 2019). 
9. European Union. Ban on Antibiotics as Growth Promoters in Animal Feed Enters into Effect. Available online: https://europa.eu/rapid/press-release_IP-05-1687_en.htm (accessed on 22 November 2019).

10. Anomaly, J. What's wrong with factory farming? Public Health Ethics 2015, 8, 246-254. [CrossRef]

11. Pluhar, E.B. Meat and morality: Alternatives to factory farming. J. Agric. Environ. Ethics 2010, $23,455-468$. [CrossRef]

12. EMA. Antimicrobial Resistance in the Environment: Considerations for Current and Future Risk Assessment of Veterinary Medicinal Products; European Medicines Agency: Amsterdam, The Netherlands, 2018.

13. Forsberg, K.J.; Reyes, A.; Wang, B.; Selleck, E.M.; Sommer, M.O.A.; Dantas, G. The shared antibiotic resistome of soil bacteria and human pathogens. Science 2012, 337, 1107-1111. [CrossRef]

14. Canteón, R. Antibiotic resistance genes from the environment: A perspective through newly identified antibiotic resistance mechanisms in the clinical setting. Clin. Microbiol. Infect. 2009, 15, 20-25. [CrossRef]

15. Surette, M.D.; Wright, G.D. Lessons from the environmental antibiotic resistome. Annu. Rev. Microbiol. 2017, 71, 309-329. [CrossRef]

16. Knapp, C.W.; Dolfing, J.; Ehlert, P.A.I.; Graham, D.W. Evidence of increasing antibiotic resistance gene abundances in archived soils since 1940. Environ. Sci. Technol. 2010, 44, 580-587. [CrossRef]

17. Heuer, H.; Schmitt, H.; Smalla, K. Antibiotic resistance gene spread due to manure application on agricultural fields. Curr. Opin. Microbiol. 2011, 14, 236-243. [CrossRef] [PubMed]

18. Graham, D.W.; Knapp, C.W.; Christensen, B.T.; McCluskey, S.; Dolfing, J. Appearance of $\beta$-lactam resistance genes in agricultural soils and clinical isolates over the 20th century. Sci. Rep. 2016, 6, 21550. [CrossRef] [PubMed]

19. Wang, F.; Xu, M.; Stedtfeld, R.D.; Sheng, H.; Fan, J.; Liu, M.; Chai, B.; Soares de Carvalho, T.; Li, H.; Li, Z.; et al. Long-term effect of different fertilization and cropping systems on the soil antibiotic resistome. Environ. Sci. Technol. 2018, 52, 13037-13046. [CrossRef] [PubMed]

20. DeFrancesco, K.A.; Cobbold, R.N.; Rice, D.H.; Besser, T.E.; Hancock, D.D. Antimicrobial resistance of commensal Escherichia coli from dairy cattle associated with recent multi-resistant salmonellosis outbreaks. Vet. Microbiol. 2004, 98, 55-61. [CrossRef]

21. Berendsen, B.J.A.; Wegh, R.S.; Memelink, J.; Zuidema, T.; Stolker, L.A.M. The analysis of animal faeces as a tool to monitor antibiotic usage. Talanta 2015, 132, 258-268. [CrossRef]

22. Guo, T.; Lou, C.; Zhai, W.; Tang, X.; Hashmi, M.Z.; Murtaza, R.; Li, Y.; Liu, X.; Xu, J. Increased occurrence of heavy metals, antibiotics and resistance genes in surface soil after long-term application of manure. Sci. Total Environ. 2018, 635, 995-1003. [CrossRef]

23. Peng, S.; Feng, Y.; Wang, Y.; Guo, X.; Chu, H.; Lin, X. Prevalence of antibiotic resistance genes in soils after continually applied with different manure for 30 years. J. Hazard. Mater. 2017, 340, 16-25. [CrossRef]

24. Jechalke, S.; Schreiter, S.; Wolters, B.; Dealtry, S.; Heuer, H.; Smalla, K. Widespread dissemination of class 1 integron components in soils and related ecosystems as revealed by cultivation-independent analysis. Front. Microbiol. 2014, 4, 420. [CrossRef]

25. Hu, H.-W.; Wang, J.-T.; Singh, B.K.; Liu, Y.-R.; Chen, Y.-L.; Zhang, Y.-J.; He, J.-Z. Diversity of herbaceous plants and bacterial communities regulates soil resistome across forest biomes. Environ. Microbiol. 2018, 20, 3186-3200. [CrossRef]

26. Clardy, J.; Fischbach, M.; Currie, C. The natural history of antibiotics. Curr. Biol. 2009, 11, R437-R441. [CrossRef]

27. Urbanová, M.; Šnajdr, J.; Baldrian, P. Composition of fungal and bacterial communities in forest litter and soil is largely determined by dominant trees. Soil Biol. Biochem. 2015, 84, 53-64. [CrossRef]

28. Nacke, H.; Goldmann, K.; Schöning, I.; Pfeiffer, B.; Kaiser, K.; Castillo-Villamizar, G.A.; Schrumpf, M.; Buscot, F.; Daniel, R.; Wubet, T. Fine spatial scale variation of soil microbial communities under European beech and Norway spruce. Front. Microbiol. 2016, 7, 2067. [CrossRef] [PubMed]

29. Fischer, M.; Bossdorf, O.; Gockel, S.; Hänsel, F.; Hemp, A.; Hessenmöller, D.; Korte, G.; Nieschulze, J.; Pfeiffer, S.; Prati, D.; et al. Implementing large-scale and long-term functional biodiversity research: The biodiversity exploratories. Basic Appl. Ecol. 2010, 11, 473-485. [CrossRef]

30. Solly, E.F.; Schöning, I.; Boch, S.; Kandeler, E.; Marhan, S.; Michalzik, B.; Müller, J.; Zscheischler, J.; Trumbore, S.E.; Schrumpf, M. Factors controlling decomposition rates of fine root litter in temperate forests and grasslands. Plant Soil 2014, 382, 203-218. [CrossRef] 
31. Vogt, J.; Klaus, V.H.; Both, S.; Fürstenau, C.; Gockel, S.; Gossner, M.M.; Heinze, J.; Hemp, A.; Hölzel, N.; Jung, K.; et al. Eleven years' data of grassland management in Germany. Biodivers. Data J. 2019, 7, e36387. [CrossRef]

32. Blüthgen, N.; Dormann, C.F.; Prati, D.; Klaus, V.H.; Kleinebecker, T.; Hölzel, N.; Alt, F.; Boch, S.; Gockel, S.; Hemp, A.; et al. A quantitative index of land-use intensity in grasslands: Integrating mowing, grazing and fertilization. Basic Appl. Ecol. 2012, 13, 207-220. [CrossRef]

33. Dean, R.B.; Dixon, W.J. Simplified statistics for small numbers of observations. Anal. Chem. 1951, $23,636-638$. [CrossRef]

34. Ihrmark, K.; Bödeker, I.T.M.; Cruz-Martinez, K.; Friberg, H.; Kubartova, A.; Schenck, J.; Strid, Y.; Stenlid, J.; Brandström-Durling, M.; Clemmensen, K.E.; et al. New primers to amplify the fungal ITS2 region-Evaluation by 454-sequencing of artificial and natural communities. FEMS Microbiol. Ecol. 2012, 82, 666-677. [CrossRef]

35. Gardes, M.; Bruns, T.D. ITS primers with enhanced specificity for basidiomycetes-Application to the identification of mycorrhizae and rusts. Mol. Ecol. 1993, 2, 113-118. [CrossRef]

36. Schloss, P.D.; Westcott, S.L.; Ryabin, T.; Hall, J.R.; Hartmann, M.; Hollister, E.B.; Lesniewski, R.A.; Oakley, B.B.; Parks, D.H.; Robinson, C.J.; et al. Introducing mothur: Open-Source, platform-independent, community-supported software for describing and comparing microbial communities. Appl. Environ. Microbiol. 2009, 75, 7537-7541. [CrossRef]

37. Boyer, F.; Mercier, C.; Bonin, A.; Le Bras, Y.; Taberlet, P.; Coissac, E. овıтоols: A unix-inspired software package for DNA metabarcoding. Mol. Ecol. Resour. 2016, 16, 176-182. [CrossRef]

38. Masella, A.P.; Bartram, A.K.; Truszkowski, J.M.; Brown, D.G.; Neufeld, J.D. PANDAseq: Paired-end assembler for illumina sequences. BMC Bioinform. 2012, 13, 31. [CrossRef]

39. Edgar, R.C.; Haas, B.J.; Clemente, J.C.; Quince, C.; Knight, R. UCHIME improves sensitivity and speed of chimera detection. Bioinformatics 2011, 27, 2194-2200. [CrossRef]

40. Rognes, T.; Flouri, T.; Nichols, B.; Quince, C.; Mahé, F. VSEARCH: A versatile open source tool for metagenomics. PeerJ 2016, 4, e2584. [CrossRef]

41. Nilsson, R.H.; Larsson, K.-H.; Taylor, A.F.S.; Bengtsson-Palme, J.; Jeppesen, T.S.; Schigel, D.; Kennedy, P.; Picard, K.; Glöckner, F.O.; Tedersoo, L.; et al. The UNITE database for molecular identification of fungi: Handling dark taxa and parallel taxonomic classifications. Nucleic Acids Res. 2019, 47, D259-D264. [CrossRef]

42. Bengtsson-Palme, J.; Ryberg, M.; Hartmann, M.; Branco, S.; Wang, Z.; Godhe, A.; De Wit, P.; Sánchez-García, M.; Ebersberger, I.; de Sousa, F.; et al. Improved software detection and extraction of ITS1 and ITS2 from ribosomal ITS sequences of fungi and other eukaryotes for analysis of environmental sequencing data. Methods Ecol. Evol. 2013, 4, 914-919. [CrossRef]

43. McMurdie, P.J.; Holmes, S. phyloseq: An R package for reproducible interactive analysis and graphics of microbiome census data. PLoS ONE 2013, 8, e61217. [CrossRef]

44. R Core Team. R: A Language and Environment for Statistical Computing; R Foundation for Statistical Computing: Vienna, Austria, 2019.

45. Oksanen, J.; Blanchet, F.G.; Friendly, M.; Kindt, R.; Legendre, P.; McGlinn, D.; Michin, P.R.; O’Hara, R.B.; Simpson, G.L.; Solymos, P.; et al. Vegan: Community Ecology Package; R Foundation for Statistical Computing: Vienna, Austria, 2019.

46. Suzuki, M.T.; Taylor, L.T.; DeLong, E.F. Quantitative analysis of small-subunit rRNA genes in mixed microbial populations via 5'-nuclease assays. Appl. Environ. Microbiol. 2000, 66, 4605-4614. [CrossRef]

47. Jechalke, S.; Dealtry, S.; Smalla, K.; Heuer, H. Quantification of IncP-1 plasmid prevalence in environmental Samples. Appl. Environ. Microbiol. 2013, 79, 1410-1413. [CrossRef]

48. Pansegrau, W.; Lanka, E.; Barth, P.T.; Figurski, D.H.; Guiney, D.G.; Haas, D.; Helinski, D.R.; Schwab, H.; Stanisich, V.A.; Thomas, C.M. Complete nucleotide sequence of Birmingham IncP $\alpha$ plasmids. J. Mol. Biol. 1994, 239, 623-663. [CrossRef]

49. Barraud, O.; Baclet, M.C.; Denis, F.; Ploy, M.C. Quantitative multiplex real-time PCR for detecting class 1, 2 and 3 integrons. J. Antimicrob. Chemother. 2010, 65, 1642-1645. [CrossRef]

50. Zhu, Y.-G.; Johnson, T.A.; Su, J.-Q.; Qiao, M.; Guo, G.-X.; Stedtfeld, R.D.; Hashsham, S.A.; Tiedje, J.M. Diverse and abundant antibiotic resistance genes in Chinese swine farms. Proc. Natl. Acad. Sci. USA 2013, 110, 3435-3440. [CrossRef] 
51. Looft, T.; Johnson, T.A.; Allen, H.K.; Bayles, D.O.; Alt, D.P.; Stedtfeld, R.D.; Sul, W.J.; Stedtfeld, T.M.; Chai, B.; Cole, J.R.; et al. In-feed antibiotic effects on the swine intestinal microbiome. Proc. Natl. Acad. Sci. USA 2012, 109, 1691-1696. [CrossRef]

52. Hu, H.-W.; Han, X.-M.; Shi, X.-Z.; Wang, J.-T.; Han, L.-L.; Chen, D.; He, J.-Z. Temporal changes of antibiotic-resistance genes and bacterial communities in two contrasting soils treated with cattle manure. FEMS Microbiol. Ecol. 2016, 92, fiv169. [CrossRef]

53. Zhao, Z.; Wang, J.; Han, Y.; Chen, J.; Liu, G.; Lu, H.; Yan, B.; Chen, S. Nutrients, heavy metals and microbial communities co-driven distribution of antibiotic resistance genes in adjacent environment of mariculture. Environ. Pollut. 2017, 220, 909-918. [CrossRef]

54. Kleiber, C.; Zeileis, A. Applied Econometrics with R; Springer New York: New York, NY, USA, 2008; ISBN 978-0-387-77316-2.

55. We, T.; Simko, V. R Package "corrplot": Visualization of a Correlation Matrix; R Foundation for Statistical Computing: Vienna, Austria, 2017.

56. Lopaka, L. NADA: Nondetects and Data Analysis for Environmental Data; R Foundation for Statistical Computing: Vienna, Austria, 2017.

57. Mcfadden, D. Conditional logit analysis of qualitative choice behavior. In Froniers in Econometrics; Zarembka, P., Ed.; Academic Press: New York, NY, USA, 1974; pp. 105-142.

58. Kaiser, K.; Wemheuer, B.; Korolkow, V.; Wemheuer, F.; Nacke, H.; Schöning, I.; Schrumpf, M.; Daniel, R. Driving forces of soil bacterial community structure, diversity, and function in temperate grasslands and forests. Sci. Rep. 2016, 6, 33696. [CrossRef]

59. Forsberg, K.J.; Patel, S.; Gibson, M.K.; Lauber, C.L.; Knight, R.; Fierer, N.; Dantas, G. Bacterial phylogeny structures soil resistomes across habitats. Nature. 2014, 509, 612-616. [CrossRef]

60. Lauber, C.L.; Hamady, M.; Knight, R.; Fierer, N. Pyrosequencing-based assessment of soil pH as a predictor of soil bacterial community structure at the continental scale. Appl. Environ. Microbiol. 2009, 75, 5111-5120. [CrossRef]

61. Rousk, J.; Bååth, E.; Brookes, P.C.; Lauber, C.L.; Lozupone, C.; Caporaso, J.G.; Knight, R.; Fierer, N. Soil bacterial and fungal communities across a $\mathrm{pH}$ gradient in an arable soil. ISME J. 2010, 4, 1340-1351. [CrossRef]

62. Allen, H.K.; Donato, J.; Wang, H.H.; Cloud-Hansen, K.A.; Davies, J.; Handelsman, J. Call of the wild: Antibiotic resistance genes in natural environments. Nat. Rev. Microbiol. 2010, 8, 251-259. [CrossRef]

63. Sköld, O. Sulfonamide resistance: Mechanisms and trends. Drug Resist. Updat. 2000, 3, 155-160. [CrossRef]

64. Sköld, O. Resistance to trimethoprim and sulfonamides. Vet. Res. 2001, 32, 261-273. [CrossRef]

65. Rawlings, D.E.; Tietze, E. Comparative biology of IncQ and IncQ-like plasmids. Microbiol. Mol. Biol. Rev. 2001, 65, 481-496. [CrossRef]

66. Antunes, P.; Machado, J.; Sousa, J.C.; Peixe, L. Dissemination of sulfonamide resistance genes (sul1, sul2, and sul3) in Portuguese Salmonella enterica strains and relation with integrons. Antimicrob. Agents Chemother. 2005, 49, 836-839. [CrossRef]

67. Seiffert, S.N.; Marschall, J.; Perreten, V.; Carattoli, A.; Furrer, H.; Endimiani, A. Emergence of Klebsiella pneumoniae co-producing NDM-1, OXA-48, CTX-M-15, CMY-16, QnrA and ArmA in Switzerland. Int. J. Antimicrob. Agents 2014, 44, 260-262. [CrossRef]

68. Guerra, B.; Junker, E.; Schroeter, A.; Malorny, B.; Lehmann, S.; Helmuth, R. Phenotypic and genotypic characterization of antimicrobial resistance in German Escherichia coli isolates from cattle, swine and poultry. J. Antimicrob. Chemother. 2003, 52, 489-492. [CrossRef]

69. Leclercq, R.; Courvalin, P. Resistance to macrolides and related antibiotics in Streptococcus pneumoniae. Antimicrob. Agents Chemother. 2002, 46, 2727-2734. [CrossRef]

70. Griffith, F. The serological classification of Streptococcus pyogenes. Epidemiol. Infect. 1934, 34, 542-584. [CrossRef]

71. Oster, P.; Zanchi, A.; Cresti, S.; Lattanzi, M.; Montagnani, F.; Cellesi, C.; Rossolini, G.M. Patterns of macrolide resistance determinants among community-acquired Streptococcus pneumoniae isolates over a 5-year period of decreased macrolide susceptibility rates. Antimicrob. Agents Chemother. 1999, 43, 2510-2512. [CrossRef]

72. Santagati, M.; Iannelli, F.; Cascone, C.; Campanile, F.; Oggioni, M.R.; Stefani, S.; Pozzi, G. The novel conjugative transposon Tn 1207.3 carries the macrolide efflux gene mef (A) in Streptococcus pyogenes. Microb. Drug Resist. 2003, 9, 243-247. [CrossRef] 
73. Haenni, M.; Saras, E.; Bertin, S.; Leblond, P.; Madec, J.-Y.; Payot, S. Diversity and mobility of integrative and conjugative elements in bovine isolates of Streptococcus agalactiae, S. dysgalactiae subsp. dysgalactiae, and S. uberis. Appl. Environ. Microbiol. 2010, 76, 7957-7965. [CrossRef]

74. Collignon, P.; Powers, J.H.; Chiller, T.M.; Aidara-Kane, A.; Aarestrup, F.M. World Health Organization ranking of antimicrobials according to their importance in human medicine: A critical step for developing risk management strategies for the use of antimicrobials in food production animals. Clin. Infect. Dis. 2009, 49, 132-141. [CrossRef]

75. Giguère, S. Antimicrobial Therapy in Veterinary Medicine; John Wiley \& Sons Inc.: Hoboken, NJ, USA, 2013. [CrossRef]

76. Bartram, D.J.; Moyaert, H.; Vanimisetti, B.H.; Ramage, C.P.; Reddick, D.; Stegemann, M.R. Comparative efficacy of tulathromycin and tildipirosin for the treatment of experimental Mycoplasma bovis infection in calves. Vet. Med. Sci. 2016, 2, 170-178. [CrossRef]

77. Baggot, J.D.; Gingerich, D.A. Pharmacokinetic interpretation of erythromycin and tylosin activity in serum after intravenous administration of a single dose to cows. Res. Vet. Sci. 1976, 21, 318-323. [CrossRef]

78. Blondeau, J. Differential impact of macrolide compounds in the selection of macrolide nonsusceptible Streptococcus pneumoniae. Therapy 2005, 2, 813-818. [CrossRef]

79. Kim, M.; Park, T.; Yu, Z. Metagenomic investigation of gastrointestinal microbiome in cattle. Asian Australasian J. Anim. Sci. 2017, 30, 1515. [CrossRef]

80. Holman, D.B.; Yang, W.; Alexander, T.W. Antibiotic treatment in feedlot cattle: A longitudinal study of the effect of oxytetracycline and tulathromycin on the fecal and nasopharyngeal microbiota. Microbiome 2019, 7, 86. [CrossRef]

81. United States Pharmacopeial Convention. The United States Pharmacopeia 31: The National Formulary 26; United States Pharmacopeial Convention: Rockville, MD, USA, 2007.

82. Ramirez, M.S.; Nikolaidis, N.; Tolmasky, M.E. Rise and dissemination of aminoglycoside resistance: The aac (6')-Ib paradigm. Front. Microbiol. 2013, 4, 121. [CrossRef]

83. Lambert, T.; Ploy, M.-C.; Courvalin, P. A spontaneous point mutation i the $a a c\left(6^{\prime}\right)-l b^{\prime}$ gene results in altered substrate specificity of aminoglycoside $6^{\prime}-\mathrm{N}$-acetyltransferase of a Pseudomonas fluorescens strain. FEMS Microbiol. Lett. 1994, 115, 297-303. [CrossRef]

84. Robicsek, A.; Strahilevitz, J.; Jacoby, G.A.; Macielag, M.; Abbanat, D.; Hye Park, C.; Bush, K.; Hooper, D.C. Fluoroquinolone-modifying enzyme: A new adaptation of a common aminoglycoside acetyltransferase. Nat. Med. 2006, 12, 83-88. [CrossRef]

85. Wallmann, J. Erfahrungen und Schlussfolgerungen aus der Antibiotikaabgabeerfassung in der Veterinärmedizin; BVL: Berlin, Germany, 2014.

86. Aidara-Kane, A.; Angulo, F.J.; Conly, J.M.; Minato, Y.; Silbergeld, E.K.; McEwen, S.A.; Collignon, P.J.; WHO guideline development group. World Health Organization $(\mathrm{WHO})$ guidelines on use of medically important antimicrobials in food-producing animals. Antimicrob. Resist. Infect. Control. 2018, 7, 7. [CrossRef]

87. Ruegg, P.L. Responsible Use of Antibiotics for Treatment of Clinical Mastitis-DAIReXNET. Available online: https://dairy-cattle.extension.org/responsible-use-of-antibiotics-for-treatment-of-clinical-mastitis/ (accessed on 10 November 2019).

88. Persson, Y.; Katholm, J.; Landin, H.; Mörk, M.J. Efficacy of enrofloxacin for the treatment of acute clinical mastitis caused by Escherichia coli in dairy cows. Vet. Rec. 2015, 176, 673. [CrossRef]

89. Kemper, N. Veterinary antibiotics in the aquatic and terrestrial environment. Ecol. Indic. 2008, 8, 1-13. [CrossRef]

90. Thiele-Bruhn, S. Pharmaceutical antibiotic compounds in soils-A review. J. Plant Nutr. Soil Sci. 2003, 166, 145-167. [CrossRef]

91. Schulz, J.; Kemper, N.; Hartung, J.; Janusch, F.; Mohring, S.A.I.; Hamscher, G. Analysis of fluoroquinolones in dusts from intensive livestock farming and the co-occurrence of fluoroquinolone-resistant Escherichia coli. Sci. Rep. 2019, 9, 5117. [CrossRef]

92. Lillenberg, M.; Litvin, S.V.; Nei, L.; Roasto, M.; Sepp, K.I. Enrofloxacin and ciprofloxacin uptake by plants from soil. Agron. Res. 2010, 8, 807-814.

93. Hu, X.; Zhou, Q.; Luo, Y. Occurrence and source analysis of typical veterinary antibiotics in manure, soil, vegetables and groundwater from organic vegetable bases, northern China. Environ. Pollut. 2010, 158, 2992-2998. [CrossRef] 
94. Alonso, A.; Sanchez, P.; Martinez, J.L. Environmental selection of antibiotic resistance genes. Environ. Microbiol. 2001, 3, 1-9. [CrossRef]

95. Yergeau, E.; Sanschagrin, S.; Maynard, C.; St-Arnaud, M.; Greer, C.W. Microbial expression profiles in the rhizosphere of willows depend on soil contamination. ISME J. 2014, 8, 344-358. [CrossRef]

96. Diene, S.M.; Rolain, J.-M. Carbapenemase genes and genetic platforms in Gram-negative bacilli: Enterobacteriaceae, Pseudomonas and Acinetobacter species. Clin. Microbiol. Infect. 2014, 20, 831-838. [CrossRef]

97. Cornaglia, G.; Giamarellou, H.; Rossolini, G.M. Metallo- $\beta$-lactamases: A last frontier for $\beta$-lactams? Lancet Infect. Dis. 2011, 11, 381-393. [CrossRef]

98. Docquier, J.-D.; Riccio, M.L.; Mugnaioli, C.; Luzzaro, F.; Endimiani, A.; Toniolo, A.; Amicosante, G.; Rossolini, G.M. IMP-12, a new plasmid-encoded metallo-beta-lactamase from a Pseudomonas putida clinical isolate. Antimicrob. Agents Chemother. 2003, 47, 1522-1528. [CrossRef] [PubMed]

99. Zhao, W.-H.; Chen, G.; Ito, R.; Kimura, S.; Hu, Z.-Q. Identification of a plasmid-borne bla ${ }_{\mathrm{IMP}-11}$ gene in clinical isolates of Escherichia coli and Klebsiella pneumoniae. J. Med. Microbiol. 2012, 61, 246-251. [CrossRef] [PubMed]

100. Wang, S.; Zhou, K.; Xiao, S.; Xie, L.; Gu, F.; Li, X.; Ni, Y.; Sun, J.; Han, L. A multidrug resistance Plasmid pIMP26, carrying bla $a_{\mathrm{IMP}-26}$, fosA5, bla $a_{\mathrm{DHA}-1}$, and qnrB4 in Enterobacter cloacae. Sci. Rep. 2019, 9, 10212. [CrossRef]

101. Braschi, I.; Blasioli, S.; Fellet, C.; Lorenzini, R.; Garelli, A.; Pori, M.; Giacomini, D. Persistence and degradation of new $\beta$-lactam antibiotics in the soil and water environment. Chemosphere 2013, 93, 152-159. [CrossRef]

102. Jechalke, S.; Heuer, H.; Siemens, J.; Amelung, W.; Smalla, K. Fate and effects of veterinary antibiotics in soil. Trends Microbiol. 2014, 9, 536-545. [CrossRef]

103. Chen, S.; Larsson, M.; Robinson, R.C.; Chen, S.L. Direct and convenient measurement of plasmid stability in lab and clinical isolates of E. coli. Sci. Rep. 2017, 7, 4788. [CrossRef]

104. Da Silva, G.; Correia, M.; Vital, C.; Ribeiro, G.; Sousa, J.C.; Leitão, R.; Peixe, L.; Duarte, A. Molecular characterization of $b a_{\mathrm{IMP}-5}$, a new integrons-borne metallo- $\beta$-lactamase gene from an Acinetobacter baumanii nosocomial isolate in Portugal. FEMS Microbiol. Lett. 2002, 215, 33-39. [CrossRef]

105. Goldmann, K.; Schöning, I.; Buscot, F.; Wubet, T. Forest management type influences diversity and community composition of soil fungi across temperate forest ecosystems. Front. Microbiol. 2015, 6, 1300. [CrossRef]

106. Fleming, A. On the antibacterial action of cultures of a penicillium, with special reference to their use in the isolation of B. influenzae. Br. J. Exp. Pathol. 1929, 10, 226-236. [CrossRef]

107. Houbraken, J.; Frisvad, J.C.; Samson, R.A. Fleming's penicillin producing strain is not Penicillium chrysogenum but $P$. rubens. IMA Fungus 2011, 2, 87-95. [CrossRef] [PubMed]

108. Burton, H.S.; Abraham, E.P. Isolation of antibiotics from a species of Cephalosporium. Cephalosporins $\mathrm{P}_{1}, \mathrm{P}_{2}$, $\mathrm{P}_{3}, \mathrm{P}_{4}$ and $\mathrm{P}_{5}$. Biochem. J. 1951, 50, 168-174. [CrossRef] [PubMed]

109. Pöggeler, S.; Hoff, B.; Kück, U. Asexual cephalosporin $C$ producer Acremonium chrysogenum carries a functional mating type locus. Appl. Environ. Microbiol. 2008, 74, 6006-6016. [CrossRef] [PubMed]

110. Heuer, H.; Smalla, K. Plasmids foster diversification and adaptation of bacterial populations in soil. FEMS Microbiol. Rev. 2012, 36, 1083-1104. [CrossRef]

111. Popowska, M.; Krawczyk-Balska, A. Broad-host-range IncP-1 plasmids and their resistance potential. Front. Microbiol. 2013, 4, 44. [CrossRef]

112. Sen, D.; Van der Auwera, G.A.; Rogers, L.M.; Thomas, C.M.; Brown, C.J.; Top, E.M. Broad-host-range plasmids from agricultural soils have IncP-1 backbones with diverse accessory genes. Appl. Environ. Microbiol. 2011, 77, 7975-7983. [CrossRef]

(C) 2020 by the authors. Licensee MDPI, Basel, Switzerland. This article is an open access article distributed under the terms and conditions of the Creative Commons Attribution (CC BY) license (http://creativecommons.org/licenses/by/4.0/). 


\subsection{Supplemental information for chapter three}

Table S1: Plot characteristics and soil properties of all 300 experimental plots.

Table S2: $\Delta$ Ct values of all analyzed target sequences in the 300 experimental plots. The non-detect $\Delta \mathrm{CT}$ values are marked in grey.

Table S3: Preliminary binomial $(A)$ or tobit regression models (B). 
Table S1: Plot characteristics and soil properties of all 300 experimental plots. Graz., Mow., Fert., LUI, Org. N and Min. $\mathbf{N}$ represent grazing, mowing, the general fertilization frequency, the land use intensity index as described in Blüthgen et al. (2012), the organic nitrogen input from organic fertilizers and the nitrogen input from mineral fertilizers from the years 2006-2016. Tree describes the dominant tree type and Moist. the mean soil moisture in May 2017. Shannon $\mathrm{H}$ represents fungal diversity as assessed by Shannon index.

\begin{tabular}{|c|c|c|c|c|c|c|c|c|c|c|}
\hline Plot ID & Graz. & Mow. & Fert. & Org. $\mathbf{N}$ & Min. N & LUI & Tree & $\mathrm{pH}$ & Moist. & $\begin{array}{l}\text { Shannon } \\
\text { H }\end{array}$ \\
\hline SEG1 & 0.0 & 2.0 & 1.9 & 0.0 & 64.4 & 2.0 & NA & 7.5 & 44.1 & 4.6 \\
\hline SEG2 & 0.4 & 1.5 & 1.8 & 52.0 & 63.5 & 1.9 & NA & 7.5 & 49.0 & 4.5 \\
\hline SEG3 & 0.5 & 1.7 & 1.8 & 0.0 & 52.9 & 2.0 & NA & 7.6 & 50.2 & 4.4 \\
\hline SEG4 & 0.3 & 0.7 & 0.0 & 18.1 & 1.8 & 1.0 & NA & 7.5 & 24.7 & 4.7 \\
\hline SEG5 & 0.1 & 1.1 & 0.0 & 11.1 & 6.8 & 1.1 & NA & 7.6 & 39.0 & 4.2 \\
\hline SEG6 & 1.7 & 0.4 & 0.0 & 0.0 & 6.8 & 1.4 & NA & 5.5 & 36.7 & 3.9 \\
\hline SEG7 & 2.6 & 0.1 & 0.0 & 0.0 & 0.0 & 1.7 & NA & 7.5 & 32.8 & 4.1 \\
\hline SEG8 & 0.8 & 1.0 & 0.6 & 9.5 & 0.0 & 1.5 & NA & 7.5 & 29.2 & 3.9 \\
\hline SEG9 & 2.9 & 0.2 & 0.0 & 0.0 & 0.0 & 1.8 & NA & 6.6 & 55.6 & 4.6 \\
\hline SEG10 & 0.6 & 1.4 & 1.8 & 0.0 & 52.9 & 2.0 & NA & 7.5 & 43.9 & 4.4 \\
\hline SEG11 & 0.6 & 1.2 & 1.8 & 0.0 & 59.7 & 1.9 & NA & 7.5 & 34.5 & 4.6 \\
\hline SEG12 & 0.0 & 2.0 & 1.9 & 0.0 & 64.4 & 2.0 & NA & 7.5 & 51.7 & 4.5 \\
\hline SEG13 & 0.2 & 1.8 & 0.6 & 8.9 & 25.2 & 1.6 & NA & 5.5 & 20.0 & 4.2 \\
\hline SEG14 & 0.6 & 0.7 & 0.0 & 44.2 & 7.7 & 1.2 & NA & 7.5 & 51.8 & 4.3 \\
\hline SEG15 & 0.0 & 1.3 & 0.0 & 32.0 & 7.3 & 1.2 & NA & 7.5 & 52.2 & 4.6 \\
\hline SEG16 & 1.0 & 0.7 & 0.0 & 0.0 & 0.0 & 1.3 & NA & 7.4 & 39.1 & 4.5 \\
\hline SEG17 & 0.8 & 1.1 & 0.0 & 3.9 & 0.0 & 1.4 & NA & 5.4 & 34.5 & 4.5 \\
\hline SEG18 & 0.0 & 1.8 & 0.0 & 32.5 & 7.7 & 1.3 & NA & 4.9 & 26.2 & 3.6 \\
\hline SEG19 & 0.8 & 0.6 & 0.0 & 0.0 & 6.8 & 1.2 & NA & 7.5 & 43.4 & 4.8 \\
\hline SEG20 & 2.2 & 0.3 & 0.0 & 0.0 & 0.0 & 1.6 & NA & 6.4 & 20.9 & 4.5 \\
\hline SEG21 & 2.6 & 0.1 & 0.0 & 19.1 & 0.0 & 1.6 & NA & 5.3 & 20.9 & 4.5 \\
\hline SEG22 & 2.8 & 0.0 & 0.0 & 3.5 & 0.0 & 1.7 & NA & 7.5 & 39.7 & 4.6 \\
\hline SEG23 & 0.0 & 2.1 & 1.0 & 23.7 & 0.0 & 1.8 & NA & 5.2 & 35.2 & 3.8 \\
\hline SEG24 & 0.0 & 1.2 & 0.0 & 18.5 & 0.0 & 1.1 & NA & 7.5 & 54.5 & 4.4 \\
\hline SEG25 & 0.0 & 2.0 & 0.0 & 0.0 & 0.0 & 1.4 & NA & 6.5 & 48.6 & 4.6 \\
\hline SEG26 & 0.0 & 2.0 & 1.0 & 22.3 & 0.0 & 1.7 & NA & 7.2 & 41.2 & 4.6 \\
\hline SEG27 & 0.0 & 1.1 & 0.0 & 0.0 & 0.0 & 1.0 & NA & 6.1 & 26.1 & 4.3 \\
\hline SEG28 & 0.0 & 1.3 & 0.0 & 0.0 & 0.0 & 1.2 & NA & 7.5 & 52.6 & 4.2 \\
\hline SEG29 & 0.1 & 0.8 & 0.0 & 0.0 & 0.0 & 0.9 & NA & 7.6 & 53.8 & 4.7 \\
\hline SEG30 & 0.0 & 1.7 & 0.0 & 0.0 & 0.0 & 1.3 & NA & 7.0 & 27.1 & 3.7 \\
\hline SEG31 & 0.0 & 1.7 & 0.0 & 0.0 & 0.0 & 1.3 & NA & 6.0 & 31.4 & 3.7 \\
\hline SEG32 & 0.0 & 1.7 & 0.0 & 0.0 & 0.0 & 1.3 & NA & 5.7 & 14.6 & 4.1 \\
\hline SEG33 & 2.1 & 0.3 & 0.9 & 18.3 & 12.0 & 1.8 & NA & 5.7 & 33.8 & 4.1 \\
\hline SEG34 & 1.2 & 0.5 & 1.6 & 27.5 & 23.1 & 1.8 & NA & 5.8 & 29.5 & 4.3 \\
\hline SEG35 & 1.0 & 0.7 & 1.6 & 33.5 & 29.9 & 1.8 & NA & 6.2 & 27.3 & 3.8 \\
\hline SEG36 & 2.1 & 0.1 & 0.0 & 6.0 & 6.8 & 1.5 & NA & 6.3 & 28.4 & 4.6 \\
\hline SEG37 & 2.7 & 0.2 & 0.0 & 17.3 & 6.4 & 1.7 & NA & 4.7 & 15.2 & 4.1 \\
\hline SEG38 & 4.3 & 0.9 & 0.0 & 4.5 & 0.0 & 2.3 & NA & 5.2 & 13.5 & 4.0 \\
\hline SEG39 & 0.8 & 0.7 & 0.2 & 6.7 & 12.0 & 1.3 & NA & 7.4 & 29.6 & 4.1 \\
\hline SEG40 & 4.1 & 0.0 & 0.0 & 6.7 & 6.4 & 2.0 & NA & 6.1 & 22.8 & 3.7 \\
\hline SEG41 & 4.1 & 0.2 & 0.0 & 32.0 & 4.6 & 2.1 & NA & 6.1 & 24.4 & 4.4 \\
\hline SEG42 & 5.2 & 0.0 & 2.2 & 23.5 & 2.7 & 2.7 & NA & 5.0 & 18.2 & 4.3 \\
\hline SEG43 & 2.5 & 0.0 & 1.8 & 6.8 & 0.0 & 2.1 & NA & 6.5 & 24.7 & 4.6 \\
\hline SEG44 & 2.1 & 0.0 & 0.3 & 0.0 & 0.0 & 1.5 & NA & 5.5 & 24.5 & 4.5 \\
\hline SEG45 & 1.8 & 0.0 & 0.0 & 9.8 & 0.0 & 1.3 & NA & 5.9 & 19.7 & 4.6 \\
\hline SEG46 & 4.4 & 0.1 & 0.0 & 0.0 & 0.0 & 2.1 & NA & 7.1 & 20.9 & 4.5 \\
\hline
\end{tabular}


Table S1 continued:

\begin{tabular}{|c|c|c|c|c|c|c|c|c|c|c|}
\hline Plot ID & Graz. & Mow. & Fert. & Org. N & Min. N & LUI & Tree & $\mathrm{pH}$ & Moist. & $\begin{array}{l}\text { Shannon } \\
\text { H }\end{array}$ \\
\hline SEG47 & 2.3 & 0.2 & 0.0 & 0.0 & 0.0 & 1.6 & NA & 5.7 & 28.7 & 4.6 \\
\hline SEG48 & 3.0 & 0.1 & 0.0 & 0.0 & 0.0 & 1.7 & NA & 6.7 & 18.4 & 4.4 \\
\hline SEG49 & 2.7 & 0 & 0 & 0 & 0 & 1.6 & NA & 6.4 & NA & 4.2 \\
\hline SEG50 & 2.1 & 0 & 0 & 2.2 & 0 & 1.5 & NA & 5.4 & 11.2 & 4.4 \\
\hline SEW1 & NA & NA & NA & NA & NA & NA & Pine & 3.6 & 11.9 & 3.9 \\
\hline SEW2 & NA & NA & NA & NA & NA & NA & Pine & 3.5 & 10.5 & 4.5 \\
\hline SEW3 & NA & NA & NA & NA & NA & NA & Pine & 3.4 & 15.3 & 4 \\
\hline SEW4 & NA & NA & NA & NA & NA & NA & Pine & 3.5 & 18.1 & 3.5 \\
\hline SEW5 & NA & NA & NA & NA & NA & NA & Beech & 3.4 & 14.2 & 3.4 \\
\hline SEW6 & NA & NA & NA & NA & NA & NA & Beech & 3.7 & 15.8 & 4.1 \\
\hline SEW7 & NA & NA & NA & NA & NA & NA & Beech & 3.8 & 17.9 & 4.3 \\
\hline SEW8 & NA & NA & NA & NA & NA & NA & Beech & 3.4 & 12.8 & 4.2 \\
\hline SEW9 & NA & NA & NA & NA & NA & NA & Beech & 3.5 & 17.8 & 3.4 \\
\hline SEW10 & NA & NA & NA & NA & NA & NA & Pine & 3.7 & 10.2 & 3.8 \\
\hline SEW11 & NA & NA & NA & NA & NA & NA & Pine & 3.7 & 15.2 & 3.9 \\
\hline SEW12 & NA & NA & NA & NA & NA & NA & Pine & 3.5 & 9.2 & 3.1 \\
\hline SEW13 & NA & NA & NA & NA & NA & NA & Pine & 3.3 & 17.3 & 4.2 \\
\hline SEW14 & NA & NA & NA & NA & NA & NA & Pine & 3.4 & NA & 4.1 \\
\hline SEW15 & NA & NA & NA & NA & NA & NA & Pine & 3.7 & 10.4 & 3.9 \\
\hline SEW16 & NA & NA & NA & NA & NA & NA & Pine & 3.6 & 13.2 & 3.4 \\
\hline SEW17 & NA & NA & NA & NA & NA & NA & Pine & 3.3 & 15.0 & 3.1 \\
\hline SEW18 & NA & NA & NA & NA & NA & NA & Pine & 3.3 & 10.4 & 3.5 \\
\hline SEW19 & NA & NA & NA & NA & NA & NA & Pine & 3.6 & 11.8 & 3 \\
\hline SEW20 & NA & NA & NA & NA & NA & NA & Pine & 3.6 & 10.6 & 4.2 \\
\hline SEW21 & NA & NA & NA & NA & NA & NA & Pine & 3.3 & 10.8 & 4 \\
\hline SEW22 & NA & NA & NA & NA & NA & NA & Oak & 3.6 & 17.2 & 4.4 \\
\hline SEW23 & NA & NA & NA & NA & NA & NA & Oak & 3.5 & 14.5 & 3.9 \\
\hline SEW24 & NA & NA & NA & NA & NA & NA & Oak & 3.7 & 18.5 & 4.4 \\
\hline SEW25 & NA & NA & NA & NA & NA & NA & Oak & 3.7 & 15.4 & 4.3 \\
\hline SEW26 & NA & NA & NA & NA & NA & NA & Oak & 3.7 & 14.1 & 4.3 \\
\hline SEW27 & NA & NA & NA & NA & NA & NA & Oak & 3.4 & 15.6 & 4.1 \\
\hline SEW28 & NA & NA & NA & NA & NA & NA & Oak & 3.5 & 14.8 & 4.2 \\
\hline SEW29 & NA & NA & NA & NA & NA & NA & Pine & 3.3 & 12.1 & 3.8 \\
\hline SEW30 & NA & NA & NA & NA & NA & NA & Pine & 3.4 & 13.9 & 3.3 \\
\hline SEW31 & NA & NA & NA & NA & NA & NA & Pine & 3.4 & NA & 4.1 \\
\hline SEW32 & NA & NA & NA & NA & NA & NA & Pine & 3.5 & 11.7 & 3.9 \\
\hline SEW33 & NA & NA & NA & NA & NA & NA & Pine & 3.4 & 11.8 & 3.1 \\
\hline SEW34 & NA & NA & NA & NA & NA & NA & Pine & 3.5 & 15.9 & 2.9 \\
\hline SEW35 & NA & NA & NA & NA & NA & NA & Beech & 3.6 & 11.9 & 4.1 \\
\hline SEW36 & NA & NA & NA & NA & NA & NA & Beech & 3.3 & 13.2 & 3.4 \\
\hline SEW37 & NA & NA & NA & NA & NA & NA & Beech & 3.6 & 17.0 & 4 \\
\hline SEW38 & NA & NA & NA & NA & NA & NA & Beech & 3.4 & 15.9 & 3.9 \\
\hline SEW39 & NA & NA & NA & NA & NA & NA & Beech & 3.7 & 11.7 & 4.1 \\
\hline SEW40 & NA & NA & NA & NA & NA & NA & Beech & 3.8 & 16.7 & 4.5 \\
\hline SEW41 & NA & NA & NA & NA & NA & NA & Beech & 3.8 & 18.5 & 4.3 \\
\hline SEW42 & NA & NA & NA & NA & NA & NA & Beech & 3.8 & 16.1 & 4.3 \\
\hline SEW43 & NA & NA & NA & NA & NA & NA & Beech & 3.7 & NA & 3.7 \\
\hline SEW44 & NA & NA & NA & NA & NA & NA & Beech & 3.7 & 20.1 & 3.9 \\
\hline SEW45 & NA & NA & NA & NA & NA & NA & Beech & 3.7 & 15.9 & 3.9 \\
\hline SEW46 & NA & NA & NA & NA & NA & NA & Beech & 3.5 & 13.9 & 3.7 \\
\hline SEW47 & NA & NA & NA & NA & NA & NA & Beech & 3.5 & 10.0 & 3.9 \\
\hline
\end{tabular}


Table S1 continued:

\begin{tabular}{|c|c|c|c|c|c|c|c|c|c|c|}
\hline Plot ID & Graz. & Mow. & Fert. & Org. N & Min. N & LUI & Tree & $\mathrm{pH}$ & Moist. & $\begin{array}{l}\text { Shannon } \\
\text { H }\end{array}$ \\
\hline SEW48 & NA & NA & NA & NA & NA & NA & Beech & 3.7 & 16.4 & 4.2 \\
\hline SEW49 & NA & NA & NA & NA & NA & NA & Beech & 3.5 & 12.6 & 4 \\
\hline SEW50 & NA & NA & NA & NA & NA & NA & Beech & 3.7 & NA & 3.9 \\
\hline HEG1 & 0.3 & 2.3 & 5.4 & 34.5 & 101 & 2.8 & NA & 6.6 & 41.4 & 3.4 \\
\hline HEG2 & 0.1 & 2.2 & 3.7 & 0 & 106 & 2.5 & NA & 7.3 & 20.6 & 4.6 \\
\hline HEG3 & 0.1 & 2.8 & 4.3 & 0 & 97.9 & 2.7 & NA & 7.3 & 25.8 & 4.6 \\
\hline HEG4 & 0.7 & 1.7 & 2.9 & 8 & 42 & 2.3 & NA & 6.5 & 26.4 & 5 \\
\hline HEG5 & 0.9 & 2 & 3.5 & 17.5 & 64.1 & 2.5 & NA & 7.2 & 35.9 & 4.6 \\
\hline HEG6 & 0.4 & 1.5 & 1.9 & 68.7 & 0 & 2 & NA & 5.9 & NA & 4.4 \\
\hline HEG7 & 2.4 & 0.2 & 0 & 7.6 & 0 & 1.6 & NA & 7 & 28.1 & 4.7 \\
\hline HEG8 & 1.8 & 0.1 & 0 & 15.6 & 0 & 1.4 & NA & 7 & 32.6 & 4.7 \\
\hline HEG9 & 0.6 & 0.1 & 0 & 0 & 0 & 0.8 & NA & 7.1 & 32.9 & 4.7 \\
\hline HEG10 & 0.2 & 1.1 & 1.2 & 48.2 & 0 & 1.6 & NA & 6.5 & 33.0 & 3.8 \\
\hline HEG11 & 0.2 & 1 & 0.9 & 48.2 & 0 & 1.4 & NA & 7.3 & 25.8 & 3 \\
\hline HEG12 & 7.3 & 0.3 & 1.3 & 0 & 28.5 & 3 & NA & 7 & 30.6 & 4.2 \\
\hline HEG13 & 0.4 & 2.5 & 0.3 & 8.8 & 5.5 & 1.8 & NA & 7.2 & 29.1 & 4.1 \\
\hline HEG14 & 0.4 & 1.2 & 3.3 & 60.6 & 50.5 & 2.2 & NA & 6.4 & 27.7 & 3.6 \\
\hline HEG15 & 0.3 & 1.2 & 3.1 & 19.3 & 61.9 & 2.2 & NA & 7.1 & 23.4 & 4.2 \\
\hline HEG16 & 1.3 & 0 & 0 & 0 & 0 & 1.1 & NA & 6.8 & 35.7 & 4.4 \\
\hline HEG17 & 0.4 & 0.1 & 0 & 0 & 0 & 0.7 & NA & 6.9 & 32.7 & 3.4 \\
\hline HEG18 & 0.4 & 0.2 & 0 & 0 & 0 & 0.8 & NA & 7.4 & 28.5 & 4.5 \\
\hline HEG19 & 0.4 & 0 & 0 & 0 & 0 & 0.7 & NA & 6.6 & 36.9 & 3.6 \\
\hline HEG20 & 0.8 & 0.1 & 0 & 0 & 0 & 1 & NA & 5.5 & 29.0 & 1.9 \\
\hline HEG21 & 0.5 & 0.1 & 0 & 0 & 0 & 0.8 & NA & 7.3 & 31.2 & 4 \\
\hline HEG22 & 0.3 & 1.7 & 0.2 & 0 & 0 & 1.5 & NA & 6.9 & 19.0 & 4.5 \\
\hline HEG23 & 0.7 & 1.1 & 0 & 8 & 0 & 1.3 & NA & 7.3 & 34.4 & 3.4 \\
\hline HEG24 & 1.2 & 1.1 & 0 & 0 & 0 & 1.5 & NA & 6.8 & 30.0 & 4.7 \\
\hline HEG25 & 1.4 & 0.6 & 0 & 0 & 0 & 1.4 & NA & 7.3 & 21.4 & 3.2 \\
\hline HEG26 & 0 & 1.2 & 0.6 & 25.8 & 4.6 & 1.3 & NA & 7.4 & 31.7 & 4.3 \\
\hline HEG27 & 0.1 & 1.2 & 2 & 0 & 44.7 & 1.8 & NA & 7.2 & 28.4 & 4 \\
\hline HEG28 & 0.1 & 1.5 & 1.4 & 2 & 38.4 & 1.7 & NA & 7.3 & 36.8 & 3.3 \\
\hline HEG29 & 0.3 & 1.6 & 1.2 & 2 & 39.9 & 1.7 & NA & 7.2 & 35.0 & 4.3 \\
\hline HEG30 & 0.2 & 2.6 & 3.1 & 10.5 & 65 & 2.4 & NA & 7.2 & 30.3 & 4 \\
\hline HEG31 & 0.5 & 1.3 & 1.9 & 0 & 49.6 & 1.9 & NA & 7.2 & 30.6 & 2.6 \\
\hline HEG32 & 1.1 & 1 & 1.9 & 0 & 42 & 2 & NA & 5.6 & 28.8 & 4 \\
\hline HEG33 & 1 & 1.2 & 1.2 & 0 & 34.4 & 1.8 & NA & 5.3 & 23.6 & 4.1 \\
\hline HEG34 & 0.4 & 1.5 & 2.2 & 68.8 & 0 & 2 & NA & 7 & 37.2 & 4.1 \\
\hline HEG35 & 1.6 & 1 & 2.1 & 55 & 13.7 & 2.2 & NA & 7 & 24.5 & 4.5 \\
\hline HEG36 & 0.6 & 1.3 & 3.2 & 34.5 & 57.3 & 2.3 & NA & 7.3 & 27.9 & 3.9 \\
\hline HEG37 & 0.6 & 1.6 & 3.6 & 24.2 & 53 & 2.4 & NA & 7.3 & 16.3 & 4.3 \\
\hline HEG38 & 3.2 & 0.2 & 0 & 0 & 0 & 1.9 & NA & 7.3 & NA & 3.6 \\
\hline HEG39 & 1.2 & 0.4 & 0 & 0 & 0 & 1.3 & NA & 6.5 & 35.9 & 4.8 \\
\hline HEG40 & 2.6 & 0 & 0 & 0 & 0 & 1.6 & NA & 6.6 & 32.6 & 4.3 \\
\hline HEG41 & 0.8 & 0.1 & 0 & 0 & 0 & 1 & NA & 7.2 & 22.3 & 4.3 \\
\hline HEG42 & 0.4 & 0 & 0 & 2.6 & 0 & 0.7 & NA & 7.2 & 40.3 & 3.4 \\
\hline HEG43 & 0.6 & 0.4 & 0 & 15.8 & 0 & 1 & NA & 7.1 & 33.9 & 4.1 \\
\hline HEG44 & 0.5 & 0.3 & 0 & 10.5 & 0 & 0.9 & NA & 7.1 & 26.3 & 3.5 \\
\hline HEG45 & 0.5 & 0.1 & 0 & 0 & 0 & 0.8 & NA & 7 & 35.9 & 2.9 \\
\hline HEG46 & 0.6 & 0.3 & 0 & 0 & 0 & 0.9 & NA & 7.4 & 20.8 & 4.1 \\
\hline HEG47 & 0.8 & 1.2 & 0.3 & 0 & 0 & 1.5 & NA & 7.2 & 29.5 & 3.5 \\
\hline HEG48 & 0.7 & 1.2 & 0.3 & 0 & 0 & 1.5 & NA & 7 & NA & 3.4 \\
\hline
\end{tabular}


Table S1 continued:

\begin{tabular}{|c|c|c|c|c|c|c|c|c|c|c|}
\hline Plot ID & Graz. & Mow. & Fert. & Org. N & Min. N & LUI & Tree & $\mathrm{pH}$ & Moist. & $\begin{array}{l}\text { Shannon } \\
\text { H }\end{array}$ \\
\hline HEG49 & 0.2 & 1.4 & 1.2 & 43.3 & 0 & 1.7 & NA & 6.7 & 31.5 & 4.1 \\
\hline HEG50 & 0.3 & 1 & 1.5 & 40.7 & 0 & 1.7 & NA & 6.9 & 33.2 & 3.7 \\
\hline HEW1 & NA & NA & NA & NA & NA & NA & Spruce & 6.2 & 30.0 & 4 \\
\hline HEW3 & NA & NA & NA & NA & NA & NA & Spruce & 5.1 & 15.0 & 4.3 \\
\hline HEW4 & NA & NA & NA & NA & NA & NA & Beech & 6.1 & 33.8 & 4.9 \\
\hline HEW5 & NA & NA & NA & NA & NA & NA & Beech & 5.3 & 33.3 & 3.1 \\
\hline HEW6 & NA & NA & NA & NA & NA & NA & Beech & 4.4 & 30.0 & 4.2 \\
\hline HEW7 & NA & NA & NA & NA & NA & NA & Beech & 4.1 & 44.2 & 4.3 \\
\hline HEW8 & NA & NA & NA & NA & NA & NA & Beech & 5.7 & NA & 3.9 \\
\hline HEW9 & NA & NA & NA & NA & NA & NA & Beech & 4.4 & 36.2 & 3.2 \\
\hline HEW10 & NA & NA & NA & NA & NA & NA & Beech & 4.9 & NA & 4.4 \\
\hline HEW11 & NA & NA & NA & NA & NA & NA & Beech & 4.9 & NA & 4.6 \\
\hline HEW12 & NA & NA & NA & NA & NA & NA & Beech & 4.1 & 25.9 & 4.6 \\
\hline HEW13 & NA & NA & NA & NA & NA & NA & Spruce & 6.8 & 31.2 & 3.9 \\
\hline HEW14 & NA & NA & NA & NA & NA & NA & Beech & 5.1 & 37.5 & 2.7 \\
\hline HEW15 & NA & NA & NA & NA & NA & NA & Beech & 4 & 30.7 & 4.5 \\
\hline HEW16 & NA & NA & NA & NA & NA & NA & Beech & 4.9 & NA & 4.9 \\
\hline HEW17 & NA & NA & NA & NA & NA & NA & Beech & 3.9 & 27.4 & 3.9 \\
\hline HEW18 & NA & NA & NA & NA & NA & NA & Beech & 5.6 & 30.2 & 4.8 \\
\hline HEW19 & NA & NA & NA & NA & NA & NA & Beech & 4.6 & 34.0 & 4.5 \\
\hline HEW20 & NA & NA & NA & NA & NA & NA & Beech & 6.7 & 36.1 & 4.5 \\
\hline HEW21 & NA & NA & NA & NA & NA & NA & Beech & 6.3 & 48.3 & 4.2 \\
\hline HEW22 & NA & NA & NA & NA & NA & NA & Beech & 4.8 & 34.5 & 4.1 \\
\hline HEW23 & NA & NA & NA & NA & NA & NA & Beech & 4.7 & 33.6 & 4 \\
\hline HEW24 & NA & NA & NA & NA & NA & NA & Beech & 4 & 32.8 & 4 \\
\hline HEW25 & NA & NA & NA & NA & NA & NA & Beech & 4.7 & 33.0 & 4.7 \\
\hline HEW26 & NA & NA & NA & NA & NA & NA & Beech & 4.3 & 29.4 & 4.2 \\
\hline HEW27 & NA & NA & NA & NA & NA & NA & Beech & 6 & 42.7 & 4.6 \\
\hline HEW28 & NA & NA & NA & NA & NA & NA & Beech & 6.2 & 41.3 & 3.8 \\
\hline HEW29 & NA & NA & NA & NA & NA & NA & Beech & 4.1 & NA & 4.5 \\
\hline HEW30 & NA & NA & NA & NA & NA & NA & Beech & 4.1 & 25.4 & 3.2 \\
\hline HEW31 & NA & NA & NA & NA & NA & NA & Beech & 4.1 & 28.3 & 4.6 \\
\hline HEW32 & NA & NA & NA & NA & NA & NA & Beech & 3.9 & 26.0 & 4.2 \\
\hline HEW33 & NA & NA & NA & NA & NA & NA & Beech & 4.8 & 37.1 & 4.4 \\
\hline HEW34 & NA & NA & NA & NA & NA & NA & Beech & 4.7 & 29.5 & 4.8 \\
\hline HEW35 & NA & NA & NA & NA & NA & NA & Beech & 4.4 & 33.1 & 4.5 \\
\hline HEW36 & NA & NA & NA & NA & NA & NA & Beech & 4.7 & 45.6 & 4.3 \\
\hline HEW37 & NA & NA & NA & NA & NA & NA & Beech & 4.4 & 31.6 & 4.2 \\
\hline HEW38 & NA & NA & NA & NA & NA & NA & Beech & 5.4 & 33.2 & 4.2 \\
\hline HEW39 & NA & NA & NA & NA & NA & NA & Beech & 4.5 & 32.5 & 4.6 \\
\hline HEW40 & NA & NA & NA & NA & NA & NA & Beech & 5.4 & 38.2 & 4.7 \\
\hline HEW41 & NA & NA & NA & NA & NA & NA & Beech & 4.6 & NA & 4.3 \\
\hline HEW42 & NA & NA & NA & NA & NA & NA & Beech & 4.2 & 31.2 & 4.6 \\
\hline HEW43 & NA & NA & NA & NA & NA & NA & Beech & 6.7 & 42.6 & 4.9 \\
\hline HEW44 & NA & NA & NA & NA & NA & NA & Beech & 5.4 & 38.7 & 4.2 \\
\hline HEW45 & NA & NA & NA & NA & NA & NA & Beech & 7.2 & NA & 3.6 \\
\hline HEW46 & NA & NA & NA & NA & NA & NA & Beech & 4.2 & 27.1 & 4.1 \\
\hline HEW47 & NA & NA & NA & NA & NA & NA & Beech & 4.9 & 34.4 & 4.5 \\
\hline HEW48 & NA & NA & NA & NA & NA & NA & Beech & 4.4 & NA & 4.4 \\
\hline HEW49 & NA & NA & NA & NA & NA & NA & Beech & 4.1 & 29.4 & 4 \\
\hline HEW50 & NA & NA & NA & NA & NA & NA & Beech & 4.8 & 31.4 & 3.8 \\
\hline
\end{tabular}


Table S1 continued:

\begin{tabular}{|c|c|c|c|c|c|c|c|c|c|c|}
\hline Plot ID & Graz. & Mow. & Fert. & Org. N & Min. $\mathbf{N}$ & LUI & Tree & $\mathrm{pH}$ & Moist. & $\begin{array}{l}\text { Shannon } \\
\text { H }\end{array}$ \\
\hline HEW51 & NA & NA & NA & NA & NA & NA & Spruce & 6.6 & 41.5 & 3.6 \\
\hline AEG1 & 0 & 2 & 1.8 & 29.3 & 49.5 & 2 & NA & 6.8 & 21.6 & 4.3 \\
\hline AEG2 & 0 & 2.8 & 8.3 & 142.7 & 62.7 & 3.3 & NA & 6.9 & 34.4 & 4.6 \\
\hline AEG3 & 0.1 & 2 & 1.1 & 41.7 & 26.1 & 1.8 & NA & 6.1 & 35.6 & 4.2 \\
\hline AEG4 & 0.7 & 1 & 1.4 & 42.5 & 39.9 & 1.8 & NA & 5.3 & 43.0 & 4.6 \\
\hline AEG5 & 0.7 & 0.9 & 1.7 & 8.9 & 54.4 & 1.8 & NA & 6.3 & 38.7 & 4.4 \\
\hline AEG6 & 2.2 & 1 & 1.7 & 19.9 & 32.3 & 2.2 & NA & 6 & 34.8 & 4.3 \\
\hline AEG7 & 0.3 & 0 & 0 & 0 & 0 & 0.5 & NA & 7.3 & 32.3 & 2.4 \\
\hline AEG8 & 0.7 & 0.9 & 0 & 0 & 0 & 1.3 & NA & 6.6 & 30.4 & 4.6 \\
\hline AEG9 & 0.5 & 0 & 0 & 0 & 0 & 0.7 & NA & 6.6 & 31.9 & 3.4 \\
\hline AEG10 & 0 & 1 & 0 & 10.2 & 2.7 & 1 & NA & 5.9 & 35.3 & 4.2 \\
\hline AEG11 & 0 & 2.8 & 1.7 & 18.7 & 29.4 & 2.1 & NA & 5.4 & 37.4 & 3.9 \\
\hline AEG12 & 0 & 2.1 & 2.4 & 42.3 & 39.5 & 2.1 & NA & 6.6 & 30.0 & 4.6 \\
\hline AEG13 & 0 & 2 & 2.5 & 42.3 & 29.4 & 2.1 & NA & 6.3 & 35.1 & 4.7 \\
\hline AEG14 & 0 & 2 & 3.6 & 55.1 & 35.5 & 2.4 & NA & 6.6 & 29.6 & 4.6 \\
\hline AEG15 & 0 & 2.9 & 6.1 & 139.3 & 25 & 3 & NA & 5.7 & 43.4 & 3.8 \\
\hline AEG16 & 0.9 & 1.2 & 0.6 & 24.5 & 0 & 1.6 & NA & 6 & 34.5 & 4.5 \\
\hline AEG17 & 0 & 2.2 & 1.6 & 45.2 & 2.7 & 2 & NA & 6.9 & 38.9 & 4.2 \\
\hline AEG18 & 0 & 2.6 & 4.2 & 104.6 & 25 & 2.6 & NA & 6.9 & 31.9 & 3.8 \\
\hline AEG19 & 2.8 & 0.7 & 1.3 & 0 & 28.6 & 2.2 & NA & 5.8 & 36.8 & 4.7 \\
\hline AEG20 & 1.5 & 0 & 0.5 & 0 & 13.6 & 1.4 & NA & 6.7 & 42.4 & 4.9 \\
\hline AEG21 & 6.2 & 0.4 & 5.2 & 98 & 1.4 & 3.5 & NA & 5.8 & 32.9 & 4.5 \\
\hline AEG22 & 0.3 & 1 & 0.4 & 7 & 0 & 1.3 & NA & 5.7 & 36.9 & 4.1 \\
\hline AEG23 & 0 & 1.8 & 0.4 & 11.2 & 0 & 1.5 & NA & 7.1 & 42.8 & 3.6 \\
\hline AEG24 & 1 & 2.1 & 2.3 & 87.3 & 0 & 2.3 & NA & 6.1 & 39.9 & 4.4 \\
\hline AEG25 & 0.4 & 0 & 0.1 & 0 & 0 & 0.8 & NA & 7.2 & 36.7 & 3.6 \\
\hline AEG26 & 2 & 0 & 0 & 9.6 & 0 & 1.4 & NA & 6.8 & NA & 4 \\
\hline AEG27 & 1.2 & 0 & 0 & 0 & 9.1 & 1.1 & NA & 6 & 30.5 & 2.2 \\
\hline AEG28 & 0.8 & 0 & 0 & 0 & 0 & 0.9 & NA & 6.1 & 26.1 & 3 \\
\hline AEG29 & 0.7 & 1.1 & 0.4 & 48.5 & 0 & 1.5 & NA & 5.9 & 15.4 & 4.4 \\
\hline AEG30 & 1.3 & 0.8 & 0.3 & 0 & 18.6 & 1.6 & NA & 6.6 & 38.5 & 4.7 \\
\hline AEG31 & 1.1 & 0.7 & 0 & 0 & 4.6 & 1.4 & NA & 6.7 & 36.1 & 4.8 \\
\hline AEG32 & 0.5 & 0 & 0 & 0 & 9.1 & 0.7 & NA & 5.4 & 42.6 & 4.5 \\
\hline AEG33 & 1.2 & 0 & 0 & 0 & 0 & 1.1 & NA & 6 & 42.6 & 4.3 \\
\hline AEG34 & 1 & 0.5 & 0 & 13.2 & 3.6 & 1.3 & NA & 6.3 & 37.3 & 3.9 \\
\hline AEG35 & 0 & 2.1 & 1.4 & 18.5 & 29.1 & 1.9 & NA & 5.3 & 39.1 & 4.1 \\
\hline AEG36 & 0 & 2 & 1.7 & 9.4 & 42.6 & 1.9 & NA & 6 & 41.2 & 4 \\
\hline AEG37 & 0.1 & 2 & 1.7 & 35.4 & 47.6 & 1.9 & NA & 6.3 & 38.7 & 3.7 \\
\hline AEG38 & 0 & 2 & 0.3 & 9.3 & 3.6 & 1.5 & NA & 5.6 & 46.9 & 4 \\
\hline AEG39 & 0 & 2 & 1.9 & 29.9 & 29.5 & 2 & NA & 6 & 33.1 & 4.8 \\
\hline AEG40 & 0.2 & 2.4 & 1.8 & 44.2 & 12.7 & 2.1 & NA & 6.9 & 34.1 & 3 \\
\hline AEG41 & 0.1 & 2.3 & 4.7 & 95.8 & 19.7 & 2.7 & NA & 6.3 & 28.8 & 4.8 \\
\hline AEG42 & 1.2 & 1.6 & 2 & 49 & 2.7 & 2.2 & NA & 7.1 & 32.7 & 4.9 \\
\hline AEG43 & 1 & 0.9 & 0.8 & 29.8 & 0 & 1.7 & NA & 6.9 & 33.1 & 4.5 \\
\hline AEG44 & 2.5 & 0 & 0 & 0 & 0 & 1.6 & NA & 7.3 & 38.4 & 4.6 \\
\hline AEG45 & 0 & 2.3 & 0.1 & 9.8 & 0 & 1.6 & NA & 5.4 & NA & 4.5 \\
\hline AEG46 & 2.4 & 0 & 0 & 0 & 0 & 1.5 & NA & 6 & 42.2 & 4.5 \\
\hline AEG47 & 0.7 & 0 & 0 & 9.6 & 0 & 0.8 & NA & 7.5 & 29.4 & 4 \\
\hline AEG48 & 0.4 & 0 & 0 & 9.6 & 0 & 0.7 & NA & 7.6 & 27.1 & 4.2 \\
\hline AEG49 & 1 & 0 & 0 & 9.6 & 0 & 1 & NA & 6 & 36.3 & 3.9 \\
\hline AEG50 & 0 & 2 & 2.1 & 69 & 12.5 & 2 & NA & 6 & 33.8 & 4.6 \\
\hline
\end{tabular}


Table S1 continued:

\begin{tabular}{|c|c|c|c|c|c|c|c|c|c|c|}
\hline Plot ID & Graz. & Mow. & Fert. & Org. N & Min. N & LUI & Tree & $\mathrm{pH}$ & Moist. & $\begin{array}{l}\text { Shannon } \\
\text { H }\end{array}$ \\
\hline AEW1 & NA & NA & NA & NA & NA & NA & Spruce & 3.3 & 38.7 & 3.6 \\
\hline AEW2 & NA & NA & NA & NA & NA & NA & Spruce & 4.8 & 23.4 & 4.5 \\
\hline AEW3 & NA & NA & NA & NA & NA & NA & Spruce & 5.6 & 34.6 & 4.1 \\
\hline AEW4 & NA & NA & NA & NA & NA & NA & Beech & 6.8 & 38.7 & 3.6 \\
\hline AEW5 & NA & NA & NA & NA & NA & NA & Beech & 4.5 & NA & 3.6 \\
\hline AEW6 & NA & NA & NA & NA & NA & NA & Beech & 5.6 & 39.9 & 4.1 \\
\hline AEW7 & NA & NA & NA & NA & NA & NA & Beech & 5 & 41.6 & 2.8 \\
\hline AEW8 & NA & NA & NA & NA & NA & NA & Beech & 6.4 & 42.9 & 3 \\
\hline AEW9 & NA & NA & NA & NA & NA & NA & Beech & 6.1 & 27.5 & 3.1 \\
\hline AEW10 & NA & NA & NA & NA & NA & NA & Spruce & 4.6 & 30.9 & 3.1 \\
\hline AEW11 & NA & NA & NA & NA & NA & NA & Spruce & 3.4 & 27.8 & 3.3 \\
\hline AEW12 & NA & NA & NA & NA & NA & NA & Spruce & 4.5 & 32.0 & 4.4 \\
\hline AEW13 & NA & NA & NA & NA & NA & NA & Spruce & 5.2 & 40.7 & 4 \\
\hline AEW14 & NA & NA & NA & NA & NA & NA & Spruce & 4.8 & 38.9 & 4.6 \\
\hline AEW15 & NA & NA & NA & NA & NA & NA & Beech & 6.4 & 36.7 & 4.1 \\
\hline AEW16 & NA & NA & NA & NA & NA & NA & Beech & 6.4 & 30.1 & 3.7 \\
\hline AEW17 & NA & NA & NA & NA & NA & NA & Beech & 6.5 & 42.6 & 4.1 \\
\hline AEW18 & NA & NA & NA & NA & NA & NA & Beech & 4.7 & 30.3 & 4.4 \\
\hline AEW19 & NA & NA & NA & NA & NA & NA & Beech & 5.1 & 32.0 & 4 \\
\hline AEW20 & NA & NA & NA & NA & NA & NA & Beech & 6.6 & 40.5 & 3.8 \\
\hline AEW21 & NA & NA & NA & NA & NA & NA & Beech & 6.3 & 28.8 & 5.3 \\
\hline AEW22 & NA & NA & NA & NA & NA & NA & Beech & 6.3 & 40.7 & 4 \\
\hline AEW23 & NA & NA & NA & NA & NA & NA & Beech & 5.6 & 20.5 & 3.9 \\
\hline AEW24 & NA & NA & NA & NA & NA & NA & Beech & 5.3 & NA & 4.6 \\
\hline AEW25 & NA & NA & NA & NA & NA & NA & Beech & 5.1 & 31.1 & 3.9 \\
\hline AEW26 & NA & NA & NA & NA & NA & NA & Beech & 5.1 & 39.4 & 3.8 \\
\hline AEW27 & NA & NA & NA & NA & NA & NA & Beech & 4.6 & 39.5 & 4 \\
\hline AEW28 & NA & NA & NA & NA & NA & NA & Beech & 4.7 & 33.4 & 4.2 \\
\hline AEW29 & NA & NA & NA & NA & NA & NA & Beech & 4.4 & 34.3 & 4.3 \\
\hline AEW30 & NA & NA & NA & NA & NA & NA & Beech & 5.8 & 39.6 & 4.4 \\
\hline AEW31 & NA & NA & NA & NA & NA & NA & Spruce & 5.6 & 33.6 & 3.9 \\
\hline AEW32 & NA & NA & NA & NA & NA & NA & Spruce & 6.9 & 13.4 & 3.8 \\
\hline AEW33 & NA & NA & NA & NA & NA & NA & Spruce & 5.8 & 26.6 & 3.9 \\
\hline AEW34 & NA & NA & NA & NA & NA & NA & Spruce & 4.9 & 29.5 & 4.4 \\
\hline AEW35 & NA & NA & NA & NA & NA & NA & Beech & 5.5 & 39.2 & 4.7 \\
\hline AEW36 & NA & NA & NA & NA & NA & NA & Beech & 6 & 29.4 & 4.5 \\
\hline AEW37 & NA & NA & NA & NA & NA & NA & Beech & 5.2 & 37.9 & 3.9 \\
\hline AEW38 & NA & NA & NA & NA & NA & NA & Beech & 6.9 & 31.9 & 4.3 \\
\hline AEW39 & NA & NA & NA & NA & NA & NA & Beech & 5.2 & 31.5 & 4.4 \\
\hline AEW40 & NA & NA & NA & NA & NA & NA & Beech & 5.3 & 35.4 & 4.5 \\
\hline AEW41 & NA & NA & NA & NA & NA & NA & Beech & 5.7 & 38.6 & 4.1 \\
\hline AEW42 & NA & NA & NA & NA & NA & NA & Beech & 6.5 & 21.7 & 4.7 \\
\hline AEW43 & NA & NA & NA & NA & NA & NA & Beech & 5.1 & 38.0 & 5 \\
\hline AEW44 & NA & NA & NA & NA & NA & NA & Beech & 6 & NA & 3.7 \\
\hline AEW45 & NA & NA & NA & NA & NA & NA & Beech & 5.8 & 26.5 & 4.4 \\
\hline AEW46 & NA & NA & NA & NA & NA & NA & Beech & 5.5 & 35.4 & 3.9 \\
\hline AEW47 & NA & NA & NA & NA & NA & NA & Beech & 5.2 & NA & 4 \\
\hline AEW48 & NA & NA & NA & NA & NA & NA & Beech & 5.8 & 31.6 & 4.2 \\
\hline AEW49 & NA & NA & NA & NA & NA & NA & Beech & 6.3 & 20.7 & 4.7 \\
\hline AEW50 & NA & NA & NA & NA & NA & NA & Beech & 5.9 & 27.0 & 3.2 \\
\hline
\end{tabular}


Table S2: $\Delta$ Ct values of all analyzed target sequences in the 300 experimental plots. The non-detect $\Delta C_{\text {T }}$ values are marked in grey.

\begin{tabular}{|c|c|c|c|c|c|c|c|c|c|c|}
\hline $\begin{array}{l}\text { Plot } \\
\text { ID }\end{array}$ & IncP-1. & $\begin{array}{l}\text { Class } 1 \\
\text { integrons. }\end{array}$ & $\begin{array}{l}a a c\left(6^{\prime}\right)- \\
l b\end{array}$ & $\operatorname{aacC1}$ & bla IMP-12 & blaIMP-5 & ermB & $m e f A$ & tet $A$ & sul2 \\
\hline SEG1 & -17 & -20.51 & -18.89 & -19.58 & -20 & -19.39 & -20.02 & -19.43 & -19.92 & -20.31 \\
\hline SEG2 & -14.5 & -20.51 & -18.18 & -19.58 & -20 & -17.43 & -19.12 & -19.04 & -19.92 & -20.31 \\
\hline SEG3 & -15.5 & -20.51 & -18.31 & -19.58 & -20 & -20.13 & -20.02 & -17.51 & -19.92 & -20.31 \\
\hline SEG4 & -16.5 & -20.51 & -18.05 & -19.58 & -20 & -20.13 & -20.02 & -19.43 & -19.92 & -20.31 \\
\hline SEG5 & -19.81 & NA & -18.28 & -19.58 & -16.77 & -18.16 & -20.02 & -19.43 & -19.92 & -20.31 \\
\hline SEG6 & -15.8 & -20.51 & -19.93 & -19.58 & -20 & -20.13 & -20.02 & -19.43 & -19.92 & -20.31 \\
\hline SEG7 & -17.7 & -20.51 & -19.93 & -19.58 & -17.81 & -17.24 & -20.02 & -19.43 & -19.92 & -20.31 \\
\hline SEG8 & -18.7 & -20.51 & -18.21 & -19.58 & -20 & -20.13 & -20.02 & -17.98 & -19.92 & -20.31 \\
\hline SEG9 & -18 & -20.51 & -19.92 & -19.58 & -20 & -20.13 & -20.02 & -19.43 & -19.92 & -20.31 \\
\hline SEG10 & -17.1 & -20.51 & -19.93 & -19.58 & -20 & -20.13 & -20.02 & -19.43 & -19.92 & -20.31 \\
\hline SEG11 & -18.4 & -20.51 & -18.92 & -19.58 & -20 & -20.13 & -20.02 & -19.43 & -19.92 & -20.31 \\
\hline SEG12 & -15.7 & -20.51 & -19.93 & -19.58 & -20 & -20.13 & -20.02 & -19.43 & -19.92 & -14.67 \\
\hline SEG13 & -16.3 & -18.1 & -19.93 & -19.58 & -18.21 & -20.13 & -20.02 & -16.5 & -19.92 & -14.65 \\
\hline SEG14 & -19.81 & -20.51 & -19.93 & -19.58 & -17.95 & -20.13 & -20.02 & -19.43 & -19.92 & -16.79 \\
\hline SEG15 & -15.4 & -20.51 & -19.93 & -19.58 & -20 & -20.13 & -20.02 & -19.43 & -19.92 & -20.31 \\
\hline SEG16 & -19.81 & -20.51 & -19.93 & -19.58 & -20 & -20.13 & -20.02 & -19.43 & -19.92 & -20.31 \\
\hline SEG17 & -19.81 & -20.51 & -19.93 & -19.58 & -20 & -20.13 & -20.02 & -19.43 & -19.92 & NA \\
\hline SEG18 & -14.1 & -20.51 & -17.29 & -19.58 & -20 & -20.13 & -20.02 & -19.43 & -19.92 & -14.18 \\
\hline SEG19 & -18.1 & -20.51 & -19.93 & -19.58 & -20 & -20.13 & -20.02 & -19.43 & -19.92 & -20.31 \\
\hline SEG20 & -15.7 & -20.51 & -19.93 & -19.58 & -20 & -20.13 & -20.02 & -19.43 & -19.92 & -20.31 \\
\hline SEG21 & -16.1 & -20.51 & -19.93 & -19.58 & -20 & -18.72 & -20.02 & -19.43 & -19.92 & -20.31 \\
\hline SEG22 & -19.81 & -20.51 & -17.64 & -19.58 & -20 & -20.13 & -20.02 & -19.43 & -19.92 & -20.31 \\
\hline SEG23 & -19.81 & NA & -19.93 & -19.58 & -19.17 & -20.13 & -20.02 & -16.98 & -19.92 & -20.31 \\
\hline SEG24 & -19.81 & -20.51 & -18.12 & -19.58 & -18.9 & -20.13 & -20.02 & -19.43 & -19.92 & -20.31 \\
\hline SEG25 & -15.9 & -20.51 & -19.93 & -19.58 & -20 & -20.13 & -20.02 & -19.43 & -19.92 & -20.31 \\
\hline SEG26 & -16.8 & -20.51 & -17.95 & -19.58 & -18.66 & -20.13 & -20.02 & -19.22 & -19.92 & -17.6 \\
\hline SEG27 & -17.4 & -20.51 & -19.93 & -19.58 & -20 & -20.13 & -20.02 & -19.43 & -19.92 & -20.31 \\
\hline SEG28 & -17.4 & -20.51 & -16.91 & -19.58 & -18.65 & -18.44 & -20.02 & -19.43 & -19.92 & -20.31 \\
\hline SEG29 & -17.4 & NA & -16.96 & -19.58 & -17.73 & -20.13 & -20.02 & -19.43 & -19.92 & -20.31 \\
\hline SEG30 & -16 & -20.51 & -19.93 & -19.58 & -17.84 & -20.13 & -20.02 & -19.43 & -18.08 & -20.31 \\
\hline SEG31 & -18.8 & -20.51 & -19.93 & -19.58 & -18.66 & -20.13 & -20.02 & -18.57 & -19.92 & -20.31 \\
\hline SEG32 & -18.4 & NA & -19.93 & -19.58 & -20 & -20.13 & -20.02 & -18.65 & -19.92 & -20.31 \\
\hline SEG33 & -15.2 & -20.51 & -19.93 & -19.58 & -17.45 & -18.22 & -20.02 & -18.34 & -19.16 & -17.3 \\
\hline SEG34 & -16.6 & -20.5 & -19.93 & -19.58 & -18.55 & -18.72 & -20.02 & -17.17 & -19.92 & -20.31 \\
\hline SEG35 & -15.4 & -20.51 & -19.93 & -19.58 & -18.36 & -20.13 & -20.02 & -17.71 & -17.4 & -20.31 \\
\hline SEG36 & -16.4 & NA & -19.93 & -19.58 & -19.38 & -20.13 & -20.02 & -19.43 & -19.37 & -18.7 \\
\hline SEG37 & -10.2 & -20.51 & -19.93 & -19.58 & -20 & -20.13 & -20.02 & -15.64 & -19.92 & -20.31 \\
\hline SEG38 & -15.4 & -20.51 & -19.93 & -19.58 & -20 & -19.04 & -20.02 & -18.31 & -19.92 & -18.3 \\
\hline SEG39 & -19.81 & -18.7 & -19.93 & -19.58 & -18.36 & -20.13 & -20.02 & -19.43 & -19.92 & -15.9 \\
\hline SEG40 & -19.4 & -20.51 & -19.93 & -19.58 & -20 & -20.13 & -20.02 & -16.78 & -19.82 & -17.8 \\
\hline SEG41 & -13.6 & -20.51 & -19.93 & -19.58 & -20 & -20.13 & -20.02 & -19.04 & -18.31 & -16.9 \\
\hline SEG42 & -14.3 & -20.51 & -19.93 & -19.58 & -19.05 & -20.13 & -20.02 & -14.52 & -19.92 & -20.31 \\
\hline SEG43 & -18 & -20.51 & -18.57 & -19.58 & -16.17 & -18.74 & -20.02 & -14.76 & -16.66 & -14.5 \\
\hline SEG44 & -15.1 & -20.51 & -19.93 & -19.58 & -17.08 & -20.13 & -20.02 & -13.64 & -19.92 & -16.8 \\
\hline SEG45 & -15.5 & -20.51 & -19.93 & -19.58 & -16.38 & -20.13 & -20.02 & -14.17 & -19.92 & -13.6 \\
\hline SEG46 & -19.81 & -20.51 & -19.93 & -19.58 & -18.66 & -20.13 & -20.02 & -18.65 & -18.57 & -16.6 \\
\hline SEG47 & -19.81 & -20.51 & -19.93 & -19.58 & -17.67 & -19.01 & -20.02 & -19.42 & -19.83 & -20.31 \\
\hline SEG48 & NA & -20.51 & -19.93 & -19.58 & -18.29 & -20.13 & -20.02 & -18 & -18.14 & -20.31 \\
\hline SEG49 & -15.5 & -19.2 & -19.5 & -19.58 & -18.76 & -20.13 & -20.02 & -19.43 & -19.92 & -17.2 \\
\hline SEG50 & -15.8 & -20.51 & -19.93 & -19.58 & -17.86 & -20.13 & -20.02 & -19.43 & -19.92 & -20.31 \\
\hline SEW1 & -19.81 & -20.51 & -19.93 & -19.58 & -20 & -20.13 & -20.02 & -19.43 & -19.92 & -20.31 \\
\hline
\end{tabular}


Table S2 continued:

\begin{tabular}{|c|c|c|c|c|c|c|c|c|c|c|}
\hline Plot ID & IncP-1. & $\begin{array}{l}\text { Class } 1 \\
\text { integrons. }\end{array}$ & $\begin{array}{l}a a c\left(6^{\prime}\right)- \\
l b\end{array}$ & $\operatorname{aacC1}$ & bla ${ }_{I M P-12}$ & bla ${ }_{I M P-5}$ & ermB & mefA & tet $A$ & sul2 \\
\hline SEW2 & -19.81 & -20.51 & -19.93 & -19.58 & -20 & -20.13 & -20.02 & -19.43 & -19.92 & -20.31 \\
\hline SEW3 & -19.81 & NA & -19.93 & -19.58 & -20 & -20.13 & -20.02 & -19.43 & -19.92 & -20.31 \\
\hline SEW4 & -19.81 & -20.51 & NA & NA & NA & NA & NA & NA & NA & -20.31 \\
\hline SEW5 & -19.81 & -20.51 & -19.93 & -19.58 & -20 & -20.13 & -20.02 & -19.43 & -19.92 & -20.31 \\
\hline SEW6 & -19.81 & -20.51 & -19.93 & -19.58 & -20 & -20.13 & -20.02 & -19.43 & -19.92 & -20.31 \\
\hline SEW7 & -19.81 & -20.51 & -19.93 & -19.58 & -19.78 & -20.13 & -20.02 & -19.43 & -19.92 & -20.31 \\
\hline SEW8 & -19.81 & -20.51 & -19.93 & -19.58 & -20 & -20.13 & -20.02 & -19.43 & -19.92 & -20.31 \\
\hline SEW9 & -19.81 & -20.51 & -19.93 & -19.58 & -20 & -20.13 & -20.02 & -19.43 & -19.92 & -20.31 \\
\hline SEW10 & -19.81 & -20.51 & -19.93 & -19.58 & -20 & -20.13 & -20.02 & -19.43 & -19.92 & -20.31 \\
\hline SEW11 & -19.81 & -20.51 & -19.93 & -19.58 & -20 & -20.13 & -20.02 & -19.43 & -19.92 & -18.2 \\
\hline SEW12 & -19.81 & -20.51 & -19.93 & -19.58 & -20 & -20.13 & -20.02 & -19.43 & -19.92 & -20.31 \\
\hline SEW13 & -19.81 & -20.51 & NA & NA & NA & NA & NA & NA & NA & -20.31 \\
\hline SEW14 & -16.7 & -20.51 & NA & NA & NA & NA & NA & NA & NA & -20.31 \\
\hline SEW15 & -19.81 & -20.51 & -19.93 & -19.58 & -20 & -20.13 & -20.02 & -19.43 & -19.92 & -17 \\
\hline SEW16 & -19.81 & -20.51 & NA & NA & NA & NA & NA & NA & NA & -20.31 \\
\hline SEW17 & -18.1 & -20.51 & NA & NA & NA & NA & NA & NA & NA & -20.31 \\
\hline SEW18 & -19.81 & -20.51 & NA & NA & NA & NA & NA & NA & NA & -20.31 \\
\hline SEW19 & -19.81 & -20.51 & NA & NA & NA & NA & NA & NA & NA & -20.31 \\
\hline SEW20 & -19.81 & -20.51 & NA & NA & NA & NA & NA & NA & NA & -20.31 \\
\hline SEW21 & -19.81 & -20.51 & NA & NA & NA & NA & NA & NA & NA & -20.31 \\
\hline SEW22 & -19.81 & -20.51 & -19.93 & -19.58 & -20 & -20.13 & -20.02 & -19.43 & -19.92 & -20.31 \\
\hline SEW23 & -19.81 & -20.51 & -19.93 & -19.58 & -20 & -20.13 & -20.02 & -19.43 & -19.92 & -20.31 \\
\hline SEW24 & -19.81 & -20.51 & -19.93 & -19.58 & -19.58 & -20.13 & -20.02 & -19.43 & -19.92 & -20.31 \\
\hline SEW25 & -19.81 & -20.51 & -19.93 & -19.58 & -17.55 & -20.13 & -20.02 & -19.43 & -19.92 & -20.31 \\
\hline SEW26 & -17.5 & -20.51 & -19.93 & -19.58 & -20 & -20.13 & -20.02 & -19.43 & -19.92 & -20.31 \\
\hline SEW27 & -19.81 & -20.51 & -19.93 & -19.58 & -20 & -20.13 & -20.02 & -19.43 & -19.92 & -20.31 \\
\hline SEW28 & -16.6 & -20.51 & -19.93 & -19.58 & -20 & -20.13 & -20.02 & -19.43 & -19.92 & -20.31 \\
\hline SEW29 & -19.81 & -20.51 & -19.93 & -19.58 & -20 & -20.13 & -20.02 & -19.43 & -19.92 & -20.31 \\
\hline SEW30 & -19.81 & -20.51 & NA & NA & NA & NA & NA & NA & NA & -20.31 \\
\hline SEW31 & -18.7 & -20.51 & -19.93 & -19.58 & -20 & -20.13 & -20.02 & -19.43 & -19.92 & -20.31 \\
\hline SEW32 & -19.81 & -20.51 & -19.93 & -19.58 & -20 & -20.13 & -20.02 & -19.43 & -19.92 & -20.31 \\
\hline SEW33 & -19.81 & -19.9 & -19.93 & -19.58 & -20 & -20.13 & -20.02 & -19.43 & -19.92 & -20.31 \\
\hline SEW34 & -19.81 & -20.51 & -19.93 & -19.58 & -20 & -20.13 & -20.02 & -19.43 & -19.92 & -20.31 \\
\hline SEW35 & -19.81 & -20.51 & -19.93 & -19.58 & -20 & -20.13 & -20.02 & -19.43 & -19.92 & -16.1 \\
\hline SEW36 & -19.81 & -20.51 & NA & NA & NA & NA & NA & NA & NA & -20.31 \\
\hline SEW37 & -19.81 & -20.51 & -19.93 & -19.58 & -20 & -20.13 & -20.02 & -19.43 & -19.92 & -20.31 \\
\hline SEW38 & -19.81 & -20.51 & -19.93 & -19.58 & -20 & -20.13 & -20.02 & -19.43 & -19.92 & -20.31 \\
\hline SEW39 & -19.81 & -20.51 & -19.93 & -19.58 & -20 & -20.13 & -20.02 & -19.43 & -19.92 & -20.31 \\
\hline SEW40 & -19.81 & -20.51 & -19.93 & -19.58 & -20 & -20.13 & -20.02 & -18.76 & -19.92 & -20.31 \\
\hline SEW41 & -17.8 & -20.51 & -19.93 & -19.58 & -20 & -20.13 & -20.01 & -19.43 & -19.92 & -20.31 \\
\hline SEW42 & -19.81 & -20.51 & -19.93 & -19.58 & -19.29 & -20.13 & -20.02 & -19.43 & -19.92 & -20.31 \\
\hline SEW43 & -19.81 & -20.51 & -19.93 & -19.58 & -17.87 & -19.05 & -20.02 & -19.43 & -19.92 & -20.31 \\
\hline SEW44 & -19.81 & -20.51 & -19.93 & -19.58 & -20 & -20.13 & -20.02 & -19.43 & -19.92 & -20.31 \\
\hline SEW45 & -19.81 & -20.51 & -19.93 & -19.58 & -18.08 & -20.13 & -20.02 & -19.43 & -19.92 & -20.31 \\
\hline SEW46 & -19.81 & NA & -19.93 & -19.58 & -20 & -20.13 & -20.02 & -19.43 & -19.92 & -18 \\
\hline SEW47 & -19.81 & -20.51 & -19.93 & -19.58 & -20 & -20.13 & -20.02 & -19.43 & -19.92 & -20.31 \\
\hline SEW48 & -19.81 & -20.51 & -19.93 & -19.58 & -20 & -20.13 & -20.02 & -19.43 & -19.92 & -20.31 \\
\hline SEW49 & -19.81 & -20.51 & NA & NA & NA & NA & NA & NA & NA & -20.31 \\
\hline SEW50 & -19.81 & -20.51 & -19.93 & -19.58 & -20 & -20.13 & -20.02 & -19.43 & -19.92 & -20.31 \\
\hline HEG1 & -19.4 & -20.51 & NA & -19.58 & -19.43 & -18.77 & -20.02 & -19.43 & -19.92 & -20.31 \\
\hline HEG2 & -18.4 & -20.51 & -19.93 & -19.58 & -19.38 & -18.54 & -20.02 & -19.43 & -19.92 & -19.6 \\
\hline
\end{tabular}


Table S2 continued:

\begin{tabular}{|c|c|c|c|c|c|c|c|c|c|c|}
\hline Plot ID & IncP-1. & $\begin{array}{l}\text { Class } 1 \\
\text { integrons. }\end{array}$ & $\begin{array}{l}a a c\left(6^{\prime}\right)- \\
l b\end{array}$ & $\operatorname{aacC1}$ & bla ${ }_{I M P-12}$ & bla ${ }_{I M P-5}$ & ermB & mefA & tet $A$ & sul2 \\
\hline HEG3 & -18.6 & -20.51 & -17.54 & -18.87 & -17.24 & -18.01 & -20.02 & -19.43 & -19.92 & -20.31 \\
\hline HEG4 & -16.3 & -18.2 & -19.01 & -19.58 & -17.36 & -17.34 & -20.02 & -16.71 & -19.92 & -15.9 \\
\hline HEG5 & -19.81 & -17.7 & -18.69 & -19.58 & -16.89 & -20.13 & -20.02 & -17.16 & -17.84 & -16.4 \\
\hline HEG6 & -17.6 & -14.5 & -19.43 & -19.58 & -19.03 & -17.07 & -14.09 & -13.64 & -15.73 & -8.6 \\
\hline HEG7 & -19.81 & -20.51 & -19.93 & -19.58 & -20 & -17.44 & -20.02 & -19.43 & -19.92 & -20.31 \\
\hline HEG8 & -19.81 & -20.51 & -16.75 & -19.58 & -17.65 & -17.8 & -20.02 & -19.43 & -19.92 & -18.8 \\
\hline HEG9 & -13.7 & -20.51 & -19.93 & -19.58 & -20 & -20.13 & -20.02 & -19.02 & -19.92 & -20.1 \\
\hline HEG10 & -16.1 & -20.51 & -18.82 & -19.58 & -17.36 & -20.13 & -20.02 & -17.59 & -19.92 & -17 \\
\hline HEG11 & -16.9 & -20.51 & -19.93 & -19.58 & -20 & -20.13 & -20.02 & -15.95 & -19.92 & -20.31 \\
\hline HEG12 & -16.9 & -20.51 & -18.48 & -18.83 & -20 & -16.63 & -20.02 & -19.43 & -19.92 & -20.31 \\
\hline HEG13 & -17.6 & -20.51 & -17.76 & -19.58 & -20 & -20.13 & -20.02 & -17.23 & -19.92 & -16 \\
\hline HEG14 & -16.2 & -20.51 & -19.93 & -19.58 & -20 & -20.13 & -20.02 & -16.67 & -19.92 & -20.31 \\
\hline HEG15 & -16.4 & -20.51 & -18.78 & -19.58 & -15.81 & -20.13 & -20.02 & -19.43 & -18.48 & -18.9 \\
\hline HEG16 & -19.81 & -20.51 & -19.04 & -19.58 & -20 & -20.13 & -20.02 & -19.43 & -19.92 & -20.31 \\
\hline HEG17 & -16.4 & -20.51 & -18.09 & -19.58 & -19.38 & -20.13 & -20.02 & -19.43 & -19.92 & -20.31 \\
\hline HEG18 & -17.6 & -20.51 & -19.93 & -19.58 & -20 & -20.13 & -20.02 & -19.43 & -19.92 & -20.31 \\
\hline HEG19 & -17.6 & -20.51 & -19.93 & -19.58 & -18.43 & -16.81 & -20.02 & -19.43 & -19.92 & -20.31 \\
\hline HEG20 & -14.3 & -20.51 & -19.93 & -19.58 & -20 & -20.13 & -20.02 & -19.43 & -19.92 & -20.31 \\
\hline HEG21 & -19.81 & -17.4 & -19.93 & -19.13 & -20 & -18.28 & -17.42 & -16.54 & -18.25 & -14.6 \\
\hline HEG22 & -18.2 & -20.51 & -17.57 & -19.58 & -20 & -20.13 & -20.02 & -17.05 & -19.92 & -20.31 \\
\hline HEG23 & -19.81 & -20.51 & -19.93 & -19.58 & -18.35 & -20.13 & -20.02 & -17.75 & -19.1 & -20.31 \\
\hline HEG24 & -16.3 & -20.51 & -18.46 & -19.58 & -16.46 & -18.23 & -20.02 & -18.42 & -19.92 & -20.31 \\
\hline HEG25 & NA & -20.51 & -19.49 & -19.57 & -20 & -20.13 & -19.64 & -19.07 & -19.92 & -20.31 \\
\hline HEG26 & -18.6 & NA & -18.4 & -19.58 & -18.81 & -20.13 & -20.02 & -17.16 & -19.92 & -20.31 \\
\hline HEG27 & -16.7 & -20.51 & -19.75 & -19.58 & -20 & -20.13 & -20.02 & -19.43 & -19.92 & -20.31 \\
\hline HEG28 & -15.2 & -20.51 & -18.74 & -19.58 & -20 & -20.13 & -20.02 & -14.97 & -17.8 & -20.31 \\
\hline HEG29 & -17.7 & -20.51 & -18.58 & -19.58 & -20 & -20.13 & -20.02 & -18.2 & -19.92 & -20.31 \\
\hline HEG30 & NA & -20.51 & -18.84 & -19.58 & -12.86 & -17.48 & -20.02 & -16.16 & -18.57 & -20.31 \\
\hline HEG31 & NA & -19 & -17.03 & -19.58 & -16.37 & -20.13 & -20.02 & -16.57 & -19.92 & -20.31 \\
\hline HEG32 & -18.5 & NA & -19.93 & -19.58 & -14.87 & -17.26 & -20.02 & -19.43 & -19.92 & -20.31 \\
\hline HEG33 & -12.5 & -15.6 & -19.93 & -19.58 & -16.68 & -14.58 & -17.62 & -15.3 & -19.92 & -15.4 \\
\hline HEG34 & -19.81 & -17.9 & -17.35 & -19.58 & -19.2 & -19.01 & -17.55 & -16.03 & -19.57 & -12.7 \\
\hline HEG35 & -15.9 & -16.3 & -18.59 & -19.58 & -20 & -20.13 & -16.45 & -14.38 & -16.34 & -10.2 \\
\hline HEG36 & -17.3 & -15.9 & -17.9 & -19.58 & -20 & -20.13 & -17.12 & -15.82 & -16.96 & -13.8 \\
\hline HEG37 & -15.1 & -15.3 & -18.64 & -18.66 & -17.88 & -16.74 & -17.87 & -15.35 & -18.74 & -13.8 \\
\hline HEG38 & -19.81 & -20.51 & -19.93 & -19.58 & -17.17 & -20.13 & -20.02 & -18.49 & -19.92 & -20.31 \\
\hline HEG39 & -19.81 & -20.51 & -18.05 & -19.58 & -17.67 & -20.13 & -20.02 & -19.43 & -19.92 & -20.31 \\
\hline HEG40 & -19.81 & -20.51 & -18.86 & -19.58 & -20 & -20.13 & -18.25 & -19.43 & -19.92 & -15.2 \\
\hline HEG41 & NA & -20.51 & -19.93 & -19.58 & -15.14 & -16.69 & -20.02 & -19.43 & -19.92 & -16.7 \\
\hline HEG42 & -16.7 & -20.51 & -19.93 & -19.58 & -18.68 & -20.13 & -20.02 & -19.43 & -19.92 & -20.31 \\
\hline HEG43 & -15.4 & -20.51 & -19.93 & -19.58 & -20 & -20.13 & -20.02 & -17.73 & -19.92 & -16.5 \\
\hline HEG44 & -17.5 & NA & -19.93 & -19.58 & -20 & -20.13 & -20.02 & -17.67 & -19.92 & -20.31 \\
\hline HEG45 & -17.6 & -20.51 & -17.21 & -19.58 & -20 & -18.86 & -20.02 & -19.43 & -19.92 & -20.31 \\
\hline HEG46 & NA & -20.51 & -17.92 & -19.58 & -20 & -20.13 & -20.02 & -19.43 & -19.92 & -20.31 \\
\hline HEG47 & NA & NA & -18.72 & -19.58 & -20 & -20.13 & -20.02 & -17.17 & -19.92 & -20.31 \\
\hline HEG48 & -17.5 & -20.51 & -18.05 & -19.58 & -16.14 & -20.13 & -20.02 & -17.98 & -19.92 & -20.31 \\
\hline HEG49 & -16.3 & -20.51 & -18.19 & -19.58 & -18.61 & -20.13 & -20.02 & -15.66 & -19.92 & -20.31 \\
\hline HEG50 & -19.81 & -20.51 & -17.63 & -19.58 & -17.41 & -16.69 & -20.02 & -17.61 & -19.92 & -20.31 \\
\hline HEW1 & -19.81 & -20.51 & -19.93 & -19.58 & -17.82 & -20.13 & -20.02 & -19.43 & -19.92 & -20.31 \\
\hline HEW2 & -15.7 & -20.51 & -19.93 & -19.58 & -19.95 & -20.12 & -20.02 & -19.43 & -19.92 & -20.3 \\
\hline HEW3 & -18.6 & -20.51 & -17.54 & -18.87 & -17.24 & -18.01 & -20.02 & -19.43 & -19.92 & -20.31 \\
\hline
\end{tabular}


Table S2 continued:

\begin{tabular}{|c|c|c|c|c|c|c|c|c|c|c|}
\hline Plot ID & IncP-1. & $\begin{array}{l}\text { Class } 1 \\
\text { integrons. }\end{array}$ & $\begin{array}{l}a a c\left(6^{\prime}\right)- \\
l b\end{array}$ & $\operatorname{aacC1}$ & blaIMP-12 & bla IMP-5 & ermB & $m e f A$ & tetA & sul2 \\
\hline HEW4 & -19.81 & -20.51 & -19.93 & -19.58 & -16.91 & -20.13 & -20.02 & -19.43 & -19.92 & -20.31 \\
\hline HEW5 & -19.81 & -20.51 & -19.93 & -19.58 & -20 & -20.13 & -20.02 & -19.43 & -19.92 & -20.31 \\
\hline HEW6 & NA & -20.51 & -19.93 & -19.58 & -18.29 & -20.13 & -20.02 & -19.43 & -19.92 & -20.31 \\
\hline HEW7 & -18.3 & -20.51 & -19.93 & -19.58 & -19.23 & -19.78 & -20.02 & -19.43 & -19.92 & -20.31 \\
\hline HEW8 & NA & -20.51 & -19.93 & -19.58 & -16.11 & -20.13 & -20.02 & -19.43 & -19.92 & -20.31 \\
\hline HEW9 & -19.81 & -20.51 & -19.93 & -19.58 & -19.04 & -19.99 & -20.02 & -19.43 & -19.92 & -20.31 \\
\hline HEW10 & -17.2 & -20.51 & -19.93 & -19.58 & -17.99 & -19.47 & -20.02 & -19.43 & -19.92 & -20.31 \\
\hline HEW11 & NA & -20.51 & -19.93 & -19.58 & -16.88 & -20.13 & -20.02 & -19.43 & -19.92 & -20.31 \\
\hline HEW12 & -19.4 & -20.51 & -19.93 & -19.58 & -17.46 & -16.38 & -20.02 & -19.43 & -19.92 & -20.31 \\
\hline HEW13 & -16.9 & -20.51 & -19.93 & -19.58 & -16.87 & -20.13 & -20.02 & -19.43 & -19.92 & -20.31 \\
\hline HEW14 & -18.2 & -20.51 & -19.93 & -19.58 & -20 & -20.13 & -20.02 & -19.43 & -19.92 & -20.31 \\
\hline HEW15 & -19.81 & -20.51 & -19.93 & -19.58 & -20 & -20.13 & -20.02 & -19.43 & -19.92 & -20.31 \\
\hline HEW16 & -19.81 & -20.51 & -19.93 & -19.58 & -16.13 & -17.66 & -20.02 & -19.43 & -19.92 & -20.31 \\
\hline HEW17 & -19.81 & -20.51 & -19.93 & -19.58 & -19.79 & -17.43 & -20.02 & -19.43 & -19.92 & -17.3 \\
\hline HEW18 & -19.81 & NA & -19.93 & -19.58 & -17.64 & -20.13 & -20.02 & -19.43 & -19.92 & -20.31 \\
\hline HEW19 & NA & -20.51 & -19.93 & -19.58 & -17.29 & -18.16 & -20.02 & -19.43 & -19.92 & -20.31 \\
\hline HEW20 & -19.81 & NA & -19.93 & -19.58 & -18.23 & -20.13 & -20.02 & -19.43 & -19.92 & -20.31 \\
\hline HEW21 & -18.4 & -20.51 & -19.93 & -19.58 & -17.45 & -20.13 & -20.02 & -19.43 & -19.92 & -20.31 \\
\hline HEW22 & -19.81 & -20.51 & -19.93 & -19.58 & -20 & -20.13 & -20.02 & -19.43 & -19.92 & -20.31 \\
\hline HEW23 & -19.81 & -20.51 & -19.93 & -19.58 & -18.84 & -20.13 & -20.02 & -19.43 & -19.92 & -20.31 \\
\hline HEW24 & -19.81 & -20.51 & -19.93 & -19.58 & -20 & -20.13 & -20.02 & -19.43 & -19.91 & -20.31 \\
\hline HEW25 & -19.81 & -20.51 & -19.93 & -19.58 & -20 & -20.13 & -20.02 & -19.43 & -19.92 & -20.31 \\
\hline HEW26 & -19.81 & -20.51 & -19.93 & -19.58 & -18.41 & -19.15 & -20.02 & -19.43 & -19.92 & -20.31 \\
\hline HEW27 & -16.8 & -20.51 & -19.93 & -19.58 & -18.59 & -20.13 & -20.02 & -19.43 & -19.92 & -20.31 \\
\hline HEW28 & -17 & -20.51 & -19.93 & -19.58 & -20 & -20.13 & -20.02 & -19.43 & -19.92 & -20.31 \\
\hline HEW29 & -18.4 & -20.51 & -19.93 & -19.58 & -17.28 & -17.79 & -20.02 & -19.43 & -19.92 & -20.31 \\
\hline HEW30 & -19.81 & -20.51 & -19.93 & -19.58 & -17.81 & -20.13 & -20.02 & -19.43 & -19.92 & -20.31 \\
\hline HEW31 & -19.81 & -20.51 & -19.93 & -19.58 & -16.72 & -17.8 & -20.02 & -19.43 & -19.92 & -20.31 \\
\hline HEW32 & -19.81 & -20.51 & -19.93 & -19.58 & -20 & -20.13 & -20.02 & -19.43 & -19.92 & -20.31 \\
\hline HEW33 & -19.81 & -20.51 & -19.93 & -19.58 & -15.84 & -19.1 & -20.02 & -19.43 & -19.92 & -20.31 \\
\hline HEW34 & NA & -20.51 & -19.93 & -19.58 & -18.33 & -16.77 & -20.02 & -19.43 & -19.92 & -20.31 \\
\hline HEW35 & NA & -20.51 & -19.93 & -19.58 & -17.64 & -19.63 & -20.02 & -19.43 & -19.92 & -20.31 \\
\hline HEW36 & NA & -20.51 & -19.93 & -19.58 & -16.54 & -20.13 & -20.02 & -19.43 & -19.92 & -20.31 \\
\hline HEW37 & -19.81 & -20.51 & -19.93 & -19.58 & -16.33 & -19.13 & -20.02 & -19.43 & -19.92 & -20.31 \\
\hline HEW38 & -19.81 & -20.51 & -19.93 & -19.58 & -16.73 & -17.15 & -20.02 & -19.43 & -19.92 & -20.31 \\
\hline HEW39 & -19.81 & -20.51 & -19.93 & -19.58 & -16.39 & -17.34 & -20.02 & -19.43 & -19.92 & -20.31 \\
\hline HEW40 & -19.81 & -20.51 & -19.93 & -19.58 & -18.01 & -20.13 & -20.02 & -19.43 & -19.92 & -20.31 \\
\hline HEW41 & -19.81 & -20.51 & -19.93 & -19.58 & -16.29 & -20.13 & -20.02 & -19.43 & -19.92 & -20.31 \\
\hline HEW42 & NA & -20.51 & -19.93 & -19.58 & -18.68 & -19.9 & -20.02 & -19.43 & -19.92 & -20.31 \\
\hline HEW43 & -19 & -20.51 & -19.93 & -19.58 & -18.88 & -20.13 & -20.02 & -19.43 & -19.92 & -20.31 \\
\hline HEW44 & -19.81 & -20.51 & -19.93 & -19.58 & -20 & -20.13 & -20.02 & -19.43 & -19.92 & -20.31 \\
\hline HEW45 & -18.1 & -20.51 & -19.93 & -19.58 & -18.76 & -20.13 & -20.02 & -19.43 & -19.92 & -17.9 \\
\hline HEW46 & -19.81 & -20.51 & -19.93 & -19.58 & -20 & -20.13 & -20.02 & -19.43 & -19.92 & -20.31 \\
\hline HEW47 & -16.6 & -20.51 & -19.93 & -19.58 & -16.2 & -18.47 & -20.02 & -19.43 & -19.92 & -20.31 \\
\hline HEW48 & -19.81 & -20.51 & -19.93 & -19.58 & -18.73 & -18.07 & -20.02 & -19.43 & -19.92 & NA \\
\hline HEW49 & -19.8 & -20.51 & -19.93 & -19.58 & -15.8 & -20.13 & -20.02 & -19.43 & -19.92 & NA \\
\hline HEW50 & -19.81 & -20.51 & -19.93 & -19.58 & -18.71 & -19.36 & -20.02 & -19.43 & -19.92 & -20.31 \\
\hline HEW51 & -17.7 & -20.51 & -19.38 & -19.58 & -20 & -19.54 & -20.02 & -19.43 & -19.92 & -20.31 \\
\hline AEG1 & -19.81 & -19.7 & -19.93 & -19.58 & -20 & -20.13 & -20.02 & -17.51 & -19.92 & -20.31 \\
\hline AEG2 & -17.5 & -17.1 & -19.93 & -19.58 & -20 & -20.13 & -20.02 & -18.26 & -19.92 & -15.3 \\
\hline AEG3 & -16.4 & -20.51 & -19.93 & -19.58 & -20 & -20.13 & -20.02 & -19.43 & -19.92 & -20.31 \\
\hline
\end{tabular}


Table S2 continued

\begin{tabular}{|c|c|c|c|c|c|c|c|c|c|c|}
\hline Plot ID & IncP-1. & $\begin{array}{l}\text { Class } 1 \\
\text { integrons. }\end{array}$ & $\begin{array}{l}a a c\left(6^{\prime}\right)- \\
l b\end{array}$ & $\operatorname{aacC1}$ & blaIMP-12 & blaIMP-5 & ermB & $m e f A$ & tet $A$ & sul2 \\
\hline AEG4 & -14.3 & -20.51 & -19.93 & -19.58 & -20 & -20.13 & -20.02 & -17.88 & -19.92 & -15.5 \\
\hline AEG5 & -16.6 & -20.51 & -19.93 & -19.58 & -20 & -20.13 & -20.02 & -19.43 & -19.92 & -17.5 \\
\hline AEG6 & NA & -20.51 & -19.93 & -19.58 & -20 & -20.13 & -20.02 & -19.43 & -19.92 & -20.31 \\
\hline AEG7 & -15.5 & -20.51 & -19.93 & -19.58 & -20 & -20.13 & -20.02 & -19.43 & -19.92 & -20.31 \\
\hline AEG8 & NA & -20.51 & -19.93 & -19.58 & -20 & -20.13 & -20.02 & -19.43 & -19.92 & -16.7 \\
\hline AEG9 & -19.81 & -20.51 & -19.93 & -19.58 & -20 & -20.13 & -20.02 & -15.23 & -19.92 & -20.31 \\
\hline AEG10 & -18.1 & -20.51 & -19.93 & -19.58 & -20 & -20.13 & -20.02 & -19.43 & -19.92 & -20.31 \\
\hline AEG11 & -18.6 & -20.51 & -19.93 & -19.58 & -20 & -20.13 & -20.02 & -19.06 & -19.92 & -20.31 \\
\hline AEG12 & -18.1 & -20.51 & -19.93 & -19.58 & -18.6 & -20.13 & -20.02 & -16.94 & -19.92 & -17.1 \\
\hline AEG13 & -17.1 & -20.51 & -19.93 & -19.58 & -16.5 & -20.13 & -20.02 & -16.42 & -19.92 & -20.31 \\
\hline AEG14 & -17.6 & -18.6 & -19.93 & -19.58 & -20 & -20.13 & -20.02 & -16.94 & -19.92 & -20.31 \\
\hline AEG15 & NA & -20.51 & -19.93 & -19.58 & -17.52 & -20.13 & -20.02 & -17.99 & -19.92 & -16.8 \\
\hline AEG16 & NA & -20.51 & -19.93 & -19.58 & -16.98 & -20.13 & -20.02 & -17.36 & -19.92 & -20.31 \\
\hline AEG17 & -19.81 & -20.51 & -19.93 & -19.58 & -20 & -19.14 & -20.02 & -19.43 & -19.92 & -20.31 \\
\hline AEG18 & -17.9 & -20.51 & -19.58 & -19.58 & -19.2 & -20.13 & -20.02 & -16.77 & -19.92 & -20.31 \\
\hline AEG19 & -15.9 & -20.51 & -19.93 & -19.58 & -20 & -20.13 & -20.02 & -18.63 & -19.92 & -20.31 \\
\hline AEG20 & -16.1 & -20.51 & -19.93 & -19.58 & -20 & -20.13 & -20.02 & -19.43 & -19.92 & -20.31 \\
\hline AEG21 & -19.3 & -20.51 & -19.93 & -19.58 & -18.87 & -20.13 & -20.02 & -18.18 & -19.92 & -16.2 \\
\hline AEG22 & -19.81 & -15 & -19.93 & -19.58 & -19.79 & -20.13 & -16.73 & -19.38 & -16.57 & -9.4 \\
\hline AEG23 & -17.3 & -17.5 & -18.23 & -19.58 & -20 & -20.13 & -20.02 & -19.43 & -19.92 & -20.31 \\
\hline AEG24 & NA & -20.51 & -19.93 & -19.58 & -20 & -20.13 & -20.02 & -15.93 & -18.86 & -17.3 \\
\hline AEG25 & -15.8 & -20.51 & -19.93 & -19.58 & -20 & -20.13 & -20.02 & -19.43 & -19.92 & -20.31 \\
\hline AEG26 & -18.5 & -20.51 & -19.93 & -19.58 & -20 & -20.13 & -20.02 & -19.43 & -19.92 & -20.31 \\
\hline AEG27 & -16.4 & -20.51 & -19.93 & -19.58 & -20 & -18.41 & -20.02 & -19.43 & -19.92 & -17.8 \\
\hline AEG28 & -15.7 & -20.51 & -19.93 & -19.58 & -19.53 & -20.13 & -20.02 & -19.43 & -19.92 & -20.31 \\
\hline AEG29 & -16 & NA & -19.93 & -19.58 & -20 & -20.13 & -20.02 & -19.43 & -19.92 & -20.31 \\
\hline AEG30 & -17.8 & -20.51 & -19.93 & -19.58 & -20 & -20.13 & -20.02 & -19.43 & -19.92 & -20.31 \\
\hline AEG31 & NA & -20.51 & -19.93 & -19.58 & -19.29 & -20.13 & -20.02 & -19.43 & -19.92 & -20.31 \\
\hline AEG32 & -12.4 & -20.51 & -19.93 & -19.58 & -16.59 & -20.13 & -20.02 & -19.43 & -19.92 & -20.31 \\
\hline AEG33 & -19.81 & -20.51 & -19.93 & -19.58 & -20 & -20.13 & -20.02 & -17.15 & -19.92 & -20.31 \\
\hline AEG34 & -19.81 & -20.51 & -19.93 & -19.58 & -20 & -20.13 & -20.02 & -17.58 & -19.92 & -20.31 \\
\hline AEG35 & -18.7 & NA & -19.93 & -19.58 & -15.18 & -20.13 & -20.02 & -16.76 & -19.92 & -16.3 \\
\hline AEG36 & -14.2 & -20.51 & -19.93 & -19.58 & -18.73 & -20.13 & -20.02 & -17.45 & -19.92 & -15.3 \\
\hline AEG37 & -18.7 & -20.51 & -19.93 & -19.58 & -18.46 & -20.13 & -20.02 & -13.68 & -19.92 & -14.1 \\
\hline AEG38 & -14 & -20.51 & -19.93 & -19.58 & -17.45 & -20.13 & -20.02 & -19.43 & -19.92 & -20.31 \\
\hline AEG39 & -17.4 & -20.51 & -19.93 & -19.58 & -17.38 & -20.13 & -20.02 & -14.32 & -19.92 & -20.31 \\
\hline AEG40 & -19.81 & -14.8 & -18.92 & -19.58 & -20 & -20.13 & -20.02 & -16.8 & -16.48 & -10.6 \\
\hline AEG41 & -19.81 & -20.51 & -19.93 & -19.58 & -20 & -20.13 & -20.02 & -17.41 & -19.92 & -20.31 \\
\hline AEG42 & -19.81 & -20.51 & -17.16 & -19.58 & -19.06 & -20.13 & -20.02 & -19.09 & -19.92 & -20.31 \\
\hline AEG43 & -14.3 & -16 & -18.02 & -19.58 & -20 & -20.13 & -20.02 & -18.59 & -19.92 & -17 \\
\hline AEG44 & -17.1 & -20.51 & -19.93 & -19.58 & -17.88 & -20.13 & -20.02 & -17.34 & -19.92 & -20.31 \\
\hline AEG45 & -16.8 & -20.51 & NA & -19.58 & -16.1 & -20.13 & -20.02 & -19.43 & -19.92 & -20.31 \\
\hline AEG46 & -16.9 & -20.51 & NA & -19.58 & -18.08 & -20.13 & -20.02 & -19.15 & -19.92 & -20.31 \\
\hline AEG47 & -14.2 & -20.51 & NA & -19.58 & -20 & -20.13 & -20.02 & -19.43 & -19.92 & -20.31 \\
\hline AEG48 & -12.3 & -20.51 & -19.93 & -19.58 & -20 & -20.13 & -20.02 & -19.43 & -19.92 & -20.31 \\
\hline AEG49 & -19.81 & -20.51 & -19.93 & -19.58 & -20 & -20.13 & -20.02 & -18.5 & -19.92 & -20.31 \\
\hline AEG50 & -19.81 & NA & -19.93 & -19.58 & -17.15 & -20.13 & -20.02 & -18.5 & -19.92 & -16.3 \\
\hline AEW1 & -19.81 & -20.51 & NA & NA & NA & NA & NA & NA & NA & -20.31 \\
\hline AEW2 & -19.81 & NA & -19.93 & -19.58 & -20 & -20.13 & -20.02 & -19.43 & -19.92 & -20.31 \\
\hline AEW3 & -19.81 & NA & -19.93 & -19.58 & -20 & -20.13 & -20.02 & -19.43 & -19.92 & -20.31 \\
\hline AEW4 & -19.81 & -20.51 & NA & -19.58 & -18.75 & -20.13 & -20.02 & -19.43 & -19.92 & -18.2 \\
\hline
\end{tabular}


Table S2 continued:

\begin{tabular}{|c|c|c|c|c|c|c|c|c|c|c|}
\hline Plot ID & IncP-1. & $\begin{array}{l}\text { Class } 1 \\
\text { integrons. }\end{array}$ & $\begin{array}{l}\operatorname{aac}\left(6^{\prime}\right)- \\
l b\end{array}$ & $\operatorname{aacC1}$ & blaIMP-12 & blaIMP-5 & ermB & mefA & tet $A$ & sul2 \\
\hline AEW5 & NA & -20.51 & NA & -19.58 & -20 & -20.13 & -20.02 & -19.43 & -19.92 & -20.31 \\
\hline AEW6 & NA & -20.51 & -19.93 & -19.58 & -20 & -19.4 & -20.02 & -19.43 & -19.92 & -17.4 \\
\hline AEW7 & -19.81 & -20.51 & -19.93 & -19.58 & -20 & -20.13 & -20.02 & -19.43 & -19.92 & -20.31 \\
\hline AEW8 & NA & -20.51 & -19.93 & -19.58 & -17.23 & -20.13 & -20.02 & -19.43 & -19.92 & -20.31 \\
\hline AEW9 & -19.81 & -20.51 & -19.93 & -19.58 & -18.3 & -20.13 & -20.02 & -19.43 & -19.92 & -20.31 \\
\hline AEW10 & -19.81 & -20.51 & -19.93 & -19.58 & -20 & -20.13 & -20.02 & -19.43 & -19.92 & -20.31 \\
\hline AEW11 & -16.4 & -20.51 & NA & NA & NA & NA & NA & NA & NA & -20.31 \\
\hline AEW12 & -18.4 & -20.51 & -19.93 & -19.58 & -20 & -20.13 & -20.02 & -19.43 & -19.92 & -20.31 \\
\hline AEW13 & -18 & -20.51 & -19.93 & -19.58 & -20 & -20.13 & -20.02 & -18.06 & -19.92 & -20.31 \\
\hline AEW14 & -17.1 & -20.51 & -19.93 & -19.58 & -20 & -20.13 & -20.02 & -19.43 & -19.92 & -18.8 \\
\hline AEW15 & NA & -20.51 & -19.93 & -19.58 & -20 & -20.13 & -20.02 & -19.43 & -19.92 & -20.31 \\
\hline AEW16 & NA & -20.51 & -19.93 & -19.58 & -20 & -16.3 & -20.02 & -19.43 & -19.92 & -16.3 \\
\hline AEW17 & -19.81 & -20.51 & -19.93 & -19.58 & -20 & -20.13 & -20.02 & -19.43 & -19.92 & -20.31 \\
\hline AEW18 & NA & -20.51 & -19.93 & -19.58 & -18.78 & -18.83 & -20.02 & -19.43 & -19.92 & -20.31 \\
\hline AEW19 & -19.81 & -20.51 & -19.93 & -19.58 & -18.03 & -20.13 & -20.02 & -19.43 & -19.92 & -20.31 \\
\hline AEW20 & -17.7 & -20.51 & -19.93 & -19.58 & -20 & -20.13 & -20.02 & -19.43 & -19.92 & -20.31 \\
\hline AEW21 & -19.81 & -20.51 & -19.93 & -19.58 & -17.6 & -19.37 & -20.02 & -19.43 & -19.92 & -18.2 \\
\hline AEW22 & -19.81 & -20.51 & -19.93 & -19.58 & -20 & -20.13 & -20.02 & -19.43 & -19.92 & -16.5 \\
\hline AEW23 & -19.81 & -20.51 & -19.93 & -19.58 & -19.26 & -20.13 & -20.02 & -19.43 & -19.92 & -20.31 \\
\hline AEW24 & NA & -20.51 & -19.93 & -19.58 & -20 & -20.13 & -20.02 & -19.43 & -19.92 & -20.31 \\
\hline AEW25 & -17.7 & -20.51 & -19.93 & -19.58 & -16.82 & -20.13 & -20.02 & -19.43 & -19.92 & -20.31 \\
\hline AEW26 & NA & -20.51 & -19.93 & -19.58 & -16.23 & -19.14 & -20.02 & -19.43 & -19.92 & -20.31 \\
\hline AEW27 & NA & -20.51 & -19.93 & -19.58 & -18.73 & -19.28 & -20.02 & -19.43 & -19.92 & -20.31 \\
\hline AEW28 & -19.81 & -20.51 & -19.93 & -19.58 & -19.79 & -20.13 & -20.02 & -19.43 & -19.92 & -20.31 \\
\hline AEW29 & -19.81 & -20.51 & -19.93 & -19.58 & -18.75 & -18.9 & -20.02 & -19.43 & -19.92 & -20.31 \\
\hline AEW30 & -19.81 & -20.51 & -19.93 & -19.58 & -17.94 & -20.13 & -20.02 & -19.43 & -19.92 & -20.31 \\
\hline AEW31 & -19.81 & -20.51 & -19.93 & -19.58 & -20 & -20.13 & -20.02 & -18.22 & -19.92 & -20.31 \\
\hline AEW32 & -19.81 & -20.51 & -19.93 & -19.58 & -20 & -20.13 & -20.02 & -19.43 & -19.92 & -20.31 \\
\hline AEW33 & -19.81 & -20.51 & -19.93 & -19.58 & -20 & -20.13 & -20.02 & -19.43 & -19.92 & -16.1 \\
\hline AEW34 & NA & -20.51 & -19.93 & -19.58 & -20 & -20.13 & -20.02 & -19.43 & -19.92 & -20.31 \\
\hline AEW35 & NA & -20.51 & -19.93 & -19.58 & -20 & -20.13 & -20.02 & -19.43 & -19.92 & -20.31 \\
\hline AEW36 & NA & -20.51 & -19.93 & -19.58 & -18.41 & -20.13 & -20.02 & -19.43 & -19.92 & -20.31 \\
\hline AEW37 & -19.81 & -20.51 & -19.93 & -19.58 & -14.99 & -20.13 & -20.02 & -19.43 & -19.92 & -20.31 \\
\hline AEW38 & -19.81 & -20.51 & -19.93 & -19.58 & -18.56 & -20.13 & -20.02 & -19.43 & -19.92 & -20.31 \\
\hline AEW39 & -19.81 & -20.51 & -19.93 & -19.58 & -20 & -20.13 & -20.02 & -19.43 & -19.92 & -20.31 \\
\hline AEW40 & -19.81 & -20.51 & -19.93 & -19.58 & -17.11 & -20.13 & -20.02 & -19.43 & -19.92 & -20.31 \\
\hline AEW41 & -19.81 & -20.51 & -19.93 & -19.58 & -20 & -20.13 & -20.02 & -19.43 & -19.92 & -20.31 \\
\hline AEW42 & -17.4 & -20.51 & -19.93 & -19.58 & -20 & -20.13 & -17.01 & -19.43 & -19.92 & -20.31 \\
\hline AEW43 & -16.7 & -20.51 & -19.93 & -19.58 & -15.21 & -16.13 & -20.02 & -19.43 & -19.92 & -20.31 \\
\hline AEW44 & -19.81 & -20.51 & -19.93 & -19.58 & -14.79 & -18.74 & -20.02 & -19.43 & -19.92 & -20.31 \\
\hline AEW45 & -16.2 & -20.51 & -19.93 & -19.58 & -18.08 & -20.13 & -20.02 & -19.43 & -19.92 & -20.31 \\
\hline AEW46 & -9.3 & -20.51 & -19.93 & -19.58 & -17.23 & -20.13 & -20.02 & -19.43 & -19.92 & -20.31 \\
\hline AEW47 & -18.3 & -20.51 & -19.93 & -19.58 & -18.37 & -20.13 & -20.02 & -19.43 & -19.92 & -20.31 \\
\hline AEW48 & -19.81 & -20.51 & -19.93 & -19.58 & -17.81 & -20.13 & -20.02 & -19.43 & -19.92 & -20.31 \\
\hline AEW49 & -19.81 & -20.51 & -19.93 & -19.58 & -17.18 & -20.13 & -20.02 & -19.43 & -19.92 & -20.31 \\
\hline AEW50 & -17.6 & -20.51 & NA & -19.58 & -20 & -20.13 & -20.02 & -19.43 & -19.92 & -20.31 \\
\hline
\end{tabular}


Table S3: Preliminary binomial (A) or tobit regression models (B). The left column describes the model components including dependent variables (the target ARG, class 1 integrons or IncP-1 plasmids), fixed independent variables ( $\mathrm{pH}$, soil moisture or Shannon index) and interchanging independent variables (grazing, mowing, fertilization, organic N, mineral N and LUI with respect to grassland data and beech, pine, spruce and oak with respect to forest data). Significant effects ( $p$-value $<0.05$ ) are highlighted in orange.

\section{$\operatorname{aac}\left(6^{\prime}\right)-\mathrm{Ib}$ with $\mathrm{pH}$}

Grazing

Mowing

Fertilization

Organic N

Mineral N

LUI

$m e f A$ with soil moisture

Grazing

Mowing

Fertilization

Organic N

Mineral N

LUI

sul2 with soil moisture

Grazing

Mowing

Fertilization

Organic N

Mineral N

LUI

tetA with soil moisture

Grazing

Mowing

Fertilization

Organic N

Mineral N

LUI

Class 1 integrons with soil Grazing

Mowing

Fertilization

Organic N

Mineral N

LUI

IncP-1 plasmids with $\mathrm{pH}$

Grazing

Mowing

Fertilization

Organic N

Mineral N

LUI

\begin{tabular}{|c|c|c|}
\hline \multicolumn{3}{|l|}{ A } \\
\hline $\mathrm{p}$ & Estimate & $\mathbf{R}^{2}$ \\
\hline 0.84 & -0.04 & 0.18 \\
\hline 0.03 & 0.45 & 0.21 \\
\hline 0.08 & 0.35 & 0.21 \\
\hline 0.43 & 0.15 & 0.18 \\
\hline 0.58 & 0.11 & 0.21 \\
\hline 0.02 & 0.49 & 0.21 \\
\hline 0.91 & -0.02 & 0.07 \\
\hline $5.1 \mathrm{E}-04$ & 0.69 & 0.14 \\
\hline $4.4 \mathrm{E}-04$ & 0.94 & 0.17 \\
\hline 6.3E-05 & 1.32 & 0.20 \\
\hline 0.45 & 0.13 & 0.07 \\
\hline $4.4 \mathrm{E}-05$ & 0.87 & 0.17 \\
\hline 0.47 & 0.13 & 0.05 \\
\hline 0.29 & 0.12 & 0.06 \\
\hline 0.02 & 0.43 & 0.09 \\
\hline 0.01 & 0.53 & 0.10 \\
\hline 0.11 & 0.28 & 0.06 \\
\hline $3.9 \mathrm{E}-03$ & 0.54 & 0.10 \\
\hline 0.23 & 0.24 & 0.09 \\
\hline 0.75 & 0.07 & 0.08 \\
\hline 0.16 & 0.29 & 0.10 \\
\hline 0.38 & 0.19 & 0.09 \\
\hline 0.17 & 0.44 & 0.09 \\
\hline 0.03 & 0.48 & 0.11 \\
\hline 0.03 & -1.06 & 0.17 \\
\hline $3.8 \mathrm{E}-03$ & 0.77 & 0.18 \\
\hline 1.7E-03 & 0.68 & 0.19 \\
\hline 0.02 & 0.47 & 0.14 \\
\hline 0.02 & 0.49 & 0.14 \\
\hline 0.03 & 0.54 & 0.14 \\
\hline 0.59 & -0.11 & 0.01 \\
\hline 0.44 & 0.16 & 0.02 \\
\hline 0.25 & 0.29 & 0.03 \\
\hline 0.45 & -0.16 & 0.02 \\
\hline 0.01 & 0.80 & 0.07 \\
\hline 0.51 & 0.14 & 0.02 \\
\hline
\end{tabular}

\begin{tabular}{|c|c|c|}
\hline p & Estimate & $\mathbf{R}^{2}$ \\
\hline 0.557 & -0.11 & 0.11 \\
\hline 0.0435 & 0.37 & 0.12 \\
\hline 0.281 & 0.19 & 0.12 \\
\hline 0.459 & 0.14 & 0.11 \\
\hline 0.882 & -0.03 & 0.11 \\
\hline 0.13 & 0.28 & 0.12 \\
\hline 0.49 & -0.16 & 0.07 \\
\hline $5.6 \mathrm{E}-04$ & 0.75 & 0.09 \\
\hline 3.4E-05 & 0.82 & 0.11 \\
\hline 3.3E-05 & 0.83 & 0.10 \\
\hline 0.14 & 0.32 & 0.07 \\
\hline 2.2E-05 & 0.90 & 0.10 \\
\hline 0.772 & 0.17 & 0.05 \\
\hline 0.06 & 1.09 & 0.06 \\
\hline 0.01 & 1.38 & 0.08 \\
\hline 2.2E-03 & 1.60 & 0.08 \\
\hline 0.16 & 0.78 & 0.06 \\
\hline $3.6 \mathrm{E}-03$ & 1.65 & 0.07 \\
\hline 0.82 & -0.05 & 0.01 \\
\hline 0.23 & -0.26 & 0.02 \\
\hline 0.61 & -0.11 & 0.02 \\
\hline 0.22 & -0.28 & 0.02 \\
\hline 0.16 & 0.30 & 0.02 \\
\hline 0.23 & -0.26 & 0.02 \\
\hline
\end{tabular}


Table S3 continued:

\begin{tabular}{|c|c|c|c|c|c|c|}
\hline \multirow[b]{2}{*}{ bla IMP-12 with soil moisture } & \multicolumn{3}{|l|}{ A } & \multicolumn{3}{|l|}{ B } \\
\hline & $\mathrm{p}$ & Estimate & $\mathbf{R}^{2}$ & p & Estimate & $\mathbf{R}^{2}$ \\
\hline Grazing & 0.78 & -0.05 & 0.04 & 0.50 & -0.17 & 0.06 \\
\hline Mowing & 0.26 & 0.20 & 0.05 & 0.16 & 0.33 & 0.06 \\
\hline Fertilization & 0.10 & 0.29 & 0.06 & 0.06 & 0.43 & 0.08 \\
\hline Organic N & 0.45 & 0.13 & 0.05 & 0.79 & 0.06 & 0.06 \\
\hline Mineral N & 0.11 & 0.51 & 0.04 & 0.21 & 0.29 & 0.06 \\
\hline LUI & 0.10 & 0.28 & 0.06 & 0.09 & 0.40 & 0.07 \\
\hline \multicolumn{7}{|l|}{ bla IMP-5 with soil moisture } \\
\hline Grazing & 0.25 & 0.22 & 0.05 & 0.26 & 0.39 & 0.05 \\
\hline Mowing & 0.89 & -0.03 & 0.04 & 0.84 & -0.07 & 0.04 \\
\hline Fertilization & 0.32 & 0.19 & 0.07 & 0.32 & 0.35 & 0.07 \\
\hline Organic N & 0.26 & -0.30 & 0.05 & 0.21 & -0.55 & 0.05 \\
\hline Mineral N & 0.02 & 0.42 & 0.07 & 0.04 & 0.65 & 0.06 \\
\hline LUI & 0.14 & 0.30 & 0.06 & 0.17 & 0.48 & 0.05 \\
\hline \multicolumn{7}{|l|}{ bla IMP-12 with Shannon index } \\
\hline Beech & 7.0E-05 & 2.13 & 0.17 & 7.4E-06 & 2.75 & 0.09 \\
\hline Pine & 0.99 & -17.40 & 0.14 & 0.99 & -13.18 & 0.07 \\
\hline Spruce & 0.04 & -1.43 & 0.09 & 0.02 & -1.95 & 0.04 \\
\hline Oak & 0.16 & -1.21 & 0.08 & 0.09 & -1.90 & 0.04 \\
\hline \multicolumn{7}{|l|}{ bla IMP-5 with Shannon index } \\
\hline Beech & 0.03 & 1.70 & 0.09 & 0.01 & 2.28 & 0.07 \\
\hline Pine & 0.99 & -16.10 & 0.08 & 0.99 & -11.94 & 0.06 \\
\hline Spruce & 0.48 & -0.56 & 0.05 & 0.30 & -1.07 & 0.04 \\
\hline Oak & 0.99 & -16.56 & 0.08 & 1.00 & -12.37 & 0.06 \\
\hline
\end{tabular}




\section{Discovery of Novel Antibiotic Resistance}

\section{Determinants in Forest and Grassland Soil Metagenomes}

Inka Marie Willms ${ }^{1}$, Aysha Kamran², Nils Frederik Aßmann¹, Denis Krone', Simon Henning Bolz",

Fabian Fiedler ${ }^{1}$ and Heiko Nacke ${ }^{1^{*}}$

${ }^{1}$ Department of Genomic and Applied Microbiology and Göttingen Genomics Laboratory, Institute of Microbiology and Genetics, Georg-August University, Göttingen, Germany

${ }^{2}$ Department of General Microbiology, Institute of Microbiology and Genetics, Georg-August

University, Göttingen, Germany

Front. Microbiol. (2019), 10:460

\section{Author Contributions to the work:}

Conceptualization: H.N.; formal analysis: H.N.; investigation, I.M.W, A.K., N.F.A., D.K., S.H.B., F.F. H.N.; resources, H.N.; data curation; I.M.W., N.F.A., D.K., S.H.B., F.F. H.N.;

writing-original draft preparation, I.M.W and H.N.; writing-review and editing, I.M.W, and H.N; visualization, H.N.; supervision, I.M.W. and H.N.; project administration, H.N.; funding acquisition, H.N. 
OPEN ACCESS

Edited by:

Ziad Daoud,

University of Balamand, Lebanon

Reviewed by:

Atte Von Wright,

University of Eastern Finland, Finland

Ghassan M. Matar,

American University of Beirut,

Lebanon

${ }^{*}$ Correspondence:

Heiko Nacke

hnacke@gwdg.de

Specialty section:

This article was submitted to Antimicrobials, Resistance

and Chemotherapy,

a section of the journal

Frontiers in Microbiology

Received: 08 December 2018

Accepted: 21 February 2019

Published: 07 March 2019

Citation:

Willms IM, Kamran A, ABmann NF, Krone D, Bolz SH, Fiedler F and Nacke H (2019) Discovery of Novel Antibiotic Resistance Determinants

in Forest and Grassland Soil

Metagenomes

Front. Microbiol. 10:460.

doi: 10.3389/fmicb.2019.00460

\section{Discovery of Novel Antibiotic Resistance Determinants in Forest and Grassland Soil Metagenomes}

\author{
Inka Marie Willms ${ }^{1}$, Aysha Kamran², Nils Frederik Aßmann', Denis Krone', \\ Simon Henning Bolz ${ }^{1}$, Fabian Fiedler ${ }^{1}$ and Heiko Nacke ${ }^{1 *}$ \\ ${ }^{1}$ Department of Genomic and Applied Microbiology and Göttingen Genomics Laboratory, Institute of Microbiology \\ and Genetics, Georg-August University, Göttingen, Germany, ${ }^{2}$ Department of General Microbiology, Institute of Microbiology \\ and Genetics, Georg-August University, Göttingen, Germany
}

Soil represents a significant reservoir of antibiotic resistance genes (ARGs), which can potentially spread across distinct ecosystems and be acquired by pathogens threatening human as well as animal health. Currently, information on the identity and diversity of these genes, enabling anticipation of possible future resistance development in clinical environments and the livestock sector, is lacking. In this study, we applied functional metagenomics to discover novel sulfonamide as well as tetracycline resistance genes in soils derived from forest and grassland. Screening of soil metagenomic libraries revealed a total of eight so far unknown ARGs. The recovered genes originate from phylogenetically diverse soil bacteria (e.g., Actinobacteria, Chloroflexi, or Proteobacteria) and encode proteins with a minimum identity of $46 \%$ to other antibiotic resistance determinants. In particular forest soil ecosystems have so far been neglected in studies focusing on antibiotic resistance. Here, we detected for the first time non-mobile dihydropteroate synthase (DHPS) genes conferring resistance to sulfonamides in forest soil with no history of exposure to these synthetic drugs. In total, three sulfonamide resistant DHPSs, differing in taxonomic origin, were discovered in beech or pine forest soil. This indicates that sulfonamide resistance naturally occurs in forest-resident soil bacterial communities. Besides forest soil-derived sulfonamide resistance proteins, we also identified a DHPS affiliated to Chloroflexi in grassland soil. This enzyme and the other recovered DHPSs confer reduced susceptibility toward sulfamethazine, which is widely used in food animal production. With respect to tetracycline resistance, four efflux proteins affiliated to the major facilitator superfamily (MFS) were identified. Noteworthy, one of these proteins also conferred reduced susceptibility toward lincomycin.

Keywords: soil metagenome, functional metagenomics, antibiotic resistance, dihydropteroate synthase, tetracycline resistance, sulfonamide resistance

\section{INTRODUCTION}

Pathogenic bacteria resistant to multiple classes of antibiotics pose risks to public health and are considered as one of the major global challenges within the 21st century. Some of the antibiotic resistance genes (ARGs) carried by these bacteria have been traced to soil origins (Forsberg et al., 2012) and can potentially spread via e.g., groundwater or wildlife (Davies and Davies, 2010). 
Nevertheless, in contrast to clinical pathogens, bacterial communities inhabiting complex environments such as soil have been rarely considered within studies focusing on antibiotic resistance (Walsh, 2013b). To assess risks of environmental resistomes and develop strategies to tackle antibiotic resistance, an improved knowledge on the ecology of resistance determinants including their origins, diversity and underlying resistance mechanisms is urgently required (Allen et al., 2009; Wang et al., 2017).

Among Earth's microbial habitats, soil harbors the highest diversity of prokaryotes including numerous multi-resistant bacteria (Delmont et al., 2011; Walsh and Duffy, 2013; Nesme and Simonet, 2015). The synthesis of antibiotics likely evolved in this habitat and promoted the development of different antimicrobial compound-specific resistance mechanisms (D'Costa et al., 2007; Walsh, 2013a). Previously unknown soil-derived ARGs were recovered from both, pristine and intensively managed sites, by function-based screening of metagenomic libraries (Allen et al., 2009; Perron et al., 2015; Lau et al., 2017). In contrast to sequence-based metagenomic library screening, this culture-independent approach is not based on conserved DNA regions and therefore allows the identification of entirely novel target genes (Nacke and Daniel, 2014; Cheng et al., 2017). For instance, a so far unknown peptide-associated macrolide resistance mechanism was uncovered by coupling functionbased metagenomic library screening and high-resolution proteomics analysis (Lau et al., 2017). Besides dependence on conserved DNA regions, the fact that various resistance genes show high levels of similarity to genes encoding other cellular functions (Martínez, 2008; Perron et al., 2015) represents another limitation of sequence-based resistome analysis. An illustrative example are efflux pumps of the resistance-nodulation-division (RND) superfamily, which can confer antibiotic resistance, but can also transport proteins involved in cell division and nodulation, or both (Piddock, 2006; Perron et al., 2015).

In this study, we used function-based metagenomic library screening to identify so far unknown tetracycline and sulfonamide resistance genes in forest and grassland soil. Due to an excellent therapeutic index, few side effects, oral administration and low cost, tetracyclines belong to the most widely used classes of broad spectrum antibiotics in clinic (Thaker et al., 2010; Wang et al., 2017). After more than 60 years of excessive tetracycline usage, tetracycline resistance became one of the most abundant antibiotic resistances among clinical and commensal microbes (Wang et al., 2017). Another class of antibiotics, sulfonamides, is also commonly prescribed to people suffering from infections (Landers et al., 2012).

ARGs present in forests and grasslands, belonging to the most abundant terrestrial ecosystems worldwide, might become clinically relevant as they can potentially spread via lateral gene transfer. Here, we report the identification of four novel tetracycline and four previously unknown sulfonamide resistance genes derived from these ecosystems. Most of the proteins encoded by the novel ARGs showed low identity to already known antibiotic resistance determinants.

\section{MATERIALS AND METHODS}

\section{Site Description, Soil Sampling, and Metagenomic Library Construction}

Soil samples were derived from forest and grassland sites of the German Biodiversity Exploratories Schorfheide-Chorin and Schwäbische Alb (Fischer et al., 2010). The land use intensity index (LUI) (Blüthgen et al., 2012) was calculated for all grassland sites. To account for interannual variation in management practices, the LUI was calculated from 2006 to 2008 (sampling year) (Table 1). LUI allows separate analysis of the intensity of grazing (calculated by considering numbers of grazing cattle, horses, or sheep, and duration of grazing with respect to each site), the mowing frequency, and the intensity of fertilization. Forest plots were dominated by European beech (Fagus sylvatica) or Scots pine (Pinus sylvestris) (Table $\mathbf{1}$ ).

The collection of the samples was performed previously as described by Nacke et al. (2011a). Descriptions of the soil characteristics are provided in Table 2. Total microbial community DNA was isolated from collected soil by employing the PowerSoil DNA isolation kit (MoBio Laboratories, Carlsbad, CA, United States) and metagenomic libraries, named AEG2, AEG3, and SEG8 were generated as described by Nacke et al. (2011b). The metagenomic libraries AEW9, SEG6, SEW2, and SEW5 were previously constructed (Nacke et al., 2011b). Names of constructed metagenomic libraries refer to the designation of the samples from which the libraries were derived.

\section{Antibiotic Resistance Screening and Sequence Analysis}

The function-based screening was based on the ability of metagenomic library-bearing Escherichia coli clones to form colonies on LB agar medium containing $50 \mathrm{mg} / \mathrm{L}$ kanamycin, which selects for the screening vector pCR-XL-TOPO (Thermo Fisher Scientific, Braunschweig, Germany), and $5 \mathrm{mg} / \mathrm{L}$ tetracycline or $250 \mathrm{mg} / \mathrm{L}$ sulfamethoxazole. Colonies formed after incubation for $1-3$ days at $37^{\circ} \mathrm{C}$ under aerobic conditions were picked for further study.

The recombinant plasmids derived from positive clones were sequenced by Microsynth Seqlab (Göttingen, Germany) using Sanger sequencing technology. All plasmid inserts were taxonomically classified using the software KAIJU (Menzel et al., 2016). An initial prediction of ORFs located on the inserts was performed by employing the ORF finder tool provided by the National Center for Biotechnology Information (NCBI) and the Artemis program (Rutherford et al., 2000; Wheeler et al., 2003). The results were verified and improved manually by e.g., GC frame plot and ribosome-binding site analysis. Subsequently, blast (Altschul et al., 1990) search against the NCBI non-redundant protein sequence database was performed. In addition, Resfams (Gibson et al., 2015), a recently generated database of protein families and associated profile hidden Markov models, representing all major ARG classes, was used for sequence comparisons. Blast searches against the ACLAME database (Leplae et al., 2010) version 0.4 and the Gypsy database (Llorens et al., 2011) release 2.0 were performed to identify 
TABLE 1 | Characteristics of the study sites.

\begin{tabular}{|c|c|c|c|c|c|}
\hline Site & Land use & Management & Treatment & Tree species & LUI (grazing, mowing, fertilization) \\
\hline AEG2 & Grassland & Meadow & Fertilized & NA & $0.00,2.07,1.27$ \\
\hline AEG3 & Grassland & Meadow & Fertilized & NA & $0.00,2.76,2.06$ \\
\hline AEW9 & Forest & Unmanaged forest & NA & Beech & NA \\
\hline SEG6 & Grassland & Mown pasture & Non-fertilized & NA & $0.29,1.38,0.00$ \\
\hline SEG8 & Grassland & Pasture & Non-fertilized & NA & $0.14,0.69,0.00$ \\
\hline SEW2 & Forest & Age class forest & NA & Pine & NA \\
\hline SEW5 & Forest & Age class forest & NA & Beech & NA \\
\hline
\end{tabular}

The table lists the sites, land use, management type, treatment, dominant tree species, and LUI, land use index (calculated for 2006-2008) for grassland samples. AEG/AEW: sites located in the Biodiversity Exploratory Schwäbische Alb; SEG/SEW: sites located in the Biodiversity Exploratory Schorfheide-Chorin.

TABLE 2 | Basic properties of soil samples.

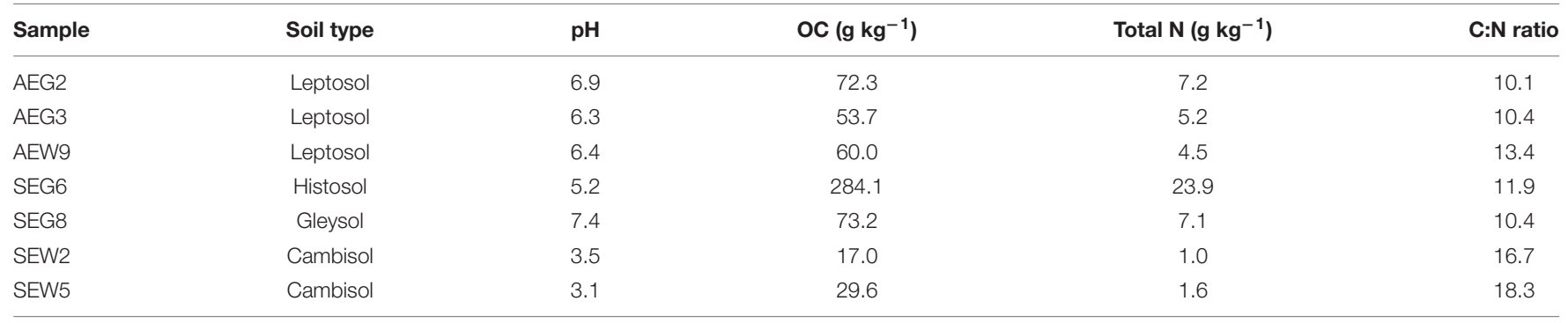

AEG/AEW: soil samples derived from the Biodiversity Exploratory Schwäbische Alb; SEG/SEW: soil samples derived from the Biodiversity Exploratory Schorfheide-Chorin.

mobile genetic elements. Moreover, the IS finder (database from 2018-09-11) (Siguier et al., 2006) was employed for identification of bacterial insertion sequences.

A neighbor-joining phylogenetic tree was constructed in MEGA (version 7.0) (Kumar et al., 2016) based on a ClustalW (Thompson et al., 1994) alignment of dihydropteroate synthase (DHPS) sequences. A total number of 1,000 bootstrap samplings were carried out to test the tree topology. Branches corresponding to partitions reproduced in less than $50 \%$ bootstrap replicates were collapsed. The evolutionary distances were computed using the number of differences method.

\section{Subcloning of ORFs Potentially Encoding Antibiotic Resistance}

To verify if candidate ORFs encode antibiotic resistance, they were subcloned into vector pCR4-TOPO (Thermo Fisher Scientific) and subsequently introduced into E. coli TOP10. Two insert sequences (corresponding plasmids, pLAEG3_tet01 and pLSEG6_tet01) encoded proteins with similarity to members of the TetR family of regulators. In this case, the gene encoding the regulator as well as the potential ARG were subcloned together. In a first step, PCR was performed for amplification of candidate ORFs (including sequences potentially comprising promoters) from plasmid DNA. PCR primers are listed in Table 3. The PCR reaction mixture $(50 \mu \mathrm{l})$ contained $10 \mu \mathrm{l} 5$-fold Phusion GC buffer, $200 \mu \mathrm{M}$ of each of the four deoxynucleoside triphosphates, 5\% DMSO, $0.2 \mu \mathrm{M}$ of each primer, $1 \mathrm{U}$ of Phusion HF DNA polymerase (Thermo Fisher Scientific), and approximately $20 \mathrm{ng}$ of plasmid DNA. The following thermal cycling scheme was used: initial denaturation at $98^{\circ} \mathrm{C}$ for $1 \mathrm{~min}$, 20 cycles of denaturation at $98^{\circ} \mathrm{C}$ for $1 \mathrm{~min}$, annealing for
45 s (annealing temperatures, see Table 3 ), and extension at $72^{\circ} \mathrm{C}$ for $30 \mathrm{~s}$ per $\mathrm{kb}$, followed by a final extension period at $72^{\circ} \mathrm{C}$ for $5 \mathrm{~min}$. PCR products were purified using the QIAquick PCR purification kit (Qiagen, Hilden, Germany) according to the instructions of the manufacturer. Subsequently, a deoxyadenosine was added to the $3^{\prime}$ termini of the DNA as described by Nacke et al. (2011b) to facilitate cloning by the TA method. The DNA was then purified using the QIAquick PCR purification kit (Qiagen) and inserted into vector pCR4-TOPO (Thermo Fisher Scientific) as described by the manufacturer. Transformation of resulting vectors into $E$. coli TOP10 chemically competent cells was performed according to the protocol of the manufacturer.

\section{Antibiotic Susceptibility Analysis}

Antibiotic susceptibility assays were conducted by using the 2fold serial microtiter broth dilution method by considering the Clinical and Laboratory Standards Institute (CLSI) guidelines document M100-S24 (2014) and the MICs were recorded after $20 \mathrm{~h}$ of incubation at $37^{\circ} \mathrm{C}$. The antibiotics cefotaxime, chloramphenicol, erythromycin, gentamicin, lincomycin, rifampicin, sulfadiazine, sulfamethoxazole, sulfamethazine, sulfisoxazole, tetracycline, and tylosin were considered. All assays were performed in duplicate. In addition, the susceptibility to different sulfonamides was further analyzed by spotting serial dilutions of cultures with starting $\mathrm{OD}_{600}$ of 0.5 onto Iso-Sensitest agar (Thermo Fisher Scientific) supplemented with sulfamethoxazole, sulfamethazine, sulfisoxazole or sulfadiazine. E. coli TOP10 carrying vector pCR4-TOPO (Thermo Fisher Scientific) was used as control. 
TABLE 3 | Primer sets designed in this study and corresponding templates.

\begin{tabular}{|c|c|c|c|}
\hline Template & Oligonucleotide & Sequence $\left(5^{\prime}\right.$ to $\left.3^{\prime}\right)$ & Annealing temperature $\left({ }^{\circ} \mathrm{C}\right)$ \\
\hline \multirow[t]{2}{*}{ pLAEG2_dhps01 } & AEG2_dhps01_for_150 & GATACCCTAACGTACTACCGC & 55 \\
\hline & AEG2_dhps01_rev & TCAGCGCGGATTCGTTC & 55 \\
\hline \multirow[t]{2}{*}{ pLAEW9_dhps01 } & AEW9_dhps01_for_150 & CCTGATCGGTCAGGTCCTTA & 55 \\
\hline & AEW9_dhps01_rev & TTACGCCGTTTGGCCC & 55 \\
\hline \multirow[t]{2}{*}{ pLSEW2_dhps01 } & SEW2_dhps01_for_150 & CCGCCCGCCGTGTG & 60 \\
\hline & SEW2_dhps01_rev & TTATGAAGCGGCGATAGCAGTAATAAC & 60 \\
\hline \multirow[t]{2}{*}{ pLSEW5_dhps01 } & SEW5_dhps01_for_104 & GGTCATCGCGACAAAGGGTG & 60 \\
\hline & SEW5_dhps01_rev & CTATACAGGCCGTCCAGCTGC & 60 \\
\hline \multirow[t]{2}{*}{ pLAEG3_tet01 } & AEG3_tet01b_for & CTATTGCTTGACGCGATCG & 55 \\
\hline & AEG3_tet01a_rev & CTATTCCGCCGGCTCAG & 55 \\
\hline \multirow[t]{2}{*}{ pLSEG6_tet01 } & SEG6_tet01b_for & TTATCCTCGACGCGCCTTG & 60 \\
\hline & SEG6_tet01a_rev & TCAGCCCGGAGCCAAGG & 60 \\
\hline \multirow[t]{2}{*}{ pLSEG8_tet01 } & SEG8_tet01_for_150 & GGATTGGAACAGACATATAGTG & 55 \\
\hline & SEG8_tet01_rev & TTACCGGTTCCCCACTG & 55 \\
\hline \multirow[t]{2}{*}{ pLSEG8_tet02 } & SEG8_tet02_for_150 & ПTAAGAGAATाTCAGGATAAAG & 50 \\
\hline & SEG8_tet02_rev & TTAACCATGCTITGTCAG & 50 \\
\hline
\end{tabular}

\section{Accession Numbers}

The insert sequences of the plasmids carried by metagenomic library clones showing decreased susceptibility to sulfamethoxazole or tetracycline have been submitted to GenBank under accession numbers MK159018 to MK159025.

\section{RESULTS AND DISCUSSION}

In order to discover so far unknown ARGs in environmental resistomes, soil metagenomic libraries were subjected to function-based screening. As sequence information is not required before screening, this is the only strategy that bears the potential to discover entirely novel ARGs (Simon and Daniel, 2009). In addition, it is selective for full-length genes and functional gene products. The soil used for construction of metagenomic libraries was derived from forest and grassland varying in land use history. Fertilized and non-fertilized grassland sites as well as pristine and age class forest sites, harboring different dominant tree species, were considered (Table 1). This enabled the identification of ARGs in soils from hardly as well as intensively managed ecosystems.

Metagenomic libraries contained approximately 39,800559,000 clones (Table 4). The quality of the libraries was controlled by determining the average insert sizes and the percentage of insert-bearing $E$. coli clones. The average insert sizes of metagenomic DNA-containing plasmids ranged from 2.6 to $6.0 \mathrm{~kb}$ and the frequency of clones carrying plasmid inserts was at least $73 \%$ (Table 4).

\section{Novel ARGs Derived From Phylogenetically Divergent Soil Bacteria}

The soil-derived metagenomic libraries were screened for resistance against tetracycline and sulfamethoxazole using selective agar medium. We recovered eight positive E. coli clones, harboring plasmids listed in Table 4, from functional screens. The entire inserts of these plasmids were sequenced and taxonomically classified, which revealed in all cases a bacterial origin (Supplementary Table S1). Some of the insert sequences are affiliated to Gram-negative bacterial phyla including Bacteroidetes and Proteobacteria whereas others belong to Actinobacteria (Supplementary Table S1). Noteworthy, one of the insert sequences was affiliated to the poorly characterized candidate phylum Zixibacteria.

Forsberg et al. (2014) reported that bacterial phyla, which were abundant in soil samples as determined by $16 \mathrm{~S}$ rRNA gene sequencing, were also well-represented among taxa inferred from antibiotic resistance-conferring metagenomic library inserts derived from the same samples. Previously, we detected Proteobacteria, Actinobacteria, Bacteroidetes, and Chloroflexi among the dominant phyla in soils of our study sites via pyrosequencing of $16 \mathrm{~S}$ rRNA genes (Kaiser et al., 2016). These phyla were also covered by the antibiotic resistanceconferring inserts described in this study (see Supplementary Table S1). Despite their high-GC content and predicted transcriptional incompatibilities with E. coli, also Actinobacteria were represented with respect to inserts of positive clones reported here and by Forsberg et al. (2014). The taxonomic origins of our resistance-conferring inserts show that the metagenomic library host E. coli allows identification of ARGs carried by phylogenetically divergent soil bacteria.

\section{Forest Soil Not Exposed to Synthetic Drugs Harbors Sulfonamide-Resistant DHPSs}

Sulfonamides are synthetic antimicrobial compounds targeting the folic acid pathway enzyme DHPS. Although all forest sites analyzed in this study exhibit no history of exposure to these synthetic compounds, three genes, AEW9_dhps01, SEW2_dhps01, and SEW5_dhps01, conferring sulfonamide resistance, were recovered from beech or pine forest soil (Tables 1, 5 and Figure 1). Furthermore, with respect to both 
TABLE 4 | Characterization of soil metagenomic libraries and designation of plasmids harbored by positive clones.

\begin{tabular}{|c|c|c|c|c|c|}
\hline Library & Number of clones & Average insert size (kb) & Insert frequency $(\%)$ & Estimated library size (Gb) & Plasmids of positive clones \\
\hline AEG2 & 115965 & 3.6 & 73 & 0.30 & pLAEG2_dhps01 \\
\hline AEG3 & 40095 & 5.8 & 85 & 0.20 & pLAEG3_tet01 \\
\hline AEW9* & 100950 & 2.6 & 89 & 0.23 & pLAEW9_dhps01 \\
\hline SEG6* & 39825 & 6.0 & 91 & 0.22 & pLSEG6_tet01 \\
\hline SEG8 & 559000 & 4.8 & 86 & 2.30 & pLSEG8_tet01-02 \\
\hline SEW2* & 135240 & 5.7 & 95 & 0.73 & pLSEW2_dhps01 \\
\hline SEW5* & 166040 & 4.0 & 95 & 0.63 & pLSEW5_dhps01 \\
\hline
\end{tabular}

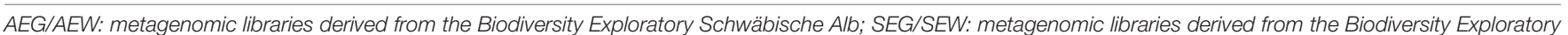

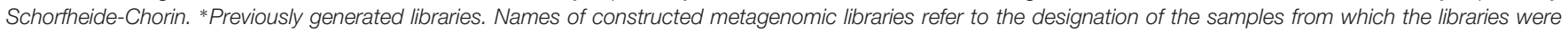
derived (see Table 2).

forest sites (SEW2 and SEW5) located in the SchorfheideChorin exploratory (Northeastern Germany), as well as the forest site (AEW9) located in the Schwäbische Alb exploratory (Southwestern Germany), to our knowledge soils were not exposed to chemicals that resemble sulfonamides in their molecular structure. Especially, in case of the site AEW9 it is unlikely that such chemicals were spread, as this site belongs to an unmanaged beech forest. Resistance to sulfonamides is commonly mediated by the mobile DHPS-encoding genes sul1, sul2, or sul3 (Sköld, 2000; Perreten and Boerlin, 2003), which have been detected in various environments such as shrimp ponds, swine farm wastewater and manured soil

TABLE 5 | Proteins encoded by genes associated with antibiotic resistance and their observed sequence identities.

\begin{tabular}{|c|c|c|c|c|c|c|}
\hline Plasmid & Gene & $\begin{array}{l}\text { No. of encoded } \\
\text { amino acids }\end{array}$ & $\begin{array}{l}\text { Closest similar } \\
\text { non-hypothetical } \\
\text { protein, accession no. } \\
\text { (no. of encoded amino } \\
\text { acids), organism }\end{array}$ & $E$-value & $\begin{array}{l}\text { Percent identity to } \\
\text { the closest similar } \\
\text { protein (Blast) }\end{array}$ & $\begin{array}{l}\text { Percent identity to the } \\
\text { closest similar protein } \\
\text { (ClustalW alignment) }\end{array}$ \\
\hline pLAEG2_dhps01 & AEG2_dhps01 & 286 & $\begin{array}{l}\text { Dihydropteroate synthase, } \\
\text { WP_116719066 (292), } \\
\text { Anaerolineaeles bacterium }\end{array}$ & $3 e-151$ & 213/282 (76\%) & $74 \%$ \\
\hline pLAEW9_dhps01 & AEW9_dhps01 & 273 & $\begin{array}{l}\text { Sulfonamide-resistant } \\
\text { dihydropteroate synthase } \\
\text { Sul3, WP_106052391 } \\
\text { (263), Victivallales }\end{array}$ & $1 e-73$ & $123 / 264$ (47\%) & $46 \%$ \\
\hline pLSEW2_dhps01 & SEW2_dhps01 & 269 & $\begin{array}{l}\text { Dihydropteroate synthase, } \\
\text { OGQ04760 (263), } \\
\text { Deltaproteobacteria } \\
\text { bacterium }\end{array}$ & $3 e-77$ & $140 / 270$ (52\%) & $52 \%$ \\
\hline pLSEW5_dhps01 & SEW5_dhps01 & 271 & $\begin{array}{l}\text { Dihydropteroate synthase, } \\
\text { OJU07522 (270), } \\
\text { Alphaproteobacteria } \\
\text { bacterium 64-11 }\end{array}$ & $3 e-99$ & $159 / 259$ (61\%) & $58 \%$ \\
\hline \multirow[t]{2}{*}{ pLAEG3_tet01 } & AEG3_tet01a & 403 & $\begin{array}{l}\text { MFS transporter, AIA16595 } \\
\text { (403), uncultured bacterium }\end{array}$ & 0.0 & $398 / 403$ (99\%) & $98 \%$ \\
\hline & AEG3_tet01b & 230 & $\begin{array}{l}\text { Bacterial regulatory protein } \\
\text { of tetR family, AIA16695 } \\
\text { (190), uncultured bacterium }\end{array}$ & $2 e-127$ & 179/190 (94\%) & $94 \%$ \\
\hline \multirow[t]{2}{*}{ pLSEG6_tet01 } & SEG6_tet01a & 408 & $\begin{array}{l}\text { MFS transporter, } \\
\text { WP_078811785 (418), } \\
\text { Prosthecobacter debontii }\end{array}$ & $2 e-128$ & 200/383 (52\%) & $49 \%$ \\
\hline & SEG6_tet01b & 197 & $\begin{array}{l}\text { TetR family transcriptional } \\
\text { regulator, PZN78209 (205), } \\
\text { Proteobacteria bacterium }\end{array}$ & $4 e-63$ & 109/194 (56\%) & $54 \%$ \\
\hline pLSEG8_tet01 & SEG8_tet01 & 432 & $\begin{array}{l}\text { MFS transporter, } \\
\text { WP075350247 (408), } \\
\text { Algoriphagus marinus }\end{array}$ & $3 e-174$ & 250/402 (62\%) & $61 \%$ \\
\hline pLSEG8_tet02 & SEG8_tet02 & 405 & $\begin{array}{l}\text { Tetracycline resistance MFS } \\
\text { efflux pump, AIA16766 } \\
\text { (418), uncultured bacterium }\end{array}$ & 0.0 & 272/402 (68\%) & $67 \%$ \\
\hline
\end{tabular}




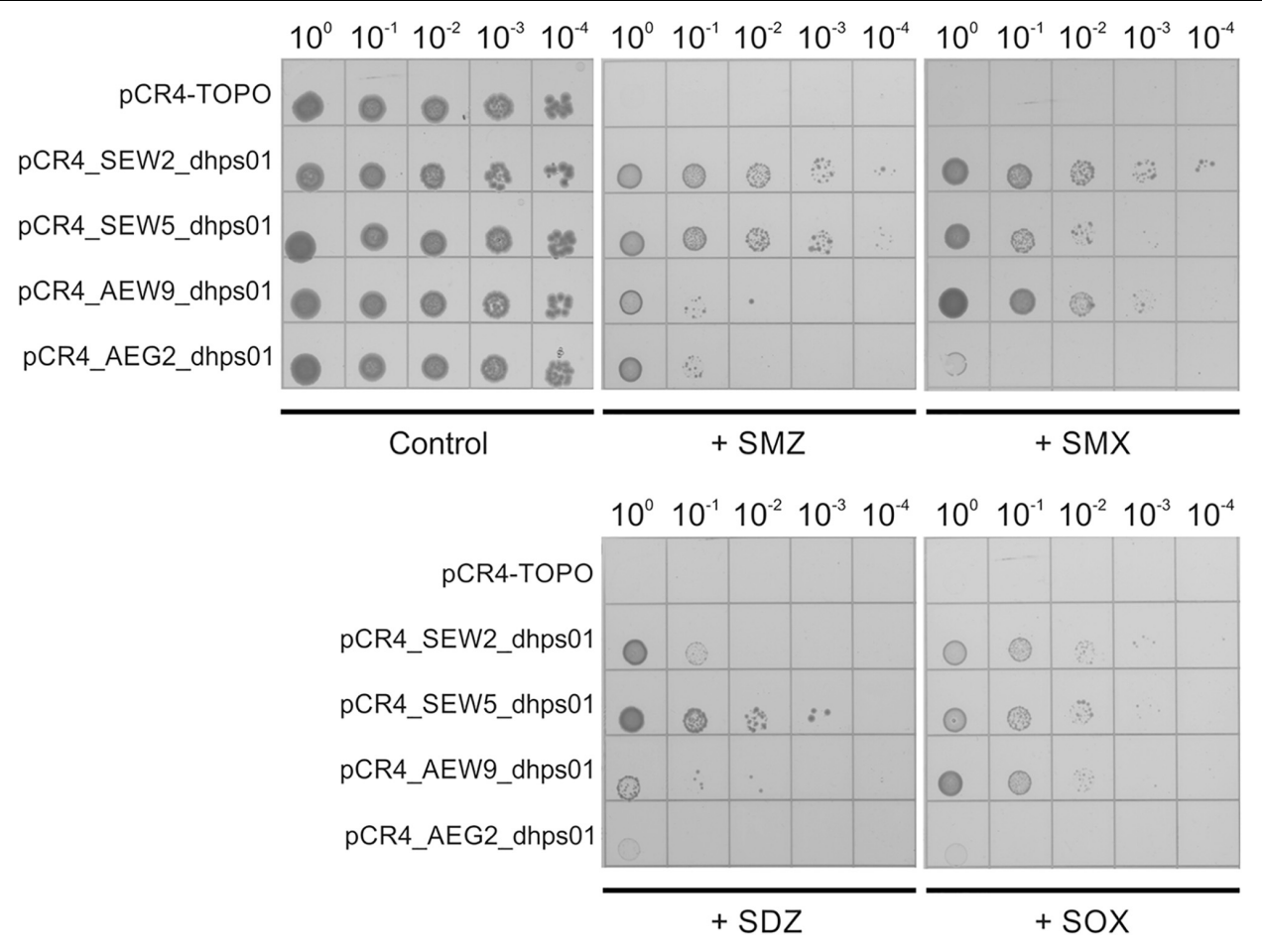

FIGURE 1 | Resistance against sulfonamide antibiotics mediated by SEW2_dhps01, SEW5_dhps01, AEW9_dhps01, and AEG2_dhps01. Five microliters of serially diluted E. coli TOP10 cultures with starting $\mathrm{OD}_{600}$ of 0.5 were spotted onto Iso-Sensitest agar plates supplemented with $1000 \mathrm{mg} / \mathrm{L}$ sulfamethazine (+ SMZ), 250 mg/L sulfamethoxazole (+ SMX), 250 mg/L sulfadiazine (+ SDZ) or 500 mg/L sulfisoxazole (+ SOX). Iso-Sensitest agar plates with no sulfonamide added (control) were also included. E. coli TOP10 cultures carrying the cloning vector pCR4-TOPO, pCR4_SEW2_dhps01, pCR4_SEW5_dhps01, pCR4_AEW9_dhps01 or pCR4_AEG2_dhps01 were considered.

(Phuong Hoa et al., 2008; Wang et al., 2014), but also in clinical isolates (Grape et al., 2003). To our knowledge, we report here for the first time the presence of functional non-mobile sulfonamide-resistant DHPSs in forest soil ecosystems. The deduced gene products of AEW9_dhps01,SEW2_dhps01, and SEW5_dhps01 showed only 46 to $58 \%$ amino acid sequence identities to the closest known DHPSs over the full length proteins (Table 5). Furthermore, AEW9_dhps01 harbors the alternative start codon GTG (all other detected dhps genes harbored the start codon ATG).

Phylogenetic analysis revealed that SEW2_DHPS01 exhibits homology with a putative DHPS affiliated to Deltaproteobacteria (Figure 2). Nevertheless, it has so far not been analyzed if this putative enzyme represents a functional DHPS, which can confer resistance to sulfonamides. In contrast to SEW2_DHPS01, AEW9_DHPS01 showed low identity (46\%) to a DHPS with confirmed sulfonamide resistance, but branched separately from this enzyme affiliated to the Lentisphaerae (family Victivallales), in a phylogenetic tree (Figure 2). The remaining sulfonamide resistance-conferring enzyme identified in forest soil, SEW5_DHPS01, was most similar (58\% identity) to a DHPS from Alphaproteobacteria. Strikingly, no mobile genetic elements were predicted with respect to the inserts comprising AEW9_dhps01,SEW2_dhps01, and SEW5_dhps01. This indicates that different bacterial phyla colonizing forest soil ecosystems harbor DHPSs, which are naturally insensitive to the inhibitory effects of sulfonamides. Furthermore, our results show that forest soil-derived DHPSs can provide high-level resistance in E. coli TOP10 (Figures 1, 3) and therefore potentially also in clinically relevant Enterobacteriaceae. As sulfonamides are used to treat gastrointestinal or urinary infections in human and belong to the most commonly sold and administered veterinary antibiotics (De Briyne et al., 2014; Santman-Berends et al., 2014), mobilization and spread of so far unknown genes conferring resistance to these synthetic compounds would have severe consequences, especially for the animal sector. In particular, SEW2_DHPS01 and SEW5_DHPS01 exhibited highlevel resistance toward sulfamethazine (Figure 1), which is widely used in food animal production (Lau et al., 2017).

\section{Discovery of a Grassland Soil-Derived DHPS Affiliated to Chloroflexi}

Recently, a fourth mobile sulfonamide resistance gene (sul4), encoding a DHPS phylogenetically related to representatives of the phylum Chloroflexi, has been discovered in polluted Indian river sediment (Razavi et al., 2017). This gene is flanked by an ISCR element, which is known to be involved in horizontal gene transfer (Razavi et al., 2017). In this study, we identified an enzyme (AEG2_DHPS01) with reduced susceptibility toward sulfonamides (Figure $\mathbf{1}$ and Table 6), showing similarity to DHPSs from Chloroflexi, in a fertilized grassland soil. 


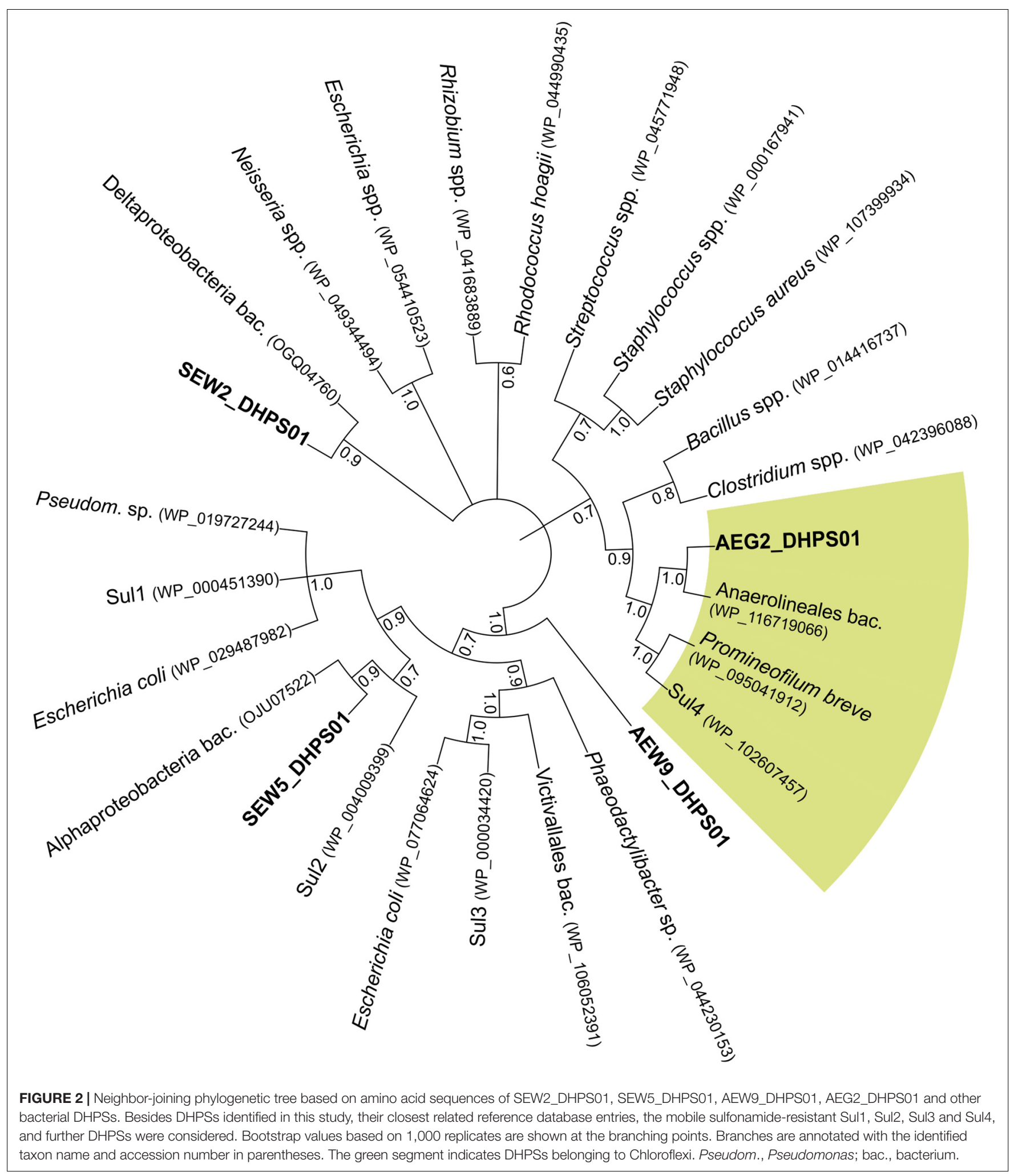

AEG2_DHPS01 shares $76 \%$ sequence identity with a DHPS from a member of the Anaerolineae (Table 5) and clusters with different Chloroflexi DHPSs including Sul4 in a phylogenetic tree (Figure 2).
As sul4 is flanked by a partial folK ORF, it might have been decontextualized from a set of chromosomal genes involved in folate synthesis (Razavi et al., 2017). Nevertheless, Razavi et al. (2017) pointed out that further investigations on Chloroflexi 
could provide additional hints about the original host of sul4 and how it has been decontextualized. With respect to the insert carrying AEG2_dhps01, no genes potentially involved in folate synthesis were identified. Instead, $A E G 2 \_d h p s 01$ is flanked by an ORF encoding a putative gene product with low similarity (23\% identity) to a primosomal protein $\mathrm{N}^{\prime}$ (replication factor $\mathrm{Y})$ - superfamily 2 helicase from an Anaerolineae bacterium (Supplementary Table S2). It is possible that this gene product can contribute to horizontal gene transfer between Chloroflexi and other bacterial taxa as helicases play a major role in replication, recombination, and repair of nucleic acid substrates (Flechsig et al., 2011; Byrd and Raney, 2012). Besides the potential helicase gene, AEG2_dhps01 is flanked by an ORF encoding a gene product with similarity to a hypothetical protein of an Anaerolineales bacterium.

Taxonomic analysis of the complete insert carrying AEG2_dhps01 confirmed that its original host belongs to the Chloroflexi (Supplementary Table S1). Thus, besides Sul4, AEG2_DHPS01 represents the so far only identified DHPS showing reduced susceptibility toward sulfonamides (Table 6), which is affiliated to the Chloroflexi. In order to analyze if sulfonamide resistance is a common characteristic of Chloroflexi, isolates belonging to this phylum should be analyzed with respect to susceptibility toward synthetic drugs in future surveys. Apart from sulfonamides, no decreased susceptibility toward other tested antibiotics was detected with respect to E. coli TOP10 carrying the subcloned dhps genes (Figure 3 and Table 6).

\section{An Efflux Protein Conferring Reduced Tetracycline and Lincomycin Susceptibility}

We identified four plasmids, pLAEG3_tet01, pLSEG6_tet01, pLSEG8_tet01, and pLSEG8_tet02, conferring efflux-mediated tetracycline resistance. All of these plasmids encode gene products with similarity to major facilitator superfamily (MFS) efflux proteins (Table 5). MFS efflux systems are widely distributed in both Gram-positive and Gram-negative bacteria (Sun et al., 2014). Accordingly, Wang et al. (2017) reported that 21 out of 24 tetracycline resistance genes, identified by functional

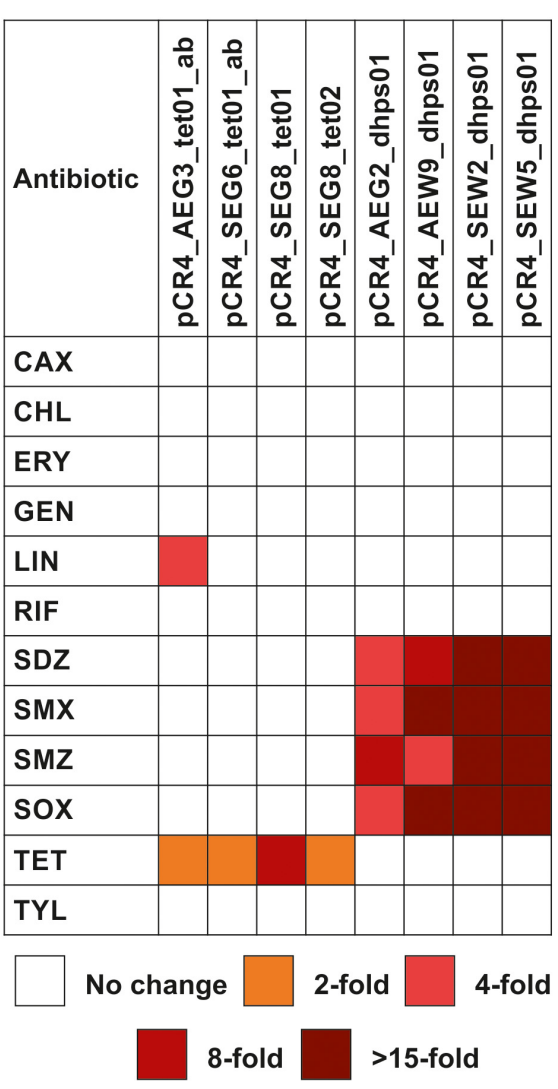

FIGURE 3 | Antibiotic susceptibility profiles of E. coli TOP10 carrying soil-derived genes involved in antibiotic resistance. The genes were subcloned into plasmid vector pCR4-TOPO. MICs of antibiotics were determined using the broth microdilution method and are presented as fold increase relative to those for E. coli TOP10 carrying the cloning vector pCR4-TOPO. CAX, cefotaxime; CHL, chloramphenicol; ERY, erythromycin; GEN, gentamicin; LIN, lincomycin; RIF, rifampicin; SDZ, sulfadiazine; SMX, sulfamethoxazole; SMZ, sulfamethazine; SOX, sulfisoxazole; TET, tetracycline; TYL, tylosin.

metagenomics in Chinese soils, were affiliated to the MFS. The proteins encoded by these 21 genes showed identities $\geq 78 \%$ to

TABLE 6 | Antibiotic susceptibility of plasmid-carrying E. coli clones.

\begin{tabular}{|c|c|c|c|c|c|c|c|c|c|c|c|c|}
\hline \multirow[t]{2}{*}{ Plasmid } & \multicolumn{12}{|c|}{ Minimal inhibitory concentration $(\mu \mathrm{g} / \mathrm{ml})$} \\
\hline & CAX & $\mathrm{CHL}$ & ERY & GEN & LIN & RIF & SDZ & SMX & SMZ & sox & TET & TYL \\
\hline Cloning vector & $<0.125$ & 2 & 1024 & 4 & 512 & 8 & 15.625 & 7.8125 & 62.5 & 15.625 & 1 & 512 \\
\hline pCR4_AEG2_dhps01 & $<0.125$ & 2 & 1024 & 4 & 512 & 8 & 62.5 & 31.25 & 500 & 62.5 & 1 & 512 \\
\hline pCR4_AEW9_dhps01 & $<0.125$ & 2 & 1024 & 4 & 512 & 8 & 125 & 500 & 250 & 1000 & 1 & 512 \\
\hline pCR4_SEW2_dhps01 & $<0.125$ & 2 & 1024 & 4 & 512 & 8 & 500 & 500 & $>1000$ & 1000 & 1 & 512 \\
\hline pCR4_SEW5_dhps01 & $<0.125$ & 2 & 1024 & 4 & 512 & 8 & $>1000$ & 500 & $>1000$ & 1000 & 1 & 512 \\
\hline pCR4_AEG3_tet01ab & $<0.125$ & 2 & 1024 & 4 & 2048 & 8 & 15.625 & 7.8125 & 62.5 & 15.625 & 2 & 512 \\
\hline pCR4_SEG6_tet01ab & $<0.125$ & 2 & 1024 & 4 & 512 & 8 & 15.625 & 7.8125 & 62.5 & 15.625 & 2 & 512 \\
\hline pCR4_SEG8_tet01 & $<0.125$ & 2 & 1024 & 4 & 512 & 8 & 15.625 & 7.8125 & 62.5 & 15.625 & 8 & 512 \\
\hline pCR4_SEG8_tet02 & $<0.125$ & 2 & 1024 & 4 & 512 & 8 & 15.625 & 7.8125 & 62.5 & 15.625 & 2 & 512 \\
\hline
\end{tabular}

CAX, cefotaxime; CHL, chloramphenicol; ERY, erythromycin; GEN, gentamicin; LIN, lincomycin; RIF, rifampicin; SDZ, sulfadiazine; SMX, sulfamethoxazole; SMZ,

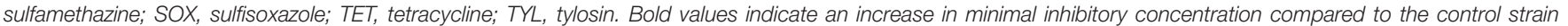
carrying the cloning vector PCR4-TOPO. 
the closest related reference database entries (Wang et al., 2017). In contrast, three out of four MFS representatives identified in this study shared $\leq 67 \%$ identity with their closest related proteins (Table 5). Besides an MFS representative, two insert sequences (corresponding plasmids, pLAEG3_tet01 and pLSEG6_tet01) encoded proteins with similarity to members of the TetR family of regulators (Table 5). These regulators are associated with antibiotic resistance and are known to control expression of MFS members (Cuthbertson and Nodwell, 2013). Noteworthy, the insert of plasmid pLtetSEG8_02 encodes a protein with similarity to an endonuclease (Supplementary Table S2), which might contribute to horizontal gene transfer.

McGarvey et al. (2012) identified a tetracycline-resistant metagenomic library clone, harboring a MFS representative, with reduced susceptibility toward rifampicin. Here, no resistance toward rifampicin was detected with respect to recombinant MFS producing E. coli clones (Figure 3). Nevertheless, the tetracycline-resistant clone carrying plasmid pCR4_AEG3_tet01ab showed reduced susceptibility toward lincomycin (Figure 3 and Table 6). The gene product AEG3_Tet01a encoded by this plasmid shows $98 \%$ identity to a soil-derived MFS from an uncultured bacterium (Table 5), which confers resistance to chloramphenicol. So far, it has not been analyzed if this chloramphenicol resistance mediating MFS identified by Forsberg et al. (2014) also encodes lincomycin resistance.

\section{CONCLUSION}

Our findings highlight the vast potential of functional metagenomics for the discovery of so far unknown antibiotic resistance determinants in environmental resistomes. We recovered several soil-derived target genes and proteins with low similarity to reference database entries from hardly as well as intensively managed forest and grassland, indicating that the resistance reservoir of the uncultured microbial majority is far from being extensively explored. As we detected here for the first time non-mobile DHPSs conferring resistance to sulfonamides in forest soil with no history of exposure to these synthetic drugs, it is possible that this characteristic naturally occurs in complex bacterial communities. Most of the detected antibiotic resistance determinants were not flanked by potential mobile genetic elements. Nevertheless, the recent finding of a fourth mobile sulfonamide resistance gene indicates ongoing forces that introduce, mobilize and maintain antibiotic resistance determinants in bacterial communities (Razavi et al., 2017). Considering, that several ARGs reported here conferred highlevel resistance to non-pathogenic E. coli, it can be assumed that this could also be the case with respect to clinically

\section{REFERENCES}

Allen, H. K., Moe, L. A., Rodbumrer, J., Gaarder, A., and Handelsman, J. (2009). Functional metagenomics reveals diverse beta-lactamases in a remote Alaskan soil. ISME J. 3, 243-251. doi: 10.1038/ismej.2008.86 relevant Enterobacteriaceae. In order to predict the emergence of antibiotic resistance, an extensive knowledge on environmental resistomes will be required, which might also direct the design of novel antibiotics that are less susceptible to resistance.

\section{DATA AVAILABILITY}

The datasets generated for this study can be found in GenBank, MK159018 to MK159025.

\section{AUTHOR CONTRIBUTIONS}

HN designed the study. IW, AK, NA, DK, SB, FF, and HN carried out field and laboratory work. IW and HN prepared and analyzed the data. All authors interpreted the results and wrote the paper.

\section{FUNDING}

This work was funded by the DFG Priority Program 1374 "Infrastructure-Biodiversity-Exploratories" (NA 848/2-1) and the Open Access Publication Funds of the Göttingen University.

\section{ACKNOWLEDGMENTS}

We thank the managers of the three Exploratories, Kirsten Reichel-Jung, Iris Steitz, Sandra Weithmann, Florian Straub, Katrin Lorenzen, Juliane Vogt, Miriam Teuscher and all former managers for their work in maintaining the plot and project infrastructure; Christiane Fischer for giving support through the central office, Andreas Ostrowski for managing the central data base, and Markus Fischer, Eduard Linsenmair, Dominik Hessenmöller, Daniel Prati, Ingo Schöning, François Buscot, Ernst-Detlef Schulze, Wolfgang W. Weisser, and the late Elisabeth Kalko for their role in setting up the Biodiversity Exploratories project. Field work permits were issued by the responsible state environmental offices of Baden-Württemberg, Thüringen, and Brandenburg. We thank Melissa Kocatuerk who contributed to the performance of the MIC assays.

\section{SUPPLEMENTARY MATERIAL}

The Supplementary Material for this article can be found online at: https://www.frontiersin.org/articles/10.3389/fmicb. 2019.00460/full\#supplementary-material

Altschul, S. F., Gish, W., Miller, W., Myers, E. W., and Lipman, D. J. (1990). Basic local alignment search tool. J. Mol. Biol. 215, 403-410. doi: 10.1016/S00222836(05)80360-2

Blüthgen, N., Dormann, C. F., Prati, D., Klaus, V. H., Kleinebecker, T., Hölzel, N., et al. (2012). A quantitative index of land-use intensity in grasslands: integrating 
mowing, grazing and fertilization. Basic Appl. Ecol. 13, 207-220. doi: 10.1016/j. baae.2012.04.001

Byrd, A. K., and Raney, K. D. (2012). Superfamily 2 helicases. Front. Biosci. 17:2070-2088. doi: 10.2741/4038

Cheng, J., Romantsov, T., Engel, K., Doxey, A. C., Rose, D. R., Neufeld, J. D., et al. (2017). Functional metagenomics reveals novel $\beta$-galactosidases not predictable from gene sequences. PLoS One 12:e0172545. doi: 10.1371/journal. pone. 0172545

Cuthbertson, L., and Nodwell, J. R. (2013). The TetR family of regulators. Microbiol. Mol. Biol. Rev. 77, 440-475. doi: 10.1128/MMBR. 00018-13

Davies, J., and Davies, D. (2010). Origins and evolution of antibiotic resistance. Microbiol. Mol. Biol. Rev. 74, 417-433. doi: 10.1128/MMBR.00016-10

D'Costa, V. M., Griffiths, E., and Wright, G. D. (2007). Expanding the soil antibiotic resistome: exploring environmental diversity. Curr. Opin. Microbiol. 10, 481-489. doi: 10.1016/j.mib.2007.08.009

De Briyne, N., Atkinson, J., Pokludová, L., and Borriello, S. P. (2014). Antibiotics used most commonly to treat animals in Europe. Vet. Rec. 175:325. doi: 10.1136/ vr.102462

Delmont, T. O., Robe, P., Cecillon, S., Clark, I. M., Constancias, F., Simonet, P., et al. (2011). Accessing the soil metagenome for studies of microbial diversity. Appl. Environ. Microbiol. 77, 1315-1324. doi: 10.1128/AEM. 01526-10

Fischer, M., Bossdorf, O., Gockel, S., Hänsel, F., Hemp, A., Hessenmöller, D., et al. (2010). Implementing large-scale and long-term functional biodiversity research: the biodiversity exploratories. Basic Appl. Ecol. 11, 473-485. doi: 10. 1016/j.baae.2010.07.009

Flechsig, H., Popp, D., and Mikhailov, A. S. (2011). In silico investigation of conformational motions in superfamily 2 helicase proteins. PLoS One 6:e21809. doi: 10.1371/journal.pone.0021809

Forsberg, K. J., Patel, S., Gibson, M. K., Lauber, C. L., Knight, R., Fierer, N., et al. (2014). Bacterial phylogeny structures soil resistomes across habitats. Nature 509, 612-616. doi: 10.1038/nature13377

Forsberg, K. J., Reyes, A., Wang, B., Selleck, E. M., Sommer, M. O., and Dantas, G. (2012). The shared antibiotic resistome of soil bacteria and human pathogens. Science 337, 1107-1111. doi: 10.1126/science.122 0761

Gibson, M. K., Forsberg, K. J., and Dantas, G. (2015). Improved annotation of antibiotic resistance determinants reveals microbial resistomes cluster by ecology. ISME J. 9, 207-216. doi: 10.1038/ismej.2014.106

Grape, M., Sundström, L., and Kronvall, G. (2003). Sulphonamide resistance gene sul3 found in Escherichia coli isolates from human sources. J. Antimicrob. Chemother. 52, 1022-1024. doi: 10.1093/jac/dkg473

Kaiser, K., Wemheuer, B., Korolkow, V., Wemheuer, F., Nacke, H., Schöning, I., et al. (2016). Driving forces of soil bacterial community structure, diversity, and function in temperate grasslands and forests. Sci. Rep. 6:33696. doi: 10.1038/ srep33696

Kumar, S., Stecher, G., and Tamura, K. (2016). MEGA7: molecular evolutionary genetics analysis version 7.0 for bigger datasets. Mol. Biol. Evol. 33, 1870-1874. doi: 10.1093/molbev/msw054

Landers, T. F., Cohen, B., Wittum, T. E., and Larson, E. L. (2012). A review of antibiotic use in food animals: perspective, policy and potential. Public Health Rep. 127, 4-22. doi: 10.1177/003335491212700103

Lau, C. H., van Engelen, K., Gordon, S., Renaud, J., and Topp, E. (2017). Novel novel antibiotic resistance determinants from agricultural soil exposed to antibiotics widely used in human medicine and animal farming. Appl. Environ. Microbiol. doi: 10.1128/AEM.00989-17 [Epub ahead of print].

Leplae, R., Lima-Mendez, G., and Toussaint, A. (2010). ACLAME: a classification of mobile genetic elements, update 2010. Nucleic Acids Res. 38, D57-D61. doi: 10.1093/nar/gkp938

Llorens, C., Futami, R., Covelli, L., Domínguez-Escribá, L., Viu, J. M., Tamarit, D., et al. (2011). The gypsy database (GyDB) of mobile genetic elements: release 2.0. Nucleic Acids Res. 39, D70-D74. doi: 10.1093/nar/gkq 1061

Martínez, J. L. (2008). Antibiotics and antibiotic resistance genes in natural environments. Science 321, 365-367. doi: 10.1126/science.1159483

McGarvey, K. M., Queitsch, K., and Fields, S. (2012). Wide variation in antibiotic resistance proteins identified by functional metagenomic screening of a soil
DNA library. Appl. Environ. Microbiol. 78, 1708-1714. doi: 10.1128/AEM. 06759-11

Menzel, P., Ng, K. L., and Krogh, A. (2016). Fast and sensitive taxonomic classification for metagenomics with Kaiju. Nat. Commun. 7:11257. doi: 10 . 1038/ncomms 11257

Nacke, H., and Daniel, R. (2014). "Approaches in metagenome research: progress and challenges," in Encyclopedia of Metagenomics, ed. K. Nelson (New York, NY: Springer)

Nacke, H., Thürmer, A., Wollherr, A., Will, C., Hodac, L., Herold, N., et al. (2011a). Pyrosequencing-based assessment of bacterial community structure along different management types in German forest and grassland soils. PLoS One 6:e17000. doi: 10.1371/journal.pone.0017000

Nacke, H., Will, C., Herzog, S., Nowka, B., Engelhaupt, M., and Daniel, R. (2011b). Identification of novel lipolytic genes and gene families by screening of metagenomic libraries derived from soil samples of the German Biodiversity Exploratories. FEMS Microbiol. Ecol. 78, 188-201. doi: 10.1111/j.1574-6941. 2011.01088.x

Nesme, J., and Simonet, P. (2015). The soil resistome: a critical review on antibiotic resistance origins, ecology and dissemination potential in telluric bacteria. Environ. Microbiol. 17, 913-930. doi: 10.1111/1462-2920.12631

Perreten, V., and Boerlin, P. (2003). A new sulfonamide resistance gene (sul3) in Escherichia coli is widespread in the pig population of Switzerland. Antimicrob. Agents Chemother. 47, 1169-1172. doi: 10.1128/AAC.47.3.1169-1172.2003

Perron, G. G., Whyte, L., Turnbaugh, P. J., Goordial, J., Hanage, W. P., Dantas, G., et al. (2015). Functional characterization of bacteria isolated from ancient arctic soil exposes diverse resistance mechanisms to modern antibiotics. PLoS One 10:e0069533. doi: 10.1371/journal.pone.0069533

Phuong Hoa, P. T., Nonaka, L., Hung Viet, P., and Suzuki, S. (2008). Detection of the sul1, sul2, and sul3 genes in sulfonamide-resistant bacteria from wastewater and shrimp ponds of north Vietnam. Sci. Total Environ. 405, 377-384. doi: 10.1016/j.scitotenv.2008.06.023

Piddock, L. J. (2006). Multidrug-resistance efflux pumps - not just for resistance. Nat. Rev. Microbiol. 4, 629-636. doi: 10.1038/nrmicro1464

Razavi, M., Marathe, N. P., Gillings, M. R., Flach, C. F., Kristiansson, E., and Joakim Larsson, D. G. (2017). Discovery of the fourth mobile sulfonamide resistance gene. Microbiome 5:160. doi: 10.1186/s40168-0170379-y

Rutherford, K., Parkhill, J., Crook, J., Horsnell, T., Rice, P., Rajandream, M. A. et al. (2000). Artemis: sequence visualization and annotation. Bioinformatics 16, 944-945. doi: 10.1093/bioinformatics/16.10.944

Santman-Berends, I., Luttikholt, S., Van den Brom, R., Van Schaik, G., Gonggrijp, M., Hage, H., et al. (2014). Estimation of the use of antibiotics in the small ruminant industry in The Netherlands in 2011 and 2012. PLoS One 9:e105052. doi: 10.1371/journal.pone.0105052

Siguier, P., Perochon, J., Lestrade, L., Mahillon, J., and Chandler, M. (2006). ISfinder: the reference centre for bacterial insertion sequences. Nucleic Acids Res. 34, D32-D36. doi: 10.1093/nar/gkj014

Simon, C., and Daniel, R. (2009). Achievements and new knowledge unraveled by metagenomic approaches. Appl. Microbiol. Biotechnol. 85, 265-276. doi: $10.1007 / \mathrm{s} 00253-009-2233-\mathrm{z}$

Sköld, O. (2000). Sulfonamide resistance: mechanisms and trends. Drug Resistance Updates 3, 155-160. doi: 10.1054/drup.2000.0146

Sun, J., Deng, Z., and Yan, A. (2014). Bacterial multidrug efflux pumps: mechanisms, physiology and pharmacological exploitations. Biochem. Biophys. Res. Commun. 453, 254-267. doi: 10.1016/j.bbrc.2014.05.090

Thaker, M., Spanogiannopoulos, P., and Wright, G. D. (2010). The tetracycline resistome. Cell. Mol. Life Sci. 67, 419-431. doi: 10.1007/s00018-009-0172-6

Thompson, J., Higgins, D., and Gibson, T. (1994). CLUSTAL W: improving the sensitivity of progressive multiple sequence alignment through sequence weighting, position-specific gap penalties and weight matrix choice. Nucleic Acids Res. 22, 4673-4680. doi: 10.1093/nar/22.22.4673

Walsh, F. (2013a). Investigating antibiotic resistance in non-clinical environments. Front. Microbiol. 4:19. doi: 10.3389/fmicb.2013.00019

Walsh, F. (2013b). The multiple roles of antibiotics and antibiotic resistance in nature. Front. Microbiol. 4:255. doi: 10.3389/fmicb.2013.00255

Walsh, F., and Duffy, B. (2013). The culturable soil antibiotic resistome: a community of multi-drug resistant bacteria. PLoS One 8:e65567. doi: 10.1371/ journal.pone.0065567 
Wang, N., Yang, X., Jiao, S., Zhang, J., Ye, B., and Gao, S. (2014). Sulfonamideresistant bacteria and their resistance genes in soils fertilized with manures from Jiangsu Province, Southeastern China. PLoS One 9:e112626. doi: 10.1371/ journal.pone.0112626

Wang, S., Gao, X., Gao, Y., Li, Y., Cao, M., Xi, Z., et al. (2017). Tetracycline resistance genes identified from distinct soil environments in china by functional metagenomics. Front. Microbiol. 8:1406. doi: 10.3389/fmicb.2017. 01406

Wheeler, D. L., Church, D. M., Federhen, S., Lash, A. E., Madden, T. L., Pontius, J. U., et al. (2003). Database resources of the national center for biotechnology. Nucleic Acids Res. 31, 28-33. doi: 10.1093/nar/gkg033
Conflict of Interest Statement: The authors declare that the research was conducted in the absence of any commercial or financial relationships that could be construed as a potential conflict of interest.

Copyright (c) 2019 Willms, Kamran, Aßmann, Krone, Bolz, Fiedler and Nacke. This is an open-access article distributed under the terms of the Creative Commons Attribution License (CC BY). The use, distribution or reproduction in other forums is permitted, provided the original author(s) and the copyright owner(s) are credited and that the original publication in this journal is cited, in accordance with accepted academic practice. No use, distribution or reproduction is permitted which does not comply with these terms. 


\subsection{Supplemental information for chapter four}

Table S1. Taxonomic classification of plasmid inserts from positive clones.

Table S2. Open reading frames potentially involved in lateral gene transfer identified on plasmids and description of corresponding gene products and their observed sequence identities. 
Table S1. Taxonomic classification of plasmid inserts from positive clones.

\begin{tabular}{ll} 
Plasmid & Taxonomic classification of insert \\
\hline pLAEG2_dhps01 & $\begin{array}{l}\text { Cellular organisms; Bacteria; Terrabacteria group; Chloroflexi; unclassified } \\
\text { OLloroflexi; unclassified Chloroflexi (miscellaneous); Chloroflexi bacterium }\end{array}$ \\
& Cellular organisms; Bacteria; Terrabacteria group; Actinobacteria; \\
pLAEW9_dhps01 & $\begin{array}{l}\text { Actinobacteria; Micrococcales; Microbacteriaceae; Microbacterium; } \\
\text { Microbacterium sp. }\end{array}$ \\
& Cellular organisms; Bacteria; unclassified Bacteria; Bacteria candidate phyla; \\
pLSEW2_dhps01 & $\begin{array}{l}\text { candidate division Zixibacteria; candidate division Zixibacteria bacterium } \\
\text { SM23_81 }\end{array}$ \\
pLSEW5_dhps01 & Cellular organisms; Bacteria; Proteobacteria; Alphaproteobacteria; \\
& Rhizobiales; Rhodobiaceae; Parvibaculum; Parvibaculum lavamentivorans \\
pLAEG3_tet01 & Cellular organisms; Bacteria; environmental samples; uncultured bacterium \\
& Cellular organisms; Bacteria; Terrabacteria group; Actinobacteria; \\
& Actinobacteria; Corynebacteriales; Mycobacteriaceae; Mycobacterium; \\
pLSEG6_tet01 & Mycobacterium rhodesiae \\
pLSEG8_tet02 & Cellular organisms; Bacteria \\
& Cellular organisms; Bacteria; FCB group; Bacteroidetes/Chlorobi group; \\
&
\end{tabular}


Table S2. Open reading frames potentially involved in lateral gene transfer identified on plasmids and description of corresponding gene products and their observed sequence identities.

\begin{tabular}{lcccccc} 
Plasmid & ORF\# & $\begin{array}{c}\text { No. of encoded } \\
\text { amino acids }\end{array}$ & $\begin{array}{c}\text { Closest similar protein potentially involved in lateral gene transfer, } \\
\text { accession no. (no. of encoded amino acids), organism }\end{array}$ & $\begin{array}{c}\text { E value } \\
\text { Percent identity to the } \\
\text { closest similar } \\
\text { bacterial protein }\end{array}$ \\
\hline pLAEG2_dhps01 & 18 & 445 & $\begin{array}{l}\text { Primosomal protein N'- superfamily II helicase, RCK75038 (471), } \\
\text { Anaerolineae bacterium }\end{array}$ & $1 \mathrm{e}-40$ & $118 / 429(28 \%)$ \\
\hline pLSEG8_tet02 & 40 & 123 & $\begin{array}{l}\text { Endonuclease domain-containing protein, WP_068706482 (129), } \\
\text { Paludibacter jiangxiensis }\end{array}$ & $4 \mathrm{e}-35$ & $57 / 115(50 \%)$ \\
\hline
\end{tabular}




\section{Globally abundant Candidatus Udaeobacter benefits}

\section{from release of antibiotics in soil and potentially performs}

\section{trace gas scavenging}

Inka M. Willms ${ }^{1}$, Anina Y. Rudolph ${ }^{1}$, Isabell Göschel ${ }^{1}$, Simon H. Bolz ${ }^{1}$, Dominik Schneider ${ }^{1}$, Caterina Penone $^{2}$, Anja Poehlein ${ }^{1}$, Ingo Schöning ${ }^{3}$, Heiko Nacke $^{1 *}$

${ }^{1}$ Department of Genomic and Applied Microbiology and Göttingen Genomics Laboratory, Institute of Microbiology and Genetics, Georg-August University of Göttingen, D-37077 Göttingen, Germanyª

2 Institute of Plant Sciences, University of Bern, $\mathrm{CH}-3013$ Bern, Switzerland ${ }^{\mathrm{b}}$

${ }^{3}$ Max Planck Institute for Biogeochemistry, D-07745 Jena, Germanyc

Running Head: Novel features of soil-resident Candidatus Udaeobacter

Revised version of this manuscript published in: mSphere (2020), 5:e00186-20

\section{Author contributions to the work}

Conceptualization, I.M.W. and H.N.; formal analysis, I.M.W., C.P., A.P., D.S. and H.N.; investigation, I.M.W., A.Y.R., I.G. and S.H.B.; resources, H.N. and I.S.; data curation, I.M.W. and H.N.; writing original draft preparation, I.M.W. and H.N.; writing - review and editing, I.M.W., H.N., D.S. and I.S.; visualization, I.M.W. and H.N.; supervision, I.M.W. and H.N.; project administration, H.N.; funding acquisition, H.N. 


\section{Abstract}

Verrucomicrobia affiliated to Candidatus Udaeobacter belong to the most abundant soil bacteria worldwide. Although the synthesis of antibiotics presumably evolved in soil and environmental pollution with antimicrobials increases, the impact of these complex molecules on $\mathrm{Ca}$. Udaeobacter remains to be elucidated. In this study, we demonstrate that $\mathrm{Ca}$. Udaeobacter representatives residing in grassland as well as forest soil ecosystems show multiresistance and even take advantage of antibiotics release. Soils treated with up to six different antibiotics exhibited a higher $\mathrm{Ca}$. Udaeobacter abundance than corresponding controls after three, eight and twenty days of incubation. In this context, we provide evidence that $\mathrm{Ca}$. Udaeobacter utilizes nutrients which are released due to antibiotic-driven lysis of other soil microbes and thereby reduces energetically expensive synthesis of required biomolecules. Moreover, genomic analysis revealed the presence of genes conferring resistance to multiple classes of antibiotics and indicates that $\mathrm{Ca}$. Udaeobacter representatives most likely oxidize the trace gas $\mathrm{H}_{2}$ to generate energy. This energy might be required for long-term persistence in terrestrial habitats, as already suggested for other dominant soil bacteria. Our study illustrates for the first time that globally abundant $\mathrm{Ca}$. Udaeobacter benefits from release of antibiotics, which confers advantages over other soil bacteria and represents a so far overlooked fundamental lifestyle feature of this poorly characterized verrucomicrobial group. Furthermore, our study suggests that $\mathrm{Ca}$. Udaeobacter representatives can utilize $\mathrm{H}_{2}$ as an alternative electron donor.

\section{Importance}

Soil bacteria have been investigated for more than a century, but one of the most dominant terrestrial groups on Earth, Candidatus Udaeobacter, remains elusive and largely unexplored. Its natural habitat is considered as a major reservoir of antibiotics, which directly or indirectly impact phylogenetically diverse microorganisms. Here, we found that $\mathrm{Ca}$. Udaeobacter representatives exhibit multi-resistance and not only evade harmful effects of antimicrobials, but even benefit from antibiotic pressure in soil. Therefore, Ca. Udaeobacter evidently affects the composition of soil resistomes worldwide and might represent a winner of rising environmental pollution with antimicrobials. In addition, our study indicates that $\mathrm{Ca}$. Udaeobacter representatives utilize $\mathrm{H}_{2}$ and thereby contribute to global hydrogen cycling. The 
here reported findings provide insights into elementary lifestyle features of $\mathrm{Ca}$. Udaeobacter, potentially contributing to its successful global dissemination. 


\section{Introduction}

Candidatus Udaeobacter representatives are encountered across soil ecosystems globally (1). Nevertheless, currently it is largely unknown, how these verrucomicrobial organisms became successful terrestrial colonizers. No Ca. Udaeobacter cultures, which would allow detailed physiological analyses, are available. Moreover, Verrucomicrobia have been under-recognized in many studies on soil bacterial communities since commonly used PCR primers widely exclude their 16S rRNA genes during amplification (2). So far, the effects of antibiotics, which can be lethal, growth-inhibiting, but also beneficial for microbial taxa, have not been analyzed with respect to $\mathrm{Ca}$. Udaeobacter.

A recently published metagenome-assembled genome (MAG) of $\mathrm{Ca}$. Udaeobacter copiosus indicates that this phylotype exhibits auxotrophies for numerous putative vitamin and costly amino acid synthesis pathways (1). It is hypothesized that essential metabolites, Ca. Udaeobacter copiosus appears incapable of synthesizing, are taken up from the environment, as the MAG is enriched with amino acid transporter and protease genes (1). Being dependent on extracellular metabolites in a densely colonized habitat like soil might entail increased influx and thus vulnerability to toxic agents secreted by microorganisms competing for scarce nutrients (3). Therefore, an efficient strategy for protection against harmful substances such as antibiotics seems likely and potentially contributed to the successful global dissemination of $\mathrm{Ca}$. Udaeobacter. This theory is supported by an enriched abundance of betalactamase genes within the phylum Verrucomicrobia, identified through function-based screening of soil metagenomic libraries (4).

In this study, for the first time, impacts of antibiotics on the ubiquitous soil bacterium Ca. Udaeobacter, a member of the Chthoniobacterales, were investigated. To enable robust assessment of its response to antibiotic treatment in a microcosm experiment, topsoil samples from forests and grasslands of two different geographic regions were considered. We monitored the abundance of $\mathrm{Ca}$. Udaeobacter relative to other bacterial taxa during microcosm incubation via amplicon sequencing of $16 \mathrm{~S}$ rRNA genes. Since primers specifically targeting this poorly characterized verrucomicrobial group are not available, we designed and evaluated oligonucleotides, which we subsequently used for qPCR-based estimation of its absolute 16S rRNA gene abundance in microcosm samples. Furthermore, a MAG of Ca. Udaeobacter was reconstructed from metagenomic sequences in order to identify antibiotic 
resistance genes (ARGs) and additional characteristics potentially contributing to its dominance in soil ecosystems.

We hypothesized that the abundance of $\mathrm{Ca}$. Udaeobacter representatives is not reduced by an elevated concentration of the broad-spectrum antibiotic amoxicillin, as it has been indicated that beta-lactamases are enriched within Verrucomicrobia (4). Taking into account that numerous antimicrobial compounds are produced and released in soil, we further hypothesized that these globally abundant bacteria are not solely resistant to a single class of antibiotics but exhibit multi-drug resistance.

\section{Results}

\section{Antibiotics evoke elevated $\mathrm{Ca}$. Udaeobacter relative abundance}

A microcosm experiment was performed to investigate how antibiotics release affects soil bacteria representing $\mathrm{Ca}$. Udaeobacter. For this experiment, initial concentrations of 77 antibiotics were determined in all considered forest and grassland soil samples derived from two geographic regions (Hainich-Dün and Schwäbische Alb, Germany) (Table S1). Except chlortetracycline $(0.011 \mathrm{mg} / \mathrm{kg}$ in forest sample AEW2), which was not applied during the microcosm experiment, each of the antimicrobial compounds exhibited a concentration below the detection limit (Table S2). Soils were treated with one antibiotic (amoxicillin), three antibiotics (amoxicillin, oxytetracycline and sulfadiazine) and six antibiotics (amoxicillin, oxytetracycline, sulfadiazine, trimethoprim, tylosin and ciprofloxacin) in high as well as low concentration (corresponding controls, not treated with antibiotics, were also considered). Subsequently, we assessed the relative abundances of bacterial taxonomic groups in soil microcosms via 16S rRNA gene-based high-throughput amplicon sequencing over a period of 20 days. Prior to antibiotic treatment, strong variations of $\mathrm{Ca}$. Udaeobacter relative abundances between the microcosm samples were determined. For example, the relative abundance of $\mathrm{Ca}$. Udaeobacter accounted for approximately $15 \%$ in beech forest soil from the Schwäbische Alb (sample AEW7), whereas only about $3 \%$ of the bacterial community in a grassland soil from the Hainich-Dün region (sample HEG7) represented Ca. Udaeobacter (Figure S1).

Strikingly, grassland as well as forest soil microcosms treated with antibiotics exhibited significantly higher relative abundances of $\mathrm{Ca}$. Udaeobacter than corresponding controls (p-value $<2 \mathrm{e}^{-16}$ ) (Fig. 1 , 
Fig. S1). This pattern was detected when a single antibiotic was added, but also when three or six antibiotics were applied in both, high and low concentration (Table S3). After three days of incubation, the treatment with six antibiotics in high concentration led to the most pronounced rise of Ca. Udaeobacter relative abundance ( $\sim 50-100 \%)$. Furthermore, the treatment with one antibiotic and three antibiotics in high concentration evoked a similar increase in $\mathrm{Ca}$. Udaeobacter relative abundance after three days of incubation ( $50-80 \%)$ (Fig. 1). With increasing days of incubation we determined a statistically significant reduction of the antibiotic treatment effect on Ca. Udaeobacter relative abundance (p-value $\left.<2 \mathrm{e}^{-16}\right)$.
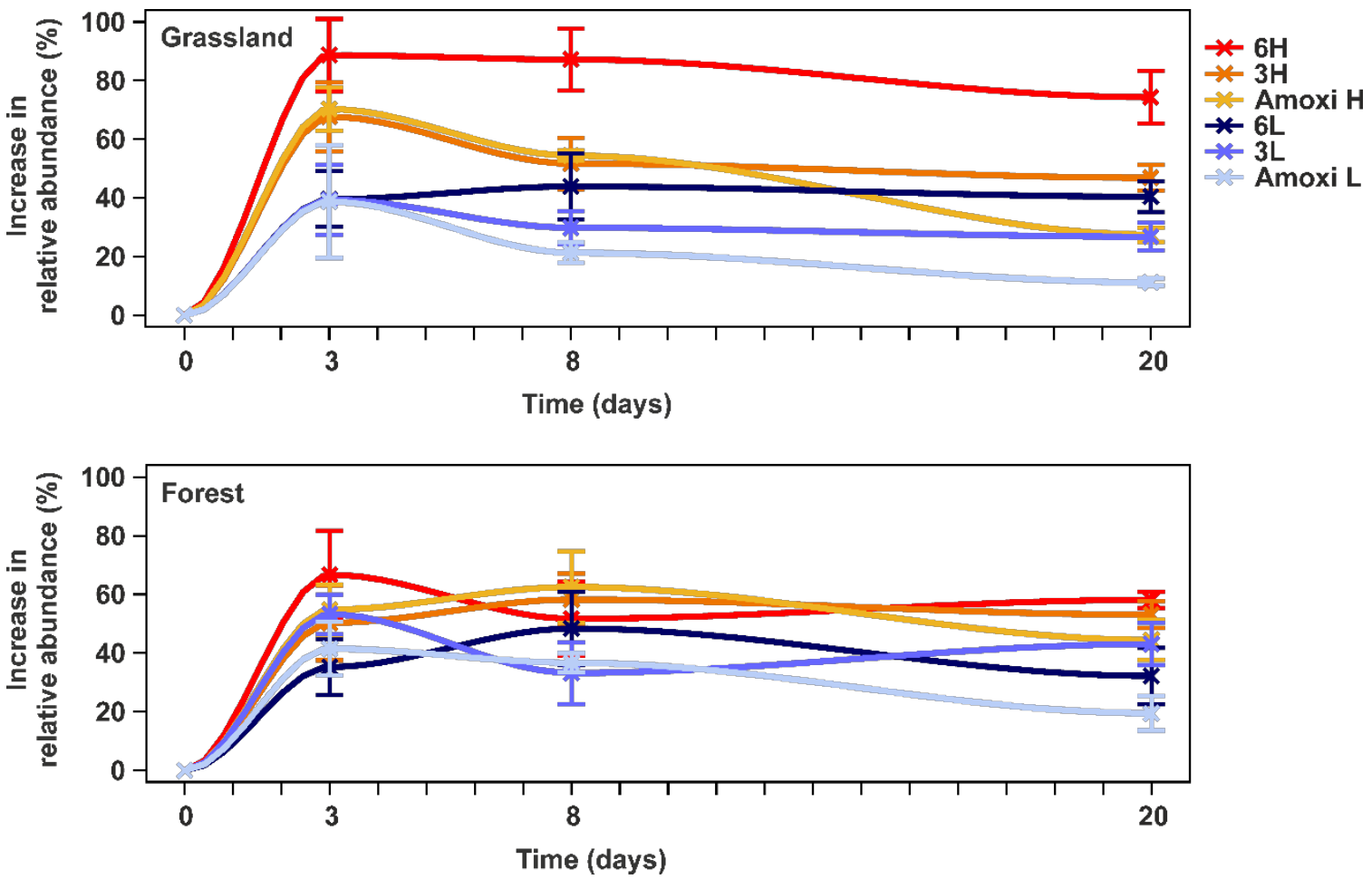

Figure 1. Increase in relative abundance of $\mathrm{Ca}$. Udaeobacter upon antibiotic treatment across grassland and forest soil microcosms. To determine the increase in $\mathrm{Ca}$. Udaeobacter relative abundance, samples treated with antibiotics were compared with corresponding controls. The increase in abundance relative to these controls is depicted. Abbreviations: Amoxi L, treatment with amoxicillin in low concentration; $3 \mathrm{~L}$, treatment with three antibiotics in low concentration; $6 \mathrm{~L}$, treatment with six antibiotics in low concentration; Amoxi $\mathrm{H}$, treatment with amoxicillin in high concentration; $3 \mathrm{H}$, treatment with three antibiotics in high concentration; $6 \mathrm{H}$, treatment with six antibiotics in high concentration. Standard errors are indicated by vertical bars. Barplots depicting abundances of Ca. Udaeobacter relative to other bacterial groups with respect to the single samples analyzed in this study are presented in Fig. S1. 


\section{First primer pair for targeted detection of $\mathrm{Ca}$. Udaeobacter}

To verify if the abundance of $\mathrm{Ca}$. Udaeobacter remains stable or even rises upon antibiotic treatment, we designed and evaluated a primer pair (UDBAC_F/UDBAC_R) for targeted detection of this verrucomicrobial group. An in silico analysis indicated that the primer pair covers approximately $97.14 \%$ of the Ca. Udaeobacter 16S rRNA gene sequences deposited in the SILVA SSU database (release 132). Within the evaluation process, the primer pair was used to generate amplicons based on DNA extracted from soils used to prepare the microcosms, as well as corresponding samples, incubated for three days after treatment with six antibiotics in high concentration. These amplicons were subsequently subjected to high-throughput sequencing and, as expected, the generated data revealed a high preference of the UDBAC primers for $\mathrm{Ca}$. Udaeobacter. Its relative abundance accounted for $99.0 \pm 0.4$ and $98.9 \pm 0.4 \%$ of the amplicon sequences derived from untreated and treated forest soils, respectively, of both geographic regions (Fig. 2). Furthermore, with respect to Schwäbische Alb grassland soils, $96.2 \pm 3$ (untreated soils) and $95.6 \pm 3.9 \%$ (treated soils) of the generated amplicons represented Ca. Udaeobacter (Fig. 2). The major fraction of amplicon sequences, derived from HainichDün grassland soils (untreated soil, $79.4 \pm 1 \%$; treated soil, $84.8 \pm 0.9 \%$ ), was also assigned to Ca. Udaeobacter (Fig. 2), but mainly due to a higher proportion of detected uncultured Verrucomicrobiaceae, its relative abundance was lower in Hainich-Dün grassland soils compared to the other considered soils. Based on this analysis, we utilized the UDBAC primers for targeted detection and quantification of $\mathrm{Ca}$. Udaeobacter $16 \mathrm{~S}$ rRNA genes in microcosm samples. 


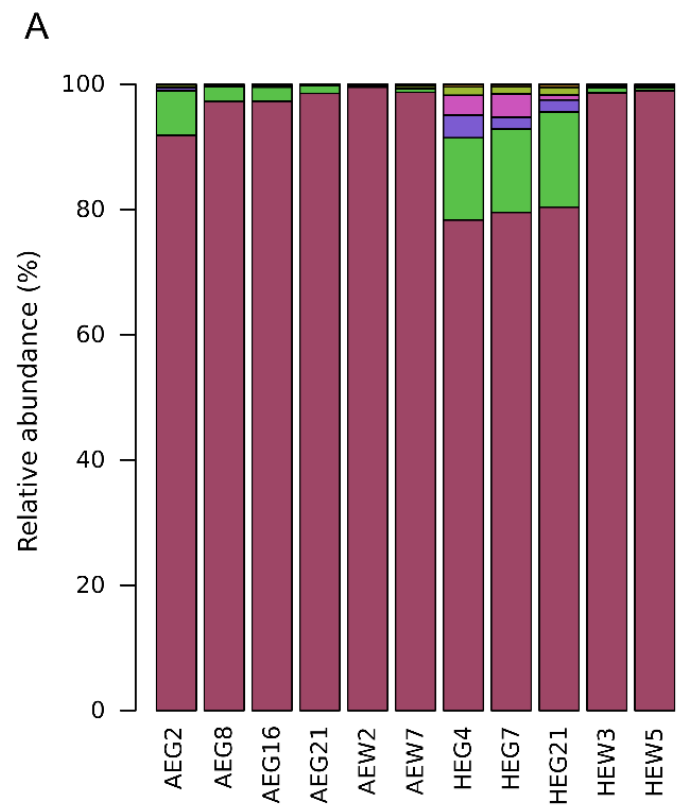

B

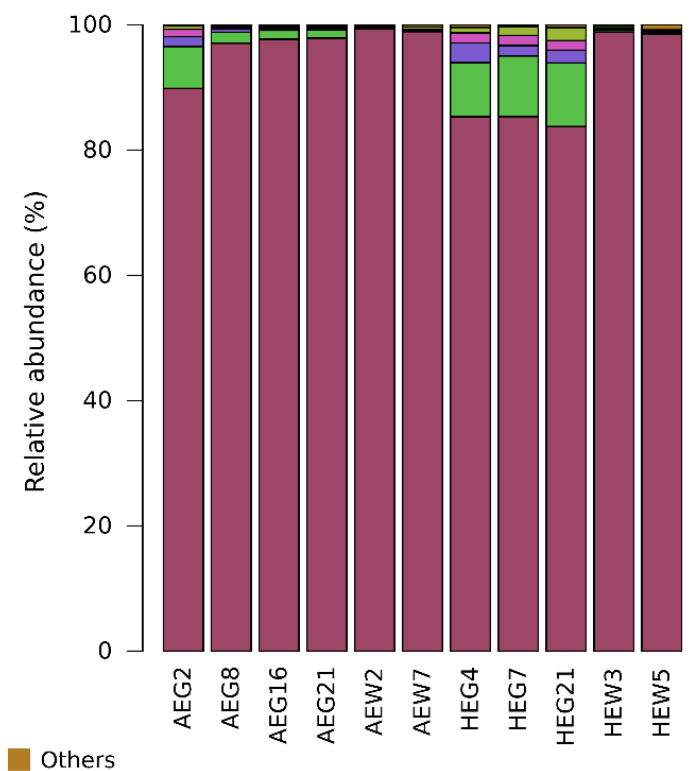

Others

Chthoniobacter

No blast hit

Luteolibacter

Uncultured Verrucomicrobiaceae

Candidatus Udaeobacter

Figure 2. Relative 16S rRNA gene abundance of bacterial groups detected with the UDBAC primer pair designed in this study. Grassland and forest soils used for microcosm preparation were considered (A). In addition, samples incubated for three days upon treatment with six different antibiotics in high concentration (B) were considered. "Others": bacterial groups showing less than $1 \%$ relative abundance. 


\section{Ca. Udaeobacter benefits from antibiotics release in soil}

The increase of $\mathrm{Ca}$. Udaeobacter abundance upon antibiotic treatment, as assessed by amplicon sequencing-based analysis, was verified via qPCR in combination with the UDBAC primers described above. This verification revealed a statistically significant rise ( $p$-value $1.84 \mathrm{e}^{-7}$ ) of $16 \mathrm{~S}$ rRNA gene abundance in soil microcosms incubated for three days upon antibiotic treatment (Fig. 3, Table S3). Since we found during our primer evaluation that mainly $\mathrm{Ca}$. Udaeobacter is covered by the UDBAC primers in these microcosms, the rise of $16 \mathrm{~S}$ rRNA gene abundance is to a high degree evoked by this verrucomicrobial group. Furthermore, similar to the amplicon sequencing-based analysis, the qPCR data also showed that the effect of antibiotic treatment on $\mathrm{Ca}$. Udaeobacter abundance decreased in the course of the microcosm experiment.

Within our qPCR-based verification, soils from both geographic regions, treated with six different antibiotics in high concentration, and corresponding controls were analyzed. In this way, we could prove that even after extensive release of multiple classes of antibiotics, Ca. Udaeobacter abundance showed no decline in forest as well as grassland soil. Moreover, our target soil bacterial group even takes advantage of antibiotics release since its 16S rRNA gene abundance was significantly higher in treated compared to control microcosms with respect to the amplicon sequencing as well as the qPCR-based data. 
AEG16

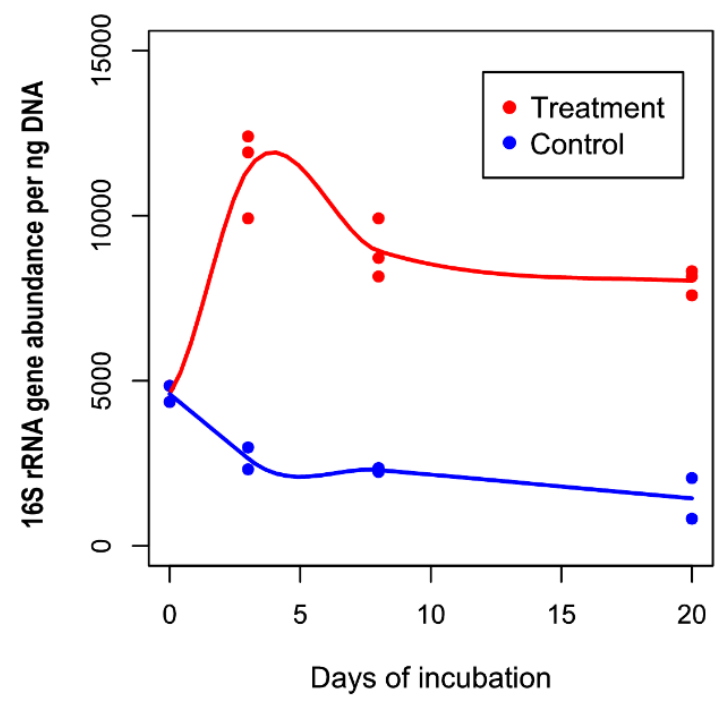

HEG7

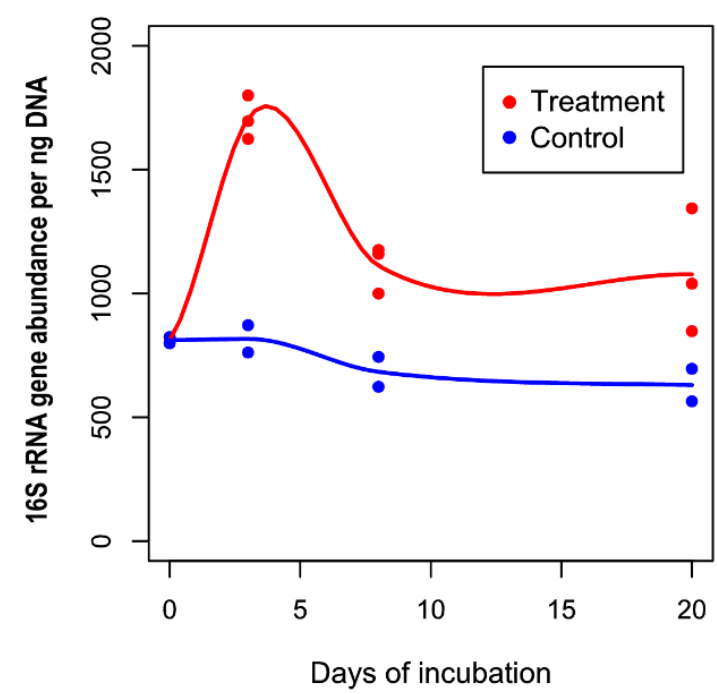

AEW7

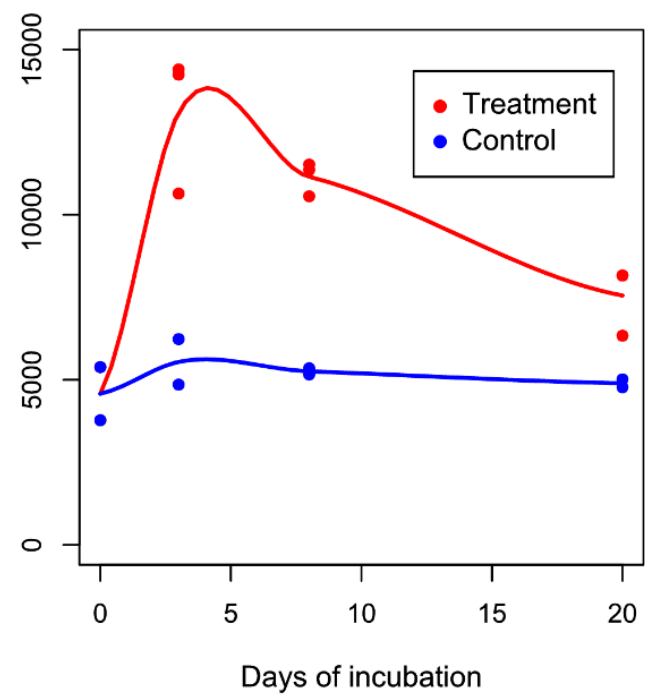

HEW5

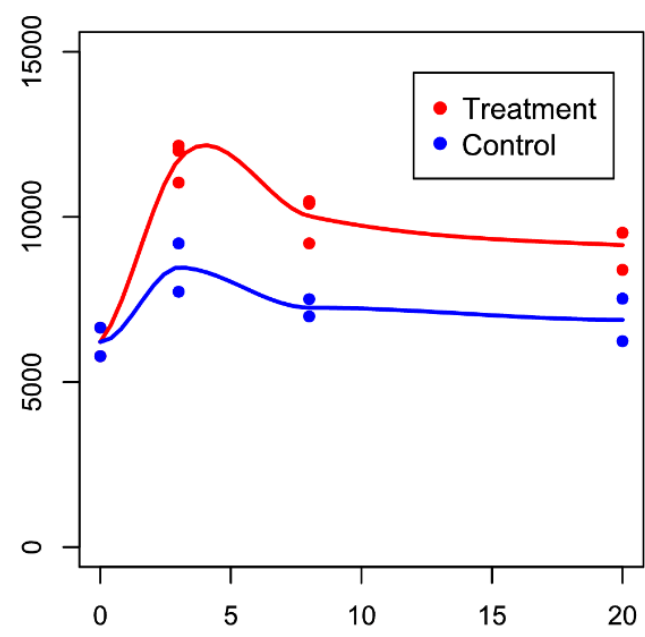

Days of incubation

Figure 3. UDBAC primer pair-based determination of 16S rRNA gene abundance via qPCR. The 16S rRNA genes were quantified with respect to a grassland soil from each geographic region (samples AEG16 and HEG7) as well as a forest soil from each geographic region (samples AEW7 and HEW5). Untreated control samples ("Control") and samples treated with six different antibiotics in high concentration ("Treatment") were considered.

\section{Ca. Udaeobacter sp. MAG harbors several antibiotic resistance genes}

Soil-derived shotgun metagenomic sequencing data, including Oxford Nanopore and Illumina MiSeq reads, was generated to assemble a MAG of a $\mathrm{Ca}$. Udaeobacter representative. In this context, we selected a forest soil sample (AEW3), extracted cells from the soil matrix, and subsequently sequenced 
DNA isolated from these cells. A forest soil sample was selected, as a Ca. Udaeobacter MAG from a grassland soil has already been reported (1). Additionally, several other verrucomicrobial MAGs were recently isolated from grassland soils (5). To extend the knowledge on verrucomicrobial representatives, we focused on genomic features of a Ca. Udaeobacter species inhabiting forest soil.

We assembled a $3.22 \mathrm{Mbp}$ MAG comprising 145 scaffolds with an average GC content of $55.2 \%$ and an average length of $22.22 \mathrm{kbp}$ (size of the longest scaffold, $92.97 \mathrm{kbp}$ ). It exhibited a 31-fold average Illumina MiSeq read coverage and a 64.6-fold average Oxford Nanopore read coverage. 3,341 open reading frames (ORFs), one partially complete $16 \mathrm{~S}$ rRNA gene $(1,139 \mathrm{bp})$, located on a contig with a 33.7-fold average Illumina MiSeq read coverage, one 5S rRNA gene and 38 tRNA genes are encoded by this MAG. The Illumina MiSeq contig coverage indicates that the $16 \mathrm{~S}$ rRNA gene occurs once in the genome, which is consistent with previous findings (6) and further validates its correct assignment to the genome bin. The $16 \mathrm{~S}$ rRNA gene shows $98.83 \%$ identity to amplicon sequence variant 6 (ASV 6 ) (query coverage: 100\%), which is the fourth most abundant ASV in all microcosm samples and increases significantly upon antibiotic treatment ( $p$-value of $\left.1.68 \mathrm{e}^{-6}\right)$. Overall, domain-specific singlecopy housekeeping gene analysis predicted $87.3 \%$ genome bin completeness with a potential contamination of $3.7 \%$. This estimation of completeness and contamination is categorized as substantially complete with low contamination (7). The affiliation of the here assembled genome bin to $\mathrm{Ca}$. Udaeobacter was validated based on phylogenetic analysis of the nucleotide sequence of $16 \mathrm{~S}$ rRNA genes as well as the occurrence and amino acid sequence of 120 marker genes. Regarding the 16S rRNA gene, our MAG clusters together with the ribosomal clone DA101, affiliated to Ca. Udaeobacter, and is clearly phylogenetically distinct from Chthoniobacter and Xiphinematobacter, which also represent Chthoniobacterales (Fig. 4).

Furthermore, the phylogenetic analysis based on the occurrence and amino acid sequence of 120 marker gene sequences of all Chthoniobacterales used for phylogenetic analysis (Table S4), assigned our MAG together with Ca. Udaeobacter copiosus to the GTDB genus AV55 (Fig. 5). As the 16S rRNA gene of our MAG is a representative of the genus Ca. Udaeobacter (Fig. 4) and Ca. Udaeobacter copiosus also clusters in the GTDB genus AV55 (Fig. 5), AV55 most likely represents the genus $\mathrm{Ca}$. Udaeobacter. The closest relative of our MAG is, based on FastANI analysis, AV55 sp003218915.1 with an average nucleotide identity (ANI) of $90 \%$ over $74.6 \%$ of the genome. These 
values are below the ANI species threshold (8) and therefore the here assembled MAG represents a novel species within Ca. Udaeobacter, which we designate Ca. Udaeobacter sp. in this manuscript.

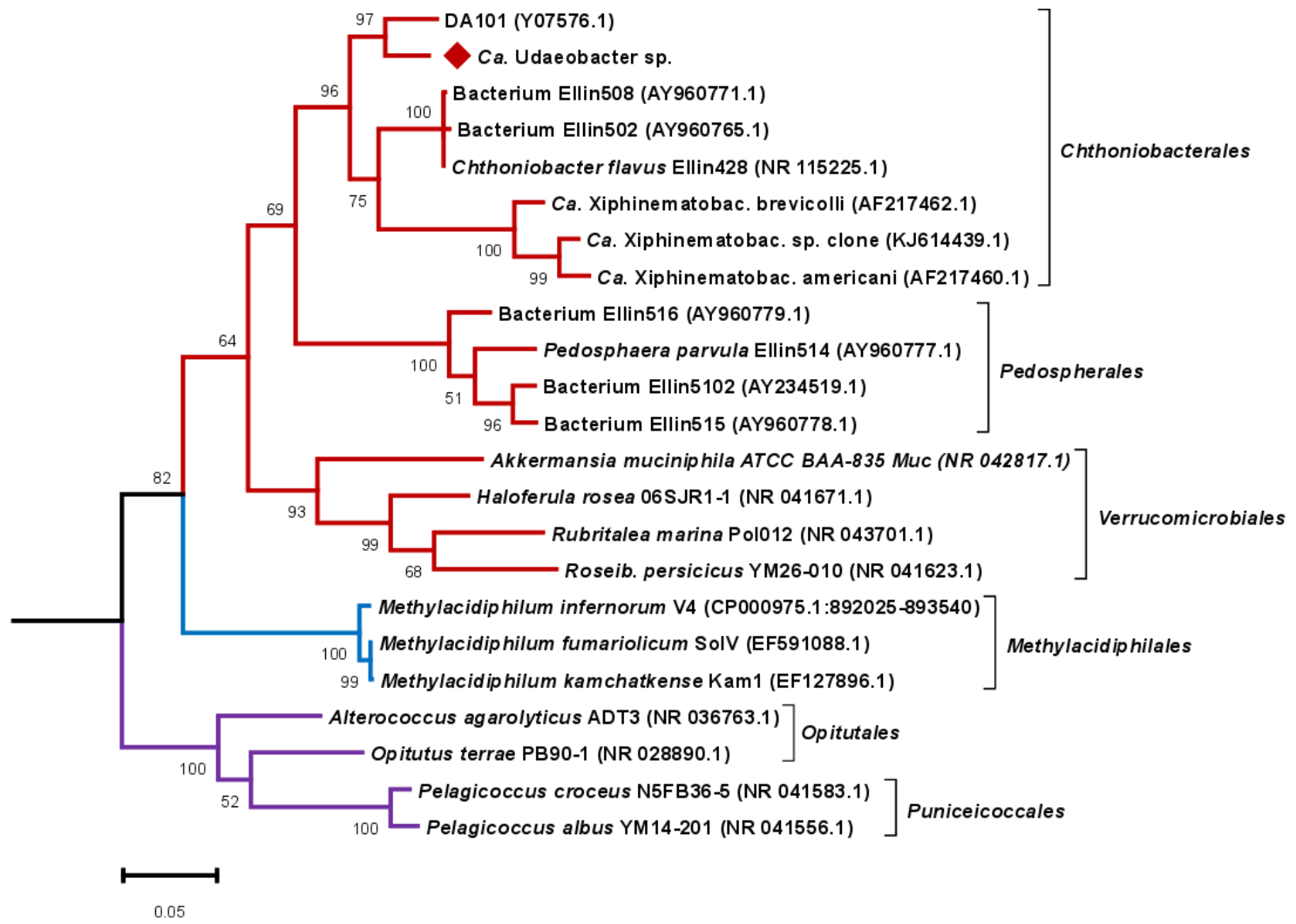

Figure 4. Phylogenetic analysis based on 16S rRNA gene sequences of verrucomicrobial representatives. The 16S rRNA gene sequence of the here assembled Ca. Udaeobacter sp. MAG is highlighted with a red diamond and clusters together with the ribosomal clone DA101, affiliated to Ca. Udaeobacter. Besides the 16S rRNA gene sequence of the MAG assembled in this study, the 16S rRNA gene sequences of 22 other verrucomicrobial representatives were considered. The tree was rooted on the 16S rRNA gene sequence of Escherichia coli K-12 MG 1655 (NC_000913.3:4035531-4037072). Red, blue and purple colored branches indicate the verrucomicrobial classes Verrucomicrobiae, Methylacidiphilae and Opitutae, respectively. Accession numbers are given in parentheses. Bootstrap values based on 500 replicates are shown at the branching points and the bar represents 0.05 changes per nucleotide position. All positions with less than $90 \%$ site coverage were eliminated. Abbreviations: Ca. Xiphinematobac., Candidatus Xiphinematobacter; Roseib., Roseibacillus. 


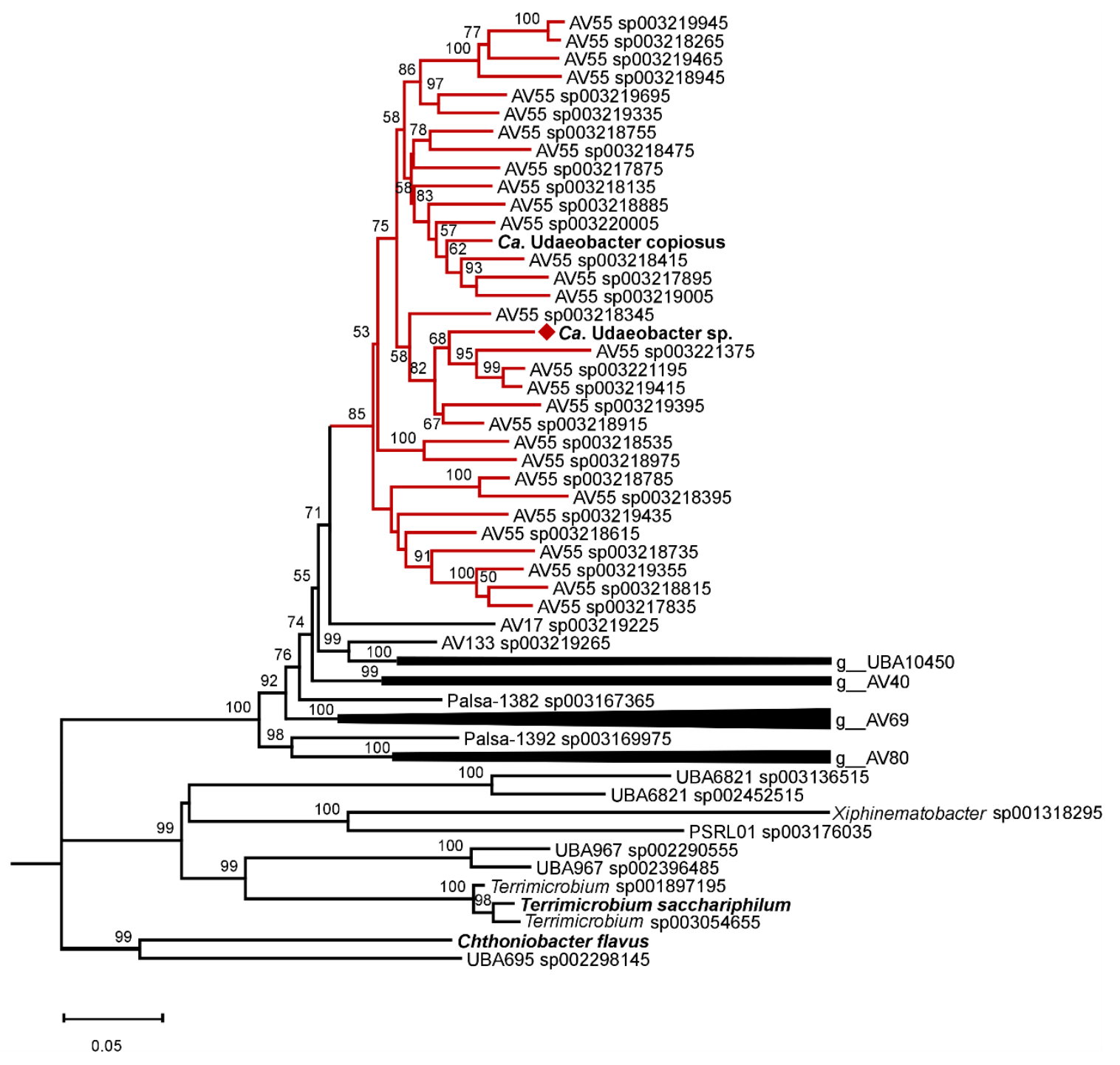

Figure 5. Phylogenetic tree based on the occurrence and amino acid sequence of 120 marker genes from Chthoniobacterales. MAGs available at GTDB as well as the Ca. Udaeobacter copiosus and the here assembled MAG were considered. The neighbor-joining tree was rooted on Escherichia coli UMN026 marker gene sequences. Red colored branches indicate the verrucomicrobial genus AV55 classified by GTDB and the red diamond highlights the here assembled $\mathrm{Ca}$. Udaeobacter sp. MAG. Bootstrap values $\geq 50$ calculated based on 500 iterations are shown at the branching points and the bar represents 0.05 changes per amino acid position. All positions with less than $90 \%$ site coverage were eliminated.

Our MAG enabled insights into the ARG and MGE repertoire of Ca. Udaeobacter (Table S5). Based on our analysis, 55 potential ARGs and 14 MGEs were identified. Highly abundant are genes coding for multidrug resistance mechanisms, especially subunits of resistance nodulation division (RND) MdtABC multidrug efflux systems and multidrug $A B C$ transporters. On contig 74 , a complete mdtABC efflux 
system is encoded including the two RND pump genes $m d t B$ and $m d t C$ as well as the periplasmatic adaptor protein gene $\mathrm{mdtA}$ (Fig. 6).

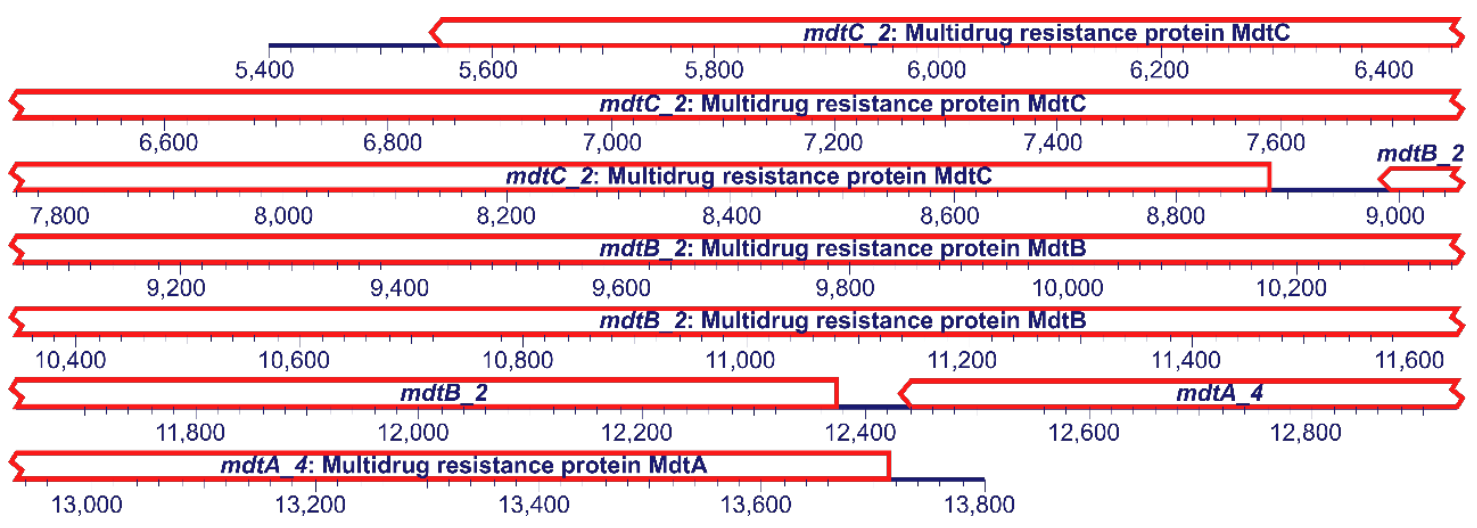

Figure 6. Genes potentially encoding a complete mdtABC multidrug efflux pump carried by contig 74 of the here reported Ca. Udaeobacter sp. MAG. An excerpt of the contig from 5,400 to 13,800 bp is depicted (total contig length: $16,800 \mathrm{bp}$ ).

Furthermore, the draft genome is enriched with genes coding for macrolide efflux pump subunits as two MacA periplasmatic adaptor, four MacB-like periplasmic core domain and five inner membrane ATP transporter (MacB) genes are present. On contig 99, a MacB efflux pump subunit including its periplasmic adaptor protein and an outer membrane secretion protein HlyD are encoded. Additionally, the organism seems to be well protected from beta-lactam antibiotics, due to six encoded betalactamases. Regarding MGEs, the MAG harbors five XerC and two XerD tyrosine recombinase as well as five insertion sequence family transposase genes. A co-location of ARGs and MGEs was not detected as the space between the only ARG (putative chloramphenicol resistance gene) and MGE (xerC, encoding a tyrosine recombinase), located on one contig, is $81.675 \mathrm{kbps}$.

We also analyzed $\mathrm{Ca}$. Udaeobacter sp. for the production of secondary metabolites such as antibiotics and identified a potential phosphonate synthesis cluster. From this cluster, only four percent of the genes show similarity to the known and validated thioplatensimycin biosynthetic gene cluster from Streptomyces platensis. Besides this, four gene clusters were identified which are potentially involved in terpene, arylpolyene and ladderane, and phosphonate synthesis. However, this similarity comprised 
only $18 \%, 16 \%, 8 \%$ and $15 \%$ of the respective genes in the corresponding clusters and these clusters have not been confirmed to produce a synthesis product.

\section{Ca. Udaeobacter sp. MAG reveals potential $\mathrm{H}_{2}$-based energy generation}

Regarding the central metabolism encoded by the $\mathrm{Ca}$. Udaeobacter sp. MAG, only one glycolysis gene is missing (the phosphoglycerate kinase gene), the pentose phosphate pathway is completely encoded and the TCA cycle includes the glyoxylate bypass enzymes. The here identified species can probably oxidize hydrogen aerobically with a small and large subunit of a Ni-Fe-S hydrogenase and an additional soluble hydrogenase, which has so far not been reported with respect to $\mathrm{Ca}$. Udaeobacter. Regarding vitamin biosynthesis, vitamin $\mathrm{B}_{12}$ (cobalamin) is most likely imported from outside of the cell indicated by five encoded vitamin B12 import ATP-binding proteins (BtuD) and two $B_{12}$ transporter proteins (BtuB) and further converted into its active form via the completely encoded adenosylcobalamin salvage pathway. The pathway for vitamin $\mathrm{B}_{9}$ (tetrahydrofolate) biosynthesis is only partially encoded as the tetrahydrofolate reductase is missing. However, $\mathrm{Ca}$. Udaeobacter is probably capable to salvage it from 5,10-methenyltetrahydrofolate as the respective pathway is completely encoded. Furthermore, a salvage pathway to generate thiamine (vitamin $\mathrm{B}_{1}$ ) from its degradation product and a partially complete pathway to synthesize vitamin $\mathrm{B}_{6}$ (four genes required for 3-amino-1-hydroxyacetone-1-phosphate synthesis from D-erythrose-4-phosphate are missing) are present in the assembled MAG.

A copper/zinc superoxide dismutase and a catalase-peroxidase gene potentially allow protection from reactive oxygen species. Furthermore, Ca. Udaeobacter sp. encodes for arginine dependent acid resistance and the biosynthesis of cadaverine from L-lysine, which protect against acidic conditions. Regarding proteinogenic amino acid biosynthesis, $\mathrm{Ca}$. Udaeobacter sp. encodes complete synthesis pathways for glycine, alanine, aspartate, glutamate, glutamine, methionine and threonine. The synthesis pathways for asparagine (1/4 enzymes missing), leucine (1/3 enzymes missing), cysteine (1/2 enzymes missing), isoleucine ( $3 / 5$ enzymes missing), arginine (3/8 enzymes missing), phenylalanine (2/3 enzymes missing), tryptophan (1/12 enzymes missing), proline (2/3 enzymes missing), serine (2/3 enzymes missing) and valine (3/4 enzymes missing) are incomplete. The amino acid synthesis pathways for histidine, lysine and tyrosine could not be identified. However, genes for 
two putative amino acid permeases (YdhG), which are predicted to be importers for $\mathrm{H}^{+}$and an undefined amino acid, as well as for three serine/threonine exchangers (SteT) which pump out threonine into the periplasm in exchange for serine, were detected.

\section{Discussion}

The here reported experiments clearly demonstrate that $\mathrm{Ca}$. Udaeobacter representatives show multiresistance and even benefit from the release of antibiotics in soil. This pattern was consistently detected although we considered samples from distinct ecosystems (beech forest, spruce forest, meadows, and pastures) of two different geographic regions. Besides the MAG reported in this study (estimated size, $\sim 3.67 \mathrm{Mbp}$; derived from a forest soil), another relatively small MAG (estimated size, $\sim 2.81 \mathrm{Mbp}$; derived from a prairie soil) of a $\mathrm{Ca}$. Udaeobacter representative ( $\mathrm{Ca}$. Udaeobacter copiosus), which indicates multiple amino acid and vitamin auxotrophies, has been described $(1,9)$. Ubiquitous soil bacteria are generally known to have larger genomes in order to cope with the highly variable and rapidly changing environmental conditions in their terrestrial habitat (1, 10-12). According to Brewer et al. (1), Ca. Udaeobacter copiosus might undergo streamlining processes to reduce the metabolic expense for synthesizing costly amino acids and vitamins, which are potentially acquired from the soil environment. The here assembled MAG of Ca. Udaeobacter sp. is missing enzymes of 13 amino acid synthesis pathways. On the other hand, 7 amino acid synthesis pathways are completely encoded. Nevertheless, it remains questionable, whether the missing enzymes of the respective biosynthetic pathways infer an amino acid auxotrophy, as Price et al. (13) have shown, that many missing enzymes from amino acid synthesis pathways can be filled and are predicted due to knowledge gaps in this field. However, the detected amino acid permeases and serine/threonine exchangers imply a dependency on extracellular amino acids or at least advantages of amino acid uptake for the growth of the Ca. Udaeobacter representative described in this study. Regarding vitamin biosynthesis, Ca. Udaeobacter sp. encodes salvage pathways for vitamin $B_{1}, B_{12}$ and $B_{9}$, as well as transporter proteins for the import of vitamin $B_{12}$. These indications, together with our experimental findings, showing that the abundance of Ca. Udaeobacter strongly increased in microcosms treated with antibiotics, points to an efficient utilization of nutrients from soil (e.g. vitamins and amino acids) upon release of antimicrobial 
substances. In this context, a scavenging lifestyle of antibiotic resistant cheater cells, proposed by Leisner, et al. (3), for environmental bacteria residing in nutrient-deprived habitats, appears quite likely with respect to members of $\mathrm{Ca}$. Udaeobacter. This would explain the strong increase of Ca. Udaeobacter abundance in coniferous and deciduous forest as well as grassland soil microcosms, treated with antibiotics. Notably, the treatment of soil with one and three antibiotics in high concentration evoked a similar increase in Ca. Udaeobacter abundance after three days of incubation (Fig. 1 and Fig. S1). This might be due to the fact that in both cases only one bactericidal antibiotic (amoxicillin) was applied, which in contrast to bacteriostatic antibiotics kills bacteria. When a second bactericidal antibiotic was added (ciprofloxacin), a stronger increase in Ca. Udaeobacter abundance could be identified after an incubation period of three days. This observation supports our theory that Ca. Udaeobacter acquires nutrients released from cells, which are killed and consequently lysed by antimicrobial compounds. With respect to treatment of soil with antibiotics in low concentration, a similar pattern was observed after a period of eight days. Moreover, it can be assumed that the treatment effect, inducing elevated $\mathrm{Ca}$. Udaeobacter abundance, declined after prolonged incubation, as added antibiotics are degraded and therefore antimicrobial-driven cell lysis decreased over time.

For protection against the variety of antimicrobials, released by antibiotic producers, and to maintain efficient scavenging in soil, multi-resistance can be considered as elementary feature of cheater cells, taking advantage of lysed cells. Accordingly, the Ca. Udaeobacter sp. MAG reported in this study encodes many multi-drug efflux pumps (mostly MdtABC efflux system and $A B C$ transporter subunits), macrolide efflux pumps (MacB ABC transporter subunits), and beta-lactam as well as other resistance genes (Table S5). This finding is supported by Forsberg et al. (4), who reported an enrichment of betalactam resistance genes within Verrucomicrobia. With respect to Ca. Udaeobacter, its ARG repertoire in combination with efficient uptake of nutrients, released by antimicrobial-driven cell lysis, potentially enables the proposed scavenging lifestyle and confers advantages over other soil bacteria upon antibiotics release.

As we could only identify few putative genes associated with secondary metabolite biosynthesis encoded in the $\mathrm{Ca}$. Udaeobacter sp. MAG, it seems unlikely that $\mathrm{Ca}$. Udaeobacter representatives produce different antibiotics, which require large polyketide and nonribosomal peptide biosynthetic gene clusters. This theory is supported by potential genome streamlining and the so far described relatively 
small Ca. Udaeobacter genomes. It seems much more plausible that $\mathrm{Ca}$. Udaeobacter obtains nutrients from cell lysis evoked by antibiotic producers without high energetic cost associated with the synthesis of antimicrobial compounds.

Regarding the central metabolism, the encoded glyoxylate bypass might be advantageous with respect to bactericidal antibiotics as it provides a means against oxidative stress. Bactericidal drugs cause a higher production of NADH through the TCA cycle which results in a higher proportion of superoxide, formed as a consequence of respiratory chain oxidation driven by oxygen and the conversion of NADH to $\operatorname{NAD}^{+}(14,15)$. Superoxides on the other hand cause iron leaching from iron-sulfur clusters and iron participates in the conversion of superoxide to hydroxyl radicals in the Fenton reaction (14). Hydroxyl radicals are extremely toxic and damage cellular proteins, lipids and DNA which leads to cell death and lysis (14). Bypassing the complete TCA cycle by the glyoxylate shunt reduces NADH production and causes a reduced sensitivity towards bactericidal antibiotics (16). Ca. Udaeobacter encodes for two enzymes (A copper/zinc superoxide dismutase and a catalase-peroxidase) that convert superoxide to oxygen, which might also have a positive effect on the sensitivity towards bactericidal antibiotics. Another potential feature of $\mathrm{Ca}$. Udaeobacter $\mathrm{sp}$. is the aerobic oxidation of hydrogen indicated by genes for an Ni-Fe-S hydrogenase enzyme complex and an additional soluble hydrogenase. Thus, Ca. Udaeobacter sp. probably has the ability to scavenge atmospheric $\mathrm{H}_{2}$ for energy production. This feature has been observed for Acidobacteria as well and was proposed as "general mechanism for dominant soil phyla to generate the maintenance energy required for long-term survival" (17). As approximately $30 \%$ of the world's soils are acidic (18), the acid resistance mechanisms (biosynthetic arginine decarboxylase and putative lysine decarboxylase) that were detected in the here assembled MAG might contribute to the global dissemination of $\mathrm{Ca}$. Udaeobacter. These mechanisms could increase the tolerance against acidic conditions, for example in some forest soils, and provide an advantage over other soil bacteria.

Our study illustrates that a group of ubiquitous soil bacteria, Ca. Udaeobacter, thrives upon release of multiple classes of antibiotics. These bacteria evade growth-inhibiting and lethal effects of antimicrobials, supporting our hypotheses, and, importantly, even take advantage of antibiotic pressure. Thus, steadily increasing global antibiotic consumption and an associated rising environmental pollution with antimicrobials might be advantageous for $\mathrm{Ca}$. Udaeobacter representatives. Furthermore, we 
found that a representative of $\mathrm{Ca}$. Udaeobacter encodes enzymes for hydrogen oxidation, supporting the hypothesis that trace gas scavenging might be a general mechanism of ubiquitous soil bacteria, to generate energy for a stable maintenance in soil. To more specifically target this verrucomicrobial group in future studies, the 16S rRNA gene-based primer pair described here will be valuable. For example, insights into the $\mathrm{Ca}$. Udaeobacter phylotype composition in various soil ecosystems can be gained via sequencing of amplicons generated using the UDBAC primers. Another important step with respect to the analysis of $\mathrm{Ca}$. Udaeobacter will be the cultivation of representatives belonging to this dominant group of soil bacteria. For instance, cultivates could be used to analyze potential hydrogenase activity of $\mathrm{Ca}$. Udaeobacter. Moreover, the findings presented in our study indicate that application of antibiotics can contribute to a successful enrichment of $\mathrm{Ca}$. Udaeobacter representatives.

\section{Materials and Methods}

\section{Sampling and soil characteristics}

Soil samples (the upper $10 \mathrm{~cm}$ of the mineral soil) were derived from plots of the German Biodiversity Exploratories Hainich-Dün (central Germany) and Schwäbische Alb (southwestern Germany) (19) in May 2017, as described by Solly et al. (20). Each study region covers the land use types forest and grassland. Grassland plots are $50 \mathrm{~m} \times 50 \mathrm{~m}$ and forest plots are $100 \mathrm{~m} \times 100 \mathrm{~m}$ in size. Detailed information on land use, dominant tree species and fertilization for every plot is provided in Table S1. The gravimetric water content of the soil was determined by drying $10 \mathrm{~g}$ at $105^{\circ} \mathrm{C}$ for $24 \mathrm{~h}$. The $\mathrm{pH}$ of each soil was determined as described by Solly et al. (20). For soil incubations, water contents of fresh soil samples were adjusted with deionized water to $60 \%$ water holding capacity (WHC) as the optimum water content for carbon mineralization usually falls in this range (21). The total WHC (equal to $100 \%$ WHC) was determined in the laboratory by means of disturbed soil samples. Fifteen $\mathrm{g}$ of fresh soil was filled in $10 \mathrm{~cm}$ high funnels which were placed in deionized water overnight until the soil was saturated with water by capillary rise. After the soil samples have been drained on sand for several hours, the soil was oven-dried at $105^{\circ} \mathrm{C}$ to a constant weight and the soil water content at total WHC was determined. Taking into account the water contents of fresh soil samples, the amount of water that had to be added to the incubated samples to reach $60 \%$ WHC was then calculated. 
All soils for the microcosm experiment were chromatographically analyzed for residues of 77 different antibiotics by JenaBios company (Jena, Germany) (Table S2).

\section{Microcosm incubations}

The water content of soil derived from the selected plots was adjusted to $60 \%$ of its water holding capacity and subsamples were frozen at $-80^{\circ} \mathrm{C}$ in order to enable analysis of soil bacterial communities at the beginning of the microcosm experiment. Subsequently, the soil was treated with six antibiotics, three antibiotics or one antibiotic in high and low concentration. This procedure was performed in triplicate. The concentrations of the used antibiotics were selected based on previous microcosm experiments (22-26). Concentrations of 10 and $100 \mathrm{mg} / \mathrm{kg}$ soil of amoxicillin (Sigma-Aldrich, Steinheim, Germany), oxytetracycline dihydrate (Sigma-Aldrich), sulfadiazine (Sigma-Aldrich), trimethoprim (Sigma-Aldrich) and tylosin tartrate (Sigma-Aldrich), as well as concentrations of 5 and $50 \mathrm{mg} / \mathrm{kg}$ soil of ciprofloxacin (Sigma-Aldrich) were used for treatment with six different antibiotics. For the treatment with three antibiotics (amoxicillin, oxytetracycline dihydrate and sulfadiazine) or one antibiotic (amoxicillin), we also used concentrations of 10 and $100 \mathrm{mg} / \mathrm{kg}$ soil. Due to insufficient solubility in water, all antibiotics, except tylosin, were spiked onto soil in solid form. Tylosin was dissolved in sterile $\mathrm{H}_{2} \mathrm{O}$ prior to soil treatment. Organic solvents were avoided as they can potentially impact soil microbial communities (23). The antibiotics were distributed in soil by vigorous mixing. Subsequently, microcosms containing $10 \mathrm{~g}$ of soil were prepared in $100 \mathrm{ml}$ bulk flasks and incubated in the dark at $20^{\circ} \mathrm{C}$. Flasks containing $10 \mathrm{~g}$ of soil, which was not treated with antibiotics, served as control (set up in duplicate). The microcosms were aerated every third day to ensure oxygen supply and the water content was ascertained to be stable via regular weighing. After 3,8 and 20 days, samples were taken $(1.25 \mathrm{~g})$ and stored at $-80^{\circ} \mathrm{C}$ for subsequent analysis.

\section{DNA extraction and sequencing of 16S rRNA gene amplicons}

Soil microbial community DNA was isolated from a total of 628 microcosm samples by using the DNeasy PowerSoil Kit (Qiagen, Hilden, Germany) according to the manufacturer's instructions. Subsequently, the DNA concentration was measured by employing the Qubit dsDNA Broad-Range Assay Kit (Thermo 
Fisher Scientific, Braunschweig, Germany) and a Qubit 3.0 Fluorometer (Thermo Fisher Scientific) following the manufacturer's instructions.

The V3-V4 region of the 16S rRNA genes was amplified by PCR, using the extracted DNA from the 628 microcosm samples and the primer pair Bact-0341-b-S-17 and S-D-Bact-0785-a-A-21 (27) with modifications for Illumina MiSeq sequencing described by Schneider et al. (28). Each PCR reaction $(50 \mu \mathrm{l})$ contained $10 \mu \mathrm{l} 5 \times$ Phusion GC buffer (Thermo Fisher Scientific), $25 \mathrm{ng}$ template DNA, $0.2 \mu \mathrm{M}$ of each primer, $0.2 \mathrm{mM}$ of each deoxynucleoside triphosphate, $0.15 \mathrm{mM} \mathrm{MgCl}_{2}$ and $1 \mathrm{U}$ Phusion HighFidelity DNA Polymerase (Thermo Fisher Scientific). PCR reactions were initiated at $98^{\circ} \mathrm{C}$ for 1 min, followed by 25 cycles of $98^{\circ} \mathrm{C}$ for $45 \mathrm{~s}, 66^{\circ} \mathrm{C}$ for $45 \mathrm{~s}$ and $72^{\circ} \mathrm{C}$ for $30 \mathrm{~s}$. The reaction ended with a final elongation step at $72^{\circ} \mathrm{C}$ for $5 \mathrm{~min}$.

Amplicons were purified with a magnetic bead purification by the automated work station Janus (PerkinElmer, Downers Grove, IL, USA) with a bead (MagSi-NGSPREP Plus - Magnetic Beads, Steinbrenner, Wiesenach, Germany) to sample ratio of 1:1. Subsequently, indexes were added at both ends of the amplicons as described by Schneider et al. (28). Sequencing of the V3-V4 region of the 16S rRNA genes was carried out using an Illumina MiSeq sequencer in paired-end mode and the MiSeq Reagent Kit v3 (600 cycles).

\section{Amplicon sequence data processing and statistical analysis}

The raw sequences were demultiplexed and sequencing adapters clipped by employing the data analysis software CASAVA (Illumina, San Diego, CA, USA). PEAR v.0.9.10 (29) was used for merging of paired-end reads, and sequences with a lower quality score than 20 or with unresolved bases were removed by applying the split_library_fastq.py script provided by QIIME 1.9.1 (30). Remaining forward and reverse primer sequences were removed using cutadapt 1.10 (31) with default settings. Reads $\geq$ $380 \mathrm{bp}$ were clustered into amplicon sequence variants (ASVs) (32) with the UNOISE2 algorithm (33) of USEARCH (34), which includes sequence error correction and de-novo chimera removal. Additional chimera removal was conducted via UCHIME (35) using the SILVA SSU database (36) (release 132) as reference. Subsequently, all quality-filtered sequences were mapped on the ASVs to determine the respective read abundance. For taxonomic classification, the ASVs were blasted against the SILVA SSU database (release 132) using the QIIME script parallel_assign_taxonomy_blast.py. Extrinsic 
domain ASVs, mitochondria, chloroplasts and unclassified ASVs were removed by employing the QIIME script filter_otu_table.py. Datasets rarefied via QIIME script single_rarefaction.py to 10,000 sequences per sample were utilized for linear mixed effect regression analysis.

The effect of antibiotic treatment on $\mathrm{Ca}$. Udaeobacter was statistically analyzed using linear mixed effect models, constructed with the R version 3.5 .3 (37) and the R library Ime4 (38). In this context, the logarithm of the abundance of $\mathrm{Ca}$. Udaeobacter served as response variable, the concentration of antibiotics for treatment and the days of incubation as fixed effects, and the microcosm ID as well as the sample plot ID represented nested random effects. Furthermore, six additional models were constructed to test for significance of each treatment variation (treatment with one antibiotic, three antibiotics and six antibiotics in high and low concentration), whereat each of the six treatments served as independent fixed effect along with the days of incubation and the nested random effects. The residuals were tested for normality and constant variance with quantile-quantile plots and residual plots using the diagnostics plots function in R. Independent variables were selected by considering collinearity, significance and explanatory power based on $p$-values, $R^{2} m$ and $R^{2} c$, calculated with the ImerTest library (39) and the r.squaredGLMM function of the MuMIn library (40). The p-values of the fixed and random effects were calculated with the Satterthwaite's method and the Chi square test of the anova function, respectively. All model formulas, sample sizes, corresponding p-values, estimates, degrees of freedom and $\mathrm{R}^{2}$ of the conducted linear regressions are listed in Table S3.

\section{Design and evaluation of $\mathrm{Ca}$. Udaeobacter-specific primers}

Primers for targeted detection of bacteria belonging to $\mathrm{Ca}$. Udaeobacter were designed based on the $16 S$ rRNA gene of the verrucomicrobial phylotype DA101 (41) using primer blast (42). An in silico PCR analysis was conducted using TestPrime 1.0 and the SILVA SSU database $(27,36)$ (release 132) as reference to evaluate the specificity of designed primers. The primer pair comprising UDBAC_F (5'CCAGAAGAGGAAGAGACGGC-3') and UDBAC_R (5'-GTCCTCAAGCACGGCAGTAT-3') was used for further validation of specificity via multiplex sequencing. In this context, MiSeq overhangs described by Schneider et al. (28) were attached to each primer and amplicons for MiSeq sequencing were produced via PCR. 
Each PCR reaction $(50 \mu \mathrm{l})$ was set up in triplicate and contained $10 \mu \mathrm{l} 5 \times$ Phusion HF buffer (Thermo Fisher Scientific), $25 \mathrm{ng}$ template DNA, $0.2 \mu \mathrm{M}$ of each primer, $0.2 \mathrm{mM}$ of each deoxynucleoside triphosphate, $1 \mathrm{mM} \mathrm{MgCl} 2$ and $1 \mathrm{U}$ Phusion High-Fidelity DNA Polymerase (Thermo Fisher Scientific). DNA extracted from all soils used for microcosm preparation and samples incubated for three days upon treatment with six antibiotics in high concentration served as templates within the PCR. The cycler program started with an initial denaturation at $98^{\circ} \mathrm{C}$ for $1 \mathrm{~min}$ followed by 25 cycles of denaturation for $10 \mathrm{~s}$ at $98^{\circ} \mathrm{C}$, annealing at $58^{\circ} \mathrm{C}$ for $30 \mathrm{~s}$ and elongation at $72^{\circ} \mathrm{C}$ for $10 \mathrm{~s}$. The final elongation step was carried out at $72^{\circ} \mathrm{C}$ for $5 \mathrm{~min}$. Generated amplicons were purified and indexed as described above. Sequencing was carried out using an Illumina MiSeq sequencer in paired-end mode and the MiSeq Reagent Kit v3 (600 cycles).

Bioinformatic processing of the raw data was performed as described above, except that reads shorter than $113 \mathrm{bp}$ and longer than $153 \mathrm{bp}$ were discarded with cutadapt 1.10 .

\section{Quantification of Ca. Udaeobacter 16S rRNA genes}

Quantitative real-time PCR ( $\mathrm{PPCR}$ ) using primer pair UDBAC was conducted to estimate the absolute abundance of $\mathrm{Ca}$. Udaeobacter $16 \mathrm{~S}$ rRNA genes in microcosms. In a first step, a DNA fragment obtained via PCR using the UDBAC primer set was cloned into vector pCR4-TOPO (Thermo Fisher Scientific) as recommended by the manufacturer, to serve as standard for qPCR. To confirm that a partial Ca. Udaeobacter 16S rRNA gene has been cloned into this vector, the insert sequence was determined by Microsynth Seqlab (Göttingen, Germany) using Sanger sequencing technology. The $16 \mathrm{~S}$ rRNA genes of $\mathrm{Ca}$. Udaeobacter representatives were quantified using an icycler iQ5 (Bio-Rad, Hercules, CA, USA), with the QuantiNova SYBR Green PCR kit (Qiagen). Each reaction had a final volume of $20 \mu$ with $10 \mu \mathrm{l}$ of $2 \times$ QuantiNova SYBR Green RT-PCR Master Mix, $0.7 \mu \mathrm{M}$ of each primer and $12.5 \mathrm{ng}$ DNA template. DNA from untreated control samples and samples treated with six different antibiotics in high concentration served as template. The amplification was conducted as recommended by the manufacturer with an initial activation step at $95^{\circ} \mathrm{C}$ for $2 \mathrm{~min}$, followed by 40 cycles of denaturation at $95^{\circ} \mathrm{C}$ for $5 \mathrm{~s}$ and combined annealing and extension at $60^{\circ} \mathrm{C}$ for $10 \mathrm{~s}$. Subsequently, melting curve analysis was conducted to ensure specific amplification. 
Scatterplots depicting the 16S rRNA gene abundance of $\mathrm{Ca}$. Udaeobacter per ng DNA in response to antibiotic treatment and sampling days were produced by employing R. In this context, a smoothed curve was generated using the loess.smooth function. The effect of the antibiotic treatment on the absolute 16S rRNA gene abundance after three days of incubation was statistically analyzed with a linear mixed effect model, as described above, whereat the logarithm of the 16S rRNA gene copies per ng DNA served as response variable, the antibiotic treatment as fixed effect and the sample plot ID as random effect.

\section{Cell extraction, sequencing and hybrid assembly of a $\mathrm{Ca}$. Udaeobacter MAG}

A frozen $\left(-20^{\circ} \mathrm{C}\right)$ forest soil sample (AEW3) was chosen as target for $\mathrm{Ca}$. Udaeobacter genome bin assembly. Cells were extracted from the soil matrix prior to DNA extraction and sequencing. For this purpose, $100 \mathrm{~g}$ frozen soil was added to $200 \mathrm{ml}$ MES buffer (pH 5.5), supplemented with $0.24 \mathrm{M} \mathrm{NH}_{4} \mathrm{Cl}$ and $100 \mathrm{mg} / \mathrm{kg}$ amoxicillin. Subsequently, the suspension was vigorously mixed with a hand mixer for eight minutes. After an incubation of $20 \mathrm{~h}$ at $160 \mathrm{rpm}$ and $20^{\circ} \mathrm{C}$, mixing was repeated and soil particles were separated from the dissociated cells by centrifugation at $1,000 \times g$ for $10 \mathrm{~min}$ at $4^{\circ} \mathrm{C}$. Afterwards, the cells in the supernatant were pelleted at $10,000 \times g$ for $30 \mathrm{~min}$ at $4^{\circ} \mathrm{C}$ and resuspended in $10 \mathrm{ml}$ MES buffer. The cell suspension was pipetted onto $10 \mathrm{ml}^{\text {OptiPrep }}{ }^{\mathrm{TM}}$ Density Gradient Medium (SigmaAldrich) $\left(1.32 \mathrm{~g} / \mathrm{ml}\right.$ iodixanol) for a density gradient centrifugation at $3,000 \times \mathrm{g}$ for $90 \mathrm{~min}$ at $4^{\circ} \mathrm{C}$. In this way, the living cells were separated from dead cell particles and other (in-)organic contaminants. A thin layer above the OptiPrep layer, containing the living cells, was carefully transferred into a new vial and washed twice with $8 \mathrm{ml}$ MES buffer at $10,000 \times g$ for $30 \mathrm{~min}$ at $4^{\circ} \mathrm{C}$. Finally, the cell suspension was pelleted at $10,000 \times g$ for $1 \mathrm{~h}$ at $4^{\circ} \mathrm{C}$, resuspended in $500 \mu \mathrm{l}$ MES buffer and stored at $4^{\circ} \mathrm{C}$. High molecular weight DNA was isolated with the MasterPure Complete DNA \& RNA Purification Kit (Biozym, Hessisch Oldendorf, Germany) following the instructions in the manual. Quality of isolated DNA was initially checked by agarose gel electrophoresis and validated by using an Agilent Bioanalyzer 2100 and an Agilent DNA 12000 Kit as recommended by the manufacturer (Agilent Technologies, Waldbronn, Germany). Purity of the isolated DNA was checked with a Nanodrop ND-1000 (PeqLab Erlangen, Germany) and subsequently the concentration was determined using the Qubit $\circledast$ dsDNA HS Assay Kit (Life Technologies GmbH, Darmstadt, Germany) and a Qubit 3.0 Fluorometer (Thermo Fisher 
Scientific). Illumina shotgun libraries were prepared using the Nextera DNA Sample Preparation Kit and subsequently sequenced on a MiSeq system with the reagent kit v3 with 600 cycles (Illumina, San Diego, CA, USA). With respect to Oxford Nanopore sequencing, $1.5 \mu \mathrm{g}$ DNA was used for library preparation using the Ligation Sequencing Kit 1D (SQK-LSK109). Sequencing was performed for $72 \mathrm{~h}$ on a MinION device Mk1B using a SpotON Flow Cell R9.4.1, resulting in 16.5 million reads. Low-quality MiSeq reads and sequencing adapters were trimmed by employing trimmomatic version 0.36 in pairedend mode (43). After sequencing and trimmomatic-based quality filtering, 40.8 million MiSeq reads with an average length and paired-end insert size of 222 and $330.5 \mathrm{bp}$, respectively, were available for further processing.

Assembly was conducted by HybridSPades (44) in meta mode with automatically assessed kmer lengths. The resulting contigs were binned into MAGs with MaxBin2 (45) and checked for completeness and contamination with CheckM v1.0.12 (7). The received MAG was reassembled with HybridSPades using automatically assessed kmer lengths and the assembly was revaluated with CheckM and QualiMap v.2.2.1 (46, 47).

Open Reading Frames (ORFs) were predicted and annotated using PROKKA version 1.13.4 (48). The relative abundance of an ASV, closely related to the PROKKA annotated 16S rRNA gene in the assembled MAG, was tested for significant rise in relative abundance upon antibiotic treatment over the time course of the microcosm experiment with a linear mixed model, where the ASV abundance served as response variable, the concentration of antibiotics for treatment and the days of incubation as fixed effects, and the microcosm ID as well as the sample plot ID represented nested random effects (Table S3). Subsequently, the MAG was analyzed in terms of energy metabolism, amino acid auxotrophies and environmental stress response via the PathoLogic (49) component of the Pathway Tools software (50) version 23.5 and the MetaCyc database (51). The encoded proteins were screened for annotated ARGs and MGEs. In addition, putatively novel resistance mechanisms were identified with deepARG (52) using a minimal sequence identity of $30 \%$ and a probability of over $90 \%$ as thresholds. Additional MGEs were identified via DIAMOND blastx (-e 0.00001 --id 50 --subject-cover 50) against the MGE database of nanoARG (53). Furthermore, the MAG was screened for secondary metabolite biosynthesis clusters via antiSMASH 5.1 (54). 


\section{Phylogenetic analysis}

A phylogenetic tree was constructed using MEGA X (55) based on 16S rRNA gene sequences of the here assembled MAG and other verrucomicrobial representatives. A total of 23 nucleotide sequences were aligned with MUSCLE (56) and the tree was calculated with 500 iterations by using the Maximum Likelihood method and the Tamura-Nei model (57). Furthermore, the partial deletion option with a site coverage cutoff of $90 \%$ was used and the tree was rooted with the 16S rRNA gene sequence of Escherichia coli K-12 MG1655.

The phylogenetic relation of the here assembled MAG to other draft genomes stored in the GTDB database (58) as well as $\mathrm{Ca}$. Udaeobacter copiosus was calculated based on the occurrence and amino acid sequence of 120 marker genes. The marker gene sequences identified by GTDB-tk (59) of all Chthoniobacterales included in the analysis (Table S4), were aligned with MUSCLE and used for calculation of a phylogenetic tree with 500 iterations by using the Neighbor-Joining Method (60). Evolutionary distances were computed using the JTT matrix-based method (61) and the partial deletion option with a site coverage cutoff of $90 \%$ was applied. Finally, the tree was rooted based on the $16 \mathrm{~S}$ rRNA gene sequence of $E$. coli UMN026 (GCA_000026325.2).

Additionally, the closest relative of our MAG was identified via FastANI based on whole-genome average nucleotide identity (62).

\section{Data availability}

The 16S rRNA gene-based amplicon sequencing data generated in this study were deposited in the Sequence Read Archive (SRA) of the NCBI under the accession number SRP226057 (bioproject accession: PRJNA576637). The Ca. Udaeobacter sp. genome bin is publicly available at the NCBI under bioproject accession number PRJNA605948 (SUB6956007). Raw sequences from which the Ca. Udaeobacter sp. genome bin was assembled are availiable at the SRA under accession number SRP249494 (bioproject accession: PRJNA605948). 


\section{References}

1. Brewer T, Handley K, Carini P, Gibert J, Fierer N. 2016. Genome reduction in an abundant and ubiquitous soil bacterium 'Candidatus Udaeobacter copiosus'. Nat Microbiol 2: 16198.

2. Bergmann GT, Bates ST, Eilers KG, Lauber CL, Caporaso JG, Walters WA, Knight R, Fierer N. 2011. The under-recognized dominance of Verrucomicrobia in soil bacterial communities. Soil Biol Biochem 43:1450-1455.

3. Leisner JJ, Jørgensen NOG, Middelboe M. 2016. Predation and selection for antibiotic resistance in natural environments. Evol Appl 9:427-434.

4. Forsberg KJ, Patel S, Gibson MK, Lauber CL, Knight R, Fierer N, Dantas G. 2014. Bacterial phylogeny structures soil resistomes across habitats. Nature 509:612-616.

5. Crits-Christoph A, Diamond S, Butterfield CN, Thomas BC, Banfield JF. 2018. Novel soil bacteria possess diverse genes for secondary metabolite biosynthesis. Nature 558:440-444.

6. Větrovský T, Baldrian P. 2013. The Variability of the 16 S rRNA Gene in Bacterial Genomes and Its Consequences for Bacterial Community Analyses. PLoS One 8:e57923.

7. Parks DH, Imelfort M, Skennerton CT, Hugenholtz P, Tyson GW. 2015. CheckM: assessing the quality of microbial genomes recovered from isolates, single cells, and metagenomes. Genome Res 25:1043-55.

8. Konstantinidis KT, Tiedje JM. 2005. Genomic insights that advance the species definition for prokaryotes. Proc Natl Acad Sci U S A 102:2567-2572.

9. Delgado-Baquerizo M, Oliverio AM, Brewer TE, Benavent-González A, Eldridge DJ, Bardgett RD, Maestre FT, Singh BK, Fierer N. 2018. A global atlas of the dominant bacteria found in soil. Science 359:320-325.

10. Fierer N. 2017. Embracing the unknown: disentangling the complexities of the soil microbiome. Nat Rev Microbiol 15:579-590.

11. Cobo-Simón M, Tamames J. 2017. Relating genomic characteristics to environmental preferences and ubiquity in different microbial taxa. BMC Genomics 18:499.

12. Land M, Hauser L, Jun S-R, Nookaew I, Leuze MR, Ahn T-H, Karpinets T, Lund O, Kora G, Wassenaar T, Poudel S, Ussery DW. 2015. Insights from 20 years of bacterial genome sequencing. Funct Integr Genomics 15:141-61. 
13. Price MN, Zane GM, Kuehl J V., Melnyk RA, Wall JD, Deutschbauer AM, Arkin AP. 2018. Filling gaps in bacterial amino acid biosynthesis pathways with high-throughput genetics. PLOS Genet 14:e1007147.

14. Kohanski MA, Dwyer DJ, Hayete B, Lawrence CA, Collins JJ. 2007. A Common Mechanism of Cellular Death Induced by Bactericidal Antibiotics. Cell 130:797-810.

15. Vinogradov AD, Grivennikova VG. 2016. Oxidation of NADH and ROS production by respiratory complex i. Biochim Biophys Acta 1857:863-871.

16. Ahn S, Jung J, Jang IA, Madsen EL, Park W. 2016. Role of glyoxylate shunt in oxidative stress response. J Biol Chem 291:11928-11938.

17. Greening C, Carere CR, Rushton-Green R, Harold LK, Hards K, Taylor MC, Morales SE, Stott MB, Cook GM. 2015. Persistence of the dominant soil phylum Acidobacteria by trace gas scavenging. Proc Natl Acad Sci U S A 112:10497-10502.

18. Uexküll HR, Mutert E.1995. Global extent, development and economic impact of acid soils, p 519. In Date RA, Grundon NJ, Raymet GE, Probert ME (ed), Plant-Soil Interactions at low pH: Principles and Management. Kluwer Acad. Publ, Dordrecht, Netherlands.

19. Fischer M, Bossdorf O, Gockel S, Hänsel F, Hemp A, Hessenmöller D, Korte G, Nieschulze J, Pfeiffer S, Prati D, Renner S, Schöning I, Schumacher U, Wells K, Buscot F, Kalko EKV, Linsenmair KE, Schulze E-D, Weisser WW. 2010. Implementing large-scale and long-term functional biodiversity research: The Biodiversity Exploratories. Basic Appl Ecol 11:473-485.

20. Solly EF, Schöning I, Boch S, Kandeler E, Marhan S, Michalzik B, Müller J, Zscheischler J, Trumbore SE, Schrumpf M. 2014. Factors controlling decomposition rates of fine root litter in temperate forests and grasslands. Plant Soil 382:203-218.

21. Rey A, Petsikos C, Jarvis PG, Grace J. 2005. Effect of temperature and moisture on rates of carbon mineralization in a Mediterranean oak forest soil under controlled and field conditions. Eur J Soil Sci 56:589-599.

22. Binh CTT, Heuer H, Gomes NCM, Kotzerke A, Fulle M, Wilke B-M, Schloter M, Smalla K. 2007. Short-term effects of amoxicillin on bacterial communities in manured soil. FEMS Microbiol Ecol 62:290-302. 
23. Vaclavik E, Halling-Sørensen B, Ingerslev F. 2004. Evaluation of manometric respiration tests to assess the effects of veterinary antibiotics in soil. Chemosphere 56:667-76.

24. Ding G-C, Radl V, Schloter-Hai B, Jechalke S, Heuer H, Smalla K, Schloter M. 2014. Dynamics of Soil Bacterial Communities in Response to Repeated Application of Manure Containing Sulfadiazine. PLoS One 9:e92958.

25. Čermák L, Kopecký J, Novotná J, Omelka M, Parkhomenko N, Plháčková K, SágováMarečková M. 2008. Bacterial communities of two contrasting soils reacted differently to lincomycin treatment. Appl Soil Ecol 40: 348-358.

26. Liu F, Ying G, Tao R, Zhao J, Yang J, Zhao L. 2009. Effects of six selected antibiotics on plant growth and soil microbial and enzymatic activities. Environ Pollut 157:1636-1642.

27. Klindworth A, Pruesse E, Schweer T, Peplies J, Quast C, Horn M, Glöckner FO. 2013. Evaluation of general $16 \mathrm{~S}$ ribosomal RNA gene PCR primers for classical and next-generation sequencing-based diversity studies. Nucleic Acids Res 41:e1.

28. Schneider D, Thürmer A, Gollnow K, Lugert R, Gunka K, Groß U, Daniel R. 2017. Gut bacterial communities of diarrheic patients with indications of Clostridioides difficile infection. Sci Data 4:170152.

29. Zhang J, Kobert K, Flouri T, Stamatakis A. 2014. PEAR: a fast and accurate Illumina PairedEnd reAd mergeR. Bioinformatics 30:614-620.

30. Caporaso JG, Kuczynski J, Stombaugh J, Bittinger K, Bushman FD, Costello EK, Fierer N, Peña AG, Goodrich JK, Gordon JI, Huttley GA, Kelley ST, Knights D, Koenig JE, Ley RE, Lozupone CA, McDonald D, Muegge BD, Pirrung M, Reeder J, Sevinsky JR, Turnbaugh PJ, Walters WA, Widmann J, Yatsunenko T, Zaneveld J, Knight R. 2010. QIIME allows analysis of high-throughput community sequencing data. Nat Methods 7:335-336.

31. Martin M. 2011. Cutadapt removes adapter sequences from high-throughput sequencing reads. EMBnet J 17:10.

32. Callahan BJ, McMurdie PJ, Holmes SP. 2017. Exact sequence variants should replace operational taxonomic units in marker-gene data analysis. ISME J 11:2639-2643.

33. Edgar RC. 2016. UNOISE2: improved error-correction for Illumina $16 \mathrm{~S}$ and ITS amplicon sequencing. bioRxiv 21. 
34. Rognes T, Flouri T, Nichols B, Quince C, Mahé F. 2016. VSEARCH: a versatile open source tool for metagenomics. PeerJ 4:e2584.

35. Edgar RC, Haas BJ, Clemente JC, Quince C, Knight R. 2011. UCHIME improves sensitivity and speed of chimera detection. Bioinformatics 27:2194-2200.

36. Yilmaz P, Parfrey LW, Yarza P, Gerken J, Pruesse E, Quast C, Schweer T, Peplies J, Ludwig W, Glöckner FO. 2014. The SILVA and "All-species Living Tree Project (LTP)" taxonomic frameworks. Nucleic Acids Res 42:D643-D648.

37. R Core Team. 2016. R: A Language and Environment for Statistical Computing. 3.3.1. Vienna, Austria. http://www.r-project.org/index.html. Retrieved 6 Dec 2019.

38. Bates D, Mächler M, Bolker B, Walker S. 2015. Fitting Linear Mixed-Effects Models Using Ime4. J Stat Softw 67.

39. Kuznetsova A, Brockhoff PB, Christensen RHB. 2017. ImerTest Package: Tests in Linear Mixed Effects Models. J Stat Softw 82.

40. Bartoń K. 2018. MuMln: Multi-Model Inference. https://cran.rproject.org/web/packages/MuMIn/. Retrieved 6 Dec 2019.

41. Felske, Akkermans. 1998. Prominent occurrence of ribosomes from an uncultured bacterium of the Verrucomicrobiales cluster in grassland soils. Lett Appl Microbiol 26:219-223.

42. Ye J, Coulouris G, Zaretskaya I, Cutcutache I, Rozen S, Madden TL. 2012. Primer-BLAST: A tool to design target-specific primers for polymerase chain reaction. BMC Bioinformatics 13:134.

43. Bolger AM, Lohse M, Usadel B. 2014. Trimmomatic: a flexible trimmer for Illumina sequence data. Bioinformatics 30:2114-2120.

44. Antipov D, Korobeynikov A, McLean JS, Pevzner PA. 2016. hybridSPAdes: an algorithm for hybrid assembly of short and long reads. Bioinformatics 32:1009-1015.

45. Wu YW, Simmons BA, Singer SW. 2015. MaxBin 2.0: An automated binning algorithm to recover genomes from multiple metagenomic datasets. Bioinformatics 32: 605-607.

46. García-Alcalde F, Okonechnikov K, Carbonell J, Cruz LM, Götz S, Tarazona S, Dopazo J, Meyer TF, Conesa A. 2012. Qualimap: evaluating next-generation sequencing alignment data. Bioinformatics 28:2678-2679. 
47. Okonechnikov K, Conesa A, García-Alcalde F. 2015. Qualimap 2: advanced multi-sample quality control for high-throughput sequencing data. Bioinformatics 32:btv566.

48. Seemann T. 2014. Prokka: rapid prokaryotic genome annotation. Bioinformatics 30:2068-9.

49. Karp PD, Latendresse M, Caspi R. 2011. The pathway tools pathway prediction algorithm. Stand Genomic Sci 5:424-429.

50. Karp PD, Latendresse M, Paley SM, Krummenacker M, Ong QD, Billington R, Kothari A, Weaver D, Lee T, Subhraveti P, Spaulding A, Fulcher C, Keseler IM, Caspi R. 2016. Pathway tools version 19.0 update: Software for pathway/genome informatics and systems biology. Brief Bioinform 17:877-890.

51. Caspi R, Billington R, Keseler IM, Kothari A, Krummenacker M, Midford PE, Ong WK, Paley S, Subhraveti P, Karp PD. 2019. The MetaCyc database of metabolic pathways and enzymes - a 2019 update. Nucleic Acids Res 48:D445-D453.

52. Arango-Argoty G, Garner E, Pruden A, Heath LS, Vikesland P, Zhang L. 2018. DeepARG: a deep learning approach for predicting antibiotic resistance genes from metagenomic data. Microbiome 6:23.

53. Arango-Argoty GA, Dai D, Pruden A, Vikesland P, Heath LS, Zhang L. 2019. NanoARG: a web service for detecting and contextualizing antimicrobial resistance genes from nanopore-derived metagenomes. Microbiome 7:88.

54. Blin K, Shaw S, Steinke K, Villebro R, Ziemert N, Lee SY, Medema MH, Weber T. 2019. antiSMASH 5.0: updates to the secondary metabolite genome mining pipeline. Nucleic Acids Res 47:W81-W87.

55. Kumar S, Stecher G, Li M, Knyaz C. 2018. MEGA X: Molecular Evolutionary Genetics Analysis across computing platforms. Mol Biol Evol 35:1547-1549.

56. Edgar RC. 2004. MUSCLE: multiple sequence alignment with high accuracy and high throughput. Nucleic Acids Res 32:1792-7.

57. Tamura K, Nei M. 1993. Estimation of the number of nucleotide substitutions in the control region of mitochondrial DNA in humans and chimpanzees. Mol Biol Evol 10:512-526. 
58. Parks DH, Chuvochina M, Waite DW, Rinke C, Skarshewski A, Chaumeil P-A, Hugenholtz P. 2018. A standardized bacterial taxonomy based on genome phylogeny substantially revises the tree of life. Nat Biotechnol 36:996.

59. Chaumeil P-A, Mussig AJ, Hugenholtz P, Parks DH. 2019. GTDB-Tk: a toolkit to classify genomes with the Genome Taxonomy Database. Bioinformatics.

60. Saitou N, Nei M. 1987. The neighbor-joining method: A new method for reconstructing phylogenetic trees. Mol Biol Evol 4:406-25.

61. Jones DT, Taylor WR, Thornton JM. 1992. The rapid generation of mutation data matrices from protein sequences. Bioinformatics 8:275-282.

62. Jain C, Rodriguez-R LM, Phillippy AM, Konstantinidis KT, Aluru S. 2018. High throughput ANI analysis of $90 \mathrm{~K}$ prokaryotic genomes reveals clear species boundaries. Nat Commun 9.

\section{Acknowledgements}

We thank the managers of the three Exploratories, Kirsten Reichel-Jung, Iris Steitz, Sandra Weithmann, Florian Straub, Katrin Lorenzen, Juliane Vogt, Miriam Teuscher and all former managers for their work in maintaining the plot and project infrastructure; Christiane Fischer and Jule Mangels for giving support through the central office, Andreas Ostrowski for managing the central data base, and Markus Fischer, Eduard Linsenmair, Dominik Hessenmöller, Daniel Prati, François Buscot, Ernst-Detlef Schulze, Wolfgang W. Weisser and the late Elisabeth Kalko for their role in setting up the Biodiversity Exploratories project.

The work has been funded by the DFG Priority Program 1374 "Infrastructure-Biodiversity-Exploratories" (NA 848/2-1). Field work permits were issued by the responsible state environmental offices of BadenWürttemberg, Thüringen, and Brandenburg.

We acknowledge support by the Open Access Publication Funds of the University of Göttingen. Furthermore, we would like to thank Dr. Sascha Dietrich for bioinformatic support and Dr. Lauren Alteio for correspondence regarding metagenome assembled genomes.

Author contributions: Conceptualization, I.M.W. and H.N.; formal analysis, I.M.W., C.P., A.P., D.S. and H.N.; investigation, I.M.W., A.Y.R., I.G. and S.H.B.; resources, H.N. and I.S.; data curation, I.M.W. and 
H.N.; writing - original draft preparation, I.M.W. and H.N.; writing - review and editing, I.M.W., H.N., D.S. and I.S.; visualization, I.M.W. and H.N.; supervision, I.M.W. and H.N.; project administration, H.N.; funding acquisition, H.N.

\section{Competing interests}

The authors declare no competing interests. 


\subsection{Supplemental information for chapter five}

Figure S1. Relative abundance of $\mathrm{Ca}$. Udaeobacter and other bacterial groups for all soil microcosms.

Table S1. Description of plot characteristics and properties of the soils used to set up the microcosms and for cell extraction.

Table S2. List of antibiotics that have been chromatographically analyzed for residues in all grassland and forest soils used for the microcosm experiment.

Table S3. Model formulas and results from linear mixed model regression analysis.

Table S4. Attributes of all Chthoniobacterales MAGs used to construct the Neighbor-joining tree.

Table S5: Antibiotic resistance genes (ARGs) and mobile genetic elements (MGE) encoded in the MAG of Ca. Udaeobacter sp. 


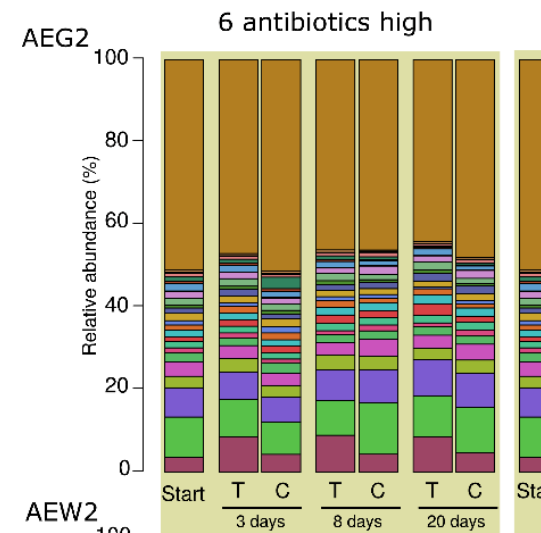

3 antibiotics high

1 antibiotic high

6 antibiotics low

3 antibiotics low

1 antibiotic low
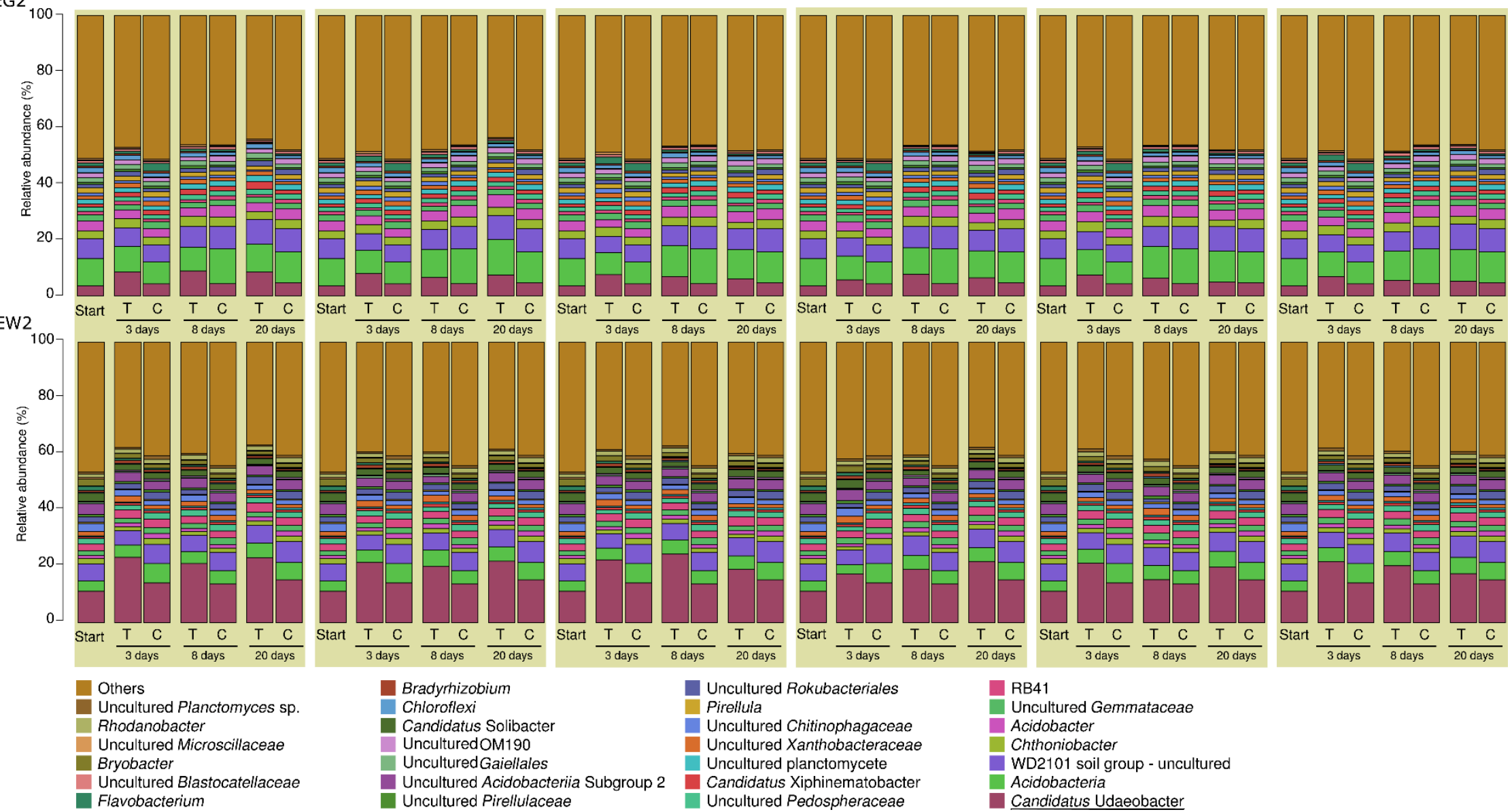

\section{Bradyrhizobium}

Candidatus Solibacter

UnculturedOM190

Uncultured Gaiellales

Uncultured Acidobacteriia
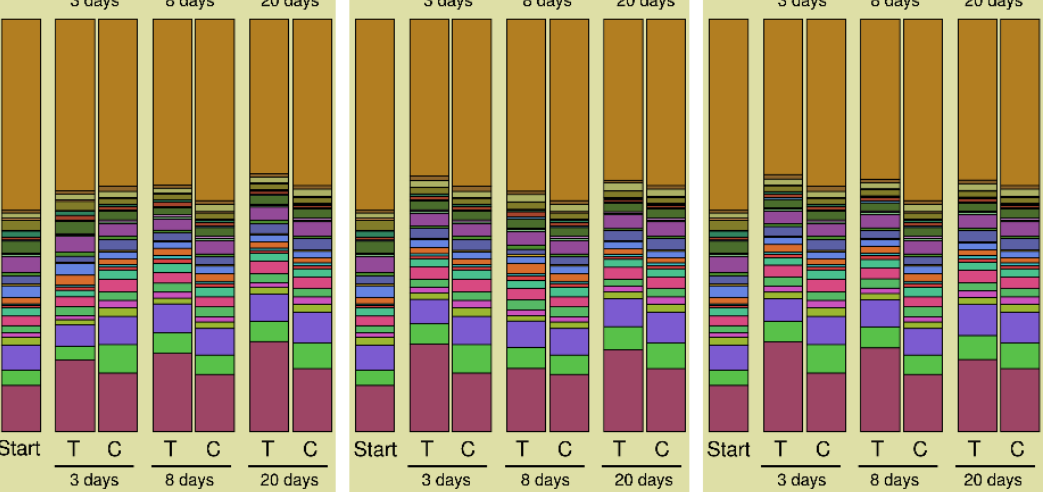

Uncultured Rokubacteriales

Pirellula

Uncultured Chitinophagaceae

- Uncultured Xanthobacteracea

Uncultured planctomycete

Uncultured Pedospheraceae

RB41

- Uncultured Gemmataceae

Acidobacter

Chthoniobacter

WD2101 soil group - unculture

Candidatus

Figure S1. Relative abundance of $\mathbf{C a}$. Udaeobacter and other bacterial groups for all soil microcosms. Untreated control samples, "C", as well as samples treated with antibiotics in high or low concentration, "T", were analyzed. Others: bacterial groups accounting for $<2 \%$ relative abundance. Results are presented as mean of replicates. With respect to all of the four forest soil samples, treatment with one antibiotic, three antibiotics and six antibiotics in high as well as low concentration was performed. Four of the seven grassland soil samples were also subjected to this antibiotic treatment procedure. In addition, the remaining three grassland soil samples (AEG16, AEG21 and HEG21) were treated with three antibiotics and six antibiotics in high as well as low concentration to further verify the effect of antibiotics release on $\mathrm{Ca}$. Udaeobacter. 


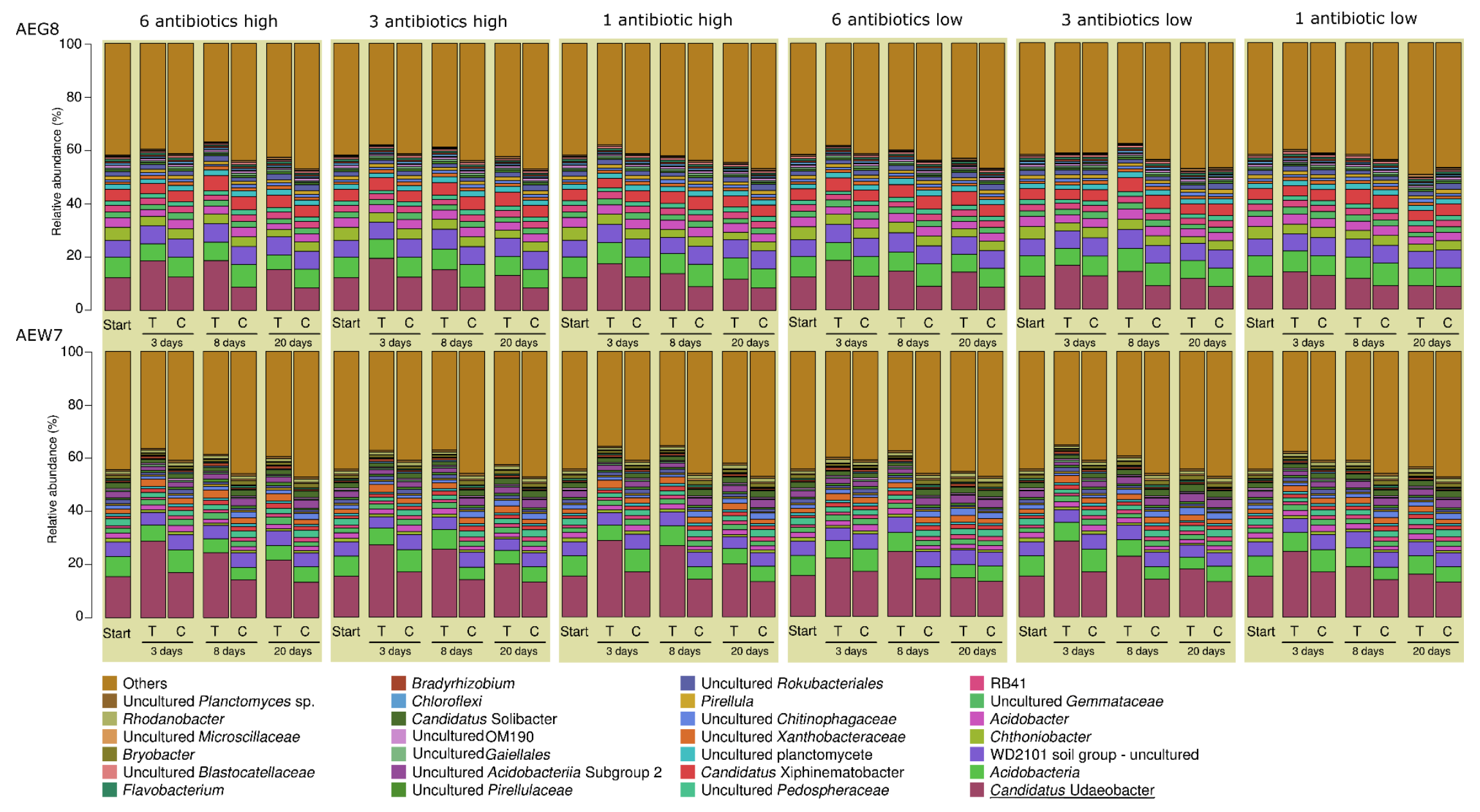

Figure S1. continued 

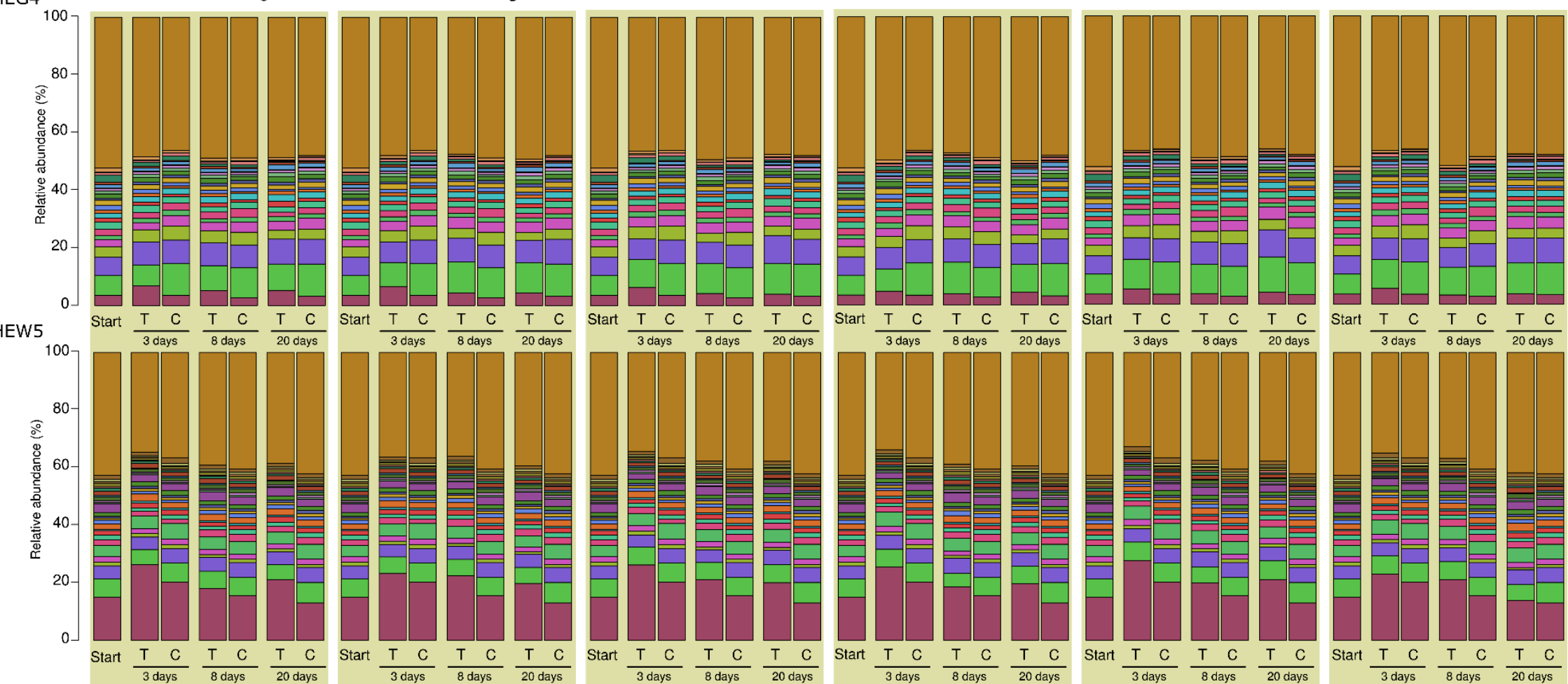
Start $\frac{T C}{3 \text { days }} \frac{T C}{8 \text { days }} \frac{T \text { days }}{20}$

\section{Others}

Uncultured Planctomyces sp.

Rhodanobacter

Uncultured Microscillaceae

Bryobacter

Uncultured Blastocatellaceae

Flavobacterium
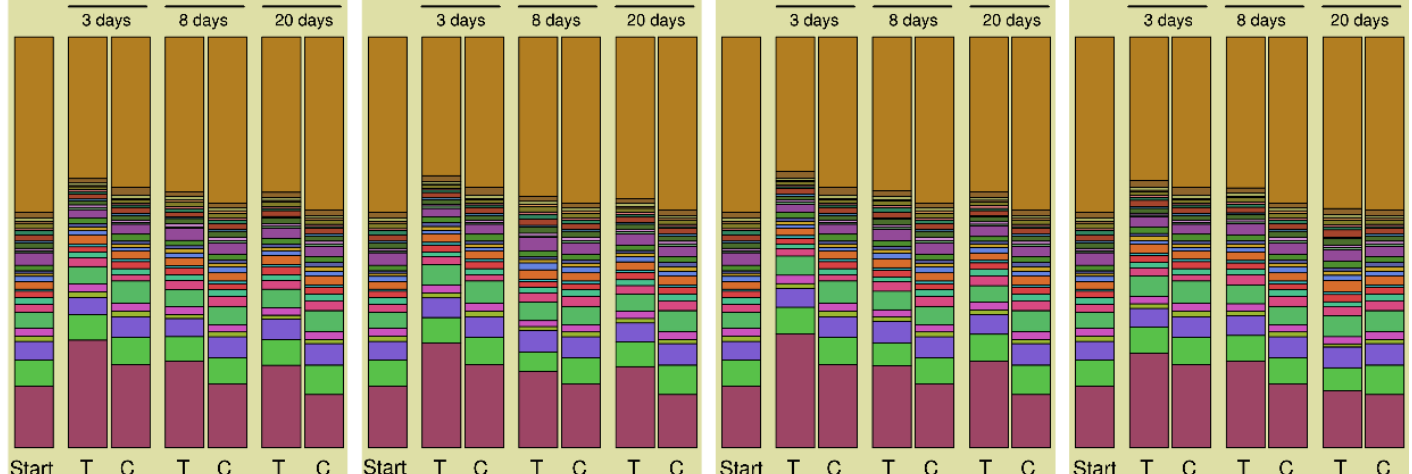

\section{Bradyrhizobium}

Chloroflexi

Uncultared OM190

UnculturedGaiellales

Uncultured Acidobacteriia Subgroup 2

- Uncultured Pirellulaceae

$\frac{T \quad C}{3 \text { days }} \frac{T \quad C}{8 \text { days }} \frac{T \quad C}{20 \text { days }}$

C

C $\stackrel{T}{ }$ C $T$ C

Start $\frac{T \quad C}{3 \text { days }} \frac{T \quad C}{8 \text { days }} \frac{T \quad C}{20 \text { days }}$

Figure S1. continued

Uncultured Rokubacteriales

Pirellula

Uncultured Chitinophagaceae

Uncultured Xanthobacteracea

Uncultured planctomycete

Candidatus Xiphinematobacte

Uncultured Pedospheraceae
RB41

Uncultured Gemmatacea

Acidobacter

Chthoniobacter

WD2101 soli group - uncultured

Acidobacteria

Candidatus Udaeobacter 
HEG7

6 antibiotics high

3 antibiotics high

1 antibiotic high

6 antibiotics low

3 antibiotics low

1 antibiotic low
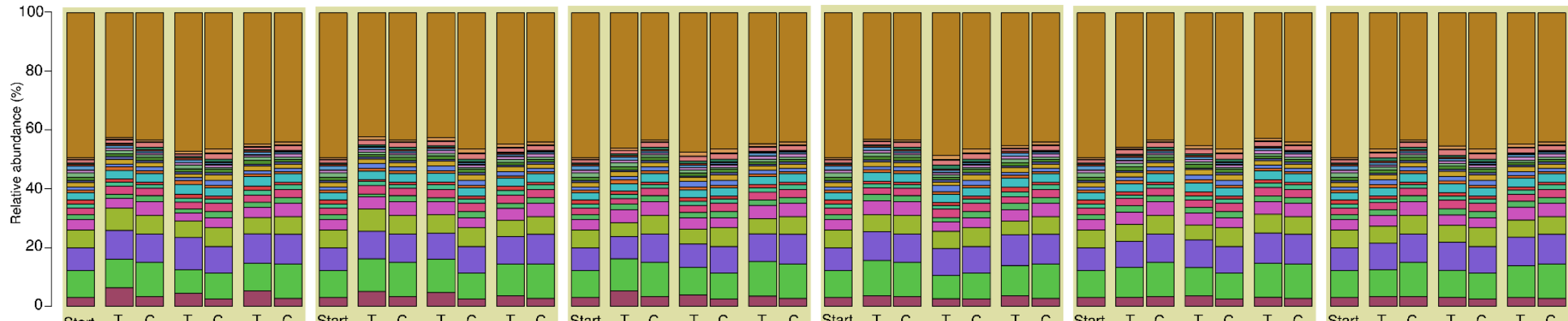

HEW3 Start $\frac{T C}{3 \text { days }} \frac{T C}{8 \text { days }} \frac{T}{20 \text { days }}$ Start $\frac{T}{3 \text { days }} \frac{\text { T }}{8 \text { days }} \frac{\text { T }}{20 \text { days }}$
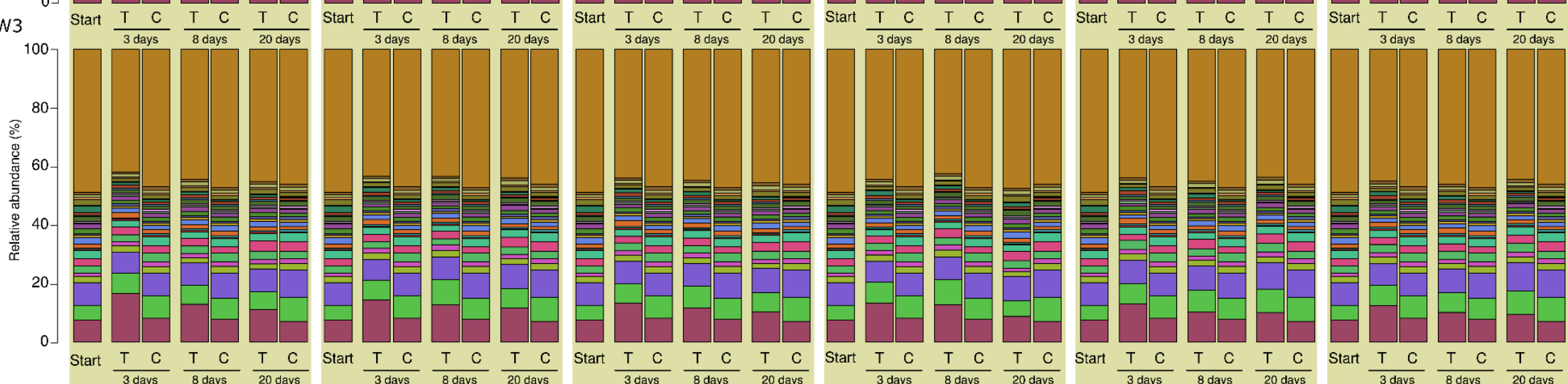

Bradyrhizobium

Others

Chloroflexi

Start $\frac{T \quad C}{3 \text { days }} \frac{T C}{8 \text { days }} \frac{T C}{20 \text { days }}$

Start $\frac{T \quad C}{3} \frac{T}{O} \quad C \quad T \quad C$

Start $T$ C $\quad$ C $\quad T \quad C \quad T \quad C$

Start $\mathrm{T} \quad \mathrm{C} \quad \mathrm{T} \quad \mathrm{C} \stackrel{\mathrm{T}}{\mathrm{C}} \mathrm{C}$

Uncultured Planctomyces sp.

Rhodanobacter

Uncultured Rokubacteriales

- RB41

Uncultured Microscillaceae

Bryobacter

Candidatus Solibacte

Uncultured OM190

Uncultured Chitinophagaceae

Uncultured Xanthobacteraceae

Uncultured Gaiellales

Uncultured Acidobacteriia Subgroup 2

Uncultured planctomycete

Flavobacter

Uncultured Pirellulaceae

Candidatus Xiphinematobacter
Uncultured Pedospheraceae

- Uncultured Gemmataceae

Acidobacter

Chthoniobacter

WD2101 soil group - uncultured

Acidobacteria

Candidatus Udaeobacter

Figure S1. continued 


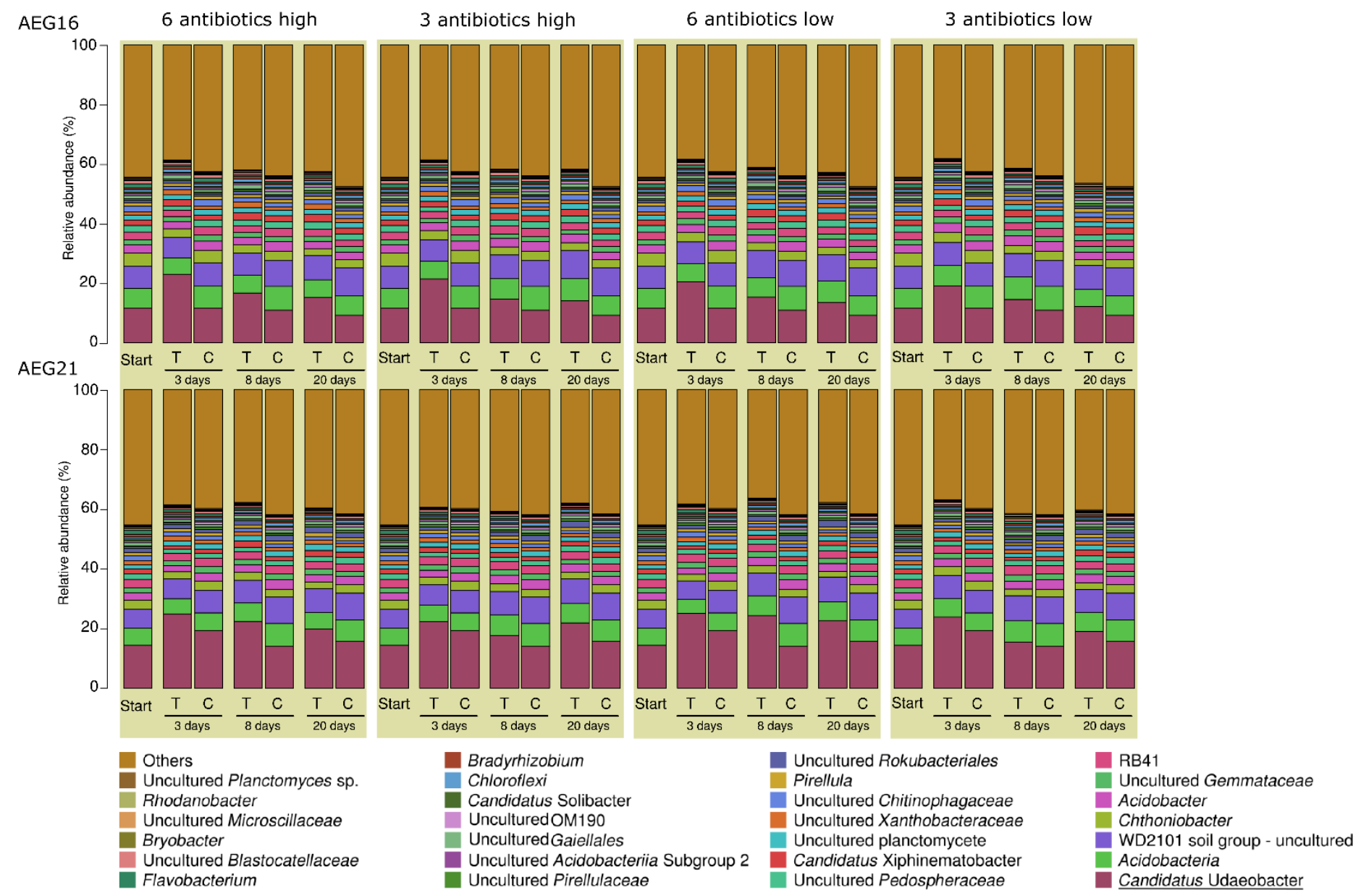

Figure S1. continued 


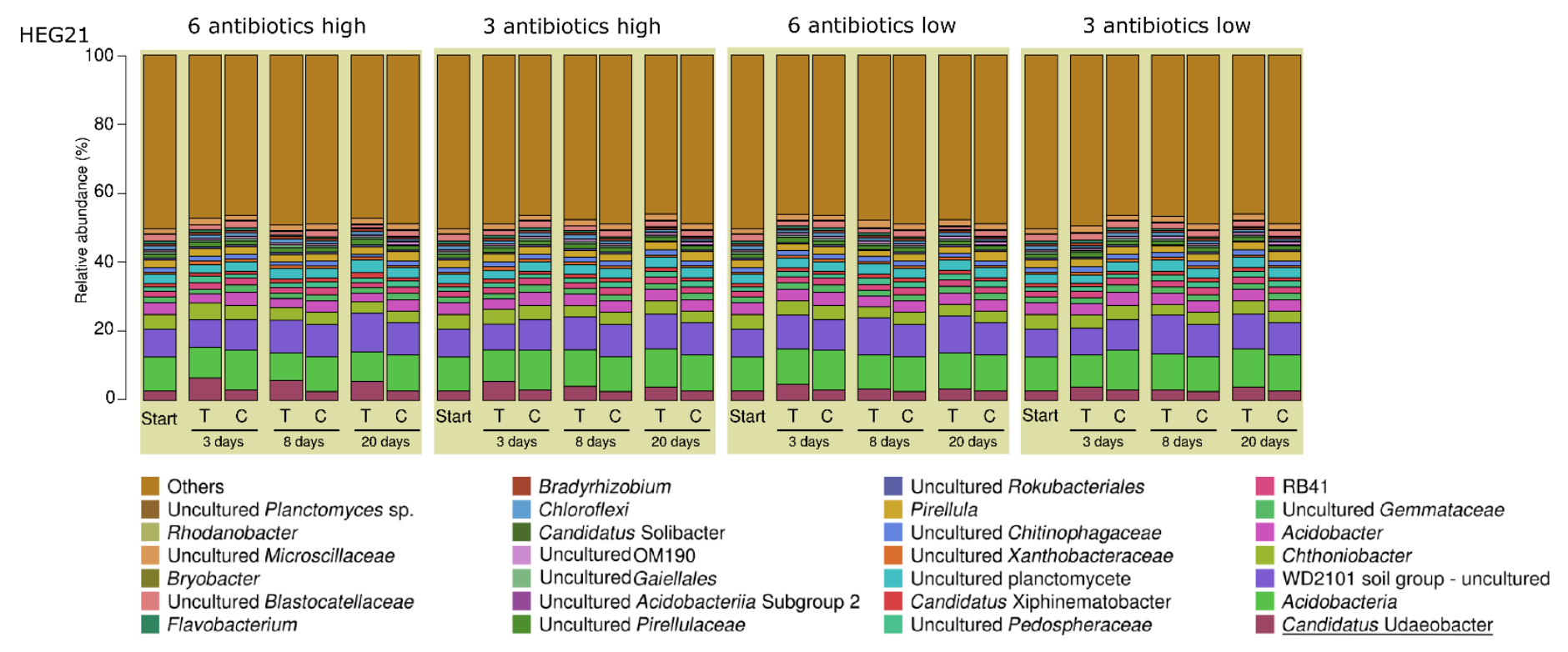

Figure S1. continued 
Table S1. Description of plot characteristics and properties of the soils used to set up the microcosms and for cell extraction. Pasture: grassland with grazing livestock, meadow: grassland without grazing livestock. AEW3 is not used for the set up of the microcosms but for cell extraction.

\begin{tabular}{lcccccr}
\hline Plot ID & Exploratory & Plot characteristics & LUI/SMI & pH & $\begin{array}{r}\text { \% } \\
\text { water }\end{array}$ & $\begin{array}{r}\text { C:N } \\
\text { ratio }\end{array}$ \\
\hline HEG4 & HAl & Mown, fertilized meadow & 2.1 & 6.5 & 35.8 & 10.7 \\
HEG7 & HAl & Pasture & 1.7 & 7 & 25.2 & 9.5 \\
HEG21 & HAl & Mown pasture & 0.7 & 7.3 & 26.5 & 10.4 \\
HEW3 & HAl & Spruce forest & 0.5 & 5.1 & 39.8 & 16.5 \\
HEW5 & HAl & Beech forest & 0.2 & 5.3 & 52.5 & 13.1 \\
AEG2 & ALB & Mown, fertilized meadow & 3.1 & 6.9 & 59.7 & 9.5 \\
AEG8 & ALB & Mown pasture & 1.3 & 6.6 & 70.4 & 10.9 \\
AEG16 & ALB & Mown, fertilized pasture & 1.7 & 6.0 & 54.7 & 10.2 \\
AEG21 & ALB & Mown, fertilized pasture & 3.9 & 5.8 & 52.9 & 10.0 \\
AEW2 & ALB & Spruce forest & 0.6 & 4.8 & 38.3 & 13.9 \\
AEW7 & ALB & Beech forest & 0.2 & 5.0 & 64.9 & 12.9 \\
AEW3 & Alb & Spruce forest & 0.5 & 5.6 & 52.7 & 13.6 \\
\hline A
\end{tabular}

Abbreviations: HAI, exploratory Hainich-Dün; ALB, exploratory Schwäbische Alb; LUI, land use intensity index; SMI, silvicultural management index, \% water, gravimetric water content; C: $\mathrm{N}$ ratio, organic carbon divided by total N. 
Table S2. List of antibiotics that have been chromatographically analyzed for residues in all grassland and forest soils used for the microcosm experiment.

\begin{tabular}{|c|c|c|}
\hline Tested antibiotics & $\begin{array}{l}\text { Detection limit ( } \begin{array}{l}\mathrm{mg} / \mathrm{kg} \\
\text { soil) }\end{array} \\
\end{array}$ & $\begin{array}{l}\text { Soil sample } \\
\text { (concentration of antibiotic) }\end{array}$ \\
\hline \multicolumn{3}{|l|}{ Sulfonamides } \\
\hline Acetylsulfadiazine & $<0.001$ & - \\
\hline Acetylsulfadimethoxine & $<0.001$ & - \\
\hline Acetylsulfamethazine & $<0.001$ & - \\
\hline Acetylsulfadoxine & $<0.001$ & - \\
\hline Acetylsulfamerazine & $<0.001$ & - \\
\hline Acetylsulfamethoxazole & $<0.001$ & - \\
\hline Acetylsulfathiazole & $<0.001$ & - \\
\hline Sulfadiazine & $<0.001$ & - \\
\hline Sulfadimethoxine & $<0.001$ & - \\
\hline Sulfamethazine & $<0.001$ & - \\
\hline Sulfadoxine & $<0.001$ & - \\
\hline Sulfamerazine & $<0.001$ & - \\
\hline Sulfamethoxazole & $<0.001$ & - \\
\hline Sulfathiazole & $<0.001$ & - \\
\hline \multicolumn{3}{|l|}{ Penicillins } \\
\hline Amoxicillin & $<0.01$ & - \\
\hline Ampicillin & $<0.01$ & - \\
\hline Benzylpenicillin & $<0.01$ & - \\
\hline Cloxacillin & $<0.01$ & - \\
\hline Dicloxacillin & $<0.01$ & - \\
\hline Oxacillin & $<0.01$ & - \\
\hline Penethamate & $<0.01$ & - \\
\hline Penicillin V & $<0.01$ & - \\
\hline \multicolumn{3}{|l|}{ Aminoglycosides } \\
\hline Apramycin & $<0.01$ & - \\
\hline Clindamycin & $<0.01$ & - \\
\hline Gentamycin C1a & $<0.05$ & - \\
\hline Lincomycin & $<0.01$ & - \\
\hline Neomycin & $<0.01$ & - \\
\hline Spectinomycin & $<0.05$ & - \\
\hline Streptomycin & $<0.01$ & - \\
\hline \multicolumn{3}{|l|}{ Polypeptides } \\
\hline Bacitracin A & $<0.01$ & - \\
\hline Collistin & $<0.03$ & - \\
\hline Nafcillin & $<0.01$ & - \\
\hline Nisin & $<0.01$ & - \\
\hline \multicolumn{3}{|l|}{ Cephalosporins } \\
\hline Cefadroxil & $<0.01$ & - \\
\hline Cefapirin & $<0.01$ & - \\
\hline Cefazolin & $<0.01$ & - \\
\hline Cefquinome & $<0.01$ & - \\
\hline Ceftiofur & $<0.01$ & - \\
\hline Cefuroxime & $<0.01$ & - \\
\hline Cephalexin & $<0.01$ & - \\
\hline \multicolumn{3}{|l|}{ Amphenicols } \\
\hline Chloramphenicol & $<0.001$ & - \\
\hline Florfenicol & $<0.001$ & - \\
\hline
\end{tabular}

Only soil samples exhibiting antibiotic concentrations above the detection limits are listed. 
Table S2. continued

\begin{tabular}{|c|c|c|}
\hline Tested antibiotics & $\begin{array}{l}\text { Detection limit } \quad \text { (mg/kg } \\
\text { soil) }\end{array}$ & $\begin{array}{l}\text { Soil sample } \\
\text { (concentration of antibiotic) }\end{array}$ \\
\hline $\begin{array}{l}\text { Thiamphenicol } \\
\text { Tetracvclines }\end{array}$ & $<0.001$ & - \\
\hline Chlortetracycline & $<0.01$ & AEW2 (0.011 mg/kg) \\
\hline Demeclocycline & $<0.003$ & 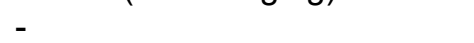 \\
\hline Doxycycline & $<0.01$ & - \\
\hline Iso-Chlortetracycline & $<0.01$ & - \\
\hline Meclocycline & $<0.01$ & - \\
\hline Metacycline & $<0.01$ & - \\
\hline Oxytetracycline & $<0.01$ & - \\
\hline Tetracycline & $<0.01$ & - \\
\hline Quinolones & & \\
\hline Ciprofloxacin & $<0.001$ & - \\
\hline Danofloxacin & $<0.01$ & - \\
\hline Difloxacin & $<0.01$ & - \\
\hline Enrofloxacin & $<0.01$ & - \\
\hline Marbofloxacin & $<0.01$ & - \\
\hline Ofloxacin & $<0.01$ & - \\
\hline Sarafloxacin & $<0.01$ & - \\
\hline Macrolides & & \\
\hline Clarithromycin & $<0.01$ & - \\
\hline Erythromycin & $<0.01$ & - \\
\hline Flavomycin & $<0.01$ & - \\
\hline Ivermectin B1a & $<0.05$ & - \\
\hline Natamycin & $<0.01$ & - \\
\hline Oleandromycin & $<0.01$ & - \\
\hline Spiramycin S-I & $<0.05$ & - \\
\hline Spiramycin S-II & $<0.01$ & - \\
\hline Spiramycin S-III & $<0.01$ & - \\
\hline Tilmicosin & $<0.01$ & - \\
\hline Tylosin & $<0.05$ & - \\
\hline Nitroimidazoles & & \\
\hline Metronidazole & $<0.01$ & - \\
\hline Ronidazole & $<0.01$ & - \\
\hline Additional antibiotics & & \\
\hline Imipenem & $<0.01$ & - \\
\hline Tiamulin & $<0.001$ & - \\
\hline Trimethoprim & $<0.01$ & - \\
\hline Tylvalosin & $<0.01$ & - \\
\hline Valnemulin & $<0.01$ & - \\
\hline Virginamycin & $<0.01$ & - \\
\hline
\end{tabular}

Only soil samples exhibiting antibiotic concentrations above the detection limits are listed. 
Table S3. Model formulas and results from linear mixed model regression analysis. The relative abundance of Ca. Udaeobacter, ASV 6 upon antibiotic treatment and the rise in absolute 16S rRNA gene abundance per ng DNA upon antibiotics release after 3 days of incubation, assessed via qPCR, was analyzed.

\begin{tabular}{|c|c|c|c|c|c|c|c|c|}
\hline Model formula & $\mathbf{N}$ & $\mathbf{R}^{2} \mathrm{~m} / \mathbf{R}^{2} \mathbf{c}$ & $\begin{array}{l}\mathbf{p} \\
\text { treat. }\end{array}$ & $\begin{array}{l}\text { Df } \\
\text { treat. }\end{array}$ & $\begin{array}{l}\text { Est. } \\
\text { treat. }\end{array}$ & p day & $\begin{array}{l}\text { Df } \\
\text { day }\end{array}$ & $\begin{array}{l}\text { Est. } \\
\text { day }\end{array}$ \\
\hline Imer(log(Ca. Udaeobacter) Concentr+Days+(1|plotID/sampleID)) & 606 & $0.04 / 0.96$ & $<2 \mathrm{e}^{-16}$ & 190 & $6.0 \mathrm{e}^{-4}$ & $<2 \mathrm{e}^{-16}$ & 403 & -0.01 \\
\hline Imer(log(Ca. Udaeobacter) SixAntib.High+Days+(1|plotID/sampleID) & 83 & $0.15 / 0.96$ & $<2 \mathrm{e}^{-16}$ & 38 & $9.8 e^{-4}$ & $1.8 \mathrm{e}^{-4}$ & 66 & -0.01 \\
\hline Imer(log(Ca. Udaeobacter) SixAntib.Low+Days+(1|plotID/sampleID) & 79 & $0.06 / 0.96$ & $1.4 \mathrm{e}^{-13}$ & 66 & 0.01 & $6.9 \mathrm{e}^{-4}$ & 66 & -0.01 \\
\hline Imer(log(Ca. Udaeobacter) ThreeAntib.High+Days+(1|plotID/sampleID) & 87 & $0.08 / 0.95$ & $<2 \mathrm{e}^{-16}$ & 74 & $1.4 e^{-3}$ & $7.4 \mathrm{e}^{-4}$ & 74 & -0.01 \\
\hline Imer(log(Ca. Udaeobacter) ThreeAntib.Low+Days+(1|plotID/sampleID) & 88 & $0.04 / 0.96$ & $8.4 e^{-14}$ & 75 & 0.01 & $9.9 \mathrm{e}^{-4}$ & 75 & -0.01 \\
\hline Imer(log(Ca. Udaeobacter) OneAntib.High+Days+(1|plotID/sampleID) & 65 & $0.1 / 0.97$ & $1.67 \mathrm{e}^{-11}$ & 25 & $4.5 e^{-3}$ & $2.5 e^{-5}$ & 50 & -0.01 \\
\hline Imer(log(Ca. Udaeobacter) OneAntib.Low+Days+(1|plotID/sampleID) & 66 & $0.04 / 0.96$ & $4.22 \mathrm{e}^{-7}$ & 53 & 0.02 & $3.0 e^{-5}$ & 52 & -0.01 \\
\hline Imer(ASV 6 Concentr+Days+(1|plotID/sampleID)) & 606 & $0.02 / 0.90$ & $1.68 e^{-6}$ & 593 & 0.04 & $<2 \mathrm{e}^{-16}$ & 593 & -1.73 \\
\hline Imer(log(16S rRNA genes per ng DNA after 3 days $) \sim$ Concentr+(1| plotID)) & 30 & $0.02 / 0.90$ & $1.84 \mathrm{e}^{-7}$ & 23 & $1.6 e^{-3}$ & NA. & NA & NA \\
\hline
\end{tabular}

Abbreviations: p, p-value ; treat., antibiotic treatment; Df, degrees of freedom; Est., estimates; N, sample size. 
Table S4. Attributes of all Chthoniobacterales MAGs used to construct the Neighbor-joining tree. The yellow highlighted MAGs cluster together with the here assembled MAG of Ca. Udaeobacter sp.

\begin{tabular}{|c|c|c|c|c|c|}
\hline $\begin{array}{l}\text { GBK assembly } \\
\text { accession }\end{array}$ & GTDB Phylogeny starting with the family & Compl. & Cont. & $\begin{array}{c}\text { Size in } \\
\text { Mbp }\end{array}$ & GC \\
\hline GCA_003221405.1 & f_UBA10450;g_AV69;s_AV69 sp003221405 & $66.6 \%$ & $2.0 \%$ & 1.94 & $55.4 \%$ \\
\hline GCA_003218375.1 & f_UBA10450;g_AV80;s_AV80 sp003218375 & $100.0 \%$ & $2.7 \%$ & 3.96 & $58.8 \%$ \\
\hline GCA_003218735.1 & f_UBA10450;g_AV55;s_AV55 sp003218735 & $72.0 \%$ & $2.6 \%$ & 1.49 & $54.5 \%$ \\
\hline GCA_003218615.1 & f_UBA10450;g_AV55;s_AV55 sp003218615 & $88.3 \%$ & $0.5 \%$ & 2.29 & $55.3 \%$ \\
\hline GCA_003219225.1 & f_UBA10450;g_AV17;s_AV17 sp003219225 & $70.5 \%$ & $0.7 \%$ & 2.04 & $58.4 \%$ \\
\hline GCA_003219215.1 & f_UBA10450;g_AV40;s_AV40 sp003219215 & $90.8 \%$ & $1.7 \%$ & 2.33 & $55.3 \%$ \\
\hline GCA_003219095.1 & f_UBA10450;g_AV69;s_AV69 sp003219095 & $71.4 \%$ & $3.2 \%$ & 2.38 & $55.1 \%$ \\
\hline GCA_003244145.1 & f_UBA10450;g_AV80;s_AV80 sp003244145 & $92.9 \%$ & $5.1 \%$ & 3.63 & $58.4 \%$ \\
\hline GCF_001613545.1 & f__Terrimicrobiaceae;g__Terrimicrobium;s__Terrimicrobium sacchariphilum & $100.0 \%$ & $2.7 \%$ & 4.75 & $60.2 \%$ \\
\hline GCA_003219465.1 & f_UBA10450;g_AV55;s_AV55 sp003219465 & $89.1 \%$ & $6.6 \%$ & 4.19 & $55.2 \%$ \\
\hline GCA_003134785.1 & f_UBA10450;g_AV80;s_AV80 sp003134785 & $100.0 \%$ & $3.4 \%$ & 4.39 & $57.8 \%$ \\
\hline GCA_003218885.1 & f__UBA10450;g_AV55;s__AV55 sp003218885 & $88.0 \%$ & $2.4 \%$ & 2.30 & $55.4 \%$ \\
\hline GCF_000173075.1 & f_Chthoniobacteraceae;g_Chthoniobacter;s_Chthoniobacter flavus & $97.3 \%$ & $2.9 \%$ & 7.85 & $61.1 \%$ \\
\hline GCA_003221295.1 & f_UBA10450;g_AV69;s_AV69 sp003221295 & $90.2 \%$ & $3.7 \%$ & 2.98 & $55.3 \%$ \\
\hline GCA_003219175.1 & f_UBA10450;g_AV69;s_AV69 sp003219175 & $98.0 \%$ & $5.7 \%$ & 3.24 & $55.0 \%$ \\
\hline GCA_003220155.1 & f_UBA10450;g_AV69;s_AV69 sp003220155 & $96.3 \%$ & $3.0 \%$ & 3.35 & $55.3 \%$ \\
\hline GCA_003167555.1 & f__UBA10450;g_AV80;s_AV80 sp003167555 & $100.0 \%$ & $3.4 \%$ & 4.20 & $58.5 \%$ \\
\hline GCA_003219195.1 & f_UBA10450;g_UBA10450;s_UBA10450 sp003219195 & $95.3 \%$ & $2.2 \%$ & 2.82 & $55.8 \%$ \\
\hline GCA_003219925.1 & f_UBA10450;g_AV69;s_AV69 sp003219925 & $81.2 \%$ & $3.0 \%$ & 2.10 & $55.3 \%$ \\
\hline GCA_003219355.1 & f_UBA $10450 ; 9 \_$__VV55;s_AV55 sp003219355 & $88.4 \%$ & $6.4 \%$ & 2.23 & $54.5 \%$ \\
\hline GCA_003445855.1 & f_UBA $10450 ; g \_$__BA $10450 ;$ s_UBA $10450 \mathrm{sp} 003445855$ & $78.0 \%$ & $1.7 \%$ & 2.10 & $55.9 \%$ \\
\hline GCA_003219995.1 & f_UBA10450;g_UBA10450;s_UBA10450 sp003219995 & $82.6 \%$ & $2.5 \%$ & 2.10 & $55.3 \%$ \\
\hline GCA_003221375.1 & f_UBA $10450 ; g \_$AV55;s_AV55 sp003221375 & $73.9 \%$ & $1.4 \%$ & 2.17 & $54.1 \%$ \\
\hline GCA_003218535.1 & f__UBA10450;g__AV55;s_AV55 sp003218535 & $92.6 \%$ & $4.4 \%$ & 2.69 & $54.5 \%$ \\
\hline GCA_003167365.1 & f__UBA10450;g_Palsa-1382;s_Palsa-1382 sp003167365 & $100.0 \%$ & $1.4 \%$ & 3.13 & $55.2 \%$ \\
\hline GCA_003219495.1 & f_UBA10450;g_AV40;s_AV40 sp003219495 & $72.9 \%$ & $1.5 \%$ & 2.11 & $56.3 \%$ \\
\hline GCA_003218305.1 & f_UBA10450;g_AV80;s_AV80 sp003218305 & $92.9 \%$ & $4.6 \%$ & 3.60 & $59.0 \%$ \\
\hline GCA_003169695.1 & f_UBA10450;g_AV80;s_AV80 sp003169695 & $99.7 \%$ & $4.7 \%$ & 4.14 & $57.2 \%$ \\
\hline GCA_001897195.1 & f__Terrimicrobiaceae;g_Terrimicrobium;s__Terrimicrobium sp001897195 & $96.6 \%$ & $3.8 \%$ & 5.06 & $60.8 \%$ \\
\hline GCA 003219125.1 & f UBA10450:q AV69;s AV69 sp003219125 & $92.3 \%$ & $4.6 \%$ & 3.20 & $55.0 \%$ \\
\hline
\end{tabular}


Table S4 continued:

\begin{tabular}{|c|c|c|c|c|c|}
\hline $\begin{array}{l}\text { GBK assembly } \\
\text { accession }\end{array}$ & GTDB Phylogeny starting with the family & Compl. & Cont. & $\begin{array}{c}\text { Size in } \\
\text { Mbp }\end{array}$ & GC \\
\hline GCA_003219435.1 & f_UBA10450;g_AV55;s_AV55 sp003219435 & $86.4 \%$ & $2.4 \%$ & 2.73 & $55.2 \%$ \\
\hline GCA_003220055.1 & f_UBA10450;g_AV40;s_AV40 sp003220055 & $81.8 \%$ & $0.2 \%$ & 2.08 & $55.5 \%$ \\
\hline GCA_003219335.1 & f_UBA10450;g_AV55;s_AV55 sp003219335 & $83.0 \%$ & $4.1 \%$ & 3.71 & $55.0 \%$ \\
\hline GCA_002290555.1 & f_Terrimicrobiaceae;g_UBA967;s_UBA967 sp002290555 & $81.1 \%$ & $0.2 \%$ & 1.82 & $56.6 \%$ \\
\hline GCA_003136515.1 & f_UBA6821;g_UBA6821;s_UBA $\overline{68} 21 \mathrm{sp} 003136515$ & $85.1 \%$ & $4.1 \%$ & 2.36 & $53.2 \%$ \\
\hline GCA_002298145.1 & f_Chthoniobacteraceae;g__UBA695;s_UBA695 sp002298145 & $92.6 \%$ & $0.7 \%$ & 4.11 & $60.5 \%$ \\
\hline GCA_003218415.1 & f_UBA10450;g__AV55;s_AV55 sp003218415 & $83.7 \%$ & $3.4 \%$ & 2.05 & $55.3 \%$ \\
\hline GCA_003219005.1 & f_UBA10450;g_AV55;s_AV55 sp003219005 & $87.8 \%$ & $1.1 \%$ & 2.69 & $55.2 \%$ \\
\hline GCA_003218975.1 & f_UBA10450;g_AV55;s_AV55 sp003218975 & $98.0 \%$ & $2.9 \%$ & 3.06 & $55.1 \%$ \\
\hline GCA_003218785.1 & f_UBA10450;g_AV55;s_AV55 sp003218785 & $85.6 \%$ & $0.7 \%$ & 2.78 & $54.9 \%$ \\
\hline GCA-003218705.1 & f UBA10450;g AV40;s AV40 sp003218705 & $76.5 \%$ & $0.8 \%$ & 1.70 & $55.4 \%$ \\
\hline GCA_003218945.1 & f_UBA10450;g_AV55;s_AV55 sp003218945 & $87.8 \%$ & $3.1 \%$ & 2.80 & $55.0 \%$ \\
\hline GCA_003219265.1 & f_UBA10450;g_AV133;s_ AV133 sp003219265 & $78.4 \%$ & $1.4 \%$ & 2.09 & $56.2 \%$ \\
\hline GCA_003218135.1 & f_UBA10450;g_AV55;s_AV55 sp003218135 & $91.2 \%$ & $3.7 \%$ & 2.75 & $54.9 \%$ \\
\hline GCA_003169975.1 & f_UBA10450;g_Palsa-1392;s_Palsa-1392 sp003169975 & $100.0 \%$ & $2.7 \%$ & 4.47 & $59.9 \%$ \\
\hline GCF_001318295.1 & f_Xiphinematobacteraceae;g__Xiphinematobacter,s__Xiphinematobacter sp001318295 & $89.9 \%$ & $0.0 \%$ & 0.92 & $47.7 \%$ \\
\hline GCA_003244125.1 & f_UBA $10450 ; g \_$AV69;s_AV69 sp003244125 _ & $66.0 \%$ & $2.3 \%$ & 2.50 & $58.7 \%$ \\
\hline GCA_003217965.1 & f_UBA10450;g_AV69;s_AV69 sp003217965 & $90.3 \%$ & $3.7 \%$ & 2.64 & $55.2 \%$ \\
\hline GCA_003218475.1 & f_UBA10450;g_AV55;s_AV55 sp003218475 & $94.7 \%$ & $3.6 \%$ & 3.16 & $54.8 \%$ \\
\hline GCA_003134765.1 & f_UBA10450;g_AV80;s_AV80 sp003134765 & $96.0 \%$ & $2.7 \%$ & 4.05 & $58.7 \%$ \\
\hline GCA-003221195.1 & f UBA10450;g AV55;s AV55 sp003221195 & $89.6 \%$ & $4.1 \%$ & 3.10 & $54.3 \%$ \\
\hline GCA_003218345.1 & f_UBA10450;g_AV55;s_AV55 sp003218345 & $82.5 \%$ & $3.2 \%$ & 2.39 & $54.5 \%$ \\
\hline GCA_003218915.1 & f_UBA10450;g_AV55;s_AV55 sp003218915 & $88.7 \%$ & $3.3 \%$ & 2.91 & $54.6 \%$ \\
\hline GCA_003220075.1 & f_UBA10450;g_AV69;s_AV69 sp003220075 & $87.4 \%$ & $4.5 \%$ & 2.79 & $55.2 \%$ \\
\hline GCA_003176035.1 & f_Xiphinematobacteraceae;g_PSRL01;S_PSRL01 sp003176035 & $70.4 \%$ & $3.4 \%$ & 1.92 & $48.5 \%$ \\
\hline GCF_003054655.1 & f_Terrimicrobiaceae;g_Terrimicrobium;s_Terrimicrobium sp003054655 & $100.0 \%$ & $2.0 \%$ & 4.75 & $60.7 \%$ \\
\hline GCA_003218265.1 & f__UBA $10450 ; g \_A V 55 ; s \_$_ AV55 sp003218265 & $66.6 \%$ & $2.2 \%$ & 2.25 & $55.0 \%$ \\
\hline GCA_003218815.1 & f_UBA10450;g_AV55;s_AV55 sp003218815 & $77.1 \%$ & $2.3 \%$ & 1.85 & $54.6 \%$ \\
\hline GCA_003218395.1 & f_UBA10450;g_AV55;s_AV55 sp003218395 & $90.7 \%$ & $4.4 \%$ & 2.95 & $54.9 \%$ \\
\hline GCA_003219695.1 & f_UBA10450;g_AV55;s_AV55 sp003219695 & $92.8 \%$ & $3.4 \%$ & 3.14 & $55.6 \%$ \\
\hline GCA_003219115.1 & f_UBA10450;g_AV69;s_AV69 sp003219115 & $82.4 \%$ & $1.0 \%$ & 2.67 & $55.3 \%$ \\
\hline
\end{tabular}


Table S4 continued:

\begin{tabular}{|c|c|c|c|c|c|}
\hline $\begin{array}{l}\text { GBK assembly } \\
\text { accession }\end{array}$ & GTDB Phylogeny starting with the family & Compl. & Cont. & $\begin{array}{l}\text { Size in } \\
\text { Mbp }\end{array}$ & GC \\
\hline GCA_003219395.1 & f__UBA10450;g_AV55;s_AV55 sp003219395 & $69.3 \%$ & $2.2 \%$ & 2.82 & $54.5 \%$ \\
\hline GCA_003219415.1 & f_UBA10450;g_AV55;s_AV55 sp003219415 & $97.8 \%$ & $3.2 \%$ & 3.62 & $54.4 \%$ \\
\hline GCA_003217875.1 & f_UBA10450;g_AV55;s_AV55 sp003217875 & $86.8 \%$ & $2.1 \%$ & 2.45 & $54.6 \%$ \\
\hline GCA_003220005.1 & f_UBA10450;g_AV55;s__AV55 sp003220005 & $82.4 \%$ & $0.7 \%$ & 2.53 & $55.0 \%$ \\
\hline GCA_002396485.1 & f__Terrimicrobiaceae;g_UBA967;s__UBA967 sp002396485 & $98.7 \%$ & $0.0 \%$ & 2.77 & $56.2 \%$ \\
\hline GCA_003217835.1 & f_UBA10450;g_AV55;s_AV55 sp003217835 & $74.3 \%$ & $0.7 \%$ & 1.75 & $54.6 \%$ \\
\hline GCA_003218525.1 & f_UBA10450;g_AV69;s_AV69 sp003218525 & $78.0 \%$ & $3.5 \%$ & 2.43 & $55.3 \%$ \\
\hline GCA_002452515.1 & f_UBA6821;g_UBA6821;s_UBA6821 sp002452515 & $90.2 \%$ & $1.4 \%$ & 2.35 & $54.0 \%$ \\
\hline GCA_003219945.1 & f__UBA10450;g_AV55;s_AV55 sp003219945 & $81.5 \%$ & $2.3 \%$ & 2.24 & $54.9 \%$ \\
\hline GCA_003218755.1 & f_UBA10450;g_AV55;s_AV55 sp003218755 & $88.5 \%$ & $3.2 \%$ & 2.63 & $54.9 \%$ \\
\hline $\begin{array}{l}\text { GCA_003217895.1 } \\
2651869889 \text { (IMG }\end{array}$ & $\begin{array}{l}f \quad \text { UBA10450;g_AV55;s_AV55 sp003217895 } \\
\text { not listed in the GTDB database (ncbi taxonomy: Chthoniobacteraceae; Candidatus }\end{array}$ & $94.3 \%$ & $2.7 \%$ & 2.74 & $55.0 \%$ \\
\hline Taxon ID) & Udaeobacter; Candidatus Udaeobacter copiosus) & $80.0 \%$ & $4.0 \%$ & 2.66 & $54.3 \%$ \\
\hline
\end{tabular}

Abbreviations: Compl, completeness estimated by Checkm; Cont, contamination estimated by Checkm; GC, GC content 


\begin{tabular}{|c|c|c|c|c|}
\hline $\begin{array}{l}\text { Detection } \\
\text { strategy }\end{array}$ & $\begin{array}{l}\text { Contig/ } \\
\text { scaffold }\end{array}$ & Annotation & Product & $\begin{array}{l}\text { deepARG predicted } \\
\text { resistance }\end{array}$ \\
\hline deepARG & 1 & $\mathrm{rlmN}$ & Dual-specificity RNA methyltransferase RImN & Phenicol \\
\hline Prokka annotation & 1 & xerC_1 & Tyrosine recombinase XerC & \\
\hline Prokka annotation & 3 & xerC_2 & Tyrosine recombinase XerC & \\
\hline deepARG & 5 & Udaeo2_04600 & multi-drug exprt ATP binding/permease protein & Multidrug \\
\hline deepARG & 6 & phoP & $\begin{array}{l}\text { Alkaline phosphatase synthesis transcriptional regulatory } \\
\text { protein PhoP }\end{array}$ & Glycopeptide \\
\hline Prokka annotation & 6 & ybhF_1 & putative multidrug $A B C$ transporter ATP-binding protein $\mathrm{YbhF}$ & \\
\hline Prokka annotation & 6 & ybhR & putative multidrug $A B C$ transporter permease $\mathrm{YbhR}$ & \\
\hline Prokka annotation & 7 & Udaeo2_06040 & Beta-lactamase & \\
\hline deepARG & 8 & mdtA_1 & multidrug resistance protein MdtA & multidrug \\
\hline Prokka annotation & 8 & mdtC_1 & Multidrug resistance protein MdtC & \\
\hline Prokka annotation & 9 & fabl & Enoyl-[acyl-carrier-protein] reductase [NADH] Fabl & \\
\hline deepARG & 11 & macA_1 & macrolide export protein & MLS \\
\hline Prokka annotation & 11 & yknY_1 & putative $A B C$ transporter ATP-binding protein $Y k n Y$ & \\
\hline Prokka annotation & 11 & macB_1 & Macrolide export ATP-binding/permease protein MacB & \\
\hline deepARG & 11 & rsmA & ribosomal RNA small subunit methyltransferase A & Aminoglycoside \\
\hline deepARG & 12 & ybhF_2 & multidrug $\mathrm{ABC}$ transporter ATP-binding protein & Bacitracin \\
\hline deepARG & 14 & czcR & Transcriptional activator protein & Glycopeptide \\
\hline Prokka annotation & 14 & macA_2 & Macrolide export protein MacA & \\
\hline deepARG & 17 & nreC & Oxygen regulatory protein $\mathrm{NreC}$ & Unclassified \\
\hline deepARG & 19 & $\mathrm{kdpD}$ & sensor protein & Unclassified \\
\hline Prokka annotation & 21 & mdtA_2 & Multidrug resistance protein MdtA & \\
\hline Prokka annotation & 22 & Udaeo2_12270 & Beta-lactamase superfamily domain protein & \\
\hline Diamond & 23 & Udaeo2_12390 & IS5 family transposase IS1355 & \\
\hline Prokka annotation & 27 & Udaeo2_13820 & IS110 family transposase ISGme8 & \\
\hline Prokka annotation & 28 & mdtA_3 & Multidrug resistance protein MdtA & \\
\hline
\end{tabular}


Table S5 continued:

\begin{tabular}{|c|c|c|c|c|}
\hline $\begin{array}{l}\text { Detection } \\
\text { strategy }\end{array}$ & $\begin{array}{l}\text { Contig/ } \\
\text { scaffold }\end{array}$ & Annotation & Product & $\begin{array}{l}\text { deepARG predicted } \\
\text { resistance }\end{array}$ \\
\hline deepARG & 28 & ybal & Putative cation/proton antiporterl YbaL & Fosmidomycin \\
\hline Prokka annotation & 30 & $\operatorname{vanB}$ & Vancomycin B-type resistance protein VanB & \\
\hline deepARG & 40 & spoVD & Stage $V$ sporulation protein $D$ & Beta-lactam \\
\hline Diamond & 42 & xerD_1 & Tyrosine recombinase XerD & \\
\hline deepARG & 46 & bepE & Efflux pump membrane transporter & Multidrug \\
\hline deepARG & 46 & $\operatorname{srpA}$ & Solvent efflux pump periplasmatic linker SrpA & Multidrug \\
\hline Prokka annotation & 49 & Udaeo2_20030 & IS110 family transposase ISGme8 & \\
\hline Diamond & 49 & Udaeo2_20040 & IS3 family transposase ISStau1 & \\
\hline Diamond & 61 & xerD_2 & Tyrosine recombinase XerD & \\
\hline Prokka annotation & 64 & Udaeo2_23300 & Beta-lactamase & \\
\hline Prokka annotation & 69 & macB_2 & Macrolide export ATP-binding/permease protein MacB & \\
\hline Prokka annotation & 69 & macB_3 & Macrolide export ATP-binding/permease protein MacB & \\
\hline deepARG & 69 & Udaeo2_24310 & Putative multidrug export ATP-binding/permease protein & Multidrug \\
\hline Prokka annotation & 74 & mdtA_4 & Multidrug resistance protein MdtA & \\
\hline Prokka annotation & 74 & mdtB_1 & Multidrug resistance protein MdtB & \\
\hline Prokka annotation & 74 & mdtB_2 & Multidrug resistance protein MdtB & \\
\hline Prokka annotation & 74 & mdtC_2 & Multidrug resistance protein MdtC & \\
\hline Prokka annotation & 78 & xerC_3 & Tyrosine recombinase XerC & \\
\hline Prokka annotation & 80 & xerC_4 & Tyrosine recombinase XerC & \\
\hline Prokka annotation & 89 & $\operatorname{lnrL}$ & Linearmycin resistance ATP-binding protein & \\
\hline Prokka annotation & 89 & InrN & Linearmycin resistance permease protein $\mathrm{LnrN}$ & \\
\hline deepARG & 89 & syrM1 & HTH-type transcriptional regulator SyrM 1 & \\
\hline deepARG & 92 & Udaeo2_28300 & Putative multidrug export ATP-binding/permease protein & Multidrug \\
\hline Diamond & 94 & recA & Protein RecA & \\
\hline deepARG & 98 & tcrA & Transcriptional regulatory protein & Glycopeptide \\
\hline
\end{tabular}

Table S5 continued: 


\begin{tabular}{lllll}
\hline $\begin{array}{l}\text { Detection } \\
\text { strategy }\end{array}$ & $\begin{array}{l}\text { Contig/ } \\
\text { scaffold }\end{array}$ & Annotation & Product & $\begin{array}{l}\text { deepARG predicted } \\
\text { resistance }\end{array}$ \\
\hline Prokka annotation & 99 & Udaeo2_29330 & macB: subunit of efflux pump conferring antibiotic resistance \\
Prokka annotation & 99 & Udaeo2_29350 & macB-like periplasmic core domain protein \\
Prokka annotation & 99 & yknY_4 & putative ABC transporter ATP-binding protein YknY \\
Prokka annotation & 99 & Udaeo2_29370 & HlyD family secretion protein \\
\hline Prokka annotation & 106 & mdtA_5 & Multidrug resistance protein MdtA \\
Prokka annotation & 106 & mdtC_3 & Multidrug resistance protein MdtC \\
\hline Prokka annotation & 109 & Udaeo2_30640 & Metallo-beta-lactamase superfamily protein \\
\hline Prokka annotation & 110 & macB_4 & Macrolide export ATP-binding/permease protein MacB \\
\hline Prokka annotation & 110 & Udaeo2_30740 & MacB-like periplasmatic core domain protein \\
\hline Prokka annotation & 110 & Udaeo2_30700 & MacB-like periplasmatic core domain protein \\
Prokka annotation & 110 & Udaeo2_30690 & MacB-like periplasmatic core domain protein \\
\hline Prokka annotation & 110 & Udaeo2_30660 & macB: subunit of efflux pump conferring antibiotic resistance \\
\hline Prokka annotation & 110 & Udaeo2_30670 & macB: subunit of efflux pump conferring antibiotic resistance \\
\hline deepARG & 112 & stp & Multidrug resistance protein Stp \\
\hline deepARG & 116 & blaP & Beta-lactamase & Tetracenomycin_C \\
\hline deepARG & 125 & Udaeo2_32650 & Metallo-beta-lactamase superfamily protein \\
\hline Prokka annotation & 131 & Udaeo2_33250 & Transposase IS116/IS110/IS902 family protein \\
\hline Diamond & 132 & xerC_5 & Tyrosine recombinase XerC \\
\hline
\end{tabular}




\section{Discussion}

Before antibiotics were discovered, bacterial infections were difficult to treat and often ended with the death of the patient. Due to the current antibiotic resistance crisis, notorious diseases that finally became treatable with the discovery of antibiotics in the $20^{\text {th }}$ century, such as tuberculosis (caused by Mycobacterium tuberculosis), diphtheria (caused by Corynebacterium diphtheriae), typhoid fever (caused by Salmonella enterica serovar Typhi) or leprosy (caused by Mycobacterium leprae), can today become problematic again. In fact, infections with antibiotic resistant strains of all mentioned bacteria have already been reported (predominantly with respect to developing countries) (Zignol et al. 2016; Mina et al. 2011; Zaki and Karande 2011; Cambau et al. 2018). Especially nosocomial infections with multidrug resistant (MDR) pathogens occur frequently and pose a serious threat to human health (Santajit and Indrawattana 2016; Partridge et al. 2018; Spigaglia, Mastrantonio, and Barbanti 2018). In future, this development may worsen considerably, if antibiotic misuse and environmental pollution with antimicrobials is not properly addressed. As a matter of fact, predictions suggest that we may even find ourselves in a post-antibiotic era where common bacterial infections can no longer be treated adequately (Runcie 2015; Reardon 2014).

The soil bacterial resistome is most likely the origin of many pathogen encoded antibiotic resistance genes (ARGs), due to the circulation of ARGs between soil, human and livestock, fostered by the evolutionary pressure from antibiotic application and pollution (Bengtsson-Palme, Kristiansson, and Larsson 2018). However, a comprehensive understanding about properties and factors influencing the soil resistome which possibly affect the development of antibiotic resistant pathogens, is still lacking. To improve this fragmentary knowledge, three different aspects with respect to the soil resistome were addressed in this thesis. First, information on how human practices and existing soil characteristics affect the soil resistome was gathered. On this account, medically relevant ARGs and mobile genetic elements (MGEs) were quantified in soil DNA from 300 forest and grassland sample plots from the

Biodiversity Exploratories. Second, knowledge about the still widely untapped variety of ARGs within the soil resistome was extended via functional screenings of grassland and forest soil metagenomic libraries. As previous findings indicate that the soil bacterial community represents the major driver for the soil ARG content (Forsberg et al. 2014), the third research focus was placed on a globally abundant 
but so far poorly characterized soil bacterial genus designated Candidatus Udaeobacter. In this context, the response of $\mathrm{Ca}$. Udaeobacter towards antibiotic exposure was investigated to gain knowledge about the resistance properties of these organisms.

\subsection{Anthropogenic and natural effectors of the soil resistome}

The aminoglycoside resistance genes $\operatorname{aac}\left(6^{\prime}\right)-I b$ and $\operatorname{aacC} 1$, the beta-lactamase genes blaImP-12 and bla IMP-5, $_{\text {, }}$ the MLS (macrolide, lincosamide and streptogramin) resistance gene ermB, the macrolide resistance gene mefA, the tetracycline resistance gene tetA as well as IncP-1 plasmids and class 1 integrons were quantified based on grassland and forest soil DNA from all 300 EPs of the Biodiversity Exploratories. Land use practices and soil features that influence the abundance of these target ARGs and MGEs were identified with a combination of two statistical analyses. First, binomial regression analysis was conducted to determine parameters influencing the occurrence of the mentioned targets. For this purpose, $\mathrm{C}_{T}$ values (the number of cycles within a real-time quantitative PCR reaction required for the fluorescent signal to cross a fixed threshold) were transformed into binary data. More precisely,

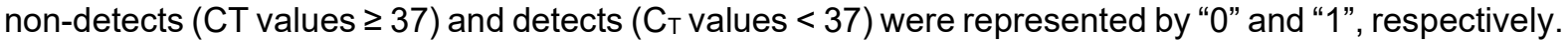
Additionally, left censored regression analyses were carried out to estimate shifts in the abundance of the selected targets without having to substitute or discard non-detects.

This combined statistical approach enabled the acquisition of valid results, despite low detection frequencies. This is due to the left censored regression approach which addresses the issue of non-detects in real-time quantitative PCR data, also referred to as censored values. In many studies, non-detects are substituted or discarded, to be able to use the remaining abundance data (Karkman et al. 2016; Dungan, Strausbaugh, and Leytem 2019). However, this can lead to false conclusions, as non-detects do not imply that the target sequence does not occur or is present at similar levels in all samples. It merely implies that its concentration lies below the detection threshold and is, thus, not measurable (McCall et al. 2014). Deleting non-detects, can also notably falsify statistical outcomes, as the proportion of censored values and uncensored values is a statistically important information (Helsel 2011). In fact, ignoring data points from non-detects has led to severe consequences in the past. For instance, NASA statisticians failed to include censored data in their analysis on the correlation between temperature and O-ring (component of the rocket booster necessary for sealing in gas) failure, which 
contributed to the death of seven people (Helsel 2011; Rogers et al. 1986). However, as non-detects were addressed properly in the present study, the results on land use practices and soil properties, affecting the abundance of medically relevant ARGs and MGEs in soil are robust and provide reliable information about effectors of the soil resistome. Due to the fact that three different geographic regions (located up to $700 \mathrm{~km}$ apart) were considered, the determined effectors potentially do not solely apply to specific environments, but rather influence the soil resistome in general. The identified effectors include land use type (grassland or forest), nitrogen input from organic fertilization, mowing frequency, soil $\mathrm{pH}$ and water content, forest soil fungal diversity as well as dominant tree type in forests.

It was found that the abundance of all target ARGs and MGEs, except the two beta-lactamase genes, were significantly elevated in grassland soils in comparison to forest soils. This may be explained by a higher $\mathrm{pH}$ (Chapter 3.2 Table S1), and a concomitant shift in microbial community composition in grassland soils, which is considered, as stated previously, the primary driver of the soil resistome (Forsberg et al. 2014). However, the closer proximity of grasslands to anthropogenic activities, including the use of antibiotics in human and veterinary medicine, could also play an important role. This assumption is supported by the significantly positive impact of organic nitrogen input through organic fertilization on the abundances of mefA and sul2, identified in this thesis. The abundances of these resistance genes are most likely increased in organically fertilized soils, as elevated amounts of antibiotic resistant bacteria (ARBs) and ARGs in manure, caused by selective pressure within the gastro-intestinal system of treated livestock, get in contact with the soil microbial community (DeFrancesco et al. 2004). In fact, livestock waste contains more (pig and chicken manure) or similar (cattle manure) amounts of ARGs in comparison to hospital waste (Figure 4) (He et al. 2020). To decrease this excessive ARG concentration in livestock manure, treatment processes, such as anaerobic digestion, have previously proven effective (He et al. 2020; Sun et al. 2016) and should therefore be applied more regularly. 


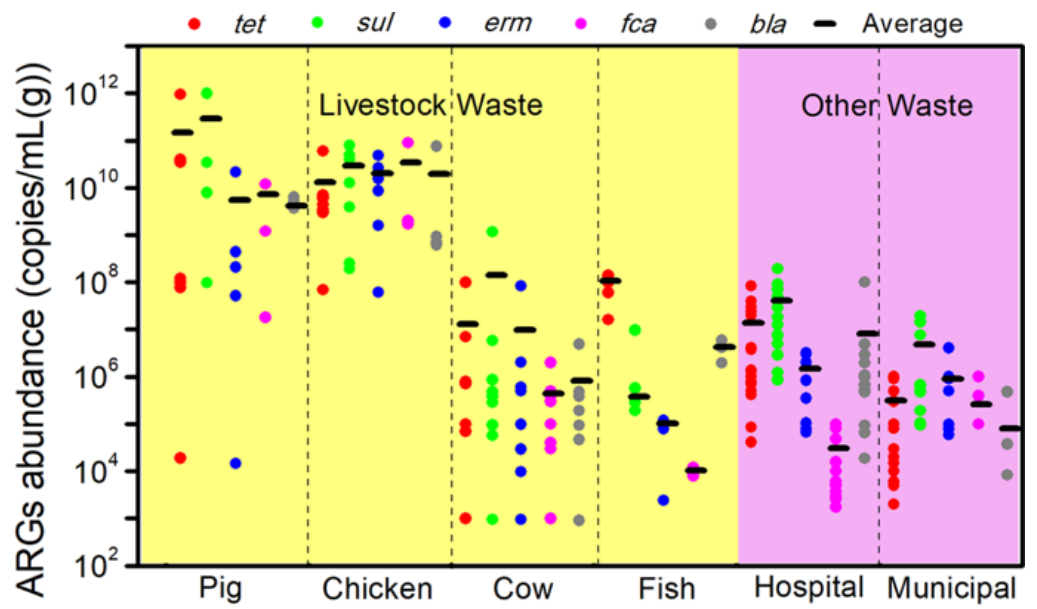

Figure 4 Abundance of selected ARGs in different livestock wastes versus hospital and municipal waste. The figure was adopted from $\mathrm{He}$ et al. 2020. Further information regarding the depicted genes can be derived from tables S2 and S5 of the same study.

Abbreviations: tet, tetracycline resistance genes; sul, sulfonamide resistance genes; erm, MLS resistance genes; fca, fluoroquinolone resistance genes, bla, $\beta$-lactam resistance genes.

Another important aspect is that applied antibiotic substances are, to a large extent, excreted functionally by treated animals, accumulate in manure and thus potentially establish a selective pressure. This promotes the acquisition and maintenance of resistance mechanisms with respect to the soil microbiome (Berendsen et al. 2015; Holman, Yang, and Alexander 2019; United States Pharmacopeial Convention. 2007). To receive indications about veterinary practices which may be problematic in terms of accumulation of medically relevant ARGs in the soil resistome, a survey was conducted with German veterinarians dealing with commonly applied antibiotic substances for the treatment of livestock. In this context, evidence indicating that the mefA abundance in soil may be influenced by the application of tulathromycin, used for treatment of bovine respiratory diseases in calves and young cattle, was gathered. The long elimination half-life of this antibiotic appears particularly problematic, as it implies that it persists for longer times in subinhibitory concentrations in the system of the treated animal, which is suspected to promote the development of antibiotic resistance (Blondeau 2005). Additionally, metaphylactic treatment, where an entire group of newly purchased calves is treated when one animal falls sick, is common practice in German conventional cattle farms and probably contributes notably to the amount of utilized tulathromycin. It is therefore reasonable to investigate resistance development upon treatment with antibiotics exhibiting long elimination half-lives more deeply in the future, likely leading to further restrictions for the usage of these antibiotics. 
The elevated abundance of sul2 in organically fertilized soils may be linked to the wide prescription range for sulfonamide antibiotics, as this leads to the application of these substances against a huge variety of different conditions in cattle. Sulfonamide resistances usually apply to all substances of this antibiotic family (Werckenthin and Schwarz 2003). Therefore, it is advisable to reconsider the prescription range for a selection of these substances in order to prevent the development of sulfonamide resistant human pathogens. Generally, the input of veterinary antibiotics, ARGs and ARBs into the soil microbial community could be limited best by decreasing the practice of factory farming which is associated with a higher risk of infection and thus a more frequent application of antibiotics (Anomaly 2015; Pluhar 2010). Furthermore, less factory farming would additionally decrease the amount of produced manure which is applied onto fields. At the same time, this would limit changes in the soil microbial community which could potentially be evoked through contact with the gut microbial bacteria of untreated animals (Udikovic-Kolic et al. 2014).

With respect to the abundance of the aminoglycoside resistance gene $\operatorname{aac}\left(6^{\prime}\right)-I b$, we determined a positive correlation with mowing frequency. A possible explanation for this correlation could be the uptake and accumulation of antibiotics by plants and the resulting development of resistant endophytes that may come into contact with the soil microbial community when plants are cut (Lillenberg et al. 2010; Hu, Zhou, and Luo 2010). Additionally, plants can release toxic aromatic compounds, root exudates, signaling molecules and antimicrobial substances upon mowing, which possibly induce elevated expression of ARGs by the soil microbial community (Alonso, Sanchez, and Martinez 2001; Yergeau et al. 2014). Antibiotic substances, distributed in the environment via surface water run offs, dust or wild animals, may also be involved in resistance development in areas which are not directly exposed to manure, and could therefore contribute to an increase in the abundance of aac(6')-Ib and other ARGs (Allen et al. 2010).

Looking at the forest samples, it was determined that the beta-lactamase gene bla IMP-12 $_{2}$ is more abundant at sites with beech trees and a high fungal diversity. The gene product of blaIMP-12 is an enzyme that cleaves aminopenicillins, carbapenems and cephalosporins (Docquier et al. 2003), the latter being synthesized by the filamentous fungus Acremonium chrysogenum (Burton and Abraham 1951; Pöggeler, Hoff, and Kück 2008). The natural synthesis of antibiotics by soil fungi as a means to take up nutrients from lysed bacterial cells when many competitors for resources are on site, evidently 
contributes to an increased blaImP-12 abundance. Furthermore, the connectedness between the soil fungal community and the dominant tree species (Goldmann et al. 2015) is indicated, as both, beech trees and a high fungal diversity, affect bla/MP-12 abundance.

In summary, this study investigates how abundances of genes conferring antibiotic resistance vary between soils affected by different land use types and practices. This includes antibiotics, such as aminoglycosides, macrolides, aminopenicillins, carbapenems and cephalosporins, all classified as critically important antibiotics for human health, as well as tetracyclines and sulfonamides, classified as highly important for human health (World Health Organisation 2019). In future studies, genes conferring resistances to further critically important antibiotics, such as glycopeptides (e.g. vancomycin) or phosphonic acid antibiotics (e.g. fosfomycin), should be investigated comprehensively. Glycopeptide and phosphonic acid antibiotics are generally not authorized in veterinary medicine for food producing animals in Germany (Silley and Stephan 2017), yet their abundance may still be elevated due to organic fertilization. The integration of intestinal bacteria of untreated livestock through application of manure into the soil microbiome has previously been shown to increase the abundance of genes conferring resistance against a variety of antibiotics, including vancomycin (Udikovic-Kolic et al. 2014; Hu et al. 2016). Furthermore, antibiotic treatment of livestock with a specific antibiotic could still elevate the abundance of genes conferring resistances against other antimicrobials, as MGEs, such as the IncP-1 plasmids can accumulate ARGs of many different classes (Popowska and Krawczyk-Balska 2013). In the light of our findings, the mentioned effect is particularly relevant since the abundance of the quantified IncP-1 plasmids and class 1 integrons was significantly elevated in grasslands.

\subsection{Novel sulfonamide and tetracycline resistance genes from forest and grassland soils}

Function-based metagenomic screenings are still the only means to identify entirely novel classes of genes and do not depend on prior information about related gene products, as it is the case for sequence-based approaches (Simon and Daniel 2011). Therefore, forest and grassland soil metagenomic libraries from sampling sites of the Schorfheide-Chorin and Schwäbische-Alb exploratories were subjected to function-based screenings for novel sulfonamide and tetracycline resistance genes. Four sulfonamide and four tetracycline resistance determinants showing only 46- 
$76 \%$ identity to known proteins from a variety of different taxa were identified. The respective range of taxa includes dominant gram-negative and gram-positive phyla (Proteobacteria, Bacteroidetes and Actinobacteria) previously detected in soils of the sampling sites by Kaiser et al. (2016). This underlines the efficiency of Escherichia coli as host for expression of ARGs from distinct origins. Nevertheless, a different expression host could potentially lead to the identification of some specific candidates that cannot be expressed by E. coli. The gram-positive Bacillus subtilis would be a promising candidate, as it is an established heterologous expression host (Cui et al. 2018) and belongs to the phylum of the Firmicutes, which includes the human pathogenic species Staphylococcus aureus and Clostridium difficile. Even though Forsberg et al. (2014) previously found that $E$. coli can express ARGs from Firmicutes, it remains doubtful that all possible resistance determinants can be found when functional screenings are performed exclusively with this species. Thus, considering other expression strains during metagenomic library screening potentially contributes to the development of a more holistic picture of the unexplored parts of the soil resistome.

The identified tetracycline resistance genes all code for major facilitator superfamily (MFS) efflux pumps which are mostly monomeric transporters that can extrude harmful substances out of the bacterial cell (Pasqua et al. 2019). Another study, in which soil metagenomic libraries were screened for tetracycline resistance genes, also identified MFS pumps as main resistance determinants (Wang et al. 2017). Together with our findings this indicates that these efflux pumps are a common tetracycline resistance mechanism in soil microbial communities in general. This is not surprising, as MFS pumps are the most abundant and diverse group of transporters throughout all domains of life (Du et al. 2018). They function not only as drug efflux pumps but are also extremely versatile due to a wide range of different substrates (Pasqua et al. 2019). MFS pumps can confer resistance against different classes of antibiotics and, due to their frequent occurrence on plasmids, may even spread throughout microbial communities via horizontal gene transfer (HGT) (Pasqua et al. 2019; Xian-Zhi and Nikaido 2009; Shi et al. 2018). Furthermore, specific MFS pumps can extrude several antibiotics out of the bacterial cell and are therefore classified as multidrug efflux (MDR) pumps (Du et al. 2018). Nevertheless, in this thesis, cross-resistance could only be observed for one candidate gene, where a fourfold increase in the minimal inhibitory concentration of lincomycin was measured. Other than that, the identified MFS transporters are tetracycline-specific which does not necessarily imply that they confer resistance to all 
antibiotics of the tetracycline class. In fact, (semi-)synthetic substances, such as tigecycline, omadacycline and eravacycline were recently designed and are functional against strains, resistant to other tetracycline representatives (Grossman 2016). Due to the recurrent tetracycline resistance of human pathogens, these (semi-)synthetic substances are mostly applied in the clinical frame nowadays (Grossman 2016). Hence, the effectivity of the here discovered MFS pumps against these tetracyclines is of interest and would provide information regarding their medical relevance. Furthermore, functional screenings for novel resistances towards the new (semi-)synthetic tetracycline substances in soil metagenomic libraries may provide information about further potentially clinically relevant ARGs of the future. One example for such a medically relevant resistance determinant with environmental origin is a flavin-dependent monooxygenase, encoded by tet $X$, which degrades tetracyclines, including tigecycline (Moore, Hughes, and Wright 2005). Notably, tetX was first discovered on transposons, harbored by Bacteroides fragilis, which is a commensal bacterium of the human colon (Speer, Bedzyk, and Salyers 1991; Huang, Lee, and Mazmanian 2011). However, highly homologous genes are encoded by bacteria colonizing soil (Cytophaga hutchinsonii, Streptomyces coelicolor, and Streptomyces avermitilis) which indicates that tetX evolved in this habitat and has potentially been mobilized (Yang et al. 2004).

All four sulfonamide resistance genes, identified in this study, encode a dihydropteroate synthase (DHPS). DHPSs catalyze the synthesis reaction from para-aminobenzoic acid (pABA) and dihydropteroate diphosphate to dihydropteroic acid in the folic acid synthesis pathway (Bermingham and Derrick 2002). Sulfonamides are synthetic antibiotics which competitively inhibit DHPSs because they are structural analogues of pABA (Sammes and Taylor 1990). Since folic acid is a coenzyme for synthesis reactions of purines, pyrimidines, and methionine, sulfonamides lead to the impairment of vital metabolic functions, such as DNA synthesis (Tibbetts and Appling 2010; Revuelta et al. 2018; Maddison, Watson, and Elliott 2008). Resistance against these antibiotic substances develops relatively fast and is mostly conferred through alternative DHPS variants (Sköld 2000). So far, four DHPS variants (sul1-4) are known to confer acquired sulfonamide resistance (Jiang et al. 2019). They are encoded on mobilizable or conjugative plasmids of different incompatibility groups and class 1 integrons (Jiang et al. 2019). Previous findings suggest that sul1-2, sul3 and sul 4 were decontextualized by mobilizing the corresponding chromosomally encoded DHPS gene (folP) from Rhodobiaceae, Leptospiraceae and 
Chloroflexi, respectively (Sánchez-Osuna et al. 2019; Razavi et al. 2017). The mobilization events most likely took place upon selective pressure established through pollution with antimicrobials, as shown for sul4 (Razavi et al. 2017). Interestingly, the resistance of the folP variants which potentially represent the origin of sul1-3, is suspected to predate the discovery of antibiotics, suggesting that bacterial pangenomes also encode for resistance mechanisms against synthetic antibiotics, prior to their discovery and application (Sánchez-Osuna et al. 2019). Sánchez-Osuna et al. (2019) explain this observation with other fitness benefits that are provided by the mutational changes which confer resistance as a side effect. The here reported findings substantiate this theory, as non-mobile sulfonamide resistance genes with distinct phylogenetic relation were identified in metagenomic DNA from forest soil without history of exposure to these synthetic drugs (Chapter 4 Figure 2, chapter 4.1 Table S1). This further underlines the relevance of functional screenings for genes conferring resistance against synthetic or semi-synthetic antimicrobial substances in soil metagenomic libraries. In addition to tigecycline, the synthetic fluoroquinolones or semi-synthetic derivates of chloramphenicol (e.g. florfenicol) would be a logical choice for screening agents, as corresponding resistances against these critically important antibiotics are especially relevant (World Health Organisation 2019).

The inserts, harboring one MFS pump and one DHPS, encode potential gene products which show similarity to an endonuclease and a superfamily 2 helicase, respectively. It is possible that these gene products contribute to HGT, yet the evidence is vague and requires further investigations. To receive more stable evidence for possible mobilization of the resistance determinants, it would, therefore, be reasonable to perform functional screenings with fosmid or cosmid vectors, in addition to plasmid libraries. These vectors can integrate much larger DNA fragments (up to $\sim 40 \mathrm{~kb}$ ), rendering the investigation of genes flanking ARGs for evidence of mobilization more promising (Taupp, Mewis, and Hallam 2011). Furthermore, large-insert metagenomic libraries would provide an opportunity to identify resistance determinants which cannot be detected by applying functional screenings of plasmid libraries. One reason for this is that regulator genes often control the expression of the resistant phenotype and can easily be lost in plasmid libraries, possibly rendering ARGs dysfunctional (Depardieu et al. 2007; Du et al. 2018). Furthermore, multimeric resistance determinants which are encoded by more than one open reading frame, like MDR pumps of the resistance nodulation division (RND) superfamily, could potentially be identified more frequently (Du et al. 2018). 


\subsection{Antibiotic resistance properties and lifestyle features of}

\section{Ca. Udaeobacter}

As Forsberg et al. (2014) determined that the composition of the soil resistome correlates with the taxonomic structure of the corresponding microbial community, in this study, a globally abundant soil verrucomicrobial genus was analyzed to deepen our understanding of this correlation. The respective genus, Ca. Udaeobacter, can make up more than $30 \%$ of $16 \mathrm{~S}$ rRNA gene sequences present in soil, with particularly high abundances in grassland soils (Figure 5) (Brewer et al. 2016).
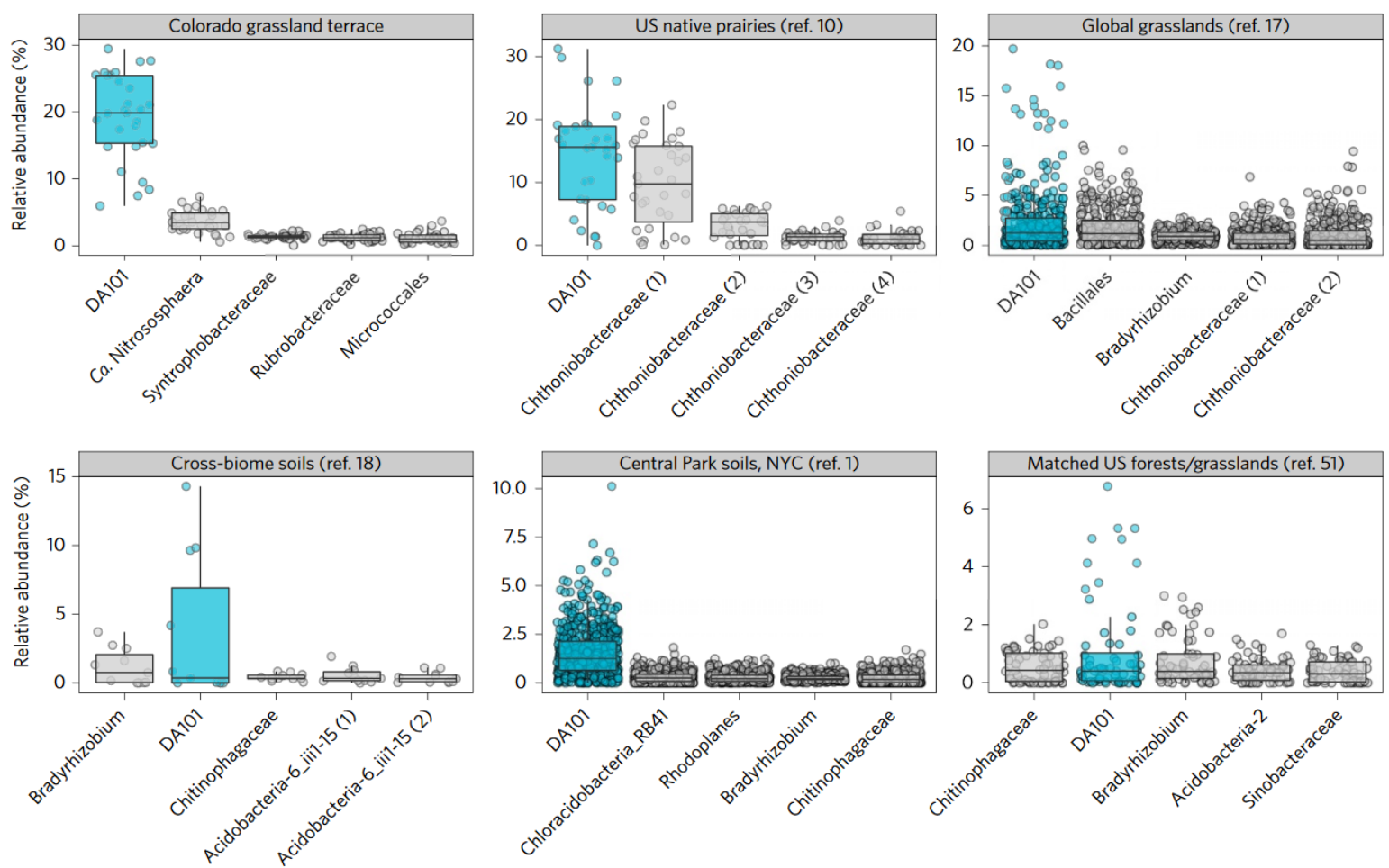

Figure 5 relative 16S rRNA gene abundance of the major five bacterial phylotypes across $>1000$ soils. Ca. Udaeobacter representatives sharing 99\%16S rRNA gene sequence identity with the ribosomal clone "DA101" are colored blue and labeled as DA101. Other taxa are indicated in grey. Taxa are listed on the $\mathrm{x}$ axis in decreasing order of their median value (mid-line of each box). The upper and lower edge of the box represent the $25^{\text {th }}$ and $75^{\text {th }}$ percentiles, respectively and the whiskers indicate the range of points, excluding outliers. The figure was adapted from Brewer et al. (2016). Information on considered data sets from previously published studies are provided in Supplementary Table 1 of Brewer et al. (2016) and in the respective references in the publication.

In general, Verrucomicrobia have long been under-recognized in studies dealing with the composition of soil microbial communities, as the majority of commonly used PCR primers do not match 
their 16S rRNA genes during amplification (Bergmann et al. 2011). This, and the fact that no isolate is available for detailed physiological analysis, are the reasons for the limited amount of information about this bacterial genus. Current knowledge is primarily based on a single reconstructed genome of a phylotype termed Ca. Udaeobacter copiosus (Brewer et al. 2016). Conspicuously, this genome is, based on the current state of studies, unusually small (estimated size, $\sim 2.81 \mathrm{Mbp}$ ) in comparison to other cosmopolitan soil bacteria (Brewer et al. 2016). It was therefore hypothesized that Ca. Udaeobacter species might have undergone genome streamlining whereby they have reduced energetically expensive metabolic pathways to increase efficiency for a life dependent on extracellular metabolites (Brewer et al. 2016).

Our investigation has provided more specific information regarding the previously proposed lifestyle of $\mathrm{Ca}$. Udaeobacter species. We found that representatives of $\mathrm{Ca}$. Udaeobacter benefit from release of antibiotics in soil, as they are multi-resistant and most likely utilize nutrients released by antibiotic- driven cell lysis, without having to bear the metabolic cost of antibiotic synthesis themselves.

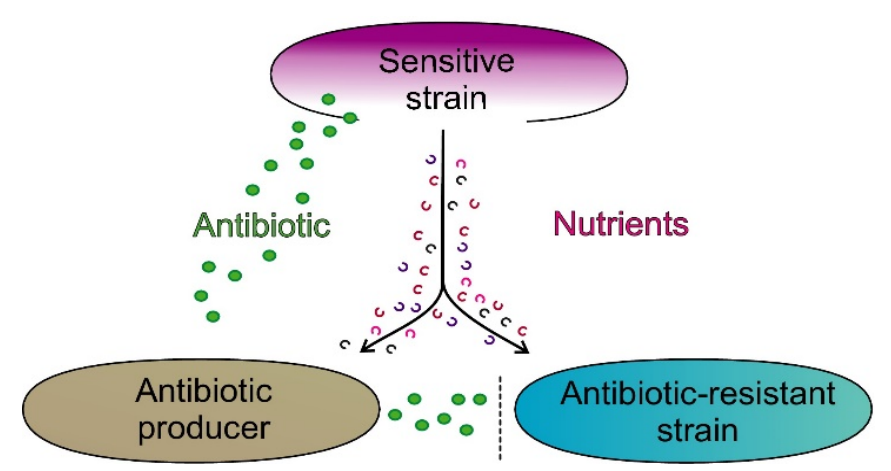

Figure 6 Overview of nutritional effect by antibioticdriven predation on antibiotic-resistant cheater cells. The figure was adapted from Leisner et al. (2016).
Bacteria, pursuing such a scavenging lifestyle are designated as antibiotic-resistant cheater cells (Figure 6) (Leisner, Jørgensen, and Middelboe 2016). With respect to Ca. Udaeobacter this hypothetical lifestyle is supported by significant growth of bacteria belonging to this genus, as a response to treatment of soil with highly concentrated mixtures of up to six different antibiotics.

Moreover, amino acid permeases and serine/threonine exchangers, vitamin B1, B12 and B9 salvage pathways and vitamin B12 importer proteins were identified upon investigation of a MAG derived from a representative of $\mathrm{Ca}$. Udaeobacter, (referred to as $\mathrm{Ca}$. Udaeobacter sp. in the following), which shows increased abundance after antibiotic treatment. These salvage pathways and transporter proteins support the hypothesis that $\mathrm{Ca}$. Udaeobacter benefits from nutrients (e.g. vitamins and amino acids) released from antibiotic-driven cell lysis. Furthermore, several ARGs were detected, providing protection against released antibiotics. Especially MDR pumps, macrolide efflux pumps and beta- 
lactam resistance genes are enriched in the genome of this organism (Chapter 5.1 Table S5). This finding is consistent with results of Forsberg et al. (2014), according to which soil-dwelling Verrucomicrobia encode a variety of beta-lactam resistance genes. Another protective mechanism against antibiotics, encoded by the MAG, constitutes the glyoxylate bypass, copper/zinc superoxide dismutase and the catalase-peroxidase as means against oxidative stress caused by bactericidal antibiotics (Chapter 5) (Kohanski et al. 2007; Vinogradov and Grivennikova 2016; Ahn et al. 2016). The glyoxylate bypass also enables $\mathrm{Ca}$. Udaeobacter to grow exclusively on substrates such as acetate, fatty acids, or ketogenic amino acids by skipping the oxidative decarboxylation steps of the TCA cycle (Dolan and Welch 2018) and thereby contributes to survival in the highly variable soil environment. Other features, which potentially contribute to survival in soils globally, are the biosynthetic arginine decarboxylase and putative lysine decarboxylase, conferring protection against acidic conditions. These two mechanisms may explain why the microcosms with acidic forest soils harbored a higher $\mathrm{Ca}$. Udaeobacter abundance than those based on neutral grassland soils (Chapter 5.1 Figure S1 and Table S1). Contrary to this finding, Brewer et al. (2016) previously reported that $\mathrm{Ca}$. Udaeobacter occurs in higher abundance in grassland than in forest soils (Brewer et al. 2016). Therefore, it would be interesting to analyze this trend more carefully in the future. This will be possible through the use of the quantitative real-time PCR primers, specifically targeting $\mathrm{Ca}$. Udaeobacter, designed and validated in this study.

A further probable lifestyle feature of $\mathrm{Ca}$. Udaeobacter $\mathrm{sp}$., is the aerobic oxidization of atmospheric $\mathrm{H}_{2}$ to sustain electron input into the respiratory chain at nutrient deprived conditions. This was found in the here reported MAG, and may also contribute to the high abundance of the corresponding genus in soils globally. In this context, $\mathrm{Ca}$. Udaeobacter sp. encodes two machineries, a membrane bound NiFeS-hydrogenase, consisting of a small and large subunit, which is coupled to electron transport chains, and a soluble cytoplasmic bidirectional NAD-reducing hydrogenase (Friedrich and Schwartz 1993; Greening et al. 2016) (Chapter 5). It was recently validated that $\mathrm{H}_{2}$ scavenging is performed by several soil-dwelling species of Actinobacteria (Greening, Constant, et al. 2015). In addition, this has also been described for verrucomicrobial methanotrophs colonizing geothermally influenced surface soils (Carere et al. 2017). Based on the identification of membrane bound NiFehydrogenases encoded by genomes of a variety of different soil bacteria it was hypothesized, that $\mathrm{H}_{2}-$ 
oxidation is a widely distributed attribute of soil-dwelling prokaryotes (Greening et al. 2015). However, until now the here provided information is, to our knowledge, the first evidence linking hydrogenase genes specifically to the genus $\mathrm{Ca}$. Udaeobacter.

The $16 \mathrm{~S}$ rRNA gene coverage of $\mathrm{Ca}$. Udaeobacter sp. indicates that a single gene copy is present in the genome, which is consistent with previous predictions (Brewer et al. 2016; Větrovský and Baldrian 2013). Hence, the high fraction of $\mathrm{Ca}$. Udaeobacter $16 \mathrm{~S}$ rRNA genes in soil seems to derive from a high cell density instead of a high $16 \mathrm{~S}$ rRNA gene copy number per cell. This is particularly relevant with respect to the global soil resistome as it consequently can be assumed that a high proportion of ARGs is encoded by $\mathrm{Ca}$. Udaeobacter representatives. Even if the true average genome size of $\mathrm{Ca}$. Udaeobacter representatives lies somewhere between $\sim 2.81 \mathrm{Mbp}$ (Ca. Udaeobacter copiosus) and $\sim 3.67 \mathrm{Mbp}$ (Ca. Udaeobacter sp.), the size difference compared to the estimated average genome size of soil bacteria (4.74 Mbp) (Brewer et al. 2016) does not relativize the here assumed huge proportion of $\mathrm{Ca}$. Udaeobacter ARGs in the global soil resistome. In fact, $\mathrm{Ca}$. Udaeobacter relative abundance is frequently more than two times higher than of other phylotypes and can even increase 100-fold upon addition of antibiotics (Chapter 5.1 Figure S1 and Table S3; Figure 5).

Regarding the clinical relevance of ARGs carried by $\mathrm{Ca}$. Udaeobacter, no resistance gene of pathogenic bacteria with a phylogenetic relation to this genus has been identified so far. However, absence of evidence does not mean evidence of absence. In fact, even though the ARGs encoded by Ca. Udaeobacter sp. are not encoded in synteny with MGEs, mobilization upon environmental antibiotic pollution and spread to pathogenic strains is possible, as it was likely the case for sul1-4 (Chapter 6.2) (Sánchez-Osuna et al. 2019; Razavi et al. 2017). Moreover, our results indicate that proximity to antibiotic usage entails a higher abundance of IncP-1 plasmids and class 1 integrons (Chapter 4 and 6.1), increasing the chance for gene mobilization. Additionally, antibiotics release in soil lead to a significant increase in $\mathrm{Ca}$. Udaeobacter abundance in our microcosm experiment, suggesting that these organisms likely represent winners of antimicrobial pollution. Taken together, antibiotic pollution of the soil environment leads to a high probability for mobilization of ARGs from Ca. Udaeobacter species, underlining the importance for in-depth studies of these organisms along with their resistance genes. Overall, the here presented lifestyle features along with the designed real-time quantitative PCR primers 
will be valuable for future investigations and may contribute to the successful development of a cultivation approach for members of this genus. 


\subsection{Literature}

Ahn S, Jung J, Jang IA, Madsen EL, Park W. 2016. Role of Glyoxylate Shunt in Oxidative Stress Response. J Biol Chem 291:11928-11938.

Allen HK, Donato J, Wang HH, Cloud-Hansen KA, Davies J, Handelsman J. 2010. Call of the wild: antibiotic resistance genes in natural environments. Nat Rev Microbiol 8:251-259.

Alonso A, Sanchez P, Martinez JL. 2001. Environmental selection of antibiotic resistance genes. Environ Microbiol 3:1-9.

Anomaly J. 2015. What's Wrong With Factory Farming? Public Health Ethics 8:246-254.

Bengtsson-Palme J, Kristiansson E, Larsson DGJ. 2018. Environmental factors influencing the development and spread of antibiotic resistance. FEMS Microbiol Rev 42: fux053.

Berendsen BJA, Wegh RS, Memelink J, Zuidema T, Stolker LAM. 2015. The analysis of animal faeces as a tool to monitor antibiotic usage. Talanta 132:258-268.

Bergmann GT, Bates ST, Eilers KG, Lauber CL, Caporaso JG, Walters WA, Knight R, Fierer N. 2011. The under-recognized dominance of Verrucomicrobia in soil bacterial communities. Soil Biol Biochem 43:1450-1455.

Bermingham A, Derrick JP. 2002. The Folic Acid Biosynthesis Pathway in Bacteria: Evaluation of Potential for Antibacterial Drug Discovery. Bioessays 24:637-648.

Blondeau J. 2005. Differential impact of macrolide compounds in the selection of macrolide nonsusceptible Streptococcus pneumoniae. Therapy 2:813-818.

Brewer TE, Handley KM, Carini P, Gilbert JA, Fierer N. 2016. Genome reduction in an abundant and ubiquitous soil bacterium 'Candidatus Udaeobacter copiosus'. Nat Microbiol 2:16198.

Burton HS, Abraham EP. 1951. Isolation of antibiotics from a species of Cephalosporium. Cephalosporins $P_{1}, P_{2}, P_{3}, P_{4}$ and $P_{5}$. Biochem J 50:168-174.

Cambau E, Saunderson P, Matsuoka M, Cole ST, Kai M, Suffys P, Rosa PS, Williams D, Gupta UD, Lavania M, Cardona-Castro N, Miyamoto Y, Hagge D, Srikantam A, Hongseng W, Indropo A, 
Vissa V, Johnson RC, Cauchoix B, Pannikar VK, Cooreman EAWD, Pemmaraju VRR, Gillini L, WHO surveillance network of antimicrobial resistance in leprosy. 2018. Antimicrobial resistance in leprosy: results of the first prospective open survey conducted by a WHO surveillance network for the period 2009-15. Clin Microbiol Infect 24:1305-1310.

Carere CR, Hards K, Houghton KM, Power JF, McDonald B, Collet C, Gapes DJ, Sparling R, Boyd ES, Cook GM, Greening C, Stott MB. 2017. Mixotrophy drives niche expansion of verrucomicrobial methanotrophs. ISME J 11:2599-2610.

Cui W, Han L, Suo F, Liu Z, Zhou L, Zhou Z. 2018. Exploitation of Bacillus subtilis as a robust workhorse for production of heterologous proteins and beyond. World J Microbiol Biotechnol 34:145.

DeFrancesco KA, Cobbold RN, Rice DH, Besser TE, Hancock DD. 2004. Antimicrobial resistance of commensal Escherichia coli from dairy cattle associated with recent multi-resistant salmonellosis outbreaks. Vet Microbiol 98:55-61.

Depardieu F, Podglajen I, Leclercq R, Collatz E, Courvalin P. 2007. Modes and Modulations of Antibiotic Resistance Gene Expression. Clin Microbiol Rev 20: 79-114.

Docquier J-D, Riccio ML, Mugnaioli C, Luzzaro F, Endimiani A, Toniolo A, Amicosante G, Rossolini GM. 2003. IMP-12, a New Plasmid-Encoded Metallo- $\beta$-Lactamase from a Pseudomonas putida Clinical Isolate. Antimicrob Agents Chemother 47:1522-1528.

Dolan SK, Welch M. 2018. The Glyoxylate Shunt, 60 Years On. Annu Rev Microbiol 72:309-330.

Du D, Wang-Kan X, Neuberger A, van Veen HW, Pos KM, Piddock LJV, Luisi BF. 2018. Multidrug efflux pumps: structure, function and regulation. Nat Rev Microbiol 16:523-539.

Dungan RS, Strausbaugh CA, Leytem AB. 2019. Survey of selected antibiotic resistance genes in agricultural and non-agricultural soils in south-central Idaho. FEMS Microbiol Ecol 95:fiz071.

Forsberg KJ, Patel S, Gibson MK, Lauber CL, Knight R, Fierer N, Dantas G. 2014. Bacterial phylogeny structures soil resistomes across habitats. Nature 509:612-616.

Friedrich B, Schwartz E. 1993. Molecular Biology of Hydrogen Utilization in Aerobic Chemolithotrophs. Annu Rev Microbiol 47:351-383. 
Goldmann K, Schöning I, Buscot F, Wubet T. 2015. Forest Management Type Influences Diversity and Community Composition of Soil Fungi across Temperate Forest Ecosystems. Front Microbiol $6: 1300$

Greening C, Biswas A, Carere CR, Jackson CJ, Taylor MC, Stott MB, Cook GM, Morales SE. 2016. Genomic and metagenomic surveys of hydrogenase distribution indicate $\mathrm{H}_{2}$ is a widely utilised energy source for microbial growth and survival. ISME J 10:761-777.

Greening C, Carere CR, Rushton-Green R, Harold LK, Hards K, Taylor MC, Morales SE, Stott MB, Cook GM. 2015. Persistence of the dominant soil phylum Acidobacteria by trace gas scavenging. Proc Natl Acad Sci U S A 112:10497-10502.

Greening C, Constant P, Hards K, Morales SE, Oakeshott JG, Russell RJ, Taylor MC, Berney M, Conrad R, Cook GM. 2015. Atmospheric Hydrogen Scavenging: from Enzymes to Ecosystems. Appl Environ Microbiol. 81:1190-1199.

Grossman TH. 2016. Tetracycline Antibiotics and Resistance. Cold Spring Harb Perspect Med 6:a025387.

He Y, Yuan Q, Mathieu J, Stadler L, Senehi N, Sun R, Alvarez PJJ. 2020. Antibiotic resistance genes from livestock waste: occurrence, dissemination, and treatment. npj Clean Water 3:4.

Helsel DR. 2011. Statistics for Censored Environmental Data Using Minitab® and R, 2nd ed. John Wiley \& Sons, Inc., Hoboken, NJ, USA.

Holman DB, Yang W, Alexander TW. 2019. Antibiotic treatment in feedlot cattle: a longitudinal study of the effect of oxytetracycline and tulathromycin on the fecal and nasopharyngeal microbiota. Microbiome 7:86.

Hu H-W, Han X-M, Shi X-Z, Wang J-T, Han L-L, Chen D, He J-Z. 2016. Temporal changes of antibioticresistance genes and bacterial communities in two contrasting soils treated with cattle manure. FEMS Microbiol Ecol 92:fiv169.

Hu X, Zhou Q, Luo Y. 2010. Occurrence and source analysis of typical veterinary antibiotics in manure, soil, vegetables and groundwater from organic vegetable bases, northern China. Environ Pollut 158:2992-2998. 
Huang JY, Lee SM, Mazmanian SK. 2011. The human commensal Bacteroides fragilis binds intestinal mucin. Anaerobe 17:137-141.

Jiang H, Cheng H, Liang Y, Yu S, Yu T, Fang J, Zhu C. 2019. Diverse Mobile Genetic Elements and Conjugal Transferability of Sulfonamide Resistance Genes (sul1, sul2, and sul3) in Escherichia coli Isolates From Penaeus vannamei and Pork From Large Markets in Zhejiang, China. Front Microbiol 10:1787.

Kaiser K, Wemheuer B, Korolkow V, Wemheuer F, Nacke H, Schöning I, Schrumpf M, Daniel R. 2016. Driving Forces of Soil Bacterial Community Structure, Diversity, and Function in Temperate Grasslands and Forests. Sci Rep 6:33696.

Karkman A, Johnson TA, Lyra C, Stedtfeld RD, Tamminen M, Tiedje JM, Virta M. 2016. High-throughput quantification of antibiotic resistance genes from an urban wastewater treatment plant. FEMS Microbiol Ecol 92:fiw014.

Kohanski MA, Dwyer DJ, Hayete B, Lawrence CA, Collins JJ. 2007. A Common Mechanism of Cellular Death Induced by Bactericidal Antibiotics. Cell 130:797-810.

Leisner JJ, Jørgensen NOG, Middelboe M. 2016. Predation and selection for antibiotic resistance in natural environments. Evol Appl 9:427-434.

Lillenberg M, Litvin SV, Nei L, Roasto M, Sepp KI. 2010. Enrofloxacin and ciprofloxacin uptake by plants from soil. Agron. Res. 8:807-814.

Maddison JE, Watson ADJ, Elliott J. 2008. Antibacterial drugs, p. 148-185. In Small Animal Clinical Pharmacology, 2nd ed. Saunders.

McCall MN, McMurray HR, Land H, Almudevar A. 2014. On non-detects in qPCR data. Bioinformatics $30: 2310-2316$

Mina N V., Burdz T, Wiebe D, Rai JS, Rahim T, Shing F, Hoang L, Bernard K. 2011. Canada's first case of a Multidrug-Resistant Corynebacterium diphtheriae strain, Isolated from a Skin Abscess. J Clin Microbiol 49:4003-4005.

Moore IF, Hughes DW, Wright GD. 2005. Tigecycline is modified by the flavin-dependent 
monooxygenase TetX. Biochemistry 44:11829-11835.

Partridge SR, Kwong SM, Firth N, Jensen SO. 2018. Mobile Genetic Elements Associated with Antimicrobial Resistance. Clin Microbiol Rev 31:e00088-17.

Pasqua M, Grossi M, Zennaro A, Fanelli G, Micheli G, Barras F, Colonna B, Prosseda G. 2019. The Varied Role of Efflux Pumps of the MFS Family in the Interplay of Bacteria with Animal and Plant Cells. Microorganisms 7:285.

Pluhar EB. 2010. Meat and Morality: Alternatives to Factory Farming. J Agric Environ Ethics 23:455468.

Pöggeler S, Hoff B, Kück U. 2008. Asexual Cephalosporin C Producer Acremonium chrysogenum Carries a Functional Mating Type Locus. Appl Environ Microbiol 74:6006-16.

Popowska M, Krawczyk-Balska A. 2013. Broad-host-range IncP-1 plasmids and their resistance potential. Front Microbiol 4:44.

Razavi M, Marathe NP, Gillings MR, Flach C-F, Kristiansson E, Joakim Larsson DG. 2017. Discovery of the Fourth Mobile Sulfonamide Resistance Gene. Microbiome 5:160.

Reardon S. 2014. WHO warns against "post-antibiotic" era. Nature News.

Revuelta JL, Serrano-Amatriain C, Ledesma-Amaro R, Jiménez A. 2018. Formation of Folates by Microorganisms: Towards the Biotechnological Production of This Vitamin. Appl Microbiol Biotechnol 102: 8613-8620.

Rogers WP, Armstrong NA, Acheson DC, Covert EE, Feynman RP, Hotz RB, Kutyna DJ, Ride SK, Rummel RW, Sutter JF, Walker ABCJ, Wheelon AD, Yeager CE. 1986. Report to the President By the Presidential Comission On the Space Shuttle Challenger Accident. Washington D.C.

Runcie H. 2015. Infection in a Pre-Antibiotic Era. J Anc Dis Prev Rem 3:2.

Sammes, P.G., and J.B. Taylor, eds. 1990. Comprehensive Medicinal Chemistry. p. 255-270. Oxford, Oxford: Pergamon Press, Oxford, New York.

Sánchez-Osuna M, Cortés P, Barbé J, Erill I. 2019. Origin of the Mobile Di-Hydro-Pteroate Synthase Gene Determining Sulfonamide Resistance in Clinical Isolates. Front Microbiol 10:3332. 
Santajit S, Indrawattana N. 2016. Mechanisms of Antimicrobial Resistance in ESKAPE Pathogens. Biomed Res Int 2016: 2475067.

Shi L, Liang Q, Feng J, Zhan Z, Zhao Y, Yang W, Yang H, Chen Y, Huang M, Tong Y, Li X, Yin Z, Wang J, Zhou D. 2018. Coexistence of Two Novel Resistance Plasmids, blakPC-2-carrying p14057A and tetA (A) -carrying p14057B, in Pseudomonas aeruginosa. Virulence 9:306-311.

Silley P, Stephan B. 2017. Prudent use and regulatory guidelines for veterinary antibiotics—politics or science? J Appl Microbiol 123:1373-1380.

Simon C, Daniel R. 2011. Metagenomic Analyses: Past and Future Trends. Appl Environ Microbiol $77: 1153-1161$.

Sköld O. 2000. Sulfonamide Resistance: Mechanisms and Trends. Drug Resist Updat 3:155-160.

Speer BS, Bedzyk L, Salyers AA. 1991. Evidence that a novel tetracycline resistance gene found on two Bacteroides transposons encodes an NADP-requiring oxidoreductase. J Bacteriol 173:176183.

Spigaglia P, Mastrantonio P, Barbanti F. 2018. Antibiotic resistances of Clostridium difficile. Adv in Exp Med 1050:137-159.

Sun W, Qian X, Gu J, Wang XJ, Duan ML. 2016. Mechanism and Effect of Temperature on Variations in Antibiotic Resistance Genes during Anaerobic Digestion of Dairy Manure. Sci Rep 6:30237.

Taupp M, Mewis K, Hallam SJ. 2011. The Art and Design of Functional Metagenomic Screens. Curr Opin Biotechnol 22:465-72.

Tibbetts AS, Appling DR. 2010. Compartmentalization of Mammalian Folate-Mediated One-Carbon Metabolism. Annu Rev Nutr 30:57-81.

Udikovic-Kolic N, Wichmann F, Broderick NA, Handelsman J. 2014. Bloom of resident antibioticresistant bacteria in soil following manure fertilization. Proc Natl Acad Sci U S A 111:1520215207.

United States Pharmacopeial Convention. 2007. The United States pharmacopeia 31; The national formulary 26. United States Pharmacopeial Convention, Rockville MD. 
Větrovský T, Baldrian P. 2013. The Variability of the 16 S rRNA Gene in Bacterial Genomes and Its Consequences for Bacterial Community Analyses. PLoS One 8:e57923.

Vinogradov AD, Grivennikova VG. 2016. Oxidation of NADH and ROS production by respiratory complex I. Biochim Biophys Acta 1857:863-71.

Wang S, Gao X, Gao Y, Li Y, Cao M, Xi Z, Zhao L, Feng Z. 2017. Tetracycline Resistance Genes Identified From Distinct Soil Environments in China by Functional Metagenomics. Front Microbiol 8:1406.

Werckenthin C, Schwarz S. 2003. Kreuzresistenzen: Beurteilung von Antibiogrammen, Auswahl von antimikrobiellen Wirkstoffen für die in-vitro Empfindlichkeitsprüfung und molekulare Grundlagen. Manuskript zur 22 Arbeits- und Fortbildungstagung Bakteriol des Arbeitskreises Veterinärmedizinischer Infekt der DVG.

World Health Organization. 2019. Critically important antimicrobials for human medicine, 6th revision. WHO

Xian-Zhi L, Nikaido H. 2009. Efflux-mediated drug resistance in bacteria: an update. Drugs 69:1555623.

Yang W, Moore IF, Koteva KP, Bareich DC, Hughes DW, Wright GD. 2004. TetX is a flavin-dependent monooxygenase conferring resistance to tetracycline antibiotics. J Biol Chem 279:52346-52352.

Yergeau E, Sanschagrin S, Maynard C, St-Arnaud M, Greer CW. 2014. Microbial expression profiles in the rhizosphere of willows depend on soil contamination. ISME J 8:344-358.

Zaki SA, Karande S. 2011. Multidrug-resistant typhoid fever: A review. J Infect Dev Ctries 5:324-337.

Zignol M, Dean AS, Falzon D, van Gemert W, Wright A, van Deun A, Portaels F, Laszlo A, Espinal MA, Pablos-Méndez A, Bloom A, Aziz MA, Weyer K, Jaramillo E, Nunn P, Floyd K, Raviglione MC. 2016. Twenty Years of Global Surveillance of Antituberculosis-Drug Resistance. N Engl J Med $375: 1081-1089$ 


\section{Appendix}

\subsection{Declaration of plagiarism}

I, Inka Marie Willms, hereby confirm that I wrote the here presented doctoral thesis "Assessment of antibiotic resistance in soil and its link to different land use types and intensities" independently, without using any means others than those mentioned in the respective chapters. I did neither seek unauthorized assistance nor did I submit this thesis in any form for another degree at any institution or university. All contributions by other authors to the here included publications are listed before the corresponding manuscripts.

Inka Marie Willms 


\subsection{Danksagung}

Zu aller Erst möchte ich Dr. Heiko Nacke für die Möglichkeit danken in diesem interessanten Projekt promovieren zu können und dafür, dass er mir ständig mit gutem Rat zur Seite stand. Vielen Dank für die zahlreichen Korrekturen, die ständige Bereitschaft zum wissenschaftlichen Austausch und die Unterstützung und das Verständnis bei Problemen aller Art! Ich bin mir sehr bewusst, dass ich großes Glück hatte einen so großartigen Betreuer gehabt zu haben, der mir genug Freiheit gegeben hat meine eigenen Ideen in die Tat umzusetzen und mir genug Halt gegeben hat um mich nicht in der großen weiten Wissenschaft zu verlieren.

Weiterer Dank geht an PD. Dr. Michael Hoppert für die Bereitschaft Co-referent dieser Arbeit zu sein und für sein Interesse an den Ergebnissen. Außerdem möchte ich Prof. Rolf Daniel für die fachliche und verwaltungsbezogene Unterstützung danken, die er diesem Projekt entgegengebracht hat. Natürlich danke ich ebenfalls der restlichen Prüfungskommission für die Durchsicht und Beurteilung meiner Arbeit.

Ohne meine Studenten Anina, Isabell, Jingyue, Melissa, Lisa und Simon, hätte ich die Laborarbeit nicht bewältigen können, die nötig war um die hier analysierten Daten zu erheben. Vielen Dank für eure Arbeit!

Ich danke der kompletten Abteilung der Genomischen und Angewandten Mikrobiologie, für die gute Arbeitsatmosphäre, was die drei Jahre meiner Doktorarbeit zu einem großen Vergnügen gemacht hat! Diesbezüglich möchte ich besonders Dr. Dominik Schneider hervorheben, der diese Arbeit, genauso wie ein weiteres Manuskript korrigiert hat und für bioinformatische Probleme immer ein hervorragender Ansprechpartner war! Lieber Dank geht außerdem an Dr. Birgit Pfeiffer für die emotionale und wissenschaftliche Unterstützung in Form von vielen Gesprächen, die mir durch so manches Doktorarbeitstief geholfen haben! Dr. Anja Poehlein möchte ich für ihre bioinformatische Unterstützung danken und dafür, eine aufmunternde Seele im Büro vorzufinden, die einen das Arbeiten an vielen Tagen um manches erleichtert hat. Ein weiterer, großer Dank geht an Dr. Robert Hertel, ohne den ich gar nicht erst an dieser Stelle stehen würde. 
Ganz lieben Dank an Avi, Miriam, Dirko, Tati, Stefani und Ines, für eine schöne Zeit und den großartigen Doktorhüten, die wir zusammen gebastelt haben. Wenigstens haben wir uns nicht nehmen lassen, die Doktorarbeiten angemessen zu zelebrieren, bei denen es möglich war!

Diese Arbeit wäre ebenfalls nie zustande gekommen, wenn ich nicht eine so tolle Familie hätte, die trotz gelegentlicher kleiner und großer Uneinigkeiten immer zusammenhält und sich unterstützt. Besonders möchte ich meiner Mama und Achim, meinen Geschwistern, Antje, Lisa und Anton, mit Florian und Christof, meinem Vater und Andrea, Oma \& Opa und Elke \& Claus dafür danken ein Teil von mir und dementsprechend dieser Arbeit zu sein.

Zuletzt möchte ich mich von ganzem Herzen bei Oleg bedanken, dass er mich gelehrt hat, dass das Leben keinen Plänen folgt und man sich wegen Angst und Zweifel nicht für Geringeres entscheiden sollte. Außerdem danke ich inm für den festen Halt, den er mir fortwährend gibt, egal wie rau die See ist. 


\subsection{Curriculum Vitae of Inka Marie Willms}

\section{EDUCATION}

May 2017-

presumably May 2020

Oct. 2014 -

Jan. 2017

Oct. 2011 -

Oct. 2014
Doctorate student at the Georg-August-University (Göttingen)

Department of Genomic and Applied Microbiology

First supervisor: Dr. Heiko Nacke

Masters degree at the Georg-August-University (Göttingen)

Master of Science in "Microbiology and Biochemistry"

- Module Highlights: General and Applied Microbiology, Structural Biochemistry, Biochemistry and Biophysics

- Degree: Master of Science - Final Grade 1.3

- Thesis: "Physiologic and genomic analysis of Bacillus phages vB-BsuM_Goe2 and vB-BsuM_Goe3“ - Grade 1.0

\section{Bachelors degree at the Carl von Ossietzky University} (Oldenburg)

Bachelor of Science in "Environmental Sciences" - Final Grade 1.9

- Module Highlights: General Microbiology, Environmental Microbiology, Genetics, Bio- and Geochemistry

- Thesis: "Generierung dreidimensionaler Darstellungen am Rasterelektronenmikroskop mit Hilfe von Z-Stapeln" - Grade 1.5

\section{ADDITIONAL WORK EXPERIENCE}

June 2017-

Jan. 2020

Sept. 2016

Dec. 2016

May 2016 -

July 2016
Project design for two bachelor and one master thesis projects as well as supervision of four bachelor and two master students in the context of the dissertation

Internship - Identification of Campylobacter jejuni phage receptor binding proteins

University of Copenhagen; Department of Veterinary and Disease Biology

\section{Student Research Assistant}

Georg-August-University; Department of General Microbiology

- Support in teaching and correction of student protocols throughout the bachelor course "General Microbiology" 
Feb. 2020

Jan. 2020

March 2019

Feb. 2019

Aug. 2018

May 2017

Feb. 2018

Sep. 2016

March 2016
Submission of first author paper "Globally abundant Candidatus Udaeobacter benefits from release of antibiotics in soil and potentially performs trace gas scavenging" to mSphere.

Willms, Yuan, Penone, Goldmann, Vogt, Wubet, Schöning, Schrumpf, Buscot, Nacke. 2020. Distribution of Medically Relevant Antibiotic Resistance Genes and Mobile Genetic Elements in Soils of Temperate Forests and Grasslands Varying in Land Use. Genes 11:150.

Willms IM, Kamran A, Aßmann NF, Krone D, Bolz SH, Fiedler F, Nacke H. 2019. Discovery of Novel Antibiotic Resistance Determinants in Forest and Grassland Soil Metagenomes. Front Microbiol 10:460.

Biodiversity Exploratories Assembly (Wernigerode, Germany) Oral presentation: "Antibiotic resistance and its link to land use" Presentation of poster: "Antibiotic resistance and its link to land use".

ISME17 (Leipzig, Germany)

Presentation of poster: "Exploring a cradle of multi-resistant bacteria- antibiotic resistance in soil and its link to different land use types and intensities".

Willms IM, Hoppert M, Hertel R. 2017. Characterization of Bacillus subtilis viruses vB_BsuM-Goe2 and vB_BsuM-Goe3. Viruses 9:146.

Biodiversity Exploratories Assembly (Wernigerode, Germany) Oral presentation: "Antibiotic resistance and its link to land use" Presentation of poster: "Antibiotic resistance and its link to land use".

Willms IM, Hertel R. 2016. Phage vB_BsuP-Goe1: The smallest identified lytic phage of Bacillus subtilis. FEMS Microbiol Lett 363 : fnw208.

VAAM-Conference (Jena, Germany) Presentation of poster: "Bacillus subtilis phages: new isolates and insights" 